\title{
Seismic Response of Rock Joints and Jointed Rock Mass
}

Manuscript Completed: October 1995

Date Published: June 1996

Prepared by

A. Ghosh, S. M. Hsiung, A. H. Chowdhury

Center for Nuclear Waste Regulatory Analyses

Southwest Research Institute

6220 Culebra Road

San Antonio, TX 78228-0510

J. Philip, NRC Project Manager

Prepared for

Division of Regulatory Applications

Office of Nuclear Regulatory Research

U.S. Nuclear Regulatory Commission

Washington, DC 20555-0001

NRC FIN B6643

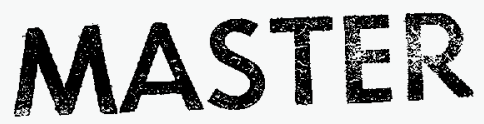




\section{DISCLAIMER}

Portions of this document may be illegible in electronic image products. Images are produced from the best available original document. 


\begin{abstract}
Long-term stability of emplacement drifts and potential near-field fluid flow resulting from coupled effects are among the concerns for safe disposal of high-level nuclear waste (HLW). A number of factors can induce drift instability or change the near-field flow patterns. Repetitive seismic loads from earthquakes and thermal loads generated by the decay of emplaced waste are two significant factors. One of two key technical uncertainties (KTU) that can potentially pose a high risk of noncompliance with the performance objectives of 10 CFR Part 60 is the prediction of thermal-mechanical (including repetitive seismic load) effects on stability of emplacement drifts and the engineered barrier system. The second KTU of concern is the prediction of thermal-mechanical-hydrological (including repetitive seismic load) effects on the host rock surrounding the engineered barrier system. The Rock Mechanics research project being conducted at the Center for Nuclear Waste Regulatory Analyses (CNWRA) is intended to address certain specific technical issues associated with these two KTUs. This research project has two major components: (i) seismic response of rock joints and a jointed rock mass and (ii) coupled thermal-mechanical-hydrological (TMH) response of a jointed rock mass surrounding the engineered barrier system (EBS). This final report summarizes the research activities concerned with the repetitive seismic load aspect of both these KTUs.
\end{abstract}

A literature review was conducted at the beginning of this research project to establish the state of knowledge available in the open literature relevant to performance of underground excavations and associated phenomena when subjected to seismic waves. Critical assessment of the information identified several technical deficiencies or lack of information, particularly with regard to analysis and prediction of dynamic response of underground structures excavated in fractured rock masses. Furthermore, the knowledge gained in this literature search was used to formulate the laboratory and field experiments conducted in this research project.

Laboratory experiments on natural joints of Apache Leap tuff using cyclic pseudostatic and dynamic loads indicate that the mobilized shear strength in the reverse direction of shearing (that is, moving toward the original starting point of shearing) is always less than that in the forward direction. This phenomenon has a significant consequence on the stability of underground openings. It was also observed that the dilation is nearly recovered in reverse shearing. These observations are consistent with some recent studies by others. The commonly used rock joint constitutive models, namely, Coulomb-Slip, Barton-Bandis, and Continuously-Yielding, were developed primarily for uniaxial shearing. Their extension to model joint reverse behavior is questionable. Although in later publications a procedure was given to use the original equations of Barton-Bandis model in reverse direction, the modified procedure to Barton-Bandis model does not consider the recovery of joint dilation in reverse direction and seems to be inconsistent with the theoretical understanding of reverse shear phenomenon. The unidirectional Coulomb-slip and Continuously-Yielding models fail to predict the reduction in shear strength in reverse shearing and the modified Barton-Bandis model predicts the reduction which is inconsistent with experimental results available in the literature. Therefore, modifications of the rock joint models to simulate the reverse response observed in experiments are desirable.

Deep underground excavations are relatively more resistant to seismic loading from a single seismic event than are surface structures. This phenomenon can be predicted by the theory of wave propagation and has been observed in actual case histories of many excavations in various geological media around the world. Current design methodology for underground excavations is based on the probable peak particle motion that an excavation will experience over its design life. However, field experiments at Lucky Friday Mine, Idaho, scale-model experiments in the laboratory conducted at the CNWRA, and 
information in the literature show that for excavations subjected to repetitive episodes of seismic motions, accumulation of shear displacement or damage along the joints is the primary mode of deformation for the rock mass. The number and extent of excursions of joint shear motion into the damage range of joint response determine the progressive damage. As a result of strain accumulation, significant damage to the opening may occur at a peak particle motion relatively smaller than the probable maximum value. The proposed repository will be subjected to repetitive seismic events. Thus, its performance should be assessed from analysis of joint damage accumulation arising from time histories of ground motion for individual seismic events. The currently available seismic design procedure does not explicitly take account of either the time history of individual events or the effects of repetitive seismic events.

The CNWRA conducted a groundwater pressure monitoring program at the Lucky Friday Mine, Idaho, in sections of three fracture zones beneath the water table over a 2-yr period to study seismic effect on groundwater hydrology. It was found, in general, that the groundwater pressure changes increased with increasing magnitude of the seismic event. For a given earthquake magnitude, the change in groundwater pressure decreases with increasing distance from the earthquake source. 


\section{CONTENTS}

Section $\quad$ Page

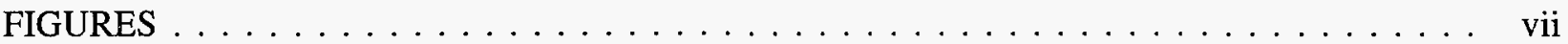

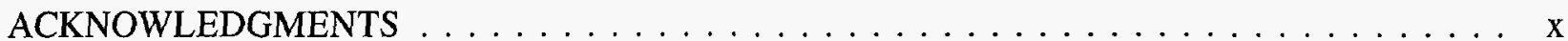

PREVIOUS REPORTS IN SERIES $\ldots \ldots \ldots \ldots \ldots \ldots \ldots \ldots \ldots \ldots \ldots$. . . . . . . . . . . $\ldots \ldots$

RELATED PUBLICATIONS $\ldots \ldots \ldots \ldots \ldots \ldots \ldots \ldots \ldots \ldots \ldots \ldots \ldots \ldots$

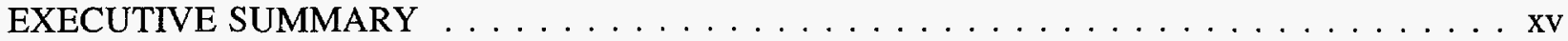

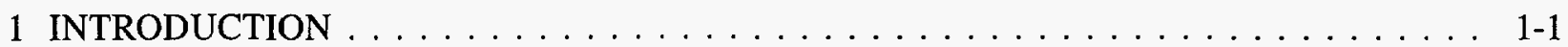

1.1 BACKGROUND AND OBJECTIVES $\ldots \ldots \ldots \ldots \ldots \ldots \ldots \ldots \ldots \ldots$

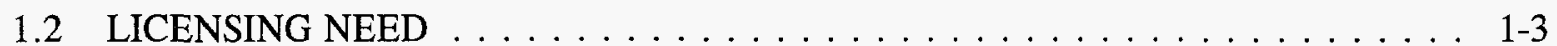

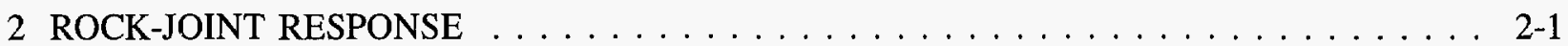

2.1 ROCK-JOINT RESPONSE UNDER PSEUDOSTATIC LOADS $\ldots \ldots \ldots \ldots$

2.1.1 Rock-Joint Response Under Normal Loads . . . . . . . . . . . . . . . 2-1

2.1.2 Rock-Joint Response Under Cyclic Pseudostatic Shear Loads . . . . . . . 2-4

2.1.2.1 Peak Shear Stress/Strength . . . . . . . . . . . . . . . 2-11

2.1.2.2 Residual Shear Stress/Strength . . . . . . . . . . . . . . . . 2-11

2.1.2.3 Joint Dilation with Shear Displacement . . . . . . . . . . . . . . 2-13

2.2 ROCK-JOINT RESPONSE UNDER DYNAMIC LOADS $\ldots \ldots \ldots \ldots \ldots \ldots$. . . . 2-15

2.2.1 Rock-Joint Response Under Harmonic Loads . . . . . . . . . . . . . . 2-15

2.2.2 Rock-Joint Response Under Earthquake Loads . . . . . . . . . . . . . 2-17

2.2.3 Potential Dynamic Impact on Rock-Joint Behavior . . . . . . . . . . . . . 2-20

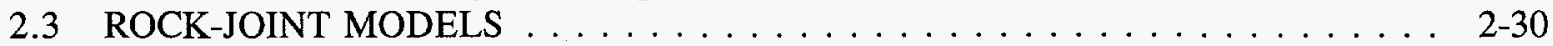

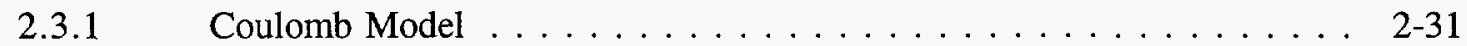

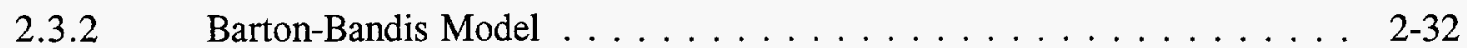

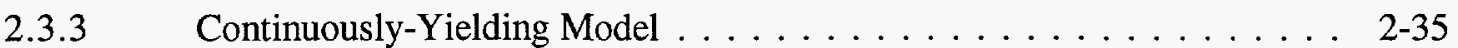

2.3.4 Numerical Simulation of Laboratory Direct Shear Experiments Under Cyclic Loading . . . . . . . . . . . . . . . . 2-37

3 ROCK-MASS RESPONSE UNDER REPETITIVE SEISMIC LOADS . . . . . . . . . . 3-1

3.1 MODEL STUDY OF BROWN AND HUDSON $\ldots \ldots \ldots \ldots \ldots \ldots \ldots \ldots$

3.2 MODEL STUDY OF BARTON AND HANSTEEN $\ldots \ldots \ldots \ldots \ldots \ldots \ldots$

3.3 FIELD STUDY AT THE LUCKY FRIDAY MINE $\ldots \ldots \ldots \ldots \ldots \ldots \ldots$

3.4 DYNAMIC SCALE-MODEL EXPERIMENT OF A JOINTED ROCK MASS _ . . 3-14

4 EFFECT OF SEISMICITY ON GROUNDWATER HYDROLOGY . . . . . . . . . . . . . 4-1

4.1 MECHANISMS OF EARTHQUAKE-INDUCED HYDROLOGIC CHANGES . . . 4-2

4.2 GROUNDWATER PRESSURE MONITORING AT LUCKY FRIDAY MINE . . . . 4-4

4.3 SHORT-TERM SEISMIC EFFECTS ON GROUNDWATER PRESSURE $\ldots \ldots$. . . . 4-6

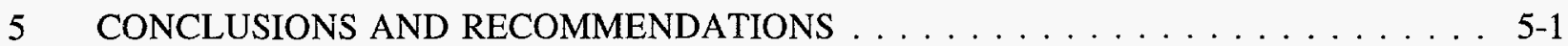

5.1 COMPREHENSIVE LITERATURE REVIEW $\ldots \ldots \ldots \ldots \ldots \ldots \ldots$. . . . . . . . $5-1$

5.2 ROCK-JOINT LABORATORY EXPERIMENTS $\ldots \ldots \ldots \ldots \ldots \ldots \ldots$. . . . . . $5-1$ 


\section{CONTENTS}

5.3 ROCK-JOINT MODELS AND ASSOCIATED COMPUTER CODE

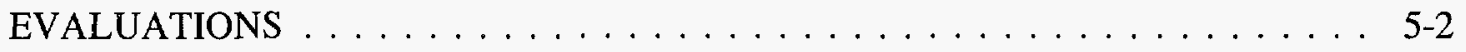

5.4 ROCK MASS DYNAMIC RESPONSE FIELD STUDY AND LABORATORY

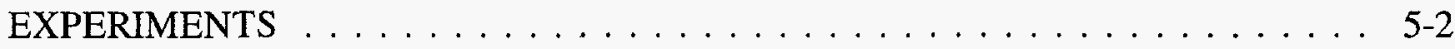

5.5 HYDROLOGIC RESPONSE FIELD STUDY $\ldots \ldots \ldots \ldots \ldots \ldots \ldots \ldots \ldots$

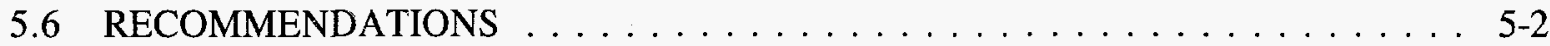

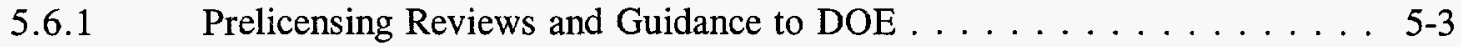

5.6.2 Development of CDMs for LARP . . . . . . . . . . . . . . 5-3

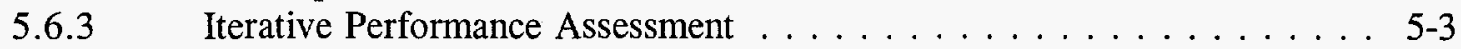

5.6.4 Further Development of Analytical Capabilities for LA Review . . . . . . 5-4

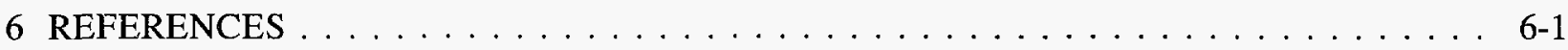




\section{FIGURES}

Figure

Page

2-1 A typical normal stress versus normal deformation response of natural joints in Apache Leap tuff . . . . . . . . . . . . . . . . . . . . . . . 2-4

2-2 Joint closure as a function of normal stress (from Barton et al., 1985) . . . . . . . . 2-5

2-3 Constant normal load and constant normal displacement shearing modes(modified from Brady and Brown, 1985) . . . . . . . . . . . . . . . . . . . 2-6

2-4 Characteristics of shear stress versus shear displacement curves following Goodman (1976) . . . . . . . . . . . . . . . . . . . . . . . . . . 2-7

2-5 Shear stress versus shear displacement response in Test 11 with Apache Leap tuff. The same specimen was subjected to increasing normal load in each cycle. . . . . . . . 2-9

2-6 Shear stress versus shear displacement response in Tests 7 through 11 . The plot shows only the first cycle of each test, which was carried out with a normal stress decrease of $1 \mathrm{MPa}$ starting from $1 \mathrm{MPa}$, in Test $7 \ldots \ldots \ldots \ldots \ldots \ldots$ 2-10

2-7 Shear stress versus shear displacement response for test no. 29 under applied normal

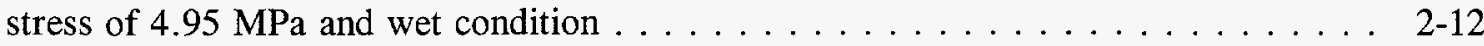

2-8 Normal displacement (dilation) response for test no. 29 under applied normal stress of $4.95 \mathrm{MPa}$ and wet condition . . . . . . . . . . . . . . . . . . . 2-13

2-9 Typical normal versus shear displacement curves for Apache Leap tuff samples . . . . 2-16

2-10 Shear stress versus shear displacement histories between 5 th and 6th seconds of the first phase of Test 14 with $1 \mathrm{MPa}$ normal stress, $1.4 \mathrm{~Hz}$ input frequency, and 12.7 mm input amplitude . . . . . . . . . . . . . . . . . . . . . 2-18

2-11 Normal stress and normal displacement (dilation) histories between 5 th and 6 th second of the first phase of Test 14 with $1 \mathrm{MPa}$ normal stress, $1.4 \mathrm{~Hz}$ input frequency, and

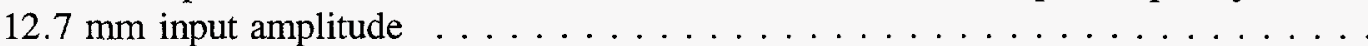

2-12 Displacement time history along the south direction of 8.1 Richter scale earthquake, September 19, 1985, in Mexico . . . . . . . . . . . . . . . . . . 2-21

2-13 Displacement spectra for the time history in Figure $2-10 \ldots \ldots \ldots \ldots$. . . . . . .

2-14 Shear stress and shear displacement history of the first of Test 24 using the displacement signal of Figure 2-10 with a maximum amplitude of $25.4 \mathrm{~mm}$. . . . . 2-23

2-15 Normal stress and normal displacement (dilation) histories between 15th and 20th seconds of the first phase of Test 24 with $1 \mathrm{MPa}$ normal stress and $25.4 \mathrm{~mm}$ maximum displacement amplitude .

2-16 Shear stress versus shear displacement curve for the first phase of Test 14 under a harmonic load with $1.4 \mathrm{~Hz}$ input frequency and $12.7 \mathrm{~mm}$ input displacement amplitude (first three cycles and the 40 th cycle) $\ldots \ldots \ldots \ldots \ldots \ldots$. . . . . . . . . . 25

2-17 Shear stress versus shear displacement curve for the first phase of Test 24 under an earthquake load with maximum input displacement amplitude of $25.4 \mathrm{~mm} \ldots \ldots$. . 2-25

2-18 Conceptual model of joint shear behavior during forward and reverse shear

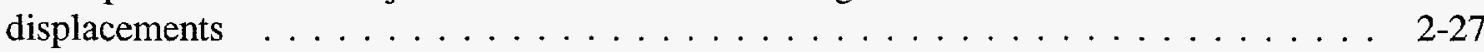

2-19 Effect of input frequency (shearing velocity) on peak joint shear strength . . . . . . 2-29

2-20 Effect of input frequency (shearing velocity) on joint shear resistance on reverse

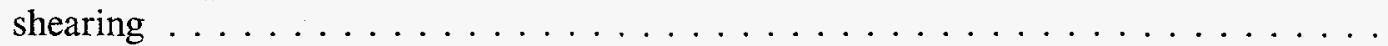




\section{FIGURES}

Figure

Page

2-21 Joint normal displacement (dilation) versus shear displacement for the first phase of Test 14 under a harmonic load with $1.4 \mathrm{~Hz}$ input frequency and $12.7 \mathrm{~mm}$ input displacement amplitude (first three cycles and the 40 th cycle) $\ldots \ldots \ldots \ldots \ldots \ldots$

2-22 Joint normal displacement (dilation) versus shear displacement for the first phase of Test 24 under an earthquake load with a maximum input displacement amplitude of

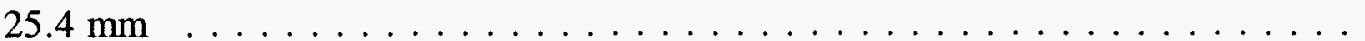

2-23 Schematic diagram of rock-joint behavior in Coulomb-Slip model of UDEC version 1.83 (ITASCA Consulting Group, Inc., 1992) . . . . . . . . . . . . . . . . .

2-24 Barton-Bandis rock joint model for shear stress versus shear displacement modeling (Barton et al., 1985)

2-25 Prediction of joint behavior using Coulomb Slip model assuming that shear stiffness $=16.93 \mathrm{GPa} / \mathrm{m}$, friction angle $=38^{\circ}$, dilation angle $=2.4^{\circ}$, and normal stress $=3 \mathrm{MPa}$ (assuming critical shear displacement is not reached) . . . . . . . . .

2-26 Prediction of joint behavior using Coulomb-Slip model assuming that shear stiffness $=16.93 \mathrm{GPa} / \mathrm{m}$, friction angle $=38^{\circ}$, dilation angle $=2.4^{\circ}$, and normal stress $=3 \mathrm{MPa}$ (assuming critical shear displacement has been reached) . . . . . . . . .

2-27 Prediction of joint behavior using Barton-Bandis model assuming joint wall compressive strength $=170.5 \mathrm{MPa}$, residual friction angle $=28.4^{\circ}$, joint roughness coefficient $=7.1$, and normal stress $=3 \mathrm{MPa} \ldots \ldots \ldots \ldots$

2-28 Prediction of joint behavior using Continuously-Yielding model assuming a constant shear stiffness $=29.312 \mathrm{GPa} / \mathrm{m}$, initial frictional angle $=39.3^{\circ}$, basic friction angle $=33.5^{\circ}$, roughness parameter $=0.0175$, and normal stress $=3 \mathrm{MPa} \ldots \ldots$. . 2-42

Final UDEC model for simulating laboratory tests on Apache Leap tuff specimens -244

2-30 UDEC results using Coulomb-Slip joint model and laboratory test results of shear stress versus shear displacement for the same joint specimen as a function of normal

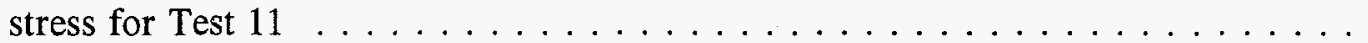

2-31 UDEC results using Barton-Bandis joint model and laboratory test results of shear stress versus shear displacement for the same joint specimen as a function of normal

2-32 UDEC results using Continuously-Yielding joint model and laboratory test results of shear stress versus shear displacement for the same joint specimen as a function of

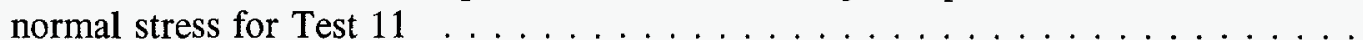

2-33 UDEC results using Coulomb-Slip joint model and laboratory test results of normal displacement versus shear displacement for the same joint specimen as a function of normal stress for Test 11

2-34 UDEC results using Barton-Bandis joint model and laboratory test results of normal displacement versus shear displacement for the same joint specimen as a function of normal stress for Test 11

2-35 UDEC results using Continuously-Yielding joint model and laboratory test results of normal displacement versus shear displacement for the same joint specimen as a function of normal stress for Test 11 


\section{FIGURES}

Figure

Page

3-1 Possible paths a specimen at various force-displacement states may follow (from

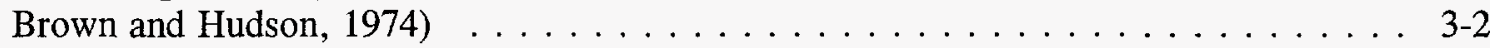

3-2 Behavior under cyclic fatigue (from Brown and Hudson, 1974) . . . . . . . . . . 3-2

3-3 Displacement measurement for extensometer No. 3 at LFM95-C1 site . . . . . . . . . 3-5

3-4 Displacement measurement for extensometer No. 5 at LFM95-C2 site . . . . . . . . . 3-6

3-5 Distribution of mine seismic events at Lucky Friday Mine near the instrument

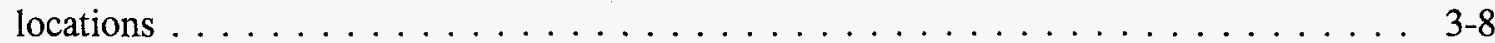

3-6 Closure of mine opening at $\mathrm{LFM} 95-\mathrm{Cl}$ site $\ldots \ldots \ldots \ldots \ldots$. . . . . . . . . . . . 3-9

3-7 Closure of mine opening at LFM95-C2 site . . . . . . . . . . . . . . . . . . . 3-10

3-8 Damage recorded at the LFM95-C2 site due to the May 22 and 23, 1991, events . . 3-12

3-9 Damage recorded at the LFM95-C2 site due to the November 11, 1991, event . . . . 3-13

3-10 Conceptual model of underground rock mass with opening . . . . . . . . . . 3-15

3-11 Physical design of scale-model rock mass with opening . . . . . . . . . . 3-18

3-12 Instrumentation on and near the opening . . . . . . . . . . . . . . . 3-19

3-13 Horizontal table displacement for scale model earthquake data set 14: maximum input

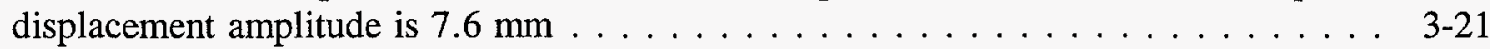

3-14 Near side tunnel block displacement for data set 14: maximum input displacement

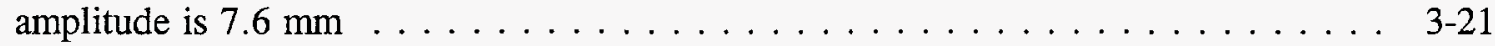

3-15 Relative displacement along the joint in the left of the tunnel wall (near side) for data set 14: maximum input displacement amplitude is $7.6 \mathrm{~mm} \ldots \ldots \ldots \ldots \ldots$. . . . . . . 22

3-16 Accumulated permanent shift of ingots on far side of opening at end of test series . . . 3-22

3-17 Permanent tunnel closure resulting from each run . . . . . . . . . . . 3-23

4-1 Zones packed off for water pressure measurement along the borehole drilled from Lucky Friday Silver Shaft at a depth of $1737 \mathrm{~m}$ below the ground surface . . . . . . . 4-6

4-2 Groundwater pressure history for Zone 1, September 18 through 20, $1991 \ldots$. . . . . 4-8

4-3 Groundwater pressure history for Zone 2, September 18 through $20,1991 \ldots$. . . . 4-8

4-4 Groundwater pressure history for Zone 3, September 18 through 20, $1991 \ldots$. . . . . 4-9

4-5 Groundwater pressure history for Zone 1, March 21 through April 10, 1991 . . . . . . 4-9

4-6 Groundwater pressure history for Zone 2, March 21 through April 10, 1991 . . . . . 4-10

4-7 Groundwater pressure history for Zone 3, March 21 through April 10, 1991 . . . . . 4-10

4-8 Change in groundwater pressure with scaled distance . . . . . . . . . . . 4-11 


\section{ACKNOWLEDGMENTS}

This report was prepared to document work performed by the Center for Nuclear Waste Regulatory Analyses (CNWRA) for the Nuclear Regulatory Commission (NRC) under Contract No. NRC-02-93-005. The activities reported here were performed on behalf of the NRC Office of Nuclear Regulatory Research, Division of Regulatory Applications. The report is an independent product of the CNWRA and does not necessarily reflect the views or regulatory position of the NRC.

The authors would like to thank W.C. Patrick and B. Sagar for the review of the report. The authors are thankful to Yolanda Lozano for skillful typing of the report and to J.W. Pryor, who provided a full range of expert editorial services in the preparation of the final document.

\section{QUALITY OF DATA}

All CNWRA-generated original data contained in this report meet the quality assurance requirements described in the CNWRA Quality Assurance Manual. Sources for other data should be consulted for determining the level of quality for those data.

\section{SOFTWARE QUALITY ASSURANCE}

The finite element codes HONDO II and SPECTROM-331, discrete element code DECICE, and distinct element codes UDEC and 3DEC were used for some of the analyses contained in this report. UDEC is controlled under the CNWRA Software Configuration Procedures. Other codes are commercially available, and the CNWRA does not have access to their source codes; therefore, they are not controlled under the CNWRA Software Configuration Procedures. 


\section{PREVIOUS REPORTS IN SERIES}

Number

CNWRA 90-004

CNWRA 90-005

CNWRA 90-006

NUREG/CR-5440

NUREG/CR-5817

Vol.1

CNWRA 92-012

NUREG/CR-5817,

Vol. 2

CNWRA 92-02S

NUREG/CR-5817, Vol. 3, No. 1

NUREG/CR-6178

NUREG/CR-6216

NUREG/CR-6283

CNWRA 95-012

CNWRA 93-01S
Name

Date Issued

Qualification Studies on the Distinct Element Code

UDEC Against Some Benchmark Analytical Problems

Development of a Rock Joint Dynamic Shear

Apparatus Test

January 1990

Qualification Studies on the Finite Element Code

HONDO II Against Some Benchmark Analytical Problems

February 1990

Critical Assessment of Seismic and Geomechanics

Literature Related to a High-Level Nuclear Waste

Underground Repository

Report on Research Activities for Calendar Year 1990

December 1991

Field Site Investigation: Effect on Mine Seismicity on a Jointed Rock Mass

December 1992

NRC High-Level Radioactive Research at CNWRA

Calendar Year 1991

May 1993

NRC High-Level Radioactive Waste Research at CNWRA December 1992 July-December 1992

NRC High-Level Radioactive Research at CNWRA. January-June 1992

May 1993

Laboratory Characterization of Rock Joints

May 1994

Evaluation of Rock Joint Models and Computer Code UDEC Against Experimental Results

November 1994

Field Site Investigation: Effect of Mine

Seismicity on Groundwater Hydrology

April 1995

An Experimental Model Study of Seismic

June 1995

Response of an Underground Opening in Jointed

Rock Mass

NRC High-Level Radioactive Waste Research at CNWRA January-June 1993

June 1993 


\section{PREVIOUS REPORTS IN SERIES (CONT'D)}

Number

CNWRA 94-01S

CNWRA 94-02S
Name

Date Issued

NRC High-Level Radioactive Waste Research at CNWRA June 1994 January-June 1994

NRC High-Level Radioactive Waste Research at CNWRA December 1994 July-December 1994 


\section{RELATED PUBLICATIONS}

Chowdhury, A.H., S.M. Hsiung, and M.P. Ahola. 1992. Options for dynamic analysis of underground facilities. Pre-Symposium Volume of ASCE Symposium on Dynamic Analysis and Design Considerations for High-Level Nuclear Waste Repositories. San Francisco, CA.

Hsiung, S.M., B.H.G. Brady, A.H. Chowdhury, and J. Philip. 1990. Verification studies on the UDEC computer model of jointed rock. Proceedings of the International Conference on Mechanics of Jointed and Faulted Rock. Vienna, Austria: Technical University of Vienna.

Hsiung, S.M., S.D. McKinnon, A.H. Chowdhury, B.W. Vanzant, and J. Philip. 1991. Field investigations for seismic effects on mechanical and geohydrologic response of underground structures in jointed rock. Proceedings of the Second International High-Level Radioactive Waste Management Conference. La Grange Park, IL: American Nuclear Society.

Hsiung, S.M., D.D. Kana, M.P. Ahola, A.H. Chowdhury, B.H.G. Brady, and J. Philip. 1991. Experimental techniques for dynamic shear testing of natural rock joints. Proceedings of the Seventh International Congress on Rock Mechanics. Aachen, Germany: International Society for Rock Mechanics.

Hsiung, S.M., A.H. Chowdhury, W. Blake, and J. Philip. 1993. Field investigation of mining-induced seismicity on local geohydrology. Proceedings of the Fourth International High-Level Radioactive Waste Management Conference and Exposition. La Grange Park, IL: American Nuclear Society: 913-920.

Hsiung, S.M., A. Ghosh, M.P. Ahola, and A.H. Chowdhury. 1993. Assessment of conventional methodologies for joint roughness coefficient determination. International Journal of Rock Mechanics and Mining Sciences and Geomechanics Abstracts 30(7): 825-830.

Hsiung, S.M., W. Blake, A.H. Chowdhury, and T.J. Williams. 1993. Effects of mining-induced seismic events on a deep underground mine. Pure and Applied Geophysics 139(3/4): 741-762.

Hsiung, S.M., A. Ghosh, and A.H. Chowdhury. 1994. An investigation of rock joint models on prediction of joint behavior under pseudostatic cyclic shear loads. Proceedings of the 1st North American Rock Mechanics Symposium. University of Texas at Austin: Austin, TX.

Hsiung, S.M., A. Ghosh, A.H. Chowdhury, and M.P. Ahola. 1995. Laboratory investigation of rock joint dynamic behavior. Proceedings of the Second International Conference on the Mechanics of Jointed and Faulted Rock. Rotterdam, The Netherlands: A.A. Balkema.

Kana, D.D., B.W. Vanzant, G.H.G. Brady, and P.K. Nair. 1989. An assessment of dynamic response prediction for a high-level nuclear waste underground repository. Transaction of the 10th International Conference on Structural Mechanics in Reactor Technology. Vol. R: 45-56.

Kana, D.D., S.M. Hsiung, and A.H. Chowdhury. 1995. A scale model study of seismic response of an underground opening. Proceedings of the 35th U.S. Symposium of Rock Mechanics. University of Nevada: Reno, NV. 



\section{EXECUTIVE SUMMARY}

The Rock Mechanics research project being conducted at the Center for Nuclear Waste Regulatory Analyses (CNWRA) has two major components: (i) investigation of seismic response of rock joints and jointed rock mass and (ii) study of coupled thermal-mechanical-hydrological (TMH) response of a jointed rock mass surrounding the engineered barrier system (EBS). This final report summarizes the research activities associated primarily with the first component of this project, presents the results, and provides recommendations for use of these results toward supporting the repository licensing function of the Nuclear Regulatory Commission (NRC). The research has been conducted with the twin focus of understanding the key parameters affecting repository performance under repeated seismic loading and evaluating current capabilities for calculating such effects. This research project uses computational methods and laboratory and field experiments to achieve its goals.

Long-term stability of emplacement drifts and potential near-field fluid flow resulting from coupled effects are among the concerns for safe disposal of high-level nuclear waste (HLW). A number of factors can induce drift instability or change the near-field flow patterns. Repetitive seismic loads from earthquakes, and thermal loads generated by the decay of emplaced waste are two significant factors. One of two key technical uncertainties (KTU) that can potentially pose a high risk of noncompliance with the performance objectives of 10 CFR Part 60 is the prediction of thermal-mechanical (including repetitive seismic load) effects on the stability of emplacement drifts and engineered barrier system. The second KTU of concern is the prediction of thermal-mechanical-hydrological (including repetitive seismic load) effects on the host rock surrounding the engineered barrier system. The research activities presented in this report are concerned with the repetitive seismic load aspect of both these KTUs.

At the inception of this project, a literature review was conducted to establish the state of knowledge relevant to dynamic performance of underground excavations. Critical assessment of the information identified several technical deficiencies and areas of limited understanding related to dynamic responses of underground structures excavated in fractured rock mass. Furthermore, the knowledge gained in this literature search was used to formulate the laboratory and field experiments conducted in this research project.

As part of this research project, a laboratory testing program on the characterization of rock joints was undertaken. The purposes of the program were to (i) generate a reliable data set for the response of natural joints to dynamic loads for understanding the key seismic parameters that will affect repository design and performance, and (ii) evaluate the existing rock-joint constitutive models for representing dynamic behavior. Activities performed under this effort included collecting jointed rock cores from the Apache Leap site, near Superior, Arizona and preparing specimens for direct joint shear tests; developing a direct shear test apparatus and a profilometer to measure the roughness of joint surfaces; conducting cyclic pseudostatic joint shear tests and dynamic joint shear tests under harmonic and earthquake loads; and characterizing mechanical properties of intact rock associated with the rock joints.

Under both cyclic pseudostatic and dynamic loads, direct shear tests on Apache Leap tuff joints indicated that the shear resistance upon reverse shearing is smaller than that of forward shearing. A major portion of joint dilation as a result of forward shearing recovers during reverse shearing. Both forward and reverse joint shearing are important phenomena for rock joints subjected to earthquake and thermal loads, unlike static load in which only forward shearing is of concern. Failure to consider the effect of reverse 
shearing on joint behavior when designing an underground structure or when analyzing its performance levels can result in overestimating the stability of emplacement drifts.

Within the range of the variation of shearing velocity used in these tests, the shearing velocity effect on rock-joint behavior seems to be minor. No noticeable effect on the peak joint shear strength and the joint shear resistance for reverse shear is observed. Unlike the cyclic pseudostatic and earthquake shear tests, the dilation curves resulting from the harmonic tests showed numerous high-frequency, stick-slip oscillations. The dynamic input also affected the size of dilation hysteresis. The dilation hysteresis for the harmonic and earthquake tests was smaller than that for the cyclic pseudostatic tests.

A program of assessment of rock joint models and qualification of the associated computer codes was also undertaken. The goal of the program was to evaluate the ability of existing rock joint models and the associated computer codes to represent dynamic or cyclic joint behavior. There were two phases in this program. In the first phase, a few commercially available computer codes were selected and evaluated using four benchmark problems involving a rock joint. These problems had closed-form solutions or suitable approximations to closed-form solutions. These commercially available codes included the distinct element codes UDEC (version 1.5) and 3DEC (version 1.0), the discrete element code DECICE, and the finite element codes HONDO II and SPECTROM 331. This first-phase study showed that only the UDEC and 3DEC (which is, in general, a three-dimensional version of UDEC) were able to reproduce the response of all four benchmark problems. As a result, they became candidates for the second-phase study in which the dynamic response of direct shear experiments on natural rock-joint surfaces would be analyzed.

The objective of the second phase of the qualification study was to determine if the existing rock joint models and the associated computer codes can simulate the laboratory experimental behavior of natural rock joints subjected to cyclic pseudostatic and dynamic loads. This phase of qualification study was conducted to address one of the findings of the literature review that there were no validated rock joint models and verified computer codes for analyzing response of jointed rock mass subjected to seismic loading. Three commonly used empirical representations for rock-joint behavior - Coulomb-Slip, Barton-Bandis, and Continuously-Yielding models - were examined in their fundamental forms, that is, using the proposed equations, to assess their abilities to predict joint behavior. These models were developed primarily for unidirectional shearing, although in later publications a procedure was given to use the original equations of Barton-Bandis model in reverse shearing direction. The modified procedure to Barton-Bandis model does not include the recovery of joint dilation in reverse direction and seems to be inconsistent with theoretical understanding of the phenomenon taking place during reverse shearing. The numerical implementation for each of these three models in the UDEC versions 1.82 and 1.83 was also evaluated by modeling five cyclic pseudostatic tests, one harmonic test, and one earthquake test on Apache Leap tuff joints. Careful examination of these results revealed that the Coulomb-Slip and Continuously-Yielding models, as implemented in these two versions of UDEC, have adopted essentially the same joint behaviors under both forward and reverse shearing conditions. The modified form of the Barton-Bandis model, as implemented in a later version of the UDEC, code was not evaluated in this report. It has a procedure to use the forward shearing equations for the reverse shearing. The CoulombSlip joint model further assumes that no joint wear will occur under either forward or reverse shearing conditions. The other two models explicitly consider the joint wear, that is, the roughness property, as a function of joint shear displacement. To preserve the necessary continuity in joint wear in case of changing direction of shear, Continuously-Yielding joint model asserts that the remaining friction property at the end of the forward shearing process should control the joint response in the reverse shearing process. In other words, the shear strength at the end of the forward shearing is considered to 
be the peak shear strength at the beginning of the reverse shearing. To simulate shear response in reverse direction, the Barton-Bandis model, takes into account only the residual friction angle if the shear reversal occurs in the pre-peak region and the ultimate friction angle, which is larger than the residual friction angle, if the shear reversal occurs in the post-peak region. Effect of remaining roughness, in terms of $\mathrm{JRC}$, of the surfaces is ignored in the procedure. As the dilation of the Barton-Bandis model is directly related with $\mathrm{JRC}$, this procedure fails to account for dilation recovery observed in experiments during reverse shearing. This procedure seems to be inconsistent with the theoretical understanding of the phenomenon and experimental observations available in the literature. The implementations of these three models in the UDEC code (versions 1.82 and 1.83) primarily follow the principle described for the Continuously-Yielding model. As a result, neither these models nor their implemented versions in the UDEC code (versions 1.82 and 1.83$)^{1}$ can simulate satisfactorily the joint shear experimental behavior during reverse shearing in which the shear strength is different from that at the end of the forward shearing.

The Barton-Bandis and Continuously-Yielding joint models link joint dilation due to shearing directly with the roughness properties. Since a joint continues to wear during the process of shearing, the dilation angle used to calculate joint dilation continues to decrease. This condition implies, therefore, that a joint will eventually stop dilating when it is completely worn. The Coulomb-Slip joint model calculates dilation based on a constant dilation angle. Dilation starts when shear strength is reached and stops when a critical shear displacement is reached.

A dilation versus shear displacement curve, predicted by the Barton-Bandis model implemented in the UDEC code (versions 1.82 and 1.83), reaches a constant value after a small shear displacement. ${ }^{2}$ This constant value is significantly smaller than the peak dilation observed in laboratory experiments. The Coulomb-Slip model implemented in the UDEC code (versions 1.82 and 1.83) predicts complete recovery of joint dilation only if the critical shear displacement is not reached. However, if the critical shear displacement is exceeded during forward shearing, dilation remains constant during the remaining period of forward shearing and the entire period of reverse shearing.

The Lucky Friday Mine, owned and operated by Hecla Mining Company and located in the Coeur d'Alene region, Idaho, was selected for studying the effect of repetitive seismic motions on excavation stability and the effect of seismic waves on groundwater pressure. More than 50 seismic events with a local Richter magnitude of 1 or larger were recorded during the 2 -yr duration of this study. The maximum magnitude recorded was about 3.5. Field measurement indicated that an underground opening may respond to mining-induced seismicity with step changes in displacements of the rock mass around the opening or step changes in opening closures. The openings at the two sites selected for the study responded to seismic events with peak particle velocities as low as $104 \mathrm{~mm} / \mathrm{s}$ and $134 \mathrm{~mm} / \mathrm{s}$. However, some seismic events with peak particle velocities greater than these did not have any noticeable effect on the openings. Also, mine seismic events with a similar magnitude of peak particle velocities did not seem to induce the same responses. Step changes in displacement or closure may have also been induced by activities such as ore mining, rock mass time-dependency, or other mining-related activities. Depending

\footnotetext{
${ }^{1}$ CNWRA validation studies resulted in correction of the UDEC-BB coding to make its prediction of rock joint behavior in the reverse direction consistent with the Barton-Bandis model described by Barton (1982) (Christianson, M. 1995. Modifications to the Barton-Bandis Joint Model in UDEC. Minneapolis, MN: ITASCA Consulting Group, Inc.).

${ }^{2}$ In the implementation of Barton-Bandis model in UDEC, joint dilation calculation has been recently revised (Christianson, M. 1995. Modifications to the Barton-Bandis Joint Model in UDEC. Minneapolis, MN: ITASCA Consulting Group, Inc.).
} 
upon the state of stress on a joint or a bedding plane, different energy inputs are required for the state of stress to reach the failure strength and thus induce slip along these discontinuities. As a result, two seismic events with the same peak particle velocity may induce different responses. Repetitive episodes of seismic events cause an accumulation of joint displacement. The mechanism of accumulation of joint displacement is analogous to stress fatigue phenomenon commonly observed for natural or artificial materials. Materials are normally weaker under fatigue conditions. This fact implies that similar or even more damage to an opening may occur due to a number of seismic events with relatively smaller magnitudes as opposed to the damage due to a single relatively stronger event.

The hydrologic effects of earthquakes are related to changes in the water conductivity and storage capacity of rocks, which result from rock deformations (opening or closure of pores and fractures) caused by stress changes associated with the earthquake. The effects include changes in groundwater pressure and discharge rate through springs, wells, and streams. Some earthquake-induced hydrologic responses develop and dissipate rapidly (within a matter of hours or a few days following the earthquake). The responses are believed to be caused by changes induced directly by the seismic waves; these are referred to as the short-term response. The others, known as the long-term response, develop more slowly and persist for a longer period of time (up to about 12 months) following the earthquake; they are thought to be caused by changes in tectonic stress and displacements occurring both before and after the earthquake and may also be dependent on storativity and fracture connectivity of the medium.

Field studies on the nature and magnitude of hydrologic responses generated by mining-induced small-magnitude earthquakes were conducted at the Lucky Friday Mine, Idaho. Effects on groundwater pressure of more than 50 seismic events of Richter magnitude 1 or larger were observed over a 2-yr period using piezometers installed in isolated sections of a 360-m long inclined borehole, drilled from the 5700-level station of the mine. Each isolated section contains at least one fracture zone or mineralized vein that locally controls fluid flow. The field work included the normal seasonal hydrologic variations, diurnal variations, mining-induced water table drawdown, and the earthquake-induced changes. The data collected were insufficient to enable the separation of possible earthquake-induced, long-term effects from the ambient response. On the other hand, the data were sampled frequently enough to recognize several episodes of earthquake-induced, short-term effects.

The observed effects consist mainly of an increase in groundwater pressure, though decreases were observed in some areas. Most of the observed changes developed rapidly, almost at the same time as the causal seismic event, and dissipated within $24 \mathrm{hr}$, thereafter. In general, the magnitude of groundwater pressure change increased with increasing event magnitude. For a given event magnitude, the groundwater pressure change decreased with increasing distance from the source location. Regression analyses were performed in an attempt to model the groundwater pressure change as a function of earthquake magnitude and source distance. The results showed that the statistical models poorly explained the variation in the data. Greater understanding of the underlying phenomena is needed to explain the variation of groundwater pressure observed in the Lucky Friday Mine. 


\section{INTRODUCTION}

\subsection{BACKGROUND AND OBJECTIVES}

The proposed high-level nuclear waste (HLW) repository at Yucca Mountain, Nevada, is to be placed about $350 \mathrm{~m}$ beneath the surface in the densely welded and devitrified part of the Topopah Spring (TSw2 unit) member of the Paintbrush tuff. The proposed repository horizon is about $225 \mathrm{~m}$ above the water table. The Yucca Mountain (YM) area is characterized by north to northwest trending mountain ranges composed of volcanic and volcanoclastic strata that dip eastward. The strata are broken into en-echelon fault blocks. The geomechanical conditions at the site are characterized by a highly fractured rock mass with prominent vertical and subvertical faults and joints. Although the International Society for Rock Mechanics (1978) suggested that the general term discontinuity be used to refer collectively to joint, fracture, fault, bedding plane, in this report the terms joint and fracture are also used. It should be noted that the terms fracture and joint are used interchangeably.

The four common geomechanics objectives related to performance of an underground excavation (Brady and Brown, 1985; Kana et al., 1991) are as follows:

(i) To ensure the overall stability and integrity of the complete rock structure, defined by mined excavations, pillar support elements, and adjacent host rock

(ii) To protect the major service openings throughout their designed duty life

(iii) To provide secure access to safe working places in and around operating activities

(iv) To preserve the integrity of and limit disruption to the host rock mass.

In the case of a mined geologic repository, achievement of these objectives is much more complicated than for other subsurface engineering structures due to the exceptionally long time period through which the openings need to be stable and the long-term performance requirements. For example, the time scale ( $\geq 10,000 \mathrm{yr}$ ) mandated for effective waste isolation calls for a broad and in-depth understanding of rock mass behavior and its associated groundwater system over a period that transcends the domain of current underground rock engineering experience. Currently available design methodology for underground openings can predict the stability for a period of only $50 \mathrm{yr}$ (Hoek and Brown, 1980). Moreover, the current design methodology does not take into account the potential effects of repetitive episodes of seismic events. The proposed repository will experience repeated episodes of the seismic motions over its designed lifetime.

Two key technical uncertainties (KTUs) that can pose a high risk of noncompliance with the performance objectives of $10 \mathrm{CFR}$ Part 60 are the prediction of thermal-mechanical (including repetitive seismic load) effects on stability of emplacement drifts and engineered barrier system (EBS), and the prediction of thermal-mechanical-hydrological (including repetitive seismic load) effects on the hot rock surrounding the engineered barrier system (EBS). The fractured rock mass will be perturbed in several ways that can affect the preclosure and postclosure performance of a HLW repository. The spatial scale of interest is the nearfield surrounding the excavations, including the emplacement drifts. First, the construction of the proposed repository changes the state of stress, which, in turn, causes mechanical deformation of the rock, including joint normal and shear deformations. Normal and shear deformations 
along the joints affect the stability of the excavations. They also affect fluid flow and solute transport in the rock mass. Second, the nuclear waste provides a heat source that is active over an extended period of time. The thermal load induces rock expansion, which may cause opening, closure, shear, and dilation of fractures. The integrity of the intact rock blocks and, consequently, the permeabilities of both matrix and fractures may change accordingly. Third, dynamic ground motions due to earthquakes and nearby underground nuclear explosions over the intended life of the proposed repository can affect its preclosure and postclosure performance. The repetitive nature of the seismic motion may induce further damage to the excavation. Movement along the joints and faults of the disturbed rock mass forms the primary mode of deformation of the nearfield rock mass. Excessive slippage of a rock block along joints may affect the performance of waste canisters inside the drifts.

A state-of-the-art literature review (Kana et al., 1991a) revealed that repetitive ground motions due to seismic activities may impact both the short- and long-term performance of a repository. The fundamental failure mechanism for an excavation subjected to repetitive seismic loading is through accumulation of shear displacements along joints. Specific seismic implications to repository design and performance may include cumulative effects of repetitive seismic loads on (i) emplacement drift stability, and (ii) change of permeability of rock surrounding the waste package, including potential creation of preferential water pathways which might connect the emplacement area with perched water zones, neighboring steep hydraulic gradient zones, or the moisture condensation zone above the emplacement area. These cumulative effects cannot be analyzed by extrapolation of response data from a single earthquake or nuclear test. New techniques need to be established to simulate a rock mass that has been subjected to repetitive seismic waves. An approach to developing such techniques includes (i) determination of the significance of the geomechanical response due to repetitive seismic events, (ii) establishment of reliable data sets that permit a better understanding of important parameters controlling the joint dynamic behavior and that reflect the relation between geomechanical responses and repetitive seismic events in a properly characterized rock mass, and (iii) determination of the adequacy of currently available rock-joint models to describe the dynamic behavior of rock joints.

Ground motion in the subsurface is significantly different from ground motion on the surface, where most research has been focused to date. Moreover, a jointed rock mass exhibits constitutive behavior quite different from that of soil. Thus, experience gained in analysis, design, and performance prediction for surface structures founded on soil is not highly relevant to the problem of dynamic analysis of underground excavations in rock.

The effects of earthquakes on groundwater flow may have some implications with respect to the performance of an underground repository. For example, it may affect the distribution of hydraulic gradient and, consequently, the groundwater travel time (GWTT). It may also affect the possibility of water flow toward the waste package. In order to understand such implications, techniques are required for the simulation of both rock mass and groundwater response to earthquakes. A reliable set of field data reflecting the relationship between seismically induced hydrologic changes and the causal earthquakes would contribute to the development of the required simulation techniques.

There is a particular need to validate models and verify the codes for dynamic analysis of underground excavations for nuclear waste isolation because of the complexity of the processes involved in deformation of jointed media, and prevailing questions about the adequacy of the constitutive relations describing the dynamic behavior of rock joints and faults, as have been identified during the comprehensive literature review. The main emphasis in validation of the models and verification of codes 
for dynamic analysis of repository design problems must be placed on execution of dynamic physical model tests, field studies, and related computational analysis.

The research activities reported herein are concerned with the repetitive seismic load aspect of both KTUs. This research project has the dual focus of (i) understanding the key parameters affecting repository performance under repeated seismic loadings, and (ii) evaluating current capabilities for calculating such effects. This research project uses computational methods and laboratory and field experiments to achieve its goals.

The objectives of this research project include:

- Critically assess, by conceptual models and experimental studies, the capabilities and limitations of analytical modeling tools currently in use for seismic analysis of underground structures

- Demonstrate by laboratory studies and instrumented field studies, the degree of validation for the analytical models and verification of computer codes used for seismic analysis of underground structures

- Assess, by instrumented field studies, the significance of seismic effect on water pressure

- Identify and assess the key seismic-related parameters that are applicable to the Yucca Mountain site

- Generate technical data for preparing licensing-related positions as they relate to the effect of seismic action on the underground repository

\subsection{LICENSING NEED}

The cumulative effects of repetitive seismic loads have implications regarding the design of underground structures and three performance objectives in 10 CFR Part 60 for the: (i) retrievability of waste requirement stated in 10 CFR 60.111; (ii) containment and radionclide release rate requirements for the waste packages and the EBS stated in 10 CFR 60.113(a)(1), and (iii) isolation requirements of the host rock stated in 10 CFR 60.112 .

The knowledge gained through laboratory, field, and numerical analysis in this research project will be needed for the Nuclear Regulatory Commission (NRC) prelicensing activities including reviews of seismic design methodology topical reports, Exploratory Studies Facility (ESF) design packages, and repository Advanced Conceptual Design (ACD). Another need is to support the ongoing development of the NRC License Application Review Plan (LARP) (Nuclear Regulatory Commission, 1994). More specifically, Compliance Determination Methods (CDMs) currently being developed for the LARP will specify the approach and acceptance criteria that the NRC will use to judge compliance with design and performance objectives and other regulatory requirements. The research results will be needed for the following CDMs: (i) CDM 4.4-Assessment of Compliance with Design Criteria for the Underground Facility, (ii) CDM 4.5.2-Assessment of Integrated Compliance with the Performance Objectives: Retrievability of Waste, (iii) CDM 4.3-Assessment of Compliance with Design Criteria for Shafts and Ramps, (iv) CDM 5.2-Assessment of Compliance with the Design Criteria for the Waste Package and 
its Components, (v) CDM 5.3-Assessment of Compliance with the Design Criteria for the Post-Closure Features of the Underground Facility, (vi) CDM 5.4-Assessment and Engineered Barrier System Compliance with the Performance Objectives, and (vii) CDM 6.2-Assessment of Compliance with the Requirement of Cumulative Releases of Radioactive Materials.

The results of this research project will be of assistance in the Iterative Performance Assessment (IPA), including auxiliary analysis. Project results will also be used to develop abstracted models for waste package and total system performance assessment. 


\section{ROCK-JOINT RESPONSE}

The performance of an underground excavation with respect to its design objectives is controlled by the stresses and displacements that develop during and after excavation under the prevailing in situ stresses, imposed seismic stress field, ground water pressure distribution, and, in the case of a HLW repository, the applied thermal load generated by the emplaced waste. The spatial distribution of rock mass strength and deformability and especially the intersecting discontinuities such as joints, fractures, faults, and bedding planes make the stress distribution and associated deformation highly discontinuous. Being generally weak, these discontinuities will directly influence rock mass deformation and stability of the underground structures under various loading conditions (Hoek and Brown, 1980; Goodman and Shi, 1985; Amadei and Savage, 1993; Kana et al., 1991a). Conditions for slip on major pervasive features such as joints and faults or for the sliding of individual rock blocks, delineated by the intersecting discontinuities, from the boundaries of excavations are governed by the shear strengths that can be developed by the discontinuities concerned.

The conditions to be considered explicitly in assessing the performance of underground excavations include (i) joints under pseudostatic loading conditions, and (ii) joints under dynamic loading conditions. This chapter discusses the response of natural joints to both pseudostatic and dynamic loads, including the results and associated inferences from the direct shear tests conducted at the Center for Nuclear Waste Regulatory Analyses (CNWRA) using Apache Leap tuff specimens.

\subsection{ROCK-JOINT RESPONSE UNDER PSEUDOSTATIC LOADS}

The construction of an underground excavation changes the state of stress due to prevailing in situ stress fields and causes stress concentration around the opening. The induced deformation field includes both deformation of intact rock blocks and movement along discontinuities. Deformation of the discontinuities may occur as sliding and separation. Discontinuities, being generally weaker than the intact rock, can accommodate only a small amount of deformation before slipping. Excessive slippage along the joints and faults may have serious consequences on the excavation stability, option for retrievability, and postclosure performance of the repository. Reversal of shearing direction is an important phenomenon in rock-joint response, especially in the case of a HLW repository. Reverse shearing can result from earthquakes, nearby underground nuclear explosions, rock bursts, and repository thermal loading. In this section, some of the important characteristics of the response of natural rock joints to pseudostatic loads are discussed. This discussion includes the response to pseudostatic cyclic loading.

\subsubsection{Rock-Joint Response Under Normal Loads}

Surfaces of discontinuities in rock are generally rough. Consequently, the neighboring blocks will be in contact only at a few locations. These points of contact are mostly the large asperities of one block touching the adjoining block, a condition which creates the initial joint aperture. As the normal load is increased across the discontinuity, the original points of contact undergo elastic deformation due to stress concentration. If the stress concentration is sufficient, crushing and tension-cracking take place at the tips of these asperities. All these processes decrease the separation between the two surfaces. As a result, more asperities of one surface come in contact with asperities of the other surface. The stiffness of the joint increases as more load is necessary to deform these newly contacting asperities. There are two physical constraints on deformation of rock joints under normal loads (Goodman, 1976). First, an open joint has no tensile strength. Second, a joint can be compressed to a maximum limit $V_{m c}$. This value 
is smaller than the joint thickness, which is the maximum aperture or the maximum distance between the two surfaces measured normal to the surface. In other words, there will be a limiting aperture of the joint even at extremely high normal load.

The deformation process of a natural joint under normal load has been modeled experimentally and analytically by several investigators. Goodman (1976) defined the relationship of normal pressure $\sigma_{n}$ versus deformation (closure) $u_{n}$ of natural joints, satisfying the above-mentioned constraints as:

$$
\frac{\sigma_{n}-\zeta}{\zeta}=A\left(\frac{u_{n}}{V_{m c}-u_{n}}\right)^{t}
$$

when $u_{n}<V_{m c}$. In this equation, $\zeta$ is the seating pressure (value of $\sigma_{n}$ at $u_{n}=0$ ) that defines the initial condition, and $A$ and $t$ are empirical constants. The slope of the $\sigma_{n}-u_{n}$ curve gives the normal stiffness, $K_{n}$, of the joint. Because $\sigma_{n}-u_{n}$ relation is nonlinear, $K_{n}$ is strongly stress dependent.

Bandis et al. (1983) suggested another hyperbolic relationship between $\sigma_{n}$ and $u_{n}$ :

$$
\sigma_{n}=\frac{u_{n}}{\left(a-b \cdot u_{n}\right)}
$$

Alternatively,

$$
\frac{u_{n}}{\sigma_{n}}=a-\left(b \cdot u_{n}\right)
$$

where $a$ and $b$ are empirical constants. Normal stiffness, $K_{n}$, for any stress, $\sigma_{n}$, is (Bandis et al., 1983):

$$
K_{n}=\frac{K_{n i}}{\left(1-\frac{u_{n}}{V_{\mathrm{mc}}}\right)^{2}}
$$

or,

$$
K_{n}=K_{n i}\left(1-\frac{\sigma_{n}}{V_{\mathrm{mc}} \cdot K_{n i}+\sigma_{n}}\right)^{-2}
$$


Bandis et al. (1983) found that plots of $u_{n} / \sigma_{n}$ versus $u_{n}$ showed linearity for a large number of data sets irrespective of stress history, loading mode, and joint type. As $u_{n}$ becomes very large, $u_{n}$ tends to the limiting value $V_{\mathrm{mc}}$, equal to $a / b$. At maximum closure, the joint normal stiffness, $K_{n}$, becomes infinite. Eq. (2-2) suggests that the initial joint stiffness, $K_{n i}$, which is defined as the slope of $\sigma_{n}-u_{n}$ curve as $\sigma_{n} \rightarrow 0$, is equal to $1 / a$, Goodman (1976) observed that the curves for unloading cycles essentially follow similar paths as for the intact rock. This observation means the elastic part of the normal deformation in a rock sample with a joint is entirely due to the deformation of the rock. Joint compression is irrecoverable. Observations by Bandis et al. (1983) suggest that the phenomenon taking place is more complex than that suggested by Goodman (1976) in Eq. (2-1). The shape of the unloading part for a jointed sample is different from that of an intact rock. This difference is probably due to some contribution of the joint asperities in the elastic portion of the normal deformation. The unloading curve is also hyperbolic.

Results obtained in the CNWRA research activities on laboratory characterization of rock joints also confirm the observations of Bandis et al. (1983). In these activities, nineteen fresh joint specimens of Apache Leap tuff were tested under cyclic pseudostatic shear loading conditions. Prior to the shear test, five repeated normal load cycles was applied to each sample. A maximum normal pressure of 8.0 $\mathrm{MPa}$ was applied across the joint with the nominal surface area of $41,300 \mathrm{~mm}^{2}$. The time required to complete a loading-unloading cycle was approximately $10 \mathrm{~min}$. Details of the experiments and the associated instrumentation are given elsewhere (Hsiung et al., 1994a; Kana et al., 1990).

Figure 2-1 shows a typical normal stress versus normal deformation response of an Apache Leap tuff specimen. In this figure, the average joint closure measured by the four proximeters is plotted against the average applied normal stress. Each of the cycles has been adjusted by subtracting the initial reading at the start of each load cycle. The normal stress, $\sigma_{n}$, versus closure, $u_{n}$, curves for all rock-joint samples show nonlinear characteristics within the range of normal stress used in the experiment. This observation is supported by the results obtained by other investigators (Goodman, 1976; Bandis et al., 1983; Wibowo et al., 1993; Bandis, 1993; Barton et al., 1985).

The $\sigma_{n}$ versus $u_{n}$ curves show some distinct characteristics. During the initial loading phase, the surfaces close significantly under a small amount of load. Deformation of the specimen at this stage is dominated by the closing of the mismatched joint surfaces. As $\sigma_{n}$ increases, the curve gradually becomes steeper. Eventually, it becomes a vertical straight line at a high normal load (Figure 2-2). At this stage, the joint is at maximum closure or very close to it and the joint normal stiffness tends to infinity. Any further increase in normal load is taken up by the rock above and below the fracture. In other words, the deformation at this stage represents the deformation characteristics of intact rock with negligible contribution from the fracture.

All specimens of Apache Leap tuff showed hysteretic behavior during unloading. Upon return to the initial state of stress, a large amount of permanent or irreversible deformation was observed. In subsequent cycles of loading and unloading, the unloading curve became increasingly steeper. Although each unloading curve persistently showed hysteresis and inelasticity, the extent of these conditions decreased significantly in second and subsequent cycles. 


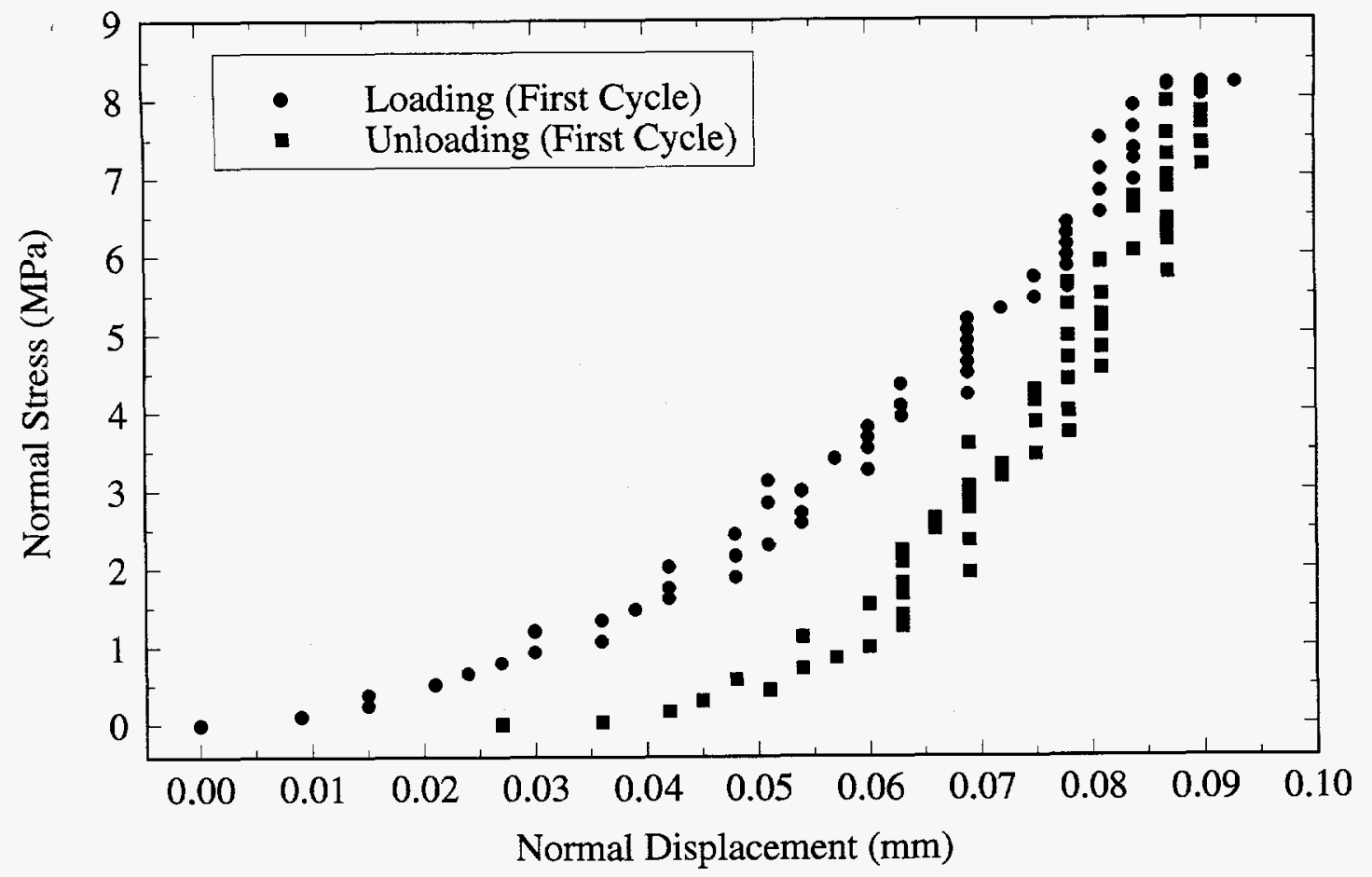

Figure 2-1. A typical normal stress versus normal deformation response of natural joints in Apache Leap tuff

Bandis et al. (1983) conducted similar compression tests on rock specimens when the rock blocks were displaced by 0.5 to $1 \mathrm{~mm}$ relative to each other. The $\sigma_{n}-u_{n}$ curves of these mismatched specimens showed characteristics similar to the mated or matched samples. The curves were nonlinear during loading and showed typical hysteretic unloading and large permanent deformation. The mismatched joints also showed lower stiffness as a result of stress concentration over smaller actual areas of contact and lack of asperity locking.

\subsubsection{Rock-Joint Response Under Cyclic Pseudostatic Shear Loads}

When one rock block slides over another under pseudostatic shear load, two phenomena can take place. These phenomena are (Patton, 1966; Brady and Brown, 1985):

- At low normal loads, the sliding of one surface over the other occurs through riding of asperities of one surface over the other, accompanied by dilation or opening up of the interface;

- At high normal loads, dilation is suppressed significantly, and shearing through the asperities dominates the response of the natural discontinuity.

Generally both of these mechanisms, combined in various proportions, produce the shear response of a rock joint. The relative importance of these mechanisms depends on the normal load acting across the interface, the hardness and roughness of the rock surface, especially with respect to the direction of shearing, material properties of the fracture and the surrounding medium, and the boundary conditions. 


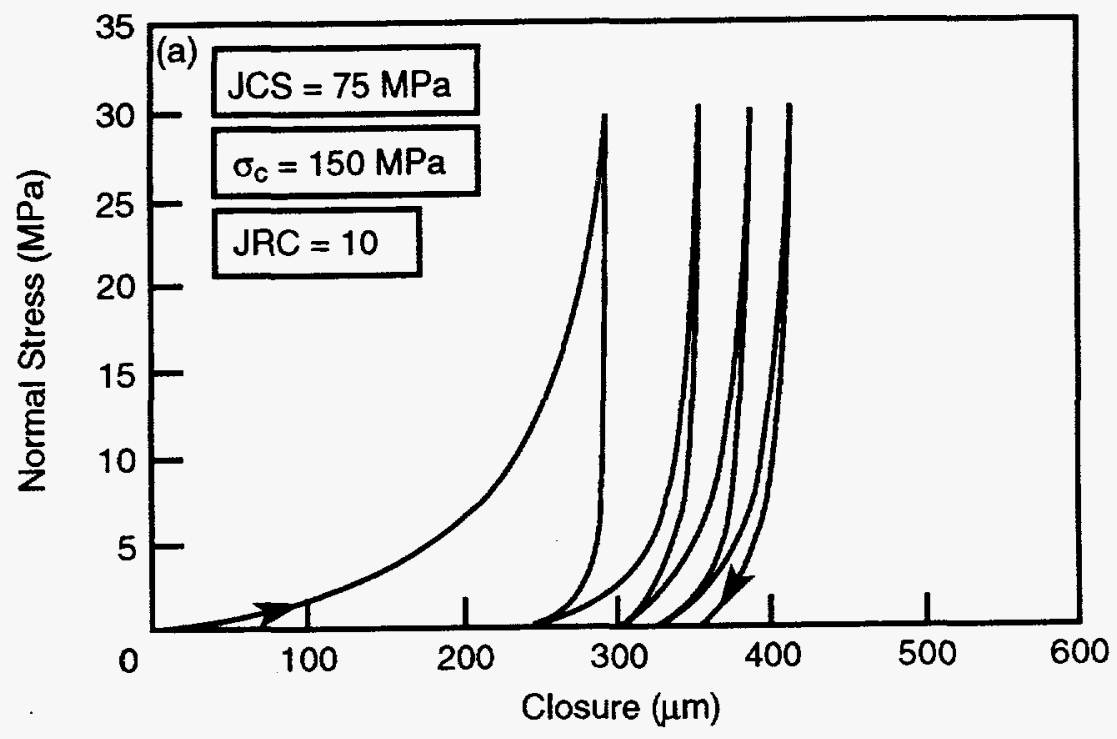

Figure 2-2. Joint closure as a function of normal stress (from Barton et al., 1985)

The boundary conditions can be either: (a) a constant normal stress, or (b) a constant or restricted normal displacement. These conditions are schematically shown in Figure 2-3. The second condition can also be expressed as constant or variable normal stiffness condition (Brady and Brown, 1985; Wibowo et al., 1993) and is most prevalent in the vicinity of underground excavations. The first condition is more applicable to near-surface slope stability problems. A direct shear test conducted under conditions of restricted normal displacement or dilation will generally show considerably higher strength than one carried out under constant normal stress. Restriction of dilatancy gives the additional shear strength as shearing through the asperities dominates the process. When the blocks are allowed to dilate, one block can slide past another by riding over some of the asperities.

Numerous references are available in the literature describing the response of both natural and artificial rock interfaces under pseudostatic shear loads measured under laboratory conditions (Patton, 1966; Hoskins et al., 1968; Ohnaka, 1975; Goodman, 1976; Barton and Choubey, 1977; Byerlee, 1978; Dieterich, 1979; Krahn and Morgenstern, 1979; Bandis et al., 1981; Morrow and Byerlee, 1984; Barton et al., 1985; Brady and Brown, 1985; Leichnitz, 1985; Swan and Zongqi, 1985; Roko et al., 1986; Yoshinaka and Yamabe, 1986; Barton, 1986; Fishman, 1988; Fortin et al., 1990; Amadei and Saeb, 1992; Biegel et al., 1992; Jing et al., 1992). The shear stress versus shear displacement curves obtained in the laboratory can be classified into two distinct types. Schematic diagrams of these curves are shown in Figure 2-4. Curve A shows a rapid rise in shear stress with increasing shear displacement up to a peak value, followed by an irregular post-peak region. The load carrying capacity decreases in the post-peak region. Goodman (1976) characterized this type of curve as representative of rough unfilled joints. The shear stress versus shear displacement curve for a direct shear test under a constant normal stress can be characterized by three regions: elastic, peak, and residual or plastic. These regions are clearly observable in Figure 2-4. The peak shear stress $\tau_{p}$ is called the peak shear strength and the minimum value of post-peak shear stress is called the residual strength, $\tau_{r}$ (Goodman, 1976). The shear stress rises 

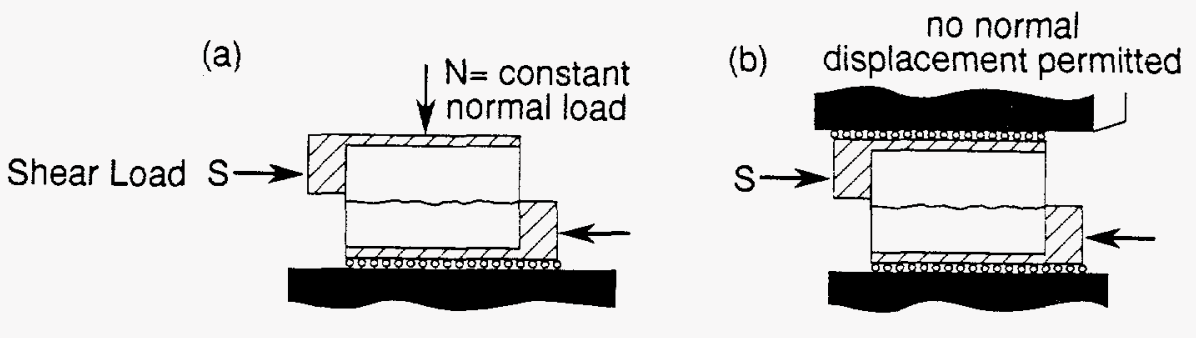

(c)

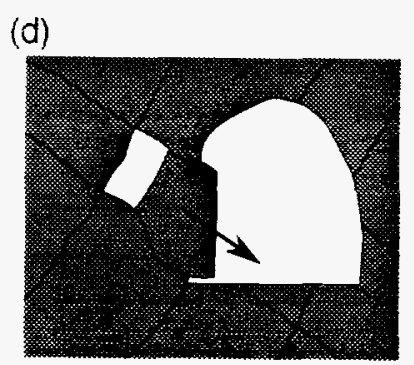

Figure 2-3. Constant normal load and constant normal displacement shearing modes (modified from Brady and Brown, 1985)

gradually in Curve B. The slope of the curve is convex downward with poorly defined peak stress and continuously changing slope. Goodman (1976) described this type of curve as representative of filled joints.

At the CNWRA, a study was undertaken to develop experimental data on natural rock-joint behavior under cyclic pseudostatic shear-loading conditions using Apache Leap tuff from Superior, Arizona. Both forward and reverse shearing are important phenomena for a rock joint subjected to earthquake and thermal loads, unlike under static loads in which forward shearing is the only concern (e.g., slope stability analysis due to gravity load only). The shear response associated with the reverse-shearing process may play a key role in determining the stability of an underground opening if the conditions are unfavorable. Therefore, a better understanding of the rock-joint response under pseudostatic cyclic load is important to the design of a stable underground excavation.

The Apache Leap tuff cores were collected using a core-drilling device with a 457-mm diameter thin-wall core barrel. Twenty-nine boreholes were drilled to collect a sufficient number of cores to prepare potentially usable joint specimens for direct shear tests. The top half of the shear specimen measured $203 \times 203 \times 102 \mathrm{~mm}$ and the bottom half measured $305 \times 203 \times 102 \mathrm{~mm}$.

In order to perform direct shear tests in the laboratory under both pseudostatic and dynamic loads, a servo-controlled test apparatus with combined normal and shear capabilities was designed, fabricated, and assembled. A description of the apparatus is given in Kana et al. (1990) and Hsiung et al. (1994b). The apparatus consists of vertical and horizontal servocontrolled loading actuators, reaction frames, shear box fixtures, and provisions for instrumenting the joint specimen. The loading capacity for each of the vertical actuators is $0.133 \mathrm{MN}$. The horizontal actuator has a capacity of $0.222 \mathrm{MN}$ and can 


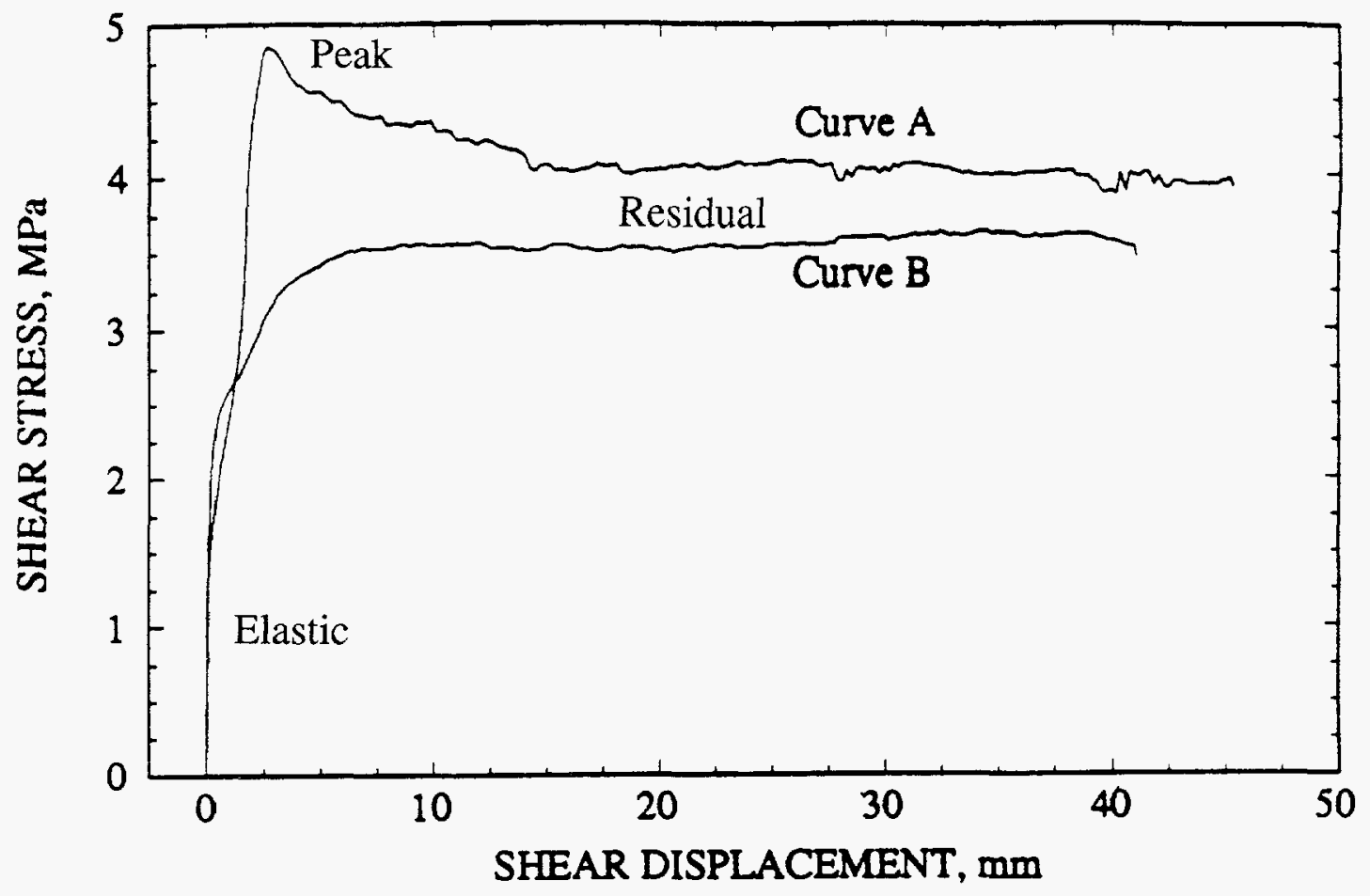

Figure 2-4. Characteristics of shear stress versus shear displacement curves following Goodman (1976)

be operated in either load or displacement control mode. Several loading patterns such as pseudostatic ramps, harmonic, and earthquake displacement time histories can be produced using a function generator. Each vertical actuator is equipped with a load cell of $0.111 \mathrm{MN}$ capacity for monitoring the applied forces. The bottom shear box and other fixed devices are bolted to a $1.22 \times 2.13 \times 0.15 \mathrm{~m}$ steel base plate for rigidity. The horizontal translation of the top shear box along the direction of shearing is guided by three rollers between the top shear box and the load frame. It is also guided by side rollers. Thus, the normal load frame and the side rollers prevent rotation of the vertical actuators and, therefore, also the top rock block, about a vertical axis perpendicular to the direction of shearing.

During a cyclic pseudostatic direct shear test, the top block was sheared about $50 \mathrm{~mm}$ in one direction, followed by a reversal of shear back to the original starting position under a predetermined constant normal stress and at a constant velocity of about $4.2 \times 10^{-2} \mathrm{~mm} / \mathrm{s}$. In some of the tests, the same process was repeated on the same joint specimen under a higher normal stress. The test sequence always followed an ascending order of normal stress. In the following discussion, the forward shear indicates that the top block is moving away from its original position with respect to the bottom block. Alternatively, reverse shear denotes that the top block is displacing toward its original position, regardless of the absolute direction of movement.

In Figure 2-5, an Apache Leap tuff sample with a fresh joint was first loaded with increasing normal stress at each shear load cycle (test number 11). Only in the first cycle, with a normal load of 1 $\mathrm{MPa}$ was the joint fresh. A fresh joint consists of two rough surfaces on which each asperity peak on one surface has matching trough on the other (Gerrard, 1985). Therefore, shear cycles with normal loads of 2.0, 3.0, 4.0, and 5.0 MPa in Figure 2-5 show the response of a surface that previously has experienced some shearing. The top block was loaded with a normal stress of $1 \mathrm{MPa}$ and was sheared about $50 \mathrm{~mm}$ 
in the forward direction, followed by a reversal of shearing back to the original or starting position. The shear cycle was repeated for normal stress equal to $2.0,3.0,4.0$, and 5.0 $\mathrm{MPa}$. The normal load applied at the top block was held constant during each shear cycle using servo-controlled hydraulic actuators. Figure 2-6 shows the first shear cycle of tests 7 through 11 . In this figure, all the curves are from fresh joints. Figures 2-5 and 2-6 show some clear differences that can be attributed as the characteristics of fresh and previously sheared joints. Figure 2-5 shows the peak behavior (Goodman, 1976) only for the first cycle. Although there is some peak behavior in the second cycle, it is not prominent and is accompanied by large shear displacement. The shear stress gradually rises to a residual value in the second and subsequent cycles and, thereafter, remains steady with increasing shear displacement (Curve $B$ in Figure 2-4). Figure 2-6 shows the peak behavior in every cycle (Curve A in Figure 2-4). This peak behavior should be attributed to the freshness of the sample. As the samples were fresh (i.e. unsheared) in every case, and shearing started from the mated position of the blocks, interlocking of the asperities could take place. These interlocked asperities resisted the shear motion, thereby generating large shear stress. After the interlocked asperities were sheared off or the asperities of one block rode over the asperities of the other block, a residual state of shear (Goodman, 1976) was reached. The minimum value of post-peak shear stress is called the residual strength (Goodman, 1976).

Figure 2-6 shows some characteristic features observed in the shear stress versus shear displacement curves using different specimens during reverse shearing. The shear resistance (shear stress) in the reverse direction is smaller than the residual shear stress during forward shear. This phenomenon has also been observed by other researchers (Zubelewicz et al., 1987; Celestino and Goodman, 1979; Gillette et al., 1983; Fishman, 1988; Plesha and Haimson, 1988; Jing et al., 1992; Wibowo et al., 1992; Huang et al., 1993; Qiu et al., 1993). Fishman (1988) suggested that the difference in shear stresses measured in the forward and reverse cycles was due to the asperities. In the forward motion, the upper block is riding over the asperities of the bottom surface. This condition provides extra resistance to shearing. While displacing in the reverse direction, the motion is downward along the asperities of the bottom surface and, as a result, develops lesser resistance to shear motion. Jing et al. (1992) suggested that the difference may be a result of different damage states of asperities on the joint surface. They implied that, on a larger scale, a rock-joint surface is normally not planar. These surfaces contain dominant wavelengths. This issue is discussed in more detail in Section 2.2.3.

One other characteristic of the shear stress versus shear displacement curve that differentiates Figures 2-5 and 2-6 is the stick-slip behavior (Lorig and Hobbs, 1990) or the sharp drop of shear stress that is recovered almost immediately. Many of the shear stress versus shear displacement curves, measured in laboratory experiments with Apache Leap tuff specimens belonging to both types A and B (Goodman, 1976; as shown in Figure 2-4), show this behavior. The intensity, loosely defined here as a combination of stress-drop amplitude and number of such events per unit shear displacement, increases with the magnitude of the applied normal stress, as shown in Figure 2-6. This phenomenon is present in both forward and reverse shear motions. Only a few of these motions are present in Figure 2-5, except in the forward motion with 1-MPa normal load and reverse motion with 5-MPa normal load. The momentary reduction in shear stress occurs as individual asperities are sheared off. It should be noted that the stick-slip behavior may also be influenced by machine stiffness (Lorig and Hobbs, 1990).

The slope of the shear stress versus shear displacement curve in the elastic region (Figures 2-5 and 2-6) is called the shear stiffness, $K_{s}$ (Goodman, 1976; Brady and Brown, 1985). In general, joints having shear stress showing type B characteristics have lower shear stiffness than those having type A features. Representative values of shear stiffness, $\boldsymbol{K}_{s}$, for different discontinuities are extremely difficult 


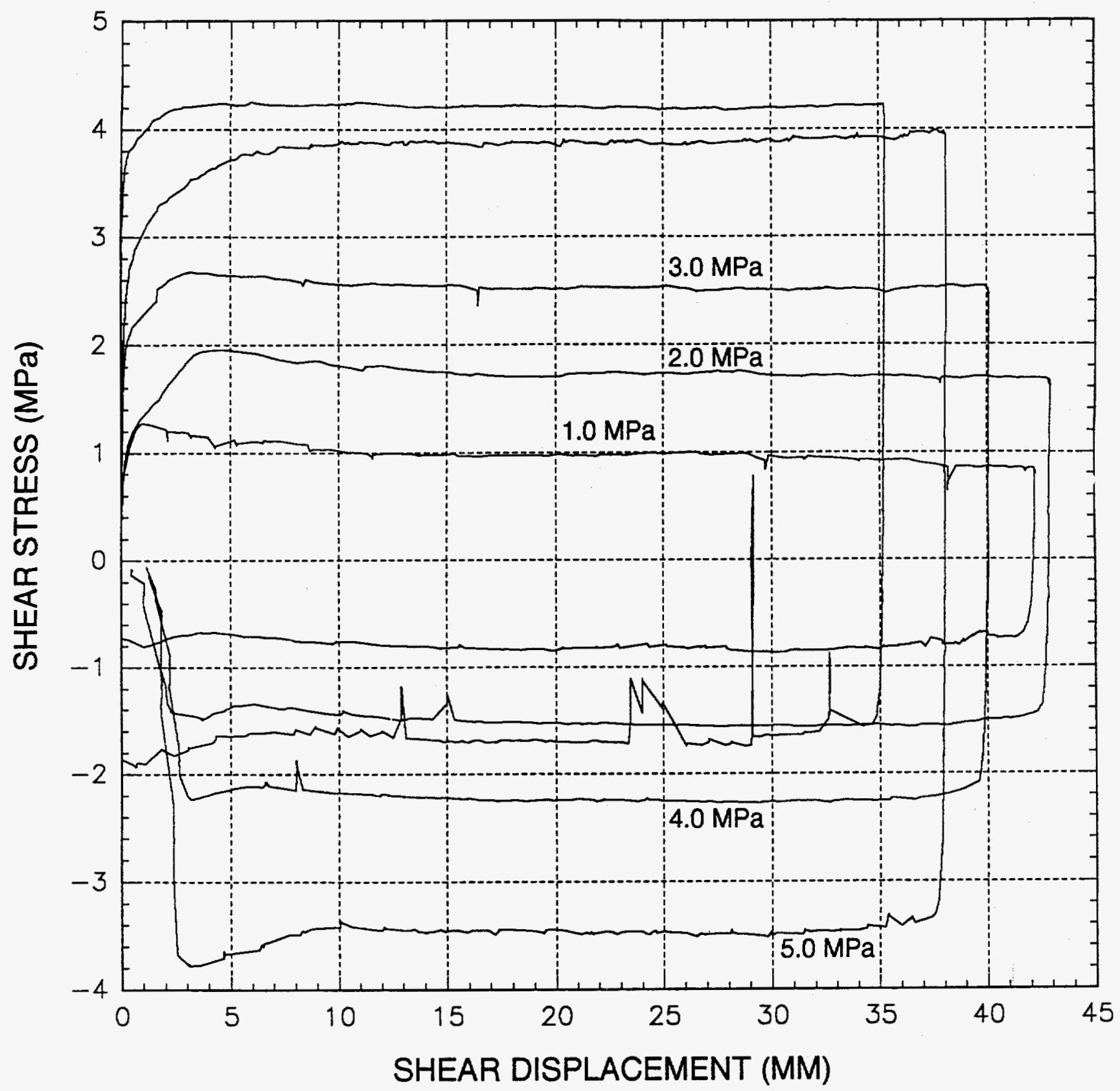

Figure 2-5. Shear stress versus shear displacement response in Test 11 with Apache Leap tuff. The same specimen was subjected to increasing normal load in each cycle. 


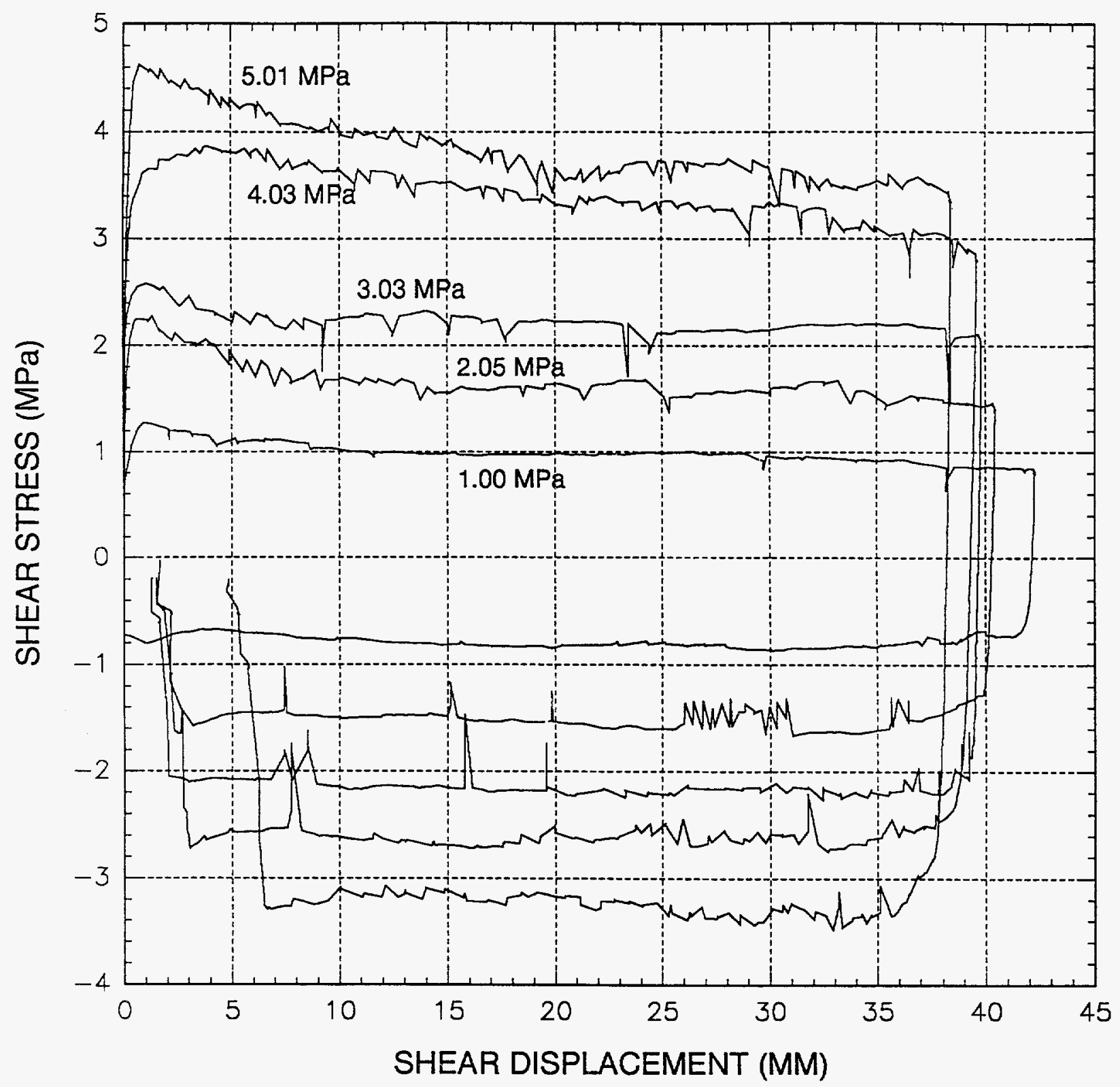

Figure 2-6. Shear stress versus shear displacement response in Tests 7 through 11. The plot shows only the first cycle of each test, which was carried out with a normal stress decrease of $1 \mathrm{MPa}$, starting from 5 MPa in Test 7. 
to measure as they are highly variable. The specimen size, applied normal stress, the testing machine, and the measuring-technique, particularly the technique of gripping the sample and the locations of displacement measuring probes (Goodman, 1976; Brady and Brown, 1985), influence the measured value of $\boldsymbol{K}_{\boldsymbol{s}}$. Therefore, $\boldsymbol{K}_{\boldsymbol{s}}$ values are often assumed in numerical analysis.

At the CNWRA, three specimens were also tested under wet conditions. These blocks were soaked in water for a week before testing. These direct shear tests were conducted to determine if wetting the welded tuff samples had any effect on the ultimate shear strength compared to dry specimens, due to possible strength reduction of asperities or lubricating effects of the moisture on the joint surface. Figure 2-7 shows the test result for the first shear cycle on specimen 29 under an applied normal stress of approximately $5 \mathrm{MPa}$. Comparison of this curve with the curve for Test 7 with applied normal stress of 5.01 MPa in Figure 2-6, which was carried out under dry conditions, shows that the magnitude of peak strength is approximately the same for both conditions. However, the curve for the wet specimen shows a more rounded peak shear strength and less stick-slip behavior throughout the shear cycle. Figure 2-8 shows corresponding normal displacement versus shear displacement response. This plot shows the peak normal displacement after approximately $25 \mathrm{~mm}$ of shear displacement and subsequent decrease during further forward shear displacement. On the contrary, the specimen for Test 7 tested under the same normal load and dry conditions, the normal displacement continually increases during the entire forward shear cycle. The reason for this particular behavior is not entirely clear. Further analyses of the joint surfaces are necessary to determine if this is a property of the wet sample condition or the nature of the joint surfaces.

\subsubsection{Peak Shear Stress/Strength}

The peak shear stress or the peak shear strength of a joint undergoing shear displacement is dependent on the normal load applied across the interface, surface characteristics such as roughness and joint wall strength, and the boundary conditions. As discussed in Section 2.1.2, fresh joints show the prominent peak behavior. This behavior has also been observed in the laboratory experiments using Apache Leap tuff samples. The first cycle of each experiment, which uses a fresh rock specimen, always shows the peak behavior. The peak behavior is not so prominent in the beginning of the first reverse cycle or in subsequent cycles. The measured peak shear strength increases with the increase of normal stress. Amonton's law (Bowden and Tabor, 1950), the power law as suggested by Archard (1958) and Murrell (1965), Coulomb's law (Brady and Brown, 1985), and Jaeger's law (Jaeger and Cook, 1979) give testimony to this fact. Experimental observation with Apache Leap tuff samples also support this fact (Hsiung et al., 1993). As discussed previously, whether asperities shear off or override each other is controlled by the joint wall strength and the imposed boundary conditions (constant stress versus constant displacement). Restricting the normal displacement increases the normal stress which, in turn, increases the peak strength. Softer wall rock does not allow large stress build up. As a result, the observed peak shear strength will be smaller. This observation is quite significant if the joint traces in a rock mass show signs of weathering.

\subsubsection{Residual Shear Stress/Strength}

Residual shear strength, $\tau_{r}$, is the minimum value of the shear stress in the post-peak region (Goodman, 1976). Rock joints that have undergone previous shear displacement do not show the peak behavior. As can be seen in Curve A of Figure 2-4, it takes a significant amount of shear displacement after the peak shear stress for a fresh joint specimen to develop the residual behavior. The amount of 


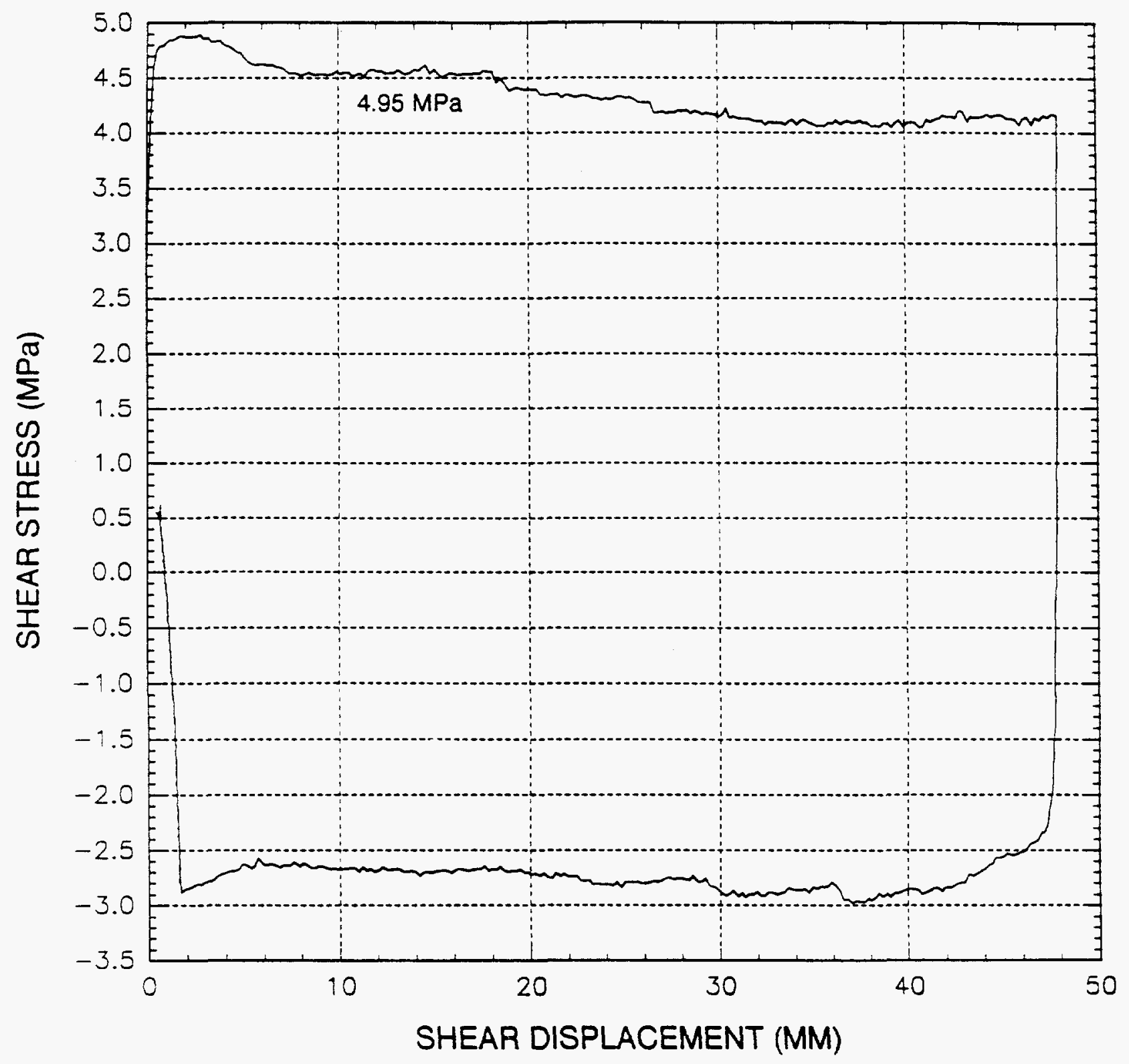

Figure 2-7. Shear stress versus shear displacement response for test no. 29 under applied normal stress of 4.95 MPa and wet condition 


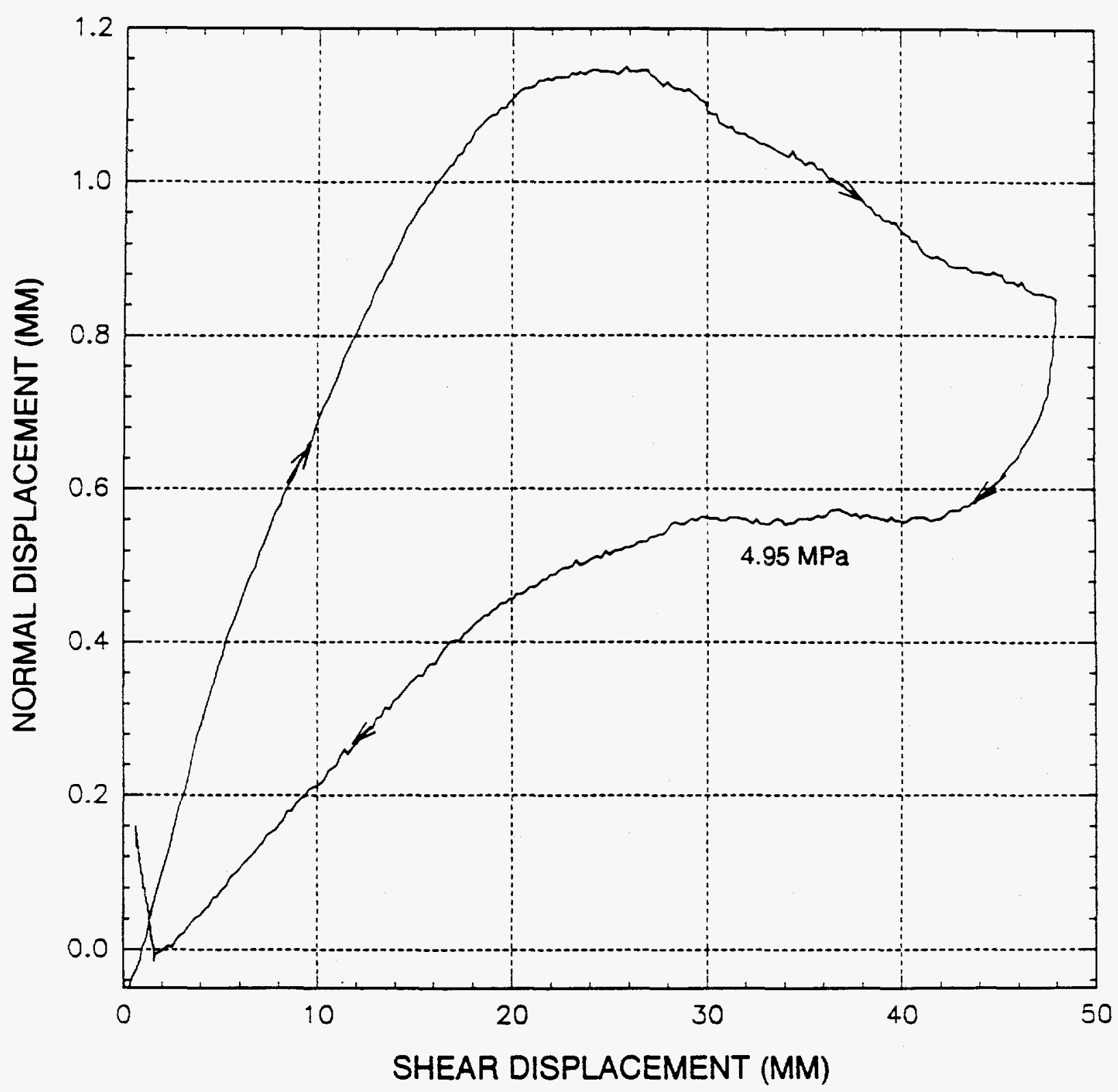

Figure 2-8. Normal displacement (dilation) response for test no. 29 under applied normal stress of 4.95 MPa and wet condition 
shear displacement needed to develop the residual characteristic may be a function of the applied normal stress, surface characteristics, strength (hardness) of the rock-joint interface and size of the rock blocks. As riding over the asperities of the bottom (fixed) block by the asperities of the top (moving) block becomes the predominant mode of shear deformation, the stick-slip behavior decreases significantly in the residual region.

The coefficient of friction, $\mu$, is defined-as the ratio of mobilized shear strength, $\tau$, to the applied normal stress, $\sigma_{n}$. Frictional strength for a variety of rock surfaces is summarized by Byerlee (1978). He classified the data into two groups according to the applied normal stress: (i) low normal stress $\left(\sigma_{n}<200 \mathrm{MPa}\right)$, and (ii) high normal stress $\left(\sigma_{n}>200 \mathrm{MPa}\right)$. The maximum friction referred to in his figures is either the peak value or the residual state. At low normal loads, a large variation of the coefficient of friction can be observed among rock types and rock surfaces. The value of $\mu$ ranges from 0.2 to 2 . At high normal loads, there is little variation in the coefficient of friction for a wide variety of gouge types, surface roughness, and rock types. However, some clay minerals show exceptionally low friction. Coefficient of friction $\mu$ is nonlinear at high normal loads. If $\mu$ decreases with increasing $\sigma_{n}$. The scatter in low normal load data is caused by (i) the fact that the effect of roughness decreases with increasing normal load and (ii) partly because these experiments were mostly carried out with unmated surfaces.

Byerlee (1978) suggested the following equations to represent the friction data for a variety of rocks and surface types in two classes:

$$
\begin{gathered}
\tau=0.85 \sigma_{n}=\tan 40^{\circ} \sigma_{n} \text { for } \sigma_{n}<200 \mathrm{MPa} \\
\tau=0.5+0.6 \sigma_{n}=0.5+\tan 31^{\circ} \sigma_{\mathrm{n}} \text { for } \sigma_{n}>200 \mathrm{MPa}
\end{gathered}
$$

Results obtained from the residual phase of the CNWRA direct shear experiments with Apache Leap tuff specimens also can be summarized following Byerlee's classification:

$$
\tau_{r}=0.20+0.81 \sigma_{n}
$$

with coefficient of determination $\mathrm{R}^{2}=90$ percent if $\sigma_{n}<200 \mathrm{MP} a$. With 59 data points and a 95-percent significance level, the null hypothesis that the constant term is equal to zero cannot be rejected. Therefore, a new regression analysis was performed forcing the constant term to be equal to zero. The new relationship is:

$$
\tau_{r}=0.86 \sigma_{n}=\tan 40.7^{\circ} \sigma_{n}
$$

with $\mathrm{R}^{2}=90$ percent.

\subsubsection{Joint Dilation with Shear Displacement}

When one rough surface slides past another rough surface, the volume change of the interface or change in aperture is generally described by the normal displacement of the interface. This dilation 
or normal displacement requires finite shear displacement to initiate. Major asperities of the opposing sides get interlocked with increasing shear displacement. Shear strength increases and the dilation against the normal load develops as the asperities of one surface try to override the asperities of the other surface. The actual dilatancy during shearing is the cumulative effect of displacement along the rough surfaces and will be a complex function of the distribution of asperities on each face, the relative positions of the two blocks, normal load, boundary conditions, and the wall strength of each surface. Whether the interlocked asperities either shear off or ride over each other is controlled by the wall strength or hardness. Except at zero normal load, it is unlikely that the blocks can be sheared without any asperity damage. When no normal load is present, asperities having an angle less than $\left(90-\phi_{b}\right)$ can be over-ridden (Goodman, 1976), when $\phi_{b}$ is the friction angle of the flat surfaces of the rock in question. As the normal load increases, the work required to dilate against the normal load may exceed the work necessary to shear through some of the asperities. Hence, the dilatancy of the joint decreases with increasing normal load and will be completely suppressed when the average normal stress reaches the unconfined compressive strength of the asperities. The shear strength of an asperity varies directly with its width. Corresponding to each value of the normal load, all asperities up to a given base width may have the possibility of shearing. In general, a weak and rough joint wall will suffer more damage (asperity breakage) during shear than a strong but smooth surface. None of these surfaces will strongly dilate (Barton and Choubey, 1977). Large dilation is observed for strong and rough joint surfaces. The dilation occurs at an increasing rate as the peak shear strength is approached. Thereafter, the rate decreases gradually with further shear displacement. Dilation may become almost constant or may even decrease at large shear displacement.

Figure 2-9 shows several typical normal displacement versus shear displacement curves observed in the laboratory using Apache Leap tuff samples. Key characteristics of these curves deserve some discussion. These features are visible in all the experiments observed in the laboratory. The normal displacement versus shear displacement curves always show a small contraction before dilation takes place. The joint closes to a maximum value and then starts dilating. The normal displacement returns to the original value as the joint displaces further. Dilation starts with further shear displacement and continues until the direction of shear is reversed. In the contraction part of the curve, maximum joint closure increases rapidly with increasing normal load. The amount of shear displacement required to reach the point of zero dilation (transition point from contraction to dilation) from the initial position increases significantly as the joint becomes smoother with repeated shear cycles and with increasing normal load in each cycle. There is a sharp drop of dilation as soon as the reverse shear cycle starts. The normal displacement curve in the reverse direction is below the dilation curve for the forward shear direction. It also goes into contraction or joint closing with the zero dilation point further away from the original position than the curve in forward shear direction. The maximum joint closure is almost the same as that in the forward cycle. The maximum contraction takes place at a shear displacement much larger than the respective shear displacement at zero dilation during forward shearing. After reaching the maximum closure, the joint again starts dilating, although the joint is still in contraction with respect to the original condition. The curve for reverse direction crosses the curve for forward direction and, in many cases, actually exhibits a small dilation at the end of the cycle. The point of intersection of the two curves is generally closer to the starting position than the zero dilation point of the curve for forward shear. The first cycle of loading always had the fresh joint.

The normal displacement versus shear displacement responses of the three specimens tested under wet conditions show that the normal displacement peaks after approximately $25 \mathrm{~mm}$ of shear displacement and subsequently decreases during further forward shear displacement. On the contrary, for the specimen tested under the same normal load under dry conditions, the normal displacement 


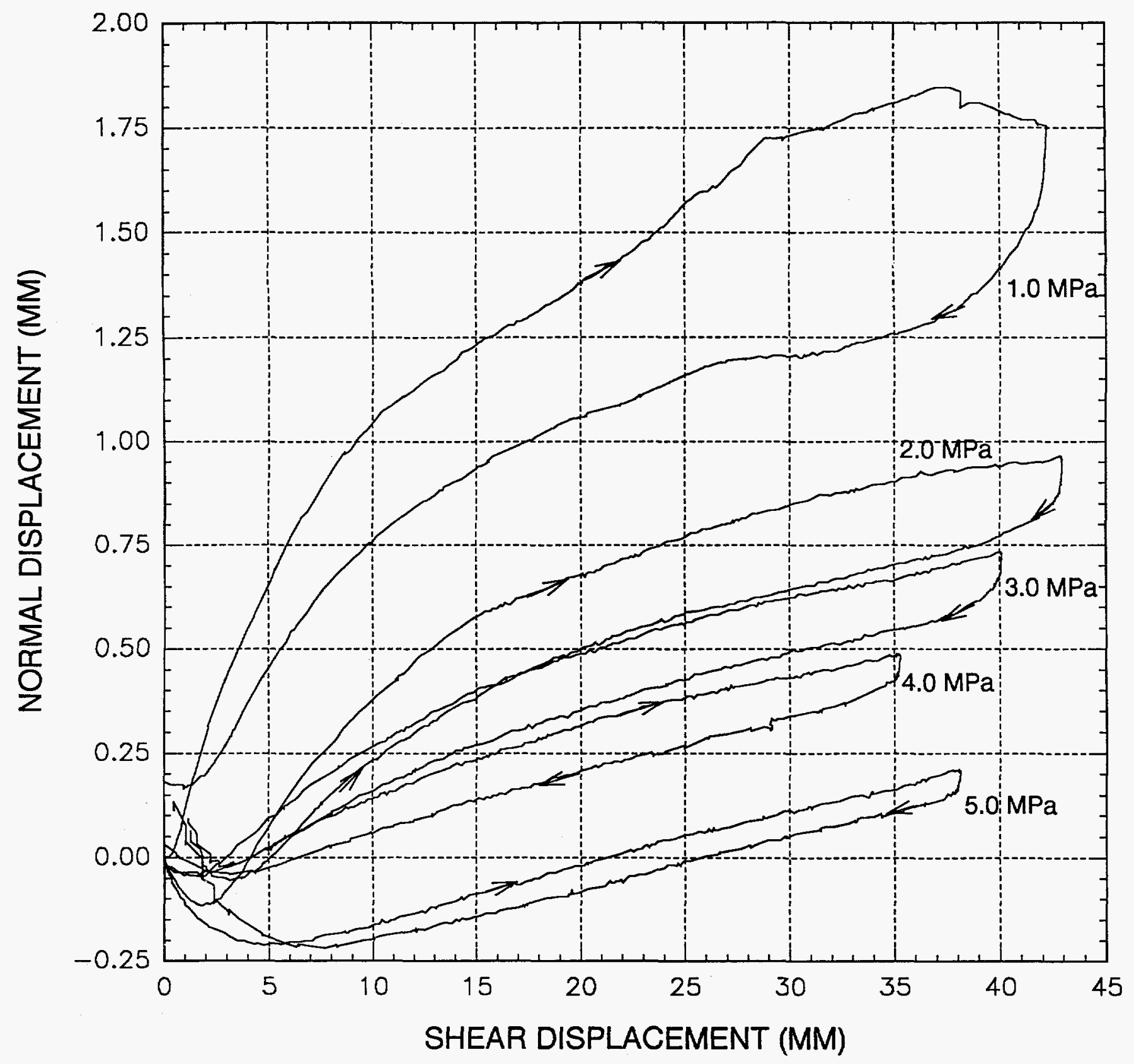

Figure 2-9. Typical normal versus shear displacement curves for Apache Leap tuff samples 
continually increases during the entire forward shear cycle. The reason for this particular behavior is not entirely clear.

\subsection{ROCK-JOINT RESPONSE UNDER DYNAMIC LOADS}

As a part of the investigation carried out at CNWRA to understand the effect of dynamic load on joint strength, experiments were carried out in the laboratory using Apache Leap tuff specimens. These laboratory experiments include rock joints tested under harmonic and simulated earthquake loads.

\subsubsection{Rock-Joint Response Under Harmonic Loads}

The response of rock joints under harmonic shear load was studied experimentally by subjecting joints to a fixed normal stress and a sine wave shear displacement drive signal. The total duration for all the harmonic tests was $30 \mathrm{~s}$, and the sampling rate was 800 points/s. The high sampling rate was intended to capture high-frequency responses of joints during the tests. Frequency and amplitude of the input displacement sine wave signal varied for different tests, with the frequency ranging from 1.4 to $3.5 \mathrm{~Hz}$ and amplitude from 6.35 to $25.4 \mathrm{~mm}$. The frequency range was considered to be commensurate with typical earthquake displacement histories. The normal stress applied for all the tests was fixed at $1.0 \mathrm{MPa}$ such that the effect of joint roughness could be evaluated. Details of the tests are given in Hsiung et al. (1994b).

The measurements of the harmonic tests include normal and shear loads, joint normal and shear displacements, acceleration response of the top block, and displacement response between the horizontal load cell and the top shear box. Figure 2-10 shows a typical measured shear displacement and shear stress time histories for Test 14 . Only the results between the 5 th and 6 th seconds are presented in the figure for clarity. When the top rock block moves away from the original position, it has been defined in this report as forward shearing, while it is reverse shearing when the top block moves toward its original position. It was found that measured displacement time histories at both ends of the top block along the shear direction were essentially the same, and no phase difference between the two was observed. This suggests that the top block was undergoing mostly rigid body motion.

Figure 2-10 indicates a phase difference between the shear displacement and shear stress time histories, with the shear displacement lagging behind. This phenomenon was observed in all harmonic tests. The delayed response of the joint shear displacement may be real joint behavior or it may be due to some other phenomenon, for example, compression and dilation of the cement grouts used to fill gaps between the steel box and the rock specimen. Further instrumentation to measure the total deformation between the horizontal load cell and the top rock block leads to the conclusion that the phase shift results from shear stress buildup to a level required to initiate joint shearing.

As expected, the dominant frequency for the shear stress time history in Figure 2-10 is $1.4 \mathrm{~Hz}$, which is the input frequency. The shear stress time history also includes some higher frequency components with relatively small magnitudes at 50 and $250 \mathrm{~Hz}$ frequencies. In other tests also, the time histories of shear stress include components at similar high frequency ranges. The fact that shearing of joint surfaces with different roughness generates similar frequency response indicates the presence of some form of natural mode response in the apparatus. The higher frequency component appears to be enhanced by the rapid stick-slip phenomenon of the interface. The same behavior was also observed during reverse shearing. 


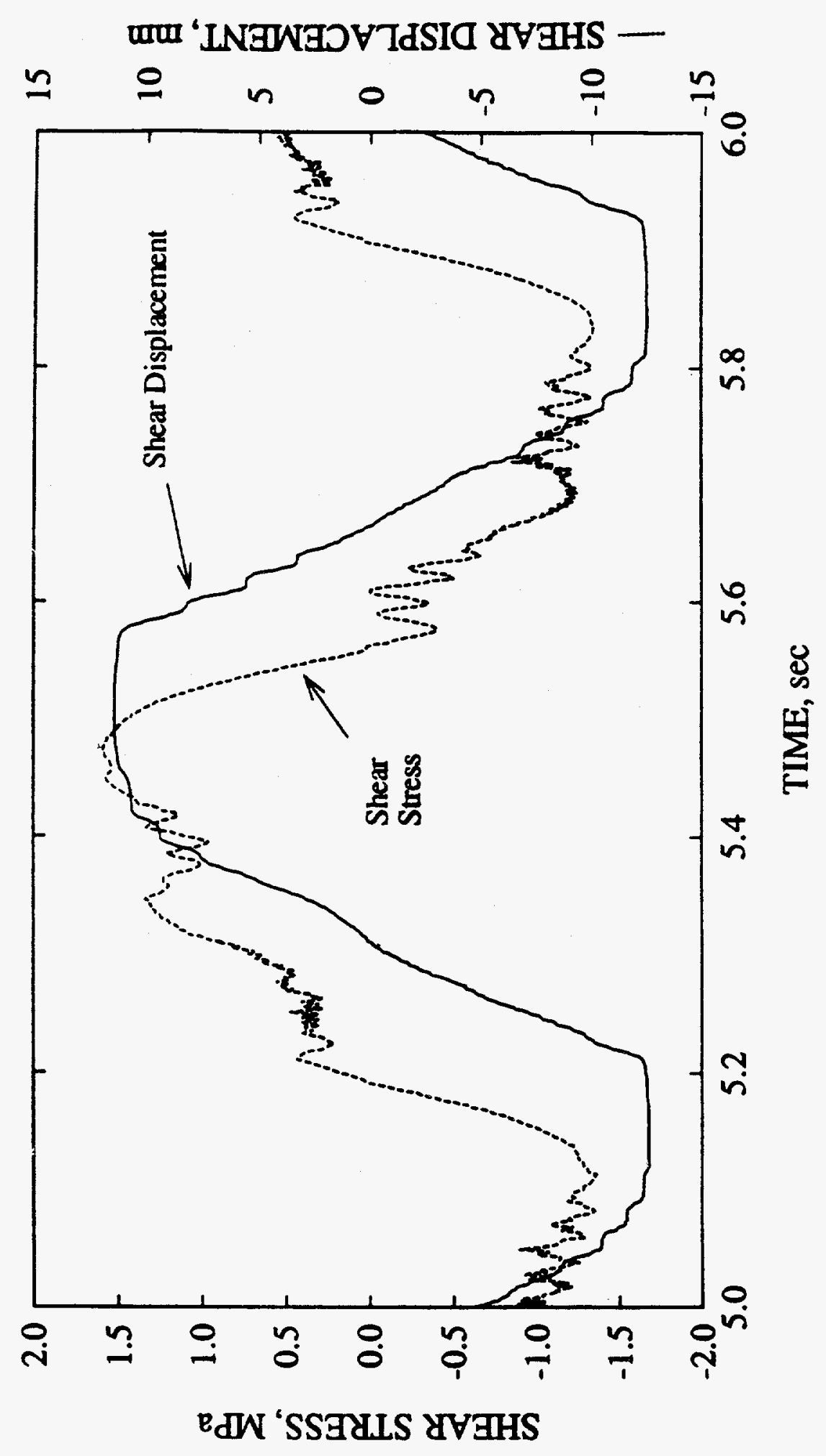

$E$

I

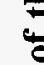

흘

in

卷

总产

.⿹气日

볼

灵

ํㅝㄹ

흥뭉

둥

苞

欲

药

를

络

㻉

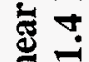

है

完总

흘 
Figure 2-11 shows the measured normal stress and normal displacement (dilation) time histories between the 5th and 6th seconds of the first phase for Test 14. The time history of the normal displacement indicates that the joint dilated during forward shearing along either side of the original position, and the dilation gradually returned during reverse shearing. The normal displacement time history of Test 14 contains a dominant frequency of $2.8 \mathrm{~Hz}$, which is twice the input frequency or frequency of the applied shear displacement. This dominant frequency of $2.8 \mathrm{~Hz}$ occurs because the magnitudes of joint dilation for forward shearing along both sides of the original position are essentially the same. If they are substantially different as in the case of Test 15 , the dominant frequency will be the same as the input frequency. The normal displacement time history also contains higher frequency response as do the shear stress and shear displacement time histories.

Unlike the pseudostatic direct shear tests, the normal stress for dynamic direct shear tests cannot be maintained as a constant during the course of an experiment (Figure 2-11). This inability is related to the capability of the test apparatus. The input for the harmonic tests changed so rapidly that the control system could not respond quickly enough to the change in force in the vertical actuators to maintain a constant normal stress at the higher frequencies. The extent of the effect of normal stress variation on the joint behavior is not clear. However, it may not necessarily affect substantially the general pattern of the responses of shear stress, shear displacement, and joint normal displacement due to the transient nature of the vibration.

\subsubsection{Rock-Joint Response Under Earthquake Loads}

The displacement drive signal used for the joint shear tests under earthquake loads was derived from the acceleration response signal recorded from the Guerrero accelerograph array for the September 19, 1985, earthquake in Mexico. The earthquake had a magnitude of 8.1 on the Richter scale. It was felt that to study the effect of earthquake on the response of natural rock joints any generic earthquake could be used to provide the input loading. The 1985 earthquake in Mexico is a large earthquake and was considered for this study. Moreover, very high quality data of this earthquake was readily available in digital form. The time history of the earthquake signal was recorded at a sampling rate of 50 data points/s. Each component lasted about $50 \mathrm{~s}$, with the strong motion lasting about $25 \mathrm{~s}$. The acceleration signal measured along the south axis appeared complete and contained sufficient data to generate a displacement drive signal for the planned joint shear tests subjected to earthquake loads. In the shear tests with the earthquake signal used as the drive signal, the data sampling rate was set at 800 points/s. At this sampling rate, the data acquisition system could capture 13 channels of measured values for about $40 \mathrm{~s}$. In order to ensure that this capacity was not exceeded, it was decided to reduce the $50 \mathrm{~s}$ data, shown in Figures 2-12 and 2-13, to $30 \mathrm{~s}$ duration. The remaining capacity of the system was used to provide the initial and trailing zero drive signals to allow manual start and stop of the data acquisition system. The reduced earthquake signal contained primarily the strong motion portion of the data, which was of major interest. In the data-reduction process, small step functions in the input drive signal were avoided due to the limitation of the horizontal actuator. Thus, the input displacement time history was developed with a ramp from zero to start the excitation and a ramp to zero to end the process. An initial input displacement drive signal was obtained by double-integration of the windowed acceleration data in the frequency domain. Before the double integration, a band-pass filter was applied to the acceleration Fourier spectra. This filter was defined by a low frequency of $0.5 \mathrm{~Hz}$ and a high frequency of $15 \mathrm{~Hz}$. The high-pass filtering was intended to eliminate the possibility of developing extremely large amplitude, low-frequency offset in the data during integration. Low-pass filtering of the data was intended to eliminate aliasing of the data due to its limited sampling rate of 50 points/s relative to the 800 points/s 
NORMAL STRESS, MPa

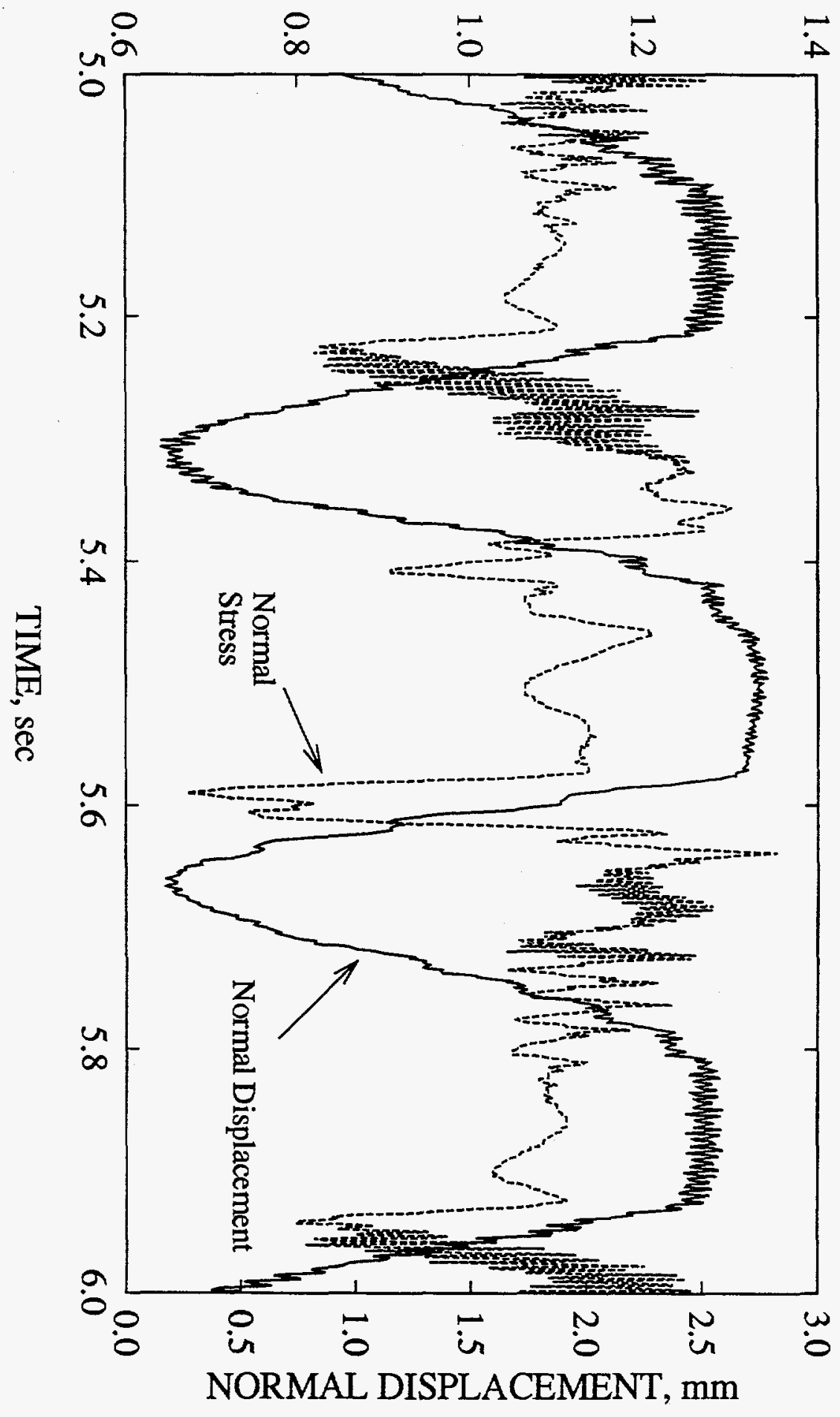




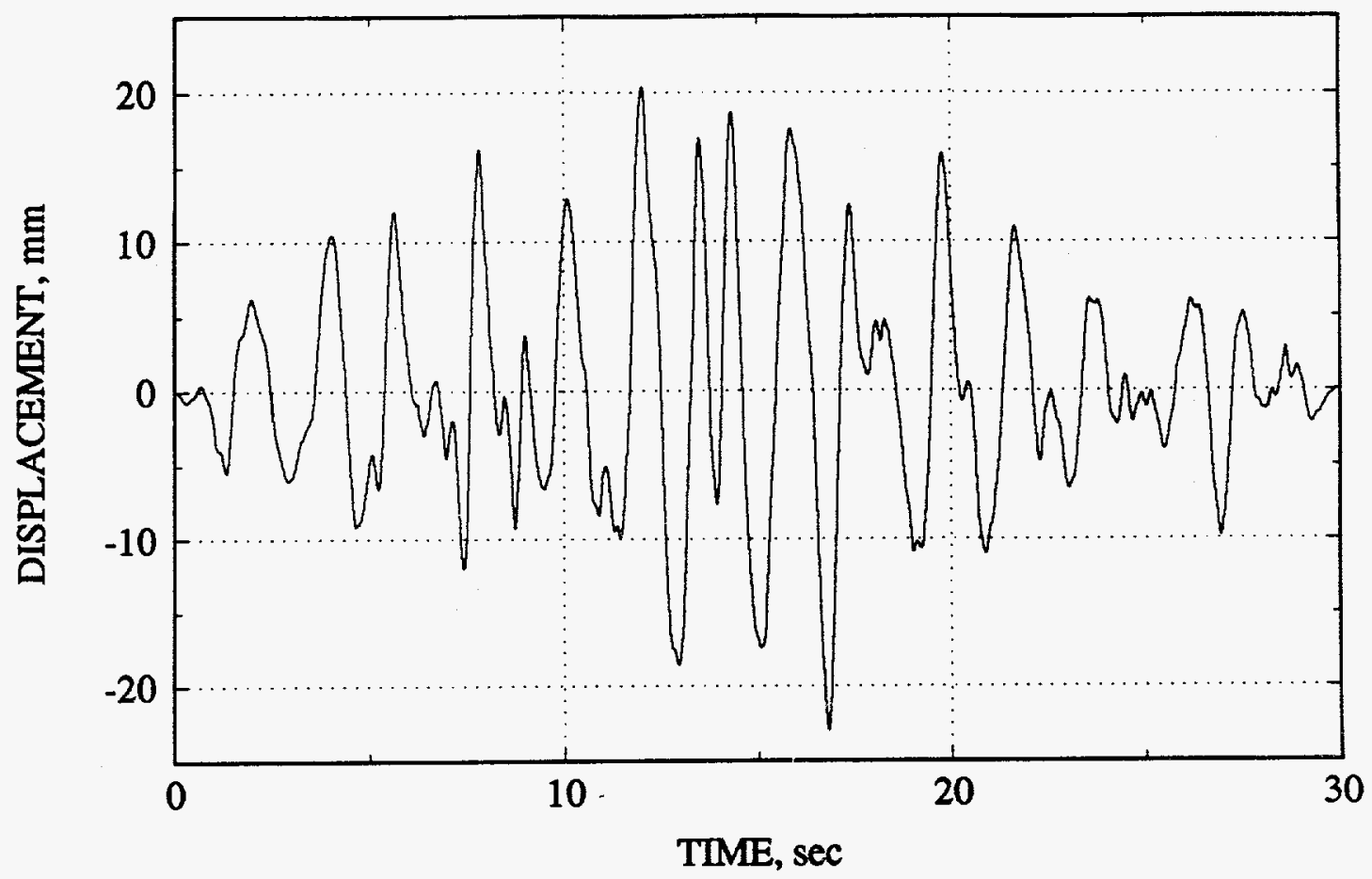

Figure 2-12. Displacement time history along the south direction of 8.1 Richter scale earthquake, September 19, 1985, in Mexico

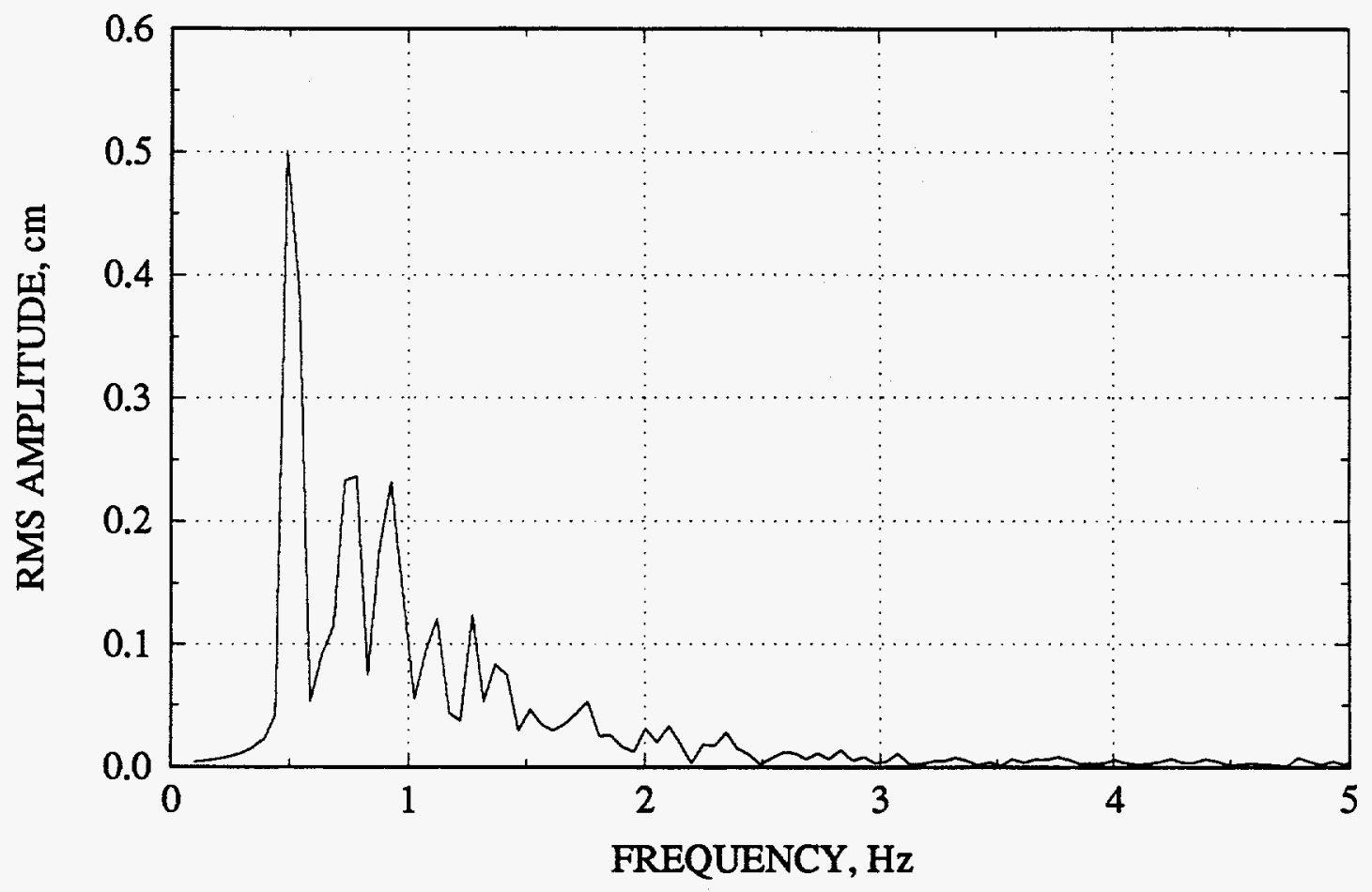

Figure 2-13. Displacement spectra for the time history in Figure 2-10 
specified for the data acquisition system. The displacement time history contains a major frequency range from 0 to $2.0 \mathrm{~Hz}$ with a dominant frequency at $0.5 \mathrm{~Hz}$ (Figure 2-13). In order to ensure that full joint responses to the displacement signal would be captured during the tests, it was decided that a square wave approximately $4 \mathrm{~s}$ in duration followed by $5 \mathrm{~s}$ of zero displacement amplitude would be initiated before the displacement drive signal. The horizontal actuator switch would be turned on to actually start a test after the square wave had passed and before the start of the actual displacement input. Consequently, the square wave input did not have any effect on the shear test results, but could be used as a visual timing signal.

The types of measurements taken for the direct shear tests on rock joints subjected to the earthquake signal were essentially the same as those for the harmonic tests. Figure 2-14 shows the measured shear displacement time history and the corresponding response of shear stress time history for Test 24. This figure clearly shows a response of the shear stress to the input square wave, which lasted about $4 \mathrm{~s}$ with an amplitude of about $0.5 \mathrm{MPa}$. In the same period, no shear displacement was observed. The actual test started at the point marked A. Similar to the harmonic tests, a phase difference between the shear stress and shear displacement with the shear displacement lagging behind was also observed. Figure 2-14 also shows that the amount of shear displacement required for the shear stress to reach peak value is relatively small compared to the shear displacement input amplitude. Consequently, the shear stress levels for each displacement cycle are fairly constant irrespective of the amplitude of the cycles. Detailed observations of the shear stress time histories showed that, in some tests, the shear stress magnitude increased sharply when the top block moved past its original position. The same observation can be made in Figure 2-10. This stress increase is related to the extent of the waviness of joint surfaces.

Figure 2-15 shows the normal stress and normal displacement responses between the 15th and 20 th second of Test 24 . The normal stress response to the earthquake displacement input included higher frequency components during the test as was observed for the harmonic tests. However, the impact of this variation on the normal displacement appears to be small. The lack of synchronization of the normal stress and displacement responses, combined with the fact that the normal displacement vibrated even when there was no shear displacement, seemed to indicate that the normal displacement variation may not be part of a joint behavior. Instead, it may be the result of interaction with some vibrational modes of the apparatus. Fortunately, the magnitude of the vibration is small for both types of tests and will not affect the study of joint dilation behavior.

\subsubsection{Potential Dynamic Impact on Rock-Joint Behavior}

Figures 2-16 and 2-17 show the characteristic joint shear stress versus shear displacement for Tests 14 and 24, respectively. Both figures include results from the first three cycles. Figure 2-16 also includes the result of the 40th cycle. For all tests, the experiment started with shearing the top block from its original position (represented as zero shear displacement) toward one end of the bottom block until a predetermined maximum value of shear displacement (based on displacement time history) was reached. The corresponding shear stress versus displacement is in the first quadrant of the figures (i.e., clockwise progression around the figure). After the maximum shear displacement in the first quadrant was reached, the top block began to move back toward and eventually past its original position. The corresponding shear stress versus displacement curves are presented in the fourth and third quadrant of the figures, respectively. After the maximum shear displacement in the third quadrant was reached, the top block moved back to its original position to complete a cycle of shear motion. The associated shear stress versus displacement curve is presented in the second quadrant of the figures. This process was repeated for a 

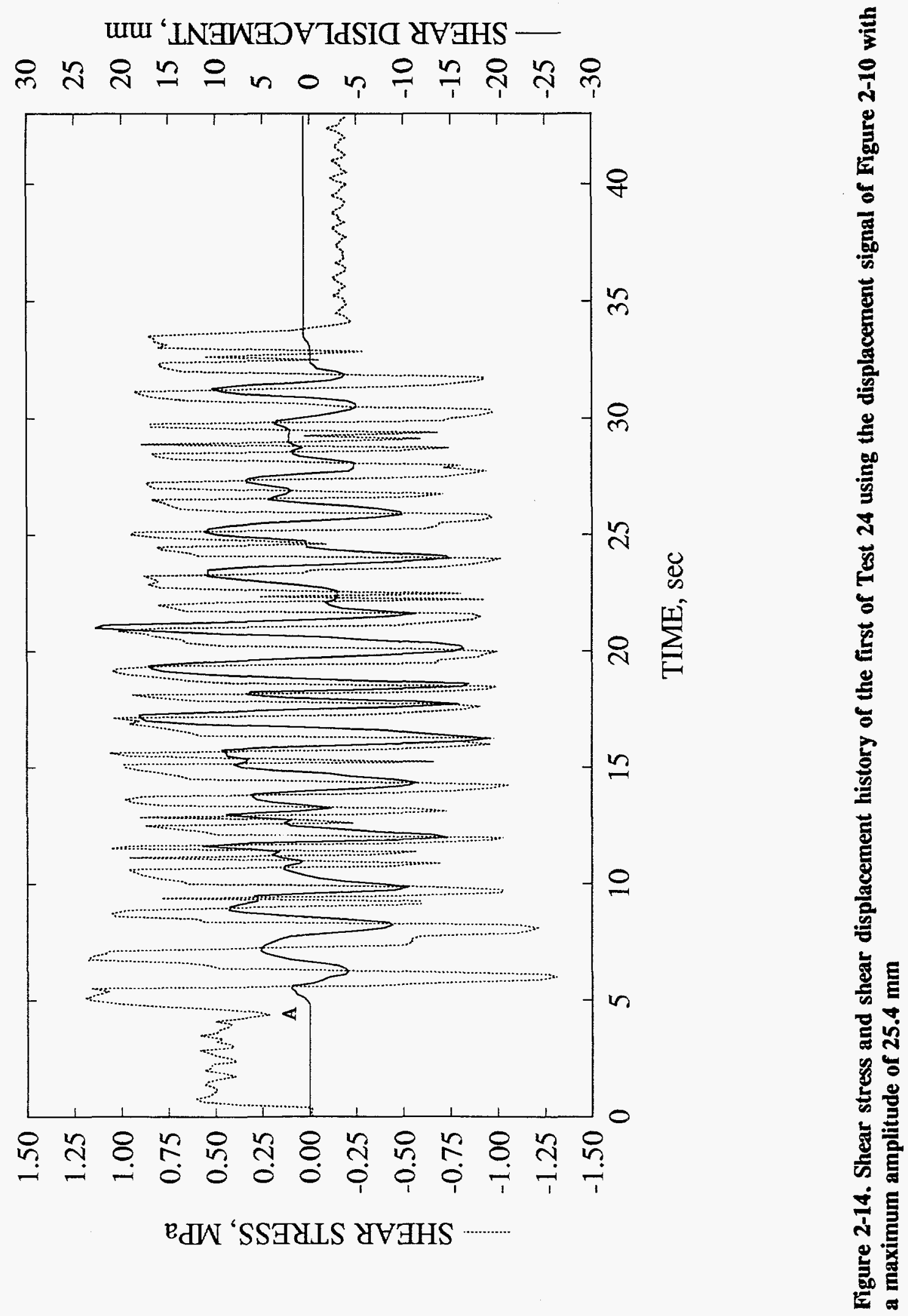


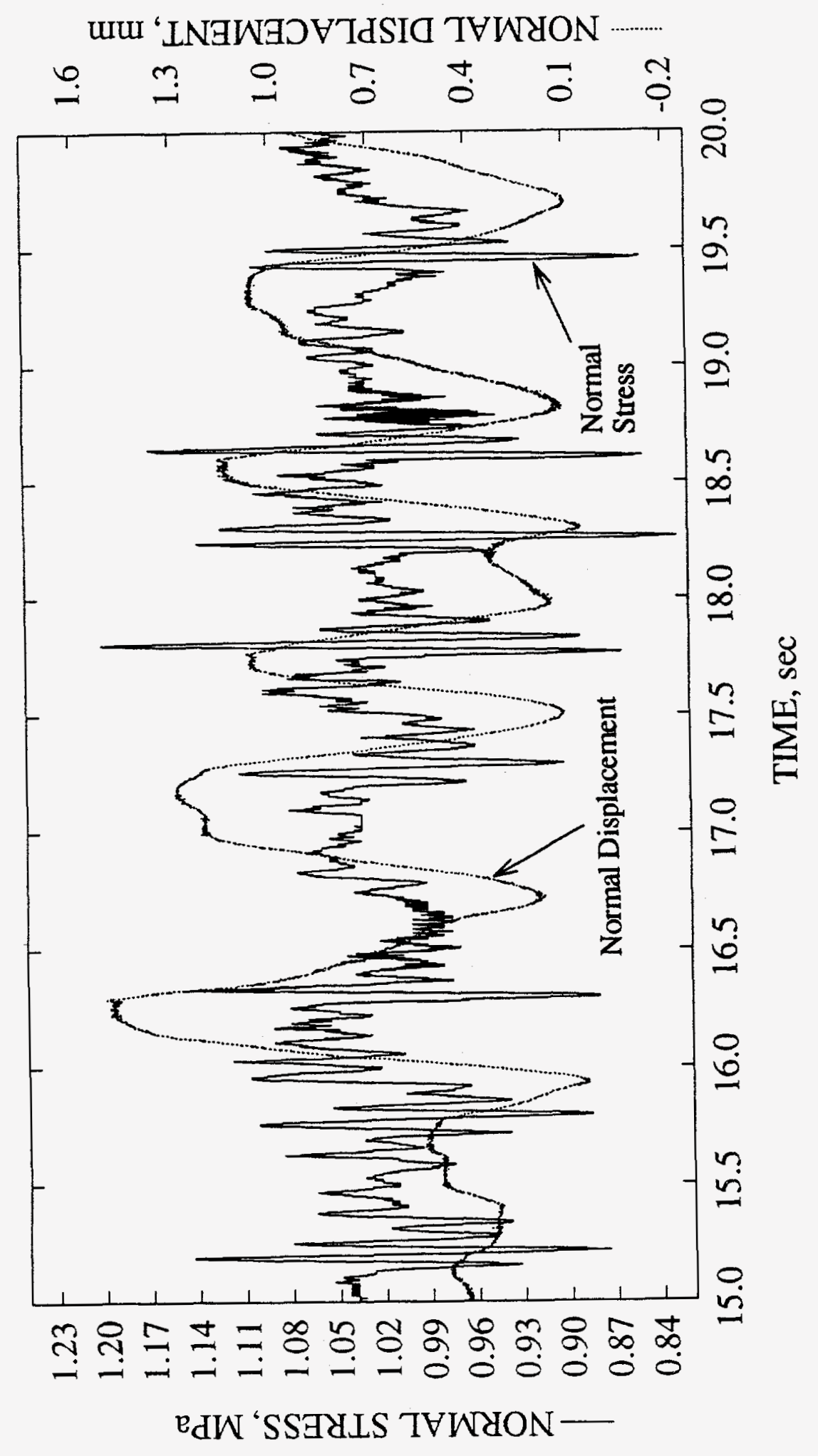

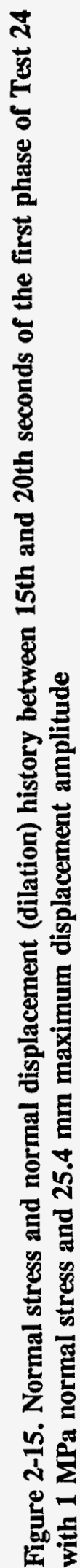




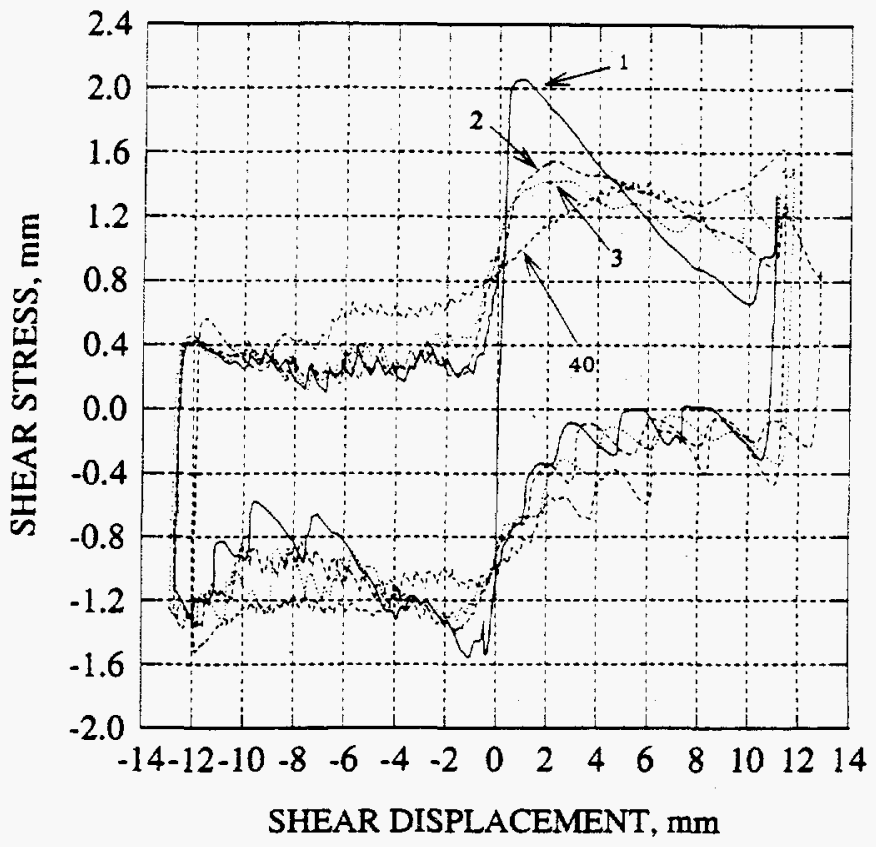

Figure 2-16. Shear stress versus shear displacement curve for the first phase of Test 14 under a harmonic load with $1.4 \mathrm{~Hz}$ input frequency and $12.7 \mathrm{~mm}$ input displacement amplitude (first three cycles and the 40 th cycle)

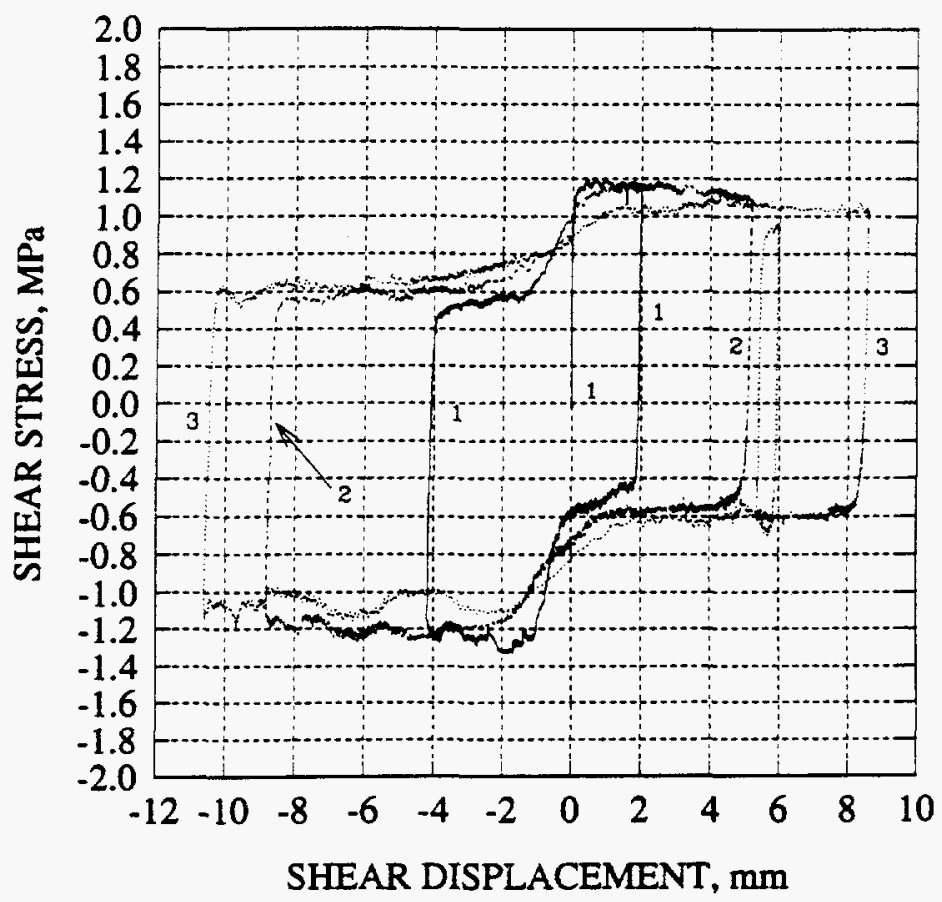

Figure 2-17. Shear stress versus shear displacement curve for the first phase of Test 24 under an earthquake load with maximum input displacement amplitude of $25.4 \mathrm{~mm}$ 
number of cycles. In the figures, the shear stress was assigned a positive sign when the shearing is along one direction; the sign becomes negative when the shearing follows the opposite direction.

As observed in the pseudostatic tests, a peak joint shear stress (peak joint shear resistance) was also observed for the first cycle for both harmonic and earthquake tests if the specimen is fresh, that is, the joint surface has never undergone any shear, either in the laboratory or in the field. The phenomenon of wear with shear displacement is also clear through the decrease of shear resistance with the number of cycles. One distinct feature of the shear stress versus shear displacement characteristics in Figures 2-16 and 2-17 is the nature of the smaller shear resistance upon reverse shearing as compared to that of forward shearing (first quadrant versus fourth quadrant, third quadrant versus second quadrant). The same behavior was also observed in all other harmonic and earthquake loading tests, pseudostatic tests using Apache Leap tuff natural joints (Figure 2-5) and reported by other researchers (Jing et al., 1992; Wibowo et al., 1992; Huang et al., 1993) for rock joint replicas under pseudostatic loads.

Jing et al. (1992) proposed a simple model to explain the difference in shear between forward and reverse directions that is based on different damage states of asperities on the joint surface. They implied that, on a larger scale, a rock-joint surface is normally not planar. Rather, it is curved and contains dominant wavelengths. These wavelengths could be either large or small. The portions of the joint surface stretched across these wavelengths are called primary asperities. There also exist, on the joint surface, higher order asperities that have much smaller sizes as compared to the primary asperities [Figure 2-18(a)]. These higher order asperities may be considered as noise on a waveform. Profiles taken from the Apache Leap tuff joints confirm the existence of the primary and higher order asperities, although the effective wavelength and amplitude were different for different joint surfaces. Since the test apparatus was designed to provide substantial constraints along the direction normal to shearing, it is reasonable to assume that the wave shape along this direction should not have a significant impact on the joint behavior. The effective wavelength and amplitude are defined as the factors that control the overall behavior of a joint. It is also likely that the effective wavelength and amplitude controlling the joint shear behavior in one direction are different from those in the opposite direction.

Three factors that may affect joint shear behavior have been suggested (Jing et al., 1992). These factors include the higher order asperities, amplitude to wavelength ratio of the joint surface curvature, and the basic friction angle of the material. The higher order asperities and the basic friction angle of the material provide the fundamental joint resistance to shear while the amplitude to wavelength ratio determines the magnitude of the tangential component of the system normal stress, $\sigma_{n s}$, (vertical stress) along the curved surface. Depending upon the direction of shear, this tangential component could either increase or decrease joint shear resistance. As shown in Figure 2-18(b), when the top rock block is moving upslope, the local direction of shear is opposite to the direction of the tangential component. Consequently, more system shear stress is needed to overcome this tangential component. If the local direction of shear is the same as that of the tangential component of the system normal stress as indicated in Figure 2-18(c) where the top rock block moves downslope, relatively smaller system shear stress is required to mobilize the joint. This conceptual model explains quite well the phenomenon that the shear resistance is smaller upon joint reverse shearing than that of the forward shearing as shown in Figures 2-16 and 2-17.

Observation of the dynamic test results of the Apache Leap tuff joints suggests that the primary asperities control the first-order shear behavior of natural rock-joint surfaces. The first-order behavior includes the basic friction, and any additional friction due to the geometry of the surfaces. Higher order 

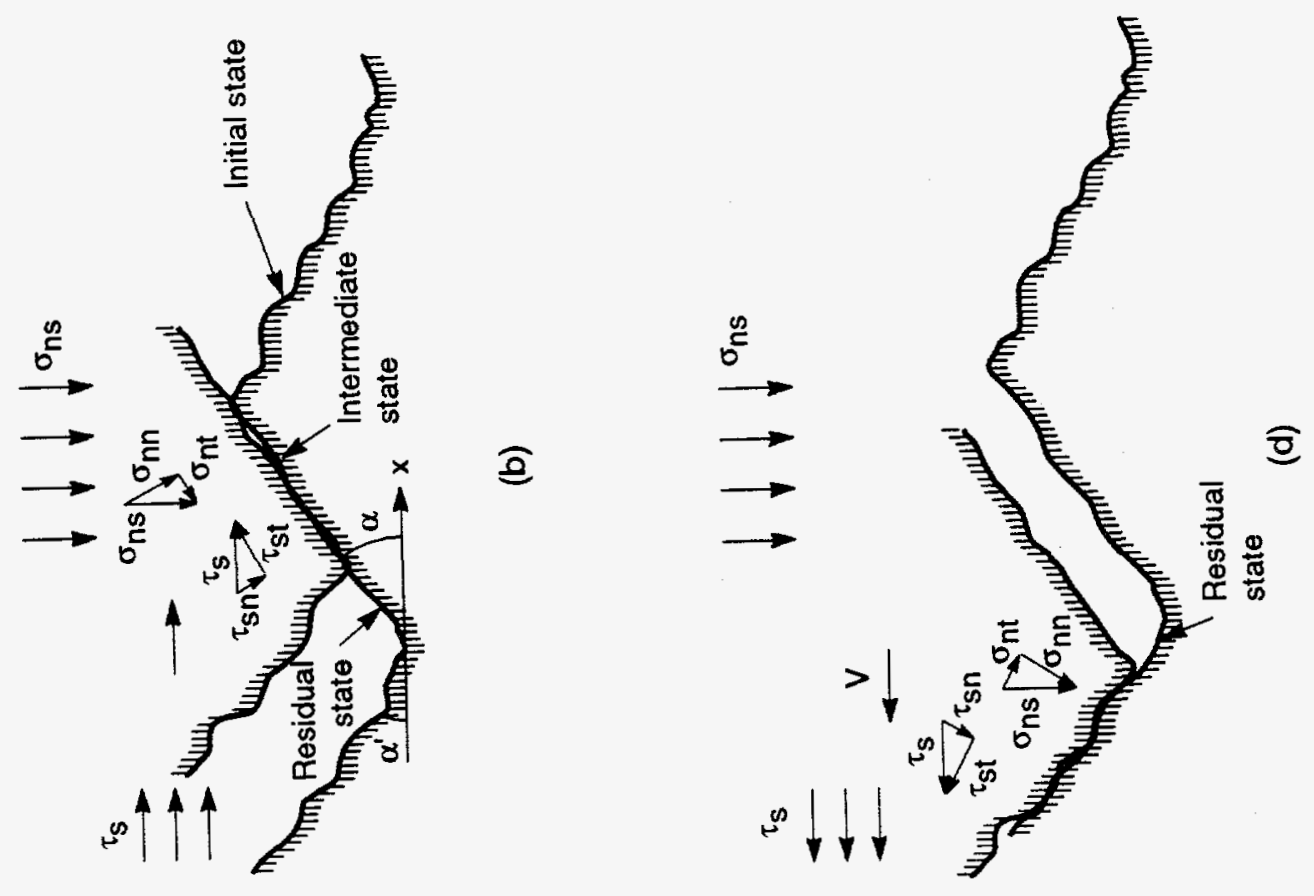

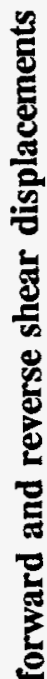
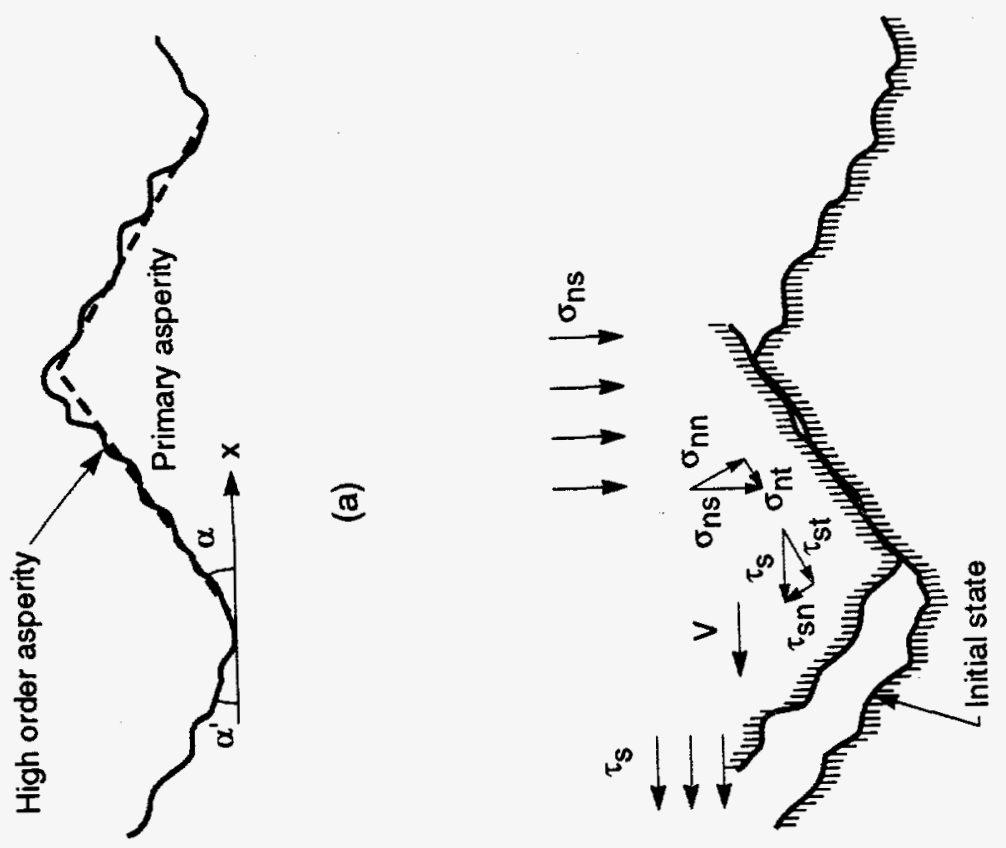

อ 
asperities control the higher order behavior of the joint surfaces, including peak shear stress at the beginning of shearing and stick-slip phenomenon. The role of the higher order asperities is expected to be relatively small, because the higher order asperities will be sheared off quickly after a few cycles of shearing.

There exists another important factor that was not included in the hypothesis proposed by Jing et al. (1992) that may also contribute to the difference in shear resistance between forward and reverse shearing; it is the normal component of the applied system shear stress to the curved surface. When the top block is climbing upward along a primary asperity, a portion of the applied shear stress (horizontal stress) contributes to the local normal stress, $\tau_{s n}$, as shown in Figure 2-18(b), which tends to resist shear.

As a result, the local shear stress is smaller than the system shear stress, $\tau_{s}$. Consequently, more system shear stress is required to overcome this additional normal stress in order to initiate slip along the joint. On the other hand, if the top rock block is moving downslope, this normal component of the system shear stress tends to offset the applied local normal stress [Figure 2-18(c)]. As a result, a smaller shear stress is required to cause slippage of the joint.

The magnitude of the shear resistance during reverse shearing may be related to a number of factors, such as the amplitude-to-wavelength ratio of the primary asperities. In some cases, the shear resistance can be very low, as shown in Figure 2-16. The difference between the shear resistances for the forward and reverse shearing may gradually become smaller as the primary asperities are gradually worn down. However, this wearing will require a substantial number of cycles of shearing, and very much depends on the amplitude-to-wavelength ratio of the joint surface curvature and the joint strength.

It has been suggested by Jing et al. (1992) that the shear resistance during reverse shearing should be more or less constant due to the absence of higher order asperities, which have been theoretically worn out or sheared off during forward shearing. The results from cyclic pseudostatic and dynamic tests on the Apache Leap tuff joints have led to a contradictory observation in which the shear stress continuously varies with shear displacement during the course of forward and reverse shearing. These variations can be better characterized as stick-slip behavior of the joint.

The stick-slip behavior may be related to joint roughness, state of normal stress, frequency of the loading cycles (velocity of shear displacement), perhaps the local strength of the asperities, and possibly enhanced by the presence of apparatus modes. As shown in Figure 2-5, the joint stick-slip behavior was not as pronounced at relatively lower normal stress level (e.g., $1 \mathrm{MPa}$ ). However, when the input frequency was increased from $2.1 \times 10^{-4} \mathrm{~Hz}$ for the pseudostatic tests to $0.5 \mathrm{~Hz}$ for the earthquake tests, or more than $1 \mathrm{~Hz}$ for the harmonic tests, the stick-slip behavior became increasingly pronounced, although the applied normal stress was $1 \mathrm{MPa}$ (Figures 2-16 and 2-17). It is also interesting to note that, in some cases of the dynamic tests, the stick-slip behavior continues even after a number of cycles of shearing, which suggests that the rock fragments, broken off from the joint surfaces in the shearing process, also resist the shearing. This observation is supported by Dieterich (1972). He concluded that stick-slip can happen only if rock fragments are present on the rock surfaces. If these rock fragments are strong, more shear stress is needed in order for the top rock block to crush or ride over them. Small shear displacement may be allowed in the process of crushing or riding over the rock fragments since these rock fragments may not be fixed in place. Therefore, the stick component should be treated more broadly.

Potential impact of dynamic input on the peak joint shear resistance was explored by comparing the results from dynamic tests with those obtained in pseudostatic tests. Natural rock joints were used in direct shear tests under pseudostatic, harmonic, and earthquake-loading conditions. Therefore, a different 
joint specimen was needed for each test, resulting in different joint characteristic for each test. Thus, it is impossible to evaluate directly the dynamic effect on the joint shear resistance, unless some means is developed to account for the effect of different joint roughness. Figure 2-19 provides an approximate means for such an evaluation. Admittedly, the conclusion that can be drawn from this figure is at best an approximation, due to a number of uncertainties involved. However, it does give an indication of the potential dynamic effect on the peak shear resistance. The horizontal axis of the figure represents the Joint Roughness Coefficient (JRC) value calculated from the tilt test, while the vertical axis represents the JRC value calculated from the direct shear test results using Eq. (2-14) discussed later. It has been determined that the tilt-test method grossly underestimates the real JRC value, as do other methods discussed by Hsiung et al. (1993c, 1994a). However, it has been shown that the JRC value from the tilt test has a strong positive correlation with the corresponding JRC values calculated from the shear test results with a correlation coefficient of about 0.85 . Therefore, it is possible to develop an empirical expression relating the JRC values from the two methods. The dotted line in Figure 2-19 shows a second order polynomial fit between JRC values from the pseudostatic test results and the corresponding JRC from the tilt test. This polynomial fit $\left(R^{2}=0.82\right)$ should provide sufficient confidence in estimating the JRC for the Apache Leap tuff joints using the tilt test. Subsequently, the estimated JRC can be used to estimate the pseudostatic peak joint shear resistance with reasonable confidence. Assuming that the peak joint shear resistance will be affected by dynamic loads (e.g., induce a higher peak shear resistance than the peak shear resistance if the same specimen were tested under pseudostatic condition), then the JRC value calculated from the dynamic joint shear resistance should be larger than the JRC value from the pseudostatic shear resistance. In other words, the dynamic JRC should fall above the second polynomial curve if plotted in Figure 2-19. Figure 2-19 includes the dynamic JRC from the harmonic and earthquake test results. Examination of the figure indicates that, in general, the dynamic JRC values do not significantly differ from the corresponding pseudostatic JRC values, except for one data point from a harmonic test result. This similarity is an indication that the dynamic input may not have an appreciable influence on the peak joint shear resistance.

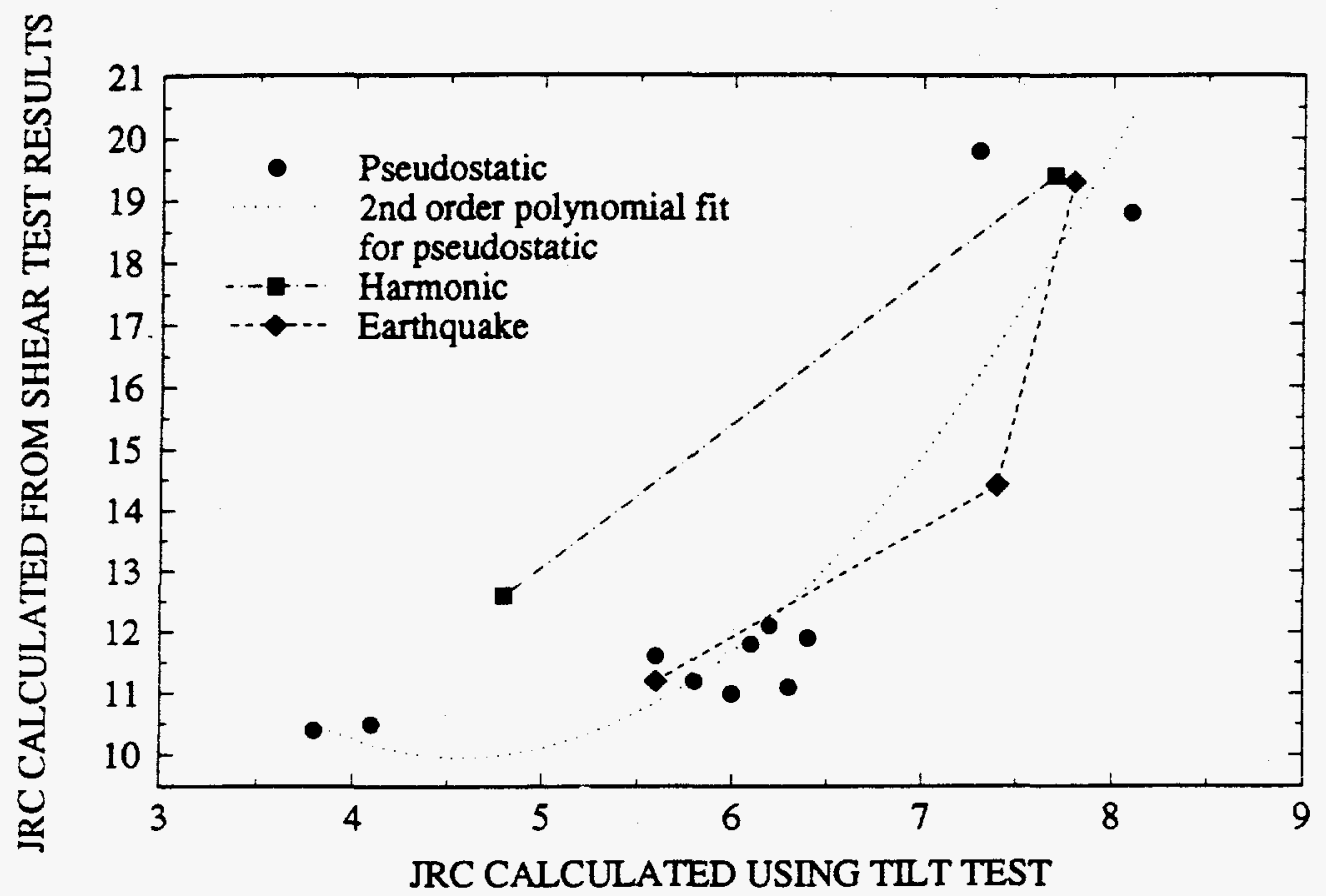

Figure 2-19. Effect of input frequency (shearing velocity) on peak joint shear strength 
Figure 2-20 shows the effect of joint roughness on the joint shear stress reduction during reverse shearing for the dynamic tests. The horizontal axis represents the JRC values that were calculated using the dynamic peak shear resistance results. The vertical axis is the ratio of the approximate shear resistance during reverse shearing to the corresponding peak shear resistance for forward shearing. There are two curves for each type of dynamic tests in the figure. The legend Earthquake, 1 denotes that the data in the first and fourth quadrants were used, while the legend Earthquake, 2 denotes that the data in the third and second quadrants were used. The same approach was used for the harmonic tests. Figure 2-20 clearly shows that the difference between the joint shear resistance during reverse shearing and the peak shear resistance will be larger for joints with rougher surfaces. The dynamic effect is, on the other hand, not clearly shown in the figure.

Figures 2-21 and 2-22 show the joint normal displacement versus shear displacement characteristic curves for the first tests of Tests 14 and 24. Again, the wear of the joint surfaces is a continuing process as is evident in these figures in which the maximum joint normal displacement continues to decrease through the cycles of shearing. It is interesting to note that joint dilation tends to decrease constantly during reverse shearing and may retain a small amount of dilation as the top rock block returns to its original position. This phenomenon can be explained quite well using the conceptual model shown in Figure 2-18. Dilation reduces when the top rock block goes downslope, which is always the case during reverse shearing if the top and bottom rock blocks are closely matched before the test begins. The normal displacement curves are highly nonlinear and are quite smooth for at least the first three cycles of all the earthquake tests. The normal displacement versus shear displacement curves for the pseudostatic tests are also highly nonlinear but quite smooth (Figure 2-6), as are those for the earthquake tests. However, for the harmonic tests, many small stick-slip oscillations that continued for several cycles were observed. This observation gives an indication of the potential impact of the input

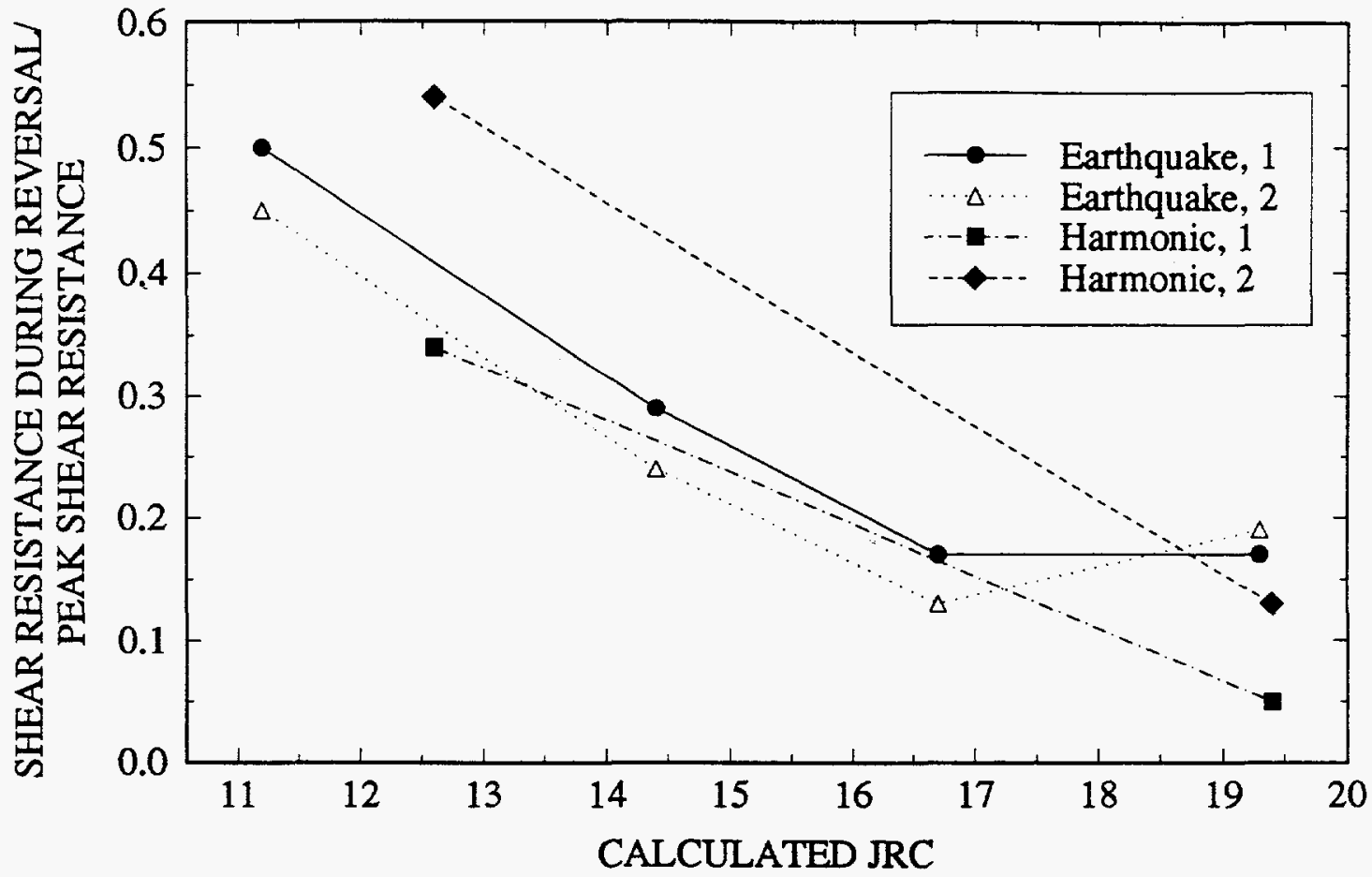

Figure 2-20. Effect of input frequency (shearing velocity) on joint shear resistance on reverse shearing 


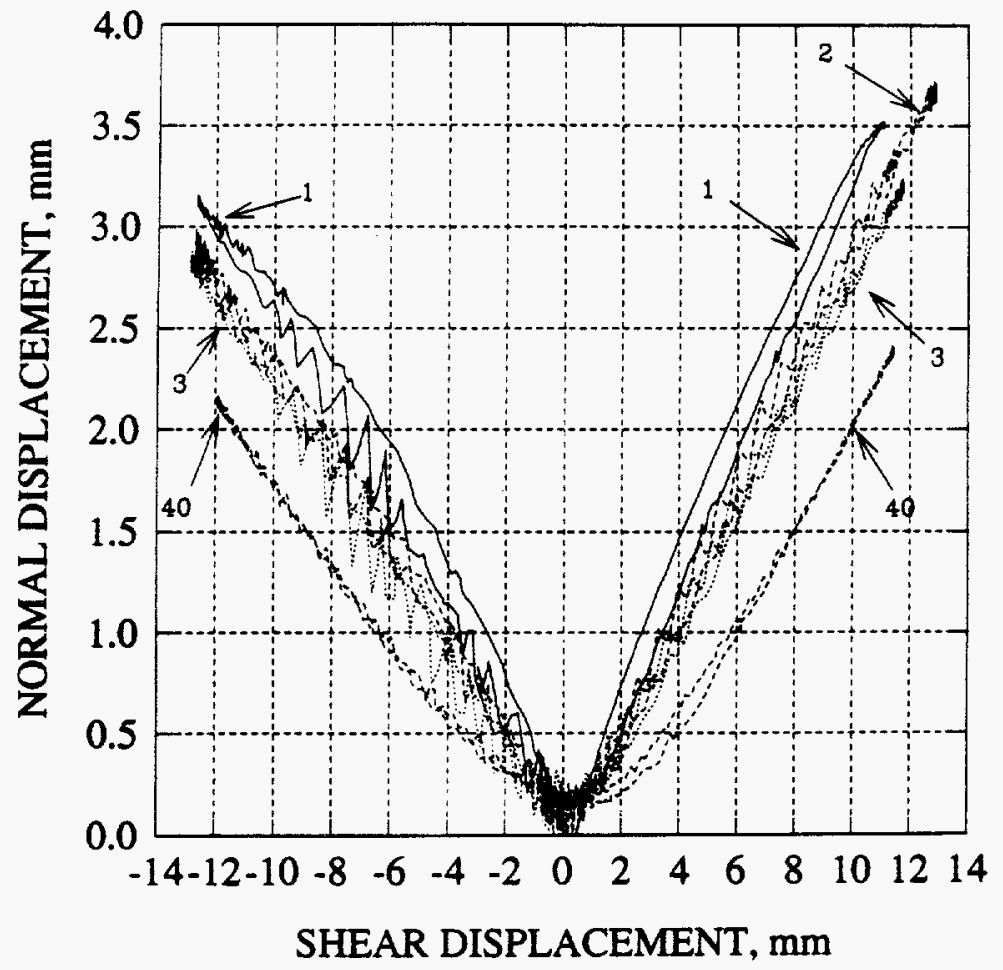

Figure 2-21. Joint normal displacement (dilation) versus shear displacement for the first phase of Test 14 under a harmonic load with $1.4 \mathrm{~Hz}$ input frequency and $12.7 \mathrm{~mm}$ input displacement amplitude (first three cycles and the 40th cycle)

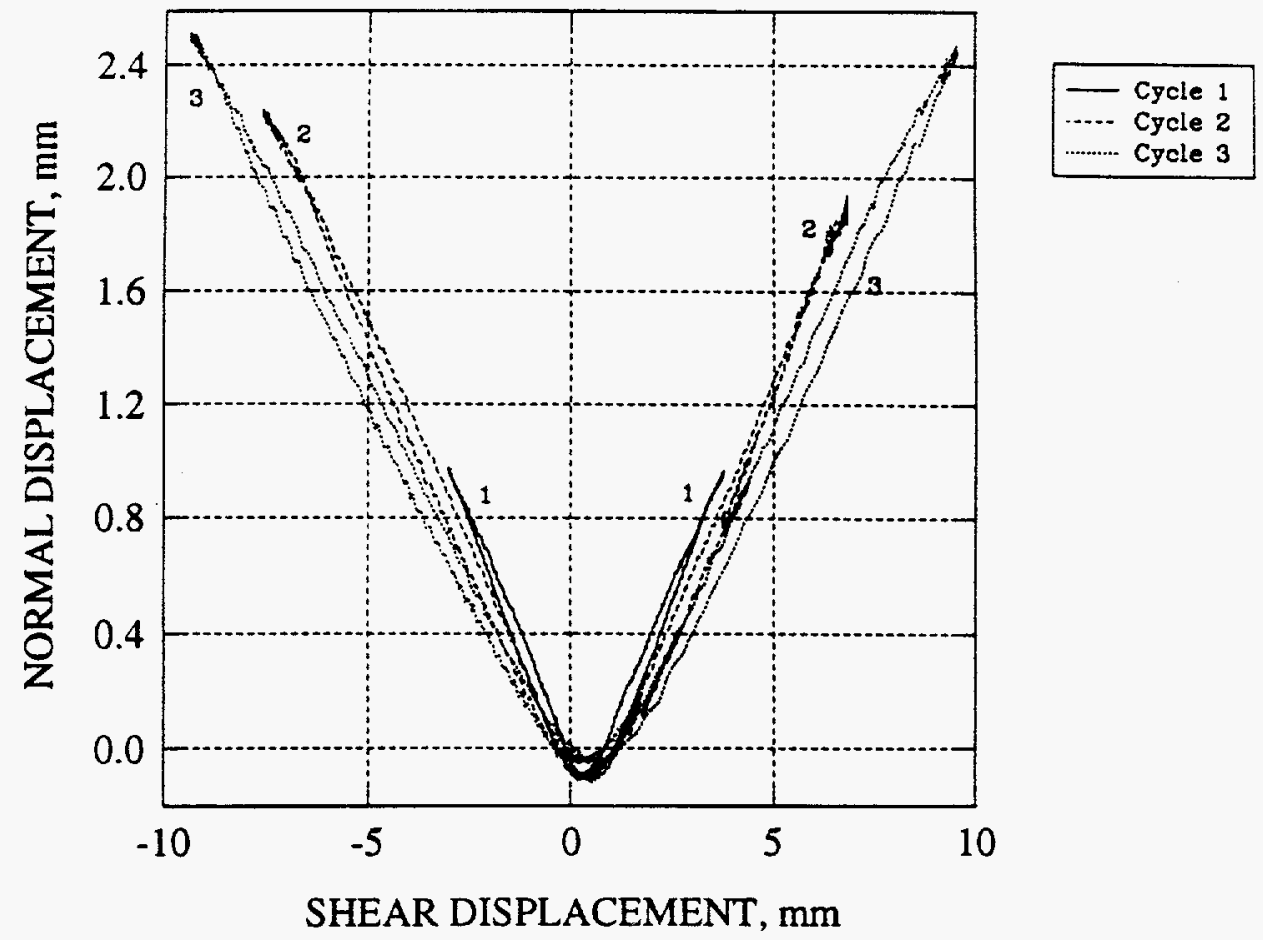

Figure 2-22. Joint normal displacement (dilation versus shear displacement for the first phase of Test 24 under an earthquake load with a maximum input displacement amplitude of $\mathbf{2 5 . 4} \mathbf{~ m m}$ 
frequencies on joint dilation, which may be related to the existence of small size rock fragments created in the process of shearing. Under pseudostatic conditions or when the input frequency was low, shear stress tends to crush these rock fragments instead of riding over them. However, under conditions of high input frequencies, or high velocity for that matter, the rock fragments are stronger and tend to resist crushing. Thus, a temporary increase in normal displacement (the top block riding over these fragments) results. It is commonly understood that rock strength depends on loading rate and generally increases with increasing loading rate. After the fragments are crushed, the normal displacement tends to return to the original path.

In Figure 2-22, the dilation curve for the 40th cycle of the test is also shown. The shape of the dilation curve and relative dilation magnitude with respect to that at zero displacement are generally correct. However, the absolute dilation is not correct. In theory, the joint dilation or joint normal displacement is the relative displacement of the two points on opposite sides of a joint. These two points should be located on the joint surfaces of the joint. In reality, however, this positioning is impossible. One of the technical difficulties is instrumentation, given that the initial aperture between the two points on the opposite sides of a joint before a shear test is very small $(0.01$ to $0.1 \mathrm{~mm})$. Even if this difficulty is overcome, there is the problem of joint wear resulting from joint shearing. After a certain degree of wearing, depending upon the strength of the joint, these two points used for the normal displacement measurement will certainly be worn away. As a result, no further dilation or normal displacement can be obtained. Because of these problems, the joint dilation measurements in this study were taken between two horizontal planes on the opposite sides of a joint. The separation of these two planes was about 6 $\mathrm{mm}$. As the joint wear continues during the shearing, the distance between the two planes becomes smaller. The amount of the decrease in the distance will be treated as a form of joint contraction due to material loss, since the noncontacting probes used for the normal displacement measurement detect only the distance between the sensor and the target plate. Consequently, it will not discriminate the actual joint normal displacement from the distance change between the two horizontal planes due to joint wear. This lack of discrimination explains the considerable amount of closure observed for the 40th cycle in Figure 2-22. The extent of the closure between the two horizontal planes is believed to be a function of joint strength.

The hysteresis between the normal displacements during forward and reverse shearing of the first cycle for the harmonic and earthquake tests is smaller than that observed for the pseudostatic tests. The only satisfactory explanation can be offered for this difference other than as discussed in the previous paragraph that, unlike the dynamic tests, joint shear stress under a pseudostatic condition tends to crush these rock fragments instead riding over them.

\subsection{ROCK-JOINT MODELS}

There are several empirical representations of the constitutive behavior of rock joints with varying degrees of complexity to simulate the phenomena taking place during shearing. Only a few of these models are used quite extensively, especially in numerical analyses. Brief descriptions of some of these models are given below. For more information, respective references should be consulted. 


\subsubsection{Coulomb Model}

The Coulomb law is the simplest model for determining the strength of rock joints. This linear shear failure criterion of a rock joint is given by (Goodman, 1976):

$$
\tau_{0}=C+\sigma_{n} \tan \phi=C+\mu \sigma_{n}
$$

where $\tau_{0}$ is the shear strength along the joint, $\sigma_{n}$ is the normal stress acting across the joint, $C$ is the cohesion, $\phi$ is the friction angle, and $\mu$ is called the coefficient of friction. Once the shear stress reaches $\tau_{0}$, the joint assumes a perfectly plastic deformation. This equation does not contain directionality and suggests the same shear strength in any direction. It also does not consider the wear of the joint and the joint dilation with continuous shear displacement.

Enhancements have been made to the basic Coulomb model to incorporate joint normal and shear stiffnesses (Crotty and Wardle, 1985; ITASCA Consulting Group, Inc., 1992). Crotty and Wardle (1985) called the enhanced model as Mohr-Coulomb model. In the enhanced model of ITASCA Consulting Group, Inc. (1992), called the Coulomb-Slip model, the joint normal response is governed by a constant normal stiffness $K_{n}$ such that

$$
\Delta \sigma_{n}=K_{n} \Delta u_{n}
$$

where $\Delta \sigma_{n}$ is the normal stress increment and $\Delta u_{n}$ is the normal displacement increment. Similarly, the shear stress and shear displacement relation is governed by a constant shear stiffness $K_{s}$ (ITASCA Consulting Group, Inc., 1992):

$$
\Delta \tau_{s}=K_{s} \Delta u_{s}^{e}
$$

or, else if $\left|\tau_{s}\right| \geq \tau_{0}$, then

$$
\tau_{s}=\operatorname{sgn}\left(\Delta u_{s}\right) \tau_{0}
$$

where $\Delta u_{s}^{e}$ is the elastic component of the shear displacement increment, $\Delta u_{s}$ is the total incremental shear displacement, and $\operatorname{sgn}\left(\Delta u_{s}\right)$ is the sign of $\Delta u_{s}$.

In addition, the Coulomb-Slip model in UDEC can simulate joint dilation occurring at the onset of slip (plastic sliding). The dilation behavior is governed by a constant dilation angle $\psi$. Dilation stops after a critical shear displacement $u_{\mathrm{cs}}$ is reached or if the normal stress is too high. This limitation simulates the observation that a joint stops dilating if the asperities are crushed after a larger shear displacement or due to high normal stress. Mathematically, the dilation behavior is represented as:

$$
\text { if }\left|\tau_{s}\right|<\tau_{0} \text {, then } \psi=0
$$


and

$$
\text { if }\left|\tau_{s}\right|=\tau_{0} \text { and }\left|u_{s}\right| \geq u_{\mathrm{cs}} \text {, then } \psi=0
$$

Figure 2-23 illustrates the joint dilation behavior in the Coulomb-Slip model.

\subsubsection{Barton-Bandis Model}

The Barton-Bandis model was proposed with the intent to take into consideration the effect of joint surface roughness on joint deformation and strength (Barton et al., 1985). The nonlinear joint strength criterion is:

$$
\tau_{0}=\sigma_{n} \tan \left[\mathrm{JRC} \log _{10}\left(\frac{\mathrm{JCS}}{\sigma_{n}}\right)+\phi_{r}\right]
$$

where, JRC is joint roughness coefficient, JRC is joint wall compressive strength, and $\phi_{r}$ is residual joint friction angle. The attrition of surface roughness or the reduction of JRC is represented in a piecewise linear manner as shown in Figure 2-24. The table in this figure gives the extent of wear of the joint, which may be expressed by:

$$
\text { If } \frac{u_{s}}{u_{s \text { peak }}}=0 \text { then } \frac{\mathrm{JRC}_{\text {mob }}}{\mathrm{JRC}_{\text {peak }}}=\frac{-\phi_{r}}{\mathrm{JRC} \log _{10}\left(\frac{\mathrm{JCS}}{\sigma_{\mathrm{n}}}\right)}
$$

in the pre-peak region,

$$
\frac{\mathrm{JRC}_{\text {mob }}}{\mathrm{JRC}_{\text {peak }}}=1.0664+1.9459 \log _{10}\left(\frac{u_{s}}{u_{s_{\text {peak }}}}\right)
$$

and in the post-peak region,

$$
\frac{\mathrm{JRC}_{\text {mob }}}{J R C_{\text {peak }}}=1.0004-0.5002 \log _{10}\left(\frac{u_{s}}{u_{s \text { peak }}}\right)
$$

When the joint is not sheared, it has a maximum $\mathrm{JRC}$ value, $\mathrm{JRC}_{\text {peak }}$. However, as the joint shearing begins, the JRC value becomes smaller as a result of roughness attrition. This JRC value is represented by $\mathrm{JRC}_{\mathrm{mob}}$ in Figure 2-24. $u_{s}$ is the joint shear displacement while $u_{s \text { peak }}$ denotes the joint shear displacement at the peak shear stress. $u_{s \text { peak }}$ is calculated using the following equation (Barton and Bandis, 1982): 


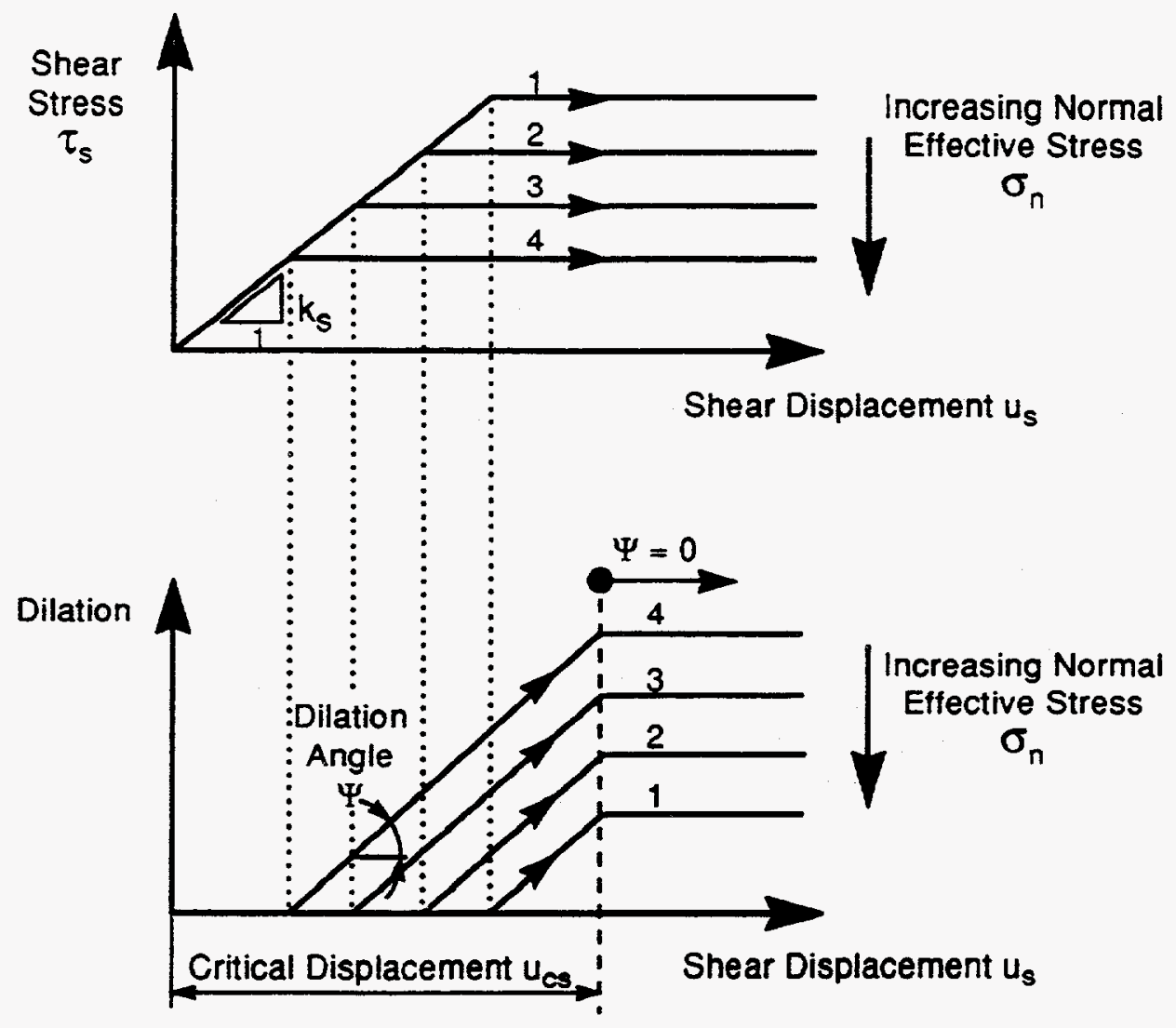

Figure 2-23. Schematic diagram of rock-joint behavior in Coulomb-Slip model of UDEC version 1.83 (ITASCA Consulting Group, Inc., 1992) 


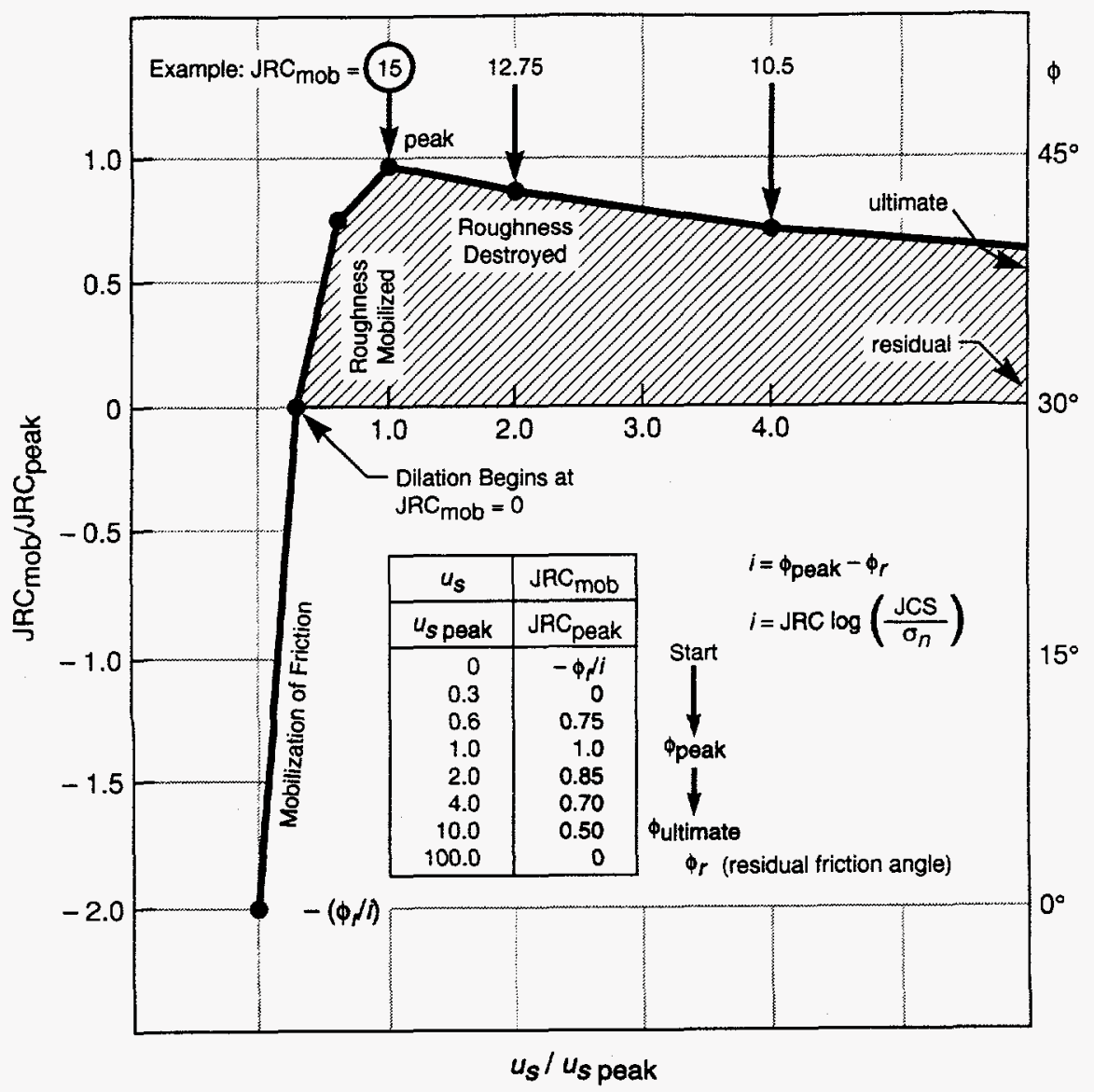

Figure 2-24. Barton-Bandis rock joint model for shear stress versus shear displacement [Reprinted with modification from International Journal of Rock Mechanics and Mining Sciences \& Geomechanics Abstracts, 22(3), N. Barton, S. Bandis, and K. Bakhtar, Strength,Deformation and Conductivity Coupling of Rock Joints, pp. 130, 1985, with kind permission from Elsevier Science Ltd, The Boulevard, Langford Lane, Kidington OX5 1GB, UK.]

$$
u_{s \text { peak }}=\frac{L_{n}}{500}\left(\frac{\mathrm{JRC}}{L_{n}}\right)^{0.33}
$$

where $L_{n}$ is the length of the test specimen.

Based on Eq. (2-14), the joint shear stress under a constant normal stress condition for a given specimen depends solely on the JRC value. When a joint is sheared in one direction, its roughness is reduced from $\mathrm{JRC}_{\text {peak }}$ to, say, $\mathrm{JRC}_{\mathrm{f}}$. If the direction of shear is reversed at this point, the effect of remaining roughness is ignored in the procedure given in Barton $(1982,1988)$. If the shear reversal occurs in the pre-peak region, the friction angle mobilized will be equal to the residual friction angle. On the other hand, if the shear reversal takes place in the post-peak region, the mobilized friction angle can be up to the ultimate friction angle which is larger than the residual friction angle, according to Barton $(1982,1988)$. As the dilation of the Barton-Bandis model is directly related with the JRC, this procedure fails to account for dilation recovery observed in experimental results during reverse shearing (Hsiung et al., 1994a; Celestino and Goodman, 1979; Zubelewicz et al., 1987; Jing et al., 1992; Wibowo et al., 1993, Huang et al., 1993; Gillette et al., 1983). This procedure seems to be inconsistent with the 
theoretical understanding of the phenomenon and experimental observations. When the ratio of the actual shear displacement $u_{s}$ to the shear displacement $u_{s}$ peak is greater than 100 , the $\mathrm{JRC}_{\text {mob }}$ becomes zero as shown in Figure 2-24. Once JRC becomes zero, the joint shear essentially resumes the Mohr-Coulomb model type of behavior.

The Barton-Bandis joint model suggests that the angle of dilation should be a function of JRC value. The relation between the JRC and dilation angle $\psi$ is approximated by:

$$
\psi=0.5 \mathrm{JRC} \log _{10}\left(\frac{\mathrm{JCS}}{\sigma_{\mathrm{n}}}\right)
$$

This equation indicates that, as joint surface wears off, its angle of dilation decreases. In other words, the rate of dilation becomes smaller as joint shearing progresses. The dilation angle will eventually become zero as $u_{s} / u_{s}$ peak becomes greater than 100 . Judging from the nature of Eq. (2-17), $\psi$ is always positive. Joint dilation will continue to increase, although at a gradually slower rate even after the direction of shear has been reversed.

\subsubsection{Continuously-Yielding Model}

The Continuously-Yielding model for rock-joint deformation (ITASCA Consulting Group, Inc., 1992; Cundall and Lemos, 1988) can simulate in a simple way the progressive damage of the joint surface under shear displacement and displays irreversible nonlinear behavior from the onset of shear loading. The response of the joint to normal compressive loading is described incrementally as:

$$
\Delta \sigma_{n}=K_{n} \Delta u_{n}
$$

where the normal stiffness of the joint $K_{n}$ is:

$$
K_{n}=a_{n} \sigma_{n}^{e_{n}}
$$

Therefore,

$$
\Delta \sigma_{n}=a_{n} \sigma_{n}^{e_{n}} \Delta u_{n}
$$

Parameters $a_{n}$ and $e_{n}$ in Eq. (2-20) are constants. Equation (2-20) models the increase in normal stiffness with an increase in normal stress. The Continuously-Yielding model displays irreversible nonlinear behavior from the onset of shear loading. The shear stress increment is described as:

$$
\Delta \tau_{s}=F K_{s} \Delta u_{s}
$$


where the shear stiffness $K_{s}$ is:

$$
K_{s}=a_{s} \sigma_{n}^{e_{s}}
$$

Therefore, the change in shear stress due to change in shear displacement is:

$$
\Delta \tau_{s}=F a_{s} \sigma_{n}^{e_{s}} \Delta u_{s}
$$

where $F$ is a factor that governs the shear stiffness, and parameters $a_{s}$ and $e_{s}$ in Equation (2-22) are constants. $F$ depends on the difference between the actual stress curve and the bounding strength curve $\tau_{0}$ and is given as:

$$
F=\frac{\left(1-\tau_{s} / \tau_{0}\right)}{(1-r)}
$$

Therefore, $\Delta \tau_{s}$ is:

$$
\Delta \tau_{s}=\frac{\left(1-\tau_{s} / \tau_{0}\right)}{(1-r)} a_{s} \sigma_{n}^{e_{s}} \Delta u_{s}
$$

The factor $r$ is initially 0 , and it restores the elastic stiffness immediately after load reversal. That means $r$ is set to $\sigma_{s} / \tau_{0}$ ( $F$ becomes 1 ) whenever the sign of $\Delta u_{s}$ is not the same as the sign of $\Delta u_{s \text { old }}$. In practice, $r$ is restricted to a maximum value of 0.75 to avoid numerical noise when the shear stress is approximately equal to the bounding strength, $\tau_{0}$. The bounding strength, $\tau_{0}$, is

$$
\tau_{0}=\sigma_{n} \tan \phi_{m} \operatorname{sgn}\left(\Delta u_{s}\right)
$$

where $\phi_{m}$ is the friction angle that would apply if the joint is to dilate at the maximum dilation angle and is initially equal to the joint initial friction angle, $\phi_{m o}$. As damage accumulates, $\phi_{m}$ is continuously reduced according to

$$
\Delta \phi_{m}=-\frac{1}{R}\left(\phi_{m}-\phi\right) \Delta u_{s}^{p}
$$

where $\Delta u_{s}^{p}$ is the plastic displacement increment and is given by

$$
\Delta u_{s}^{p}=(1-F)\left|\Delta u_{s}\right|
$$


and $\phi$ is the basic friction angle of the rock surface. $R$ is a material parameter with a dimension of length that expresses the joint roughness. A large value of $R$ produces slower reduction of $\phi_{m}$ and a higher peak. The peak is reached when the bounding strength equals the shear stress. After the peak, the joint is in the softening region and the value of $F$ becomes negative.

\subsubsection{Numerical Simulation of Laboratory Direct Shear Experiments Under Cyclic Loading}

An assessment of rock-joint models and qualification of the associated computer codes was undertaken at the CNWRA. The goal of the program was to evaluate the ability of existing rock-joint models and the associated computer codes to simulate cyclic pseudostatic and dynamic joint behavior. There were two phases of this program. In the first phase of the qualification study, a few commercially available computer codes were selected and evaluated for the response of four well-established benchmark problems involving a rock joint that have closed-form solutions (Brady et al., 1990b; Hsiung and Chowdhury, 1991, 1993; Hsiung et al., 1993; Brandshaug et al., 1990). These commercially available codes included the distinct element codes UDEC (version 1.5, ITASCA Consulting Group, Inc., 1989) and 3DEC (version 1.0, Cundall, 1988), the discrete element code DECICE (Williams et al., 1985), and the finite element codes HONDO II (Key et al., 1978) and SPECTROM-331 (Key, 1987). The first phase of this study was intended to confirm whether each code could reproduce the rock-joint response of these benchmark problems. Codes with an acceptable performance were candidates for the second phase of the qualification study, in which the dynamic response of well-designed and executed direct shear laboratory experiments would be analyzed. The first phase of this study showed that only UDEC and 3DEC (which is, in general, a three dimensional version of UDEC) were able to reproduce the response of all four benchmark problems. The UDEC code was selected for the second phase of this study. The objective of the second phase of qualification study was to evaluate the existing rock-joint models and the associated computer code against experimental results (Hsiung et al., 1994b).

The ability of Coulomb-Slip, Barton-Bandis, and Continuously-Yielding rock joint models to simulate joint shear response under cyclic loading, both pseudostatic and dynamic, was evaluated in two ways: (i) using the fundamental forms (the equations given for each model) of the models, and (ii) using these models as implemented in the UDEC computer code. As these models are independent of shearing velocity, it is sufficient to evaluate the models in their fundamental forms pseudostatically. Evaluation using the UDEC code includes both cyclic pseudostatic and dynamic (both harmonic and earthquake) loads. Versions 1.82 and 1.83 of UDEC were used in this evaluation. Changes made in version 1.83 do not affect the rock joint models. Details of this study are given in Hsiung et al. (1994a, 1994b).

For a joint with a shear stiffness, $K_{s}$, of $16.93 \mathrm{GPa} / \mathrm{m}$, a cohesion $C$ of zero, a friction angle, $\phi$, of $38^{\circ}$, a constant dilation angle, $\psi$, of $2.4^{\circ}$, the predicted joint behavior using the Coulomb-Slip model subjected to a normal stress, $\sigma_{n}$, of $3 \mathrm{MPa}$ has been illustrated in Figures 2-25 and 2-26. In Figure 2-25, the critical shear displacement is not reached while it is about $10.52 \mathrm{~mm}$ for Figure 2-26. For shear loading, shear displacement is linear and reversible up to when the joint shear strength is reached and then is perfectly plastic. Reverse shearing after plastic yield is accompanied by permanent shear displacement and hysteresis. The shear strengths for both forward and reverse directions are the same, indicating that the Coulomb-Slip model cannot adequately represent the joint shear behavior during reverse shearing. Two dilation curves are shown in Figures 2-25 and 2-26. Curve Dilation 1 represents the dilation behavior following the definition of Eq. (2-13). Curve Dilation 2 is obtained by assuming that joint dilation is dependent on shearing direction. In this particular case, the sign of the dilation angle is 


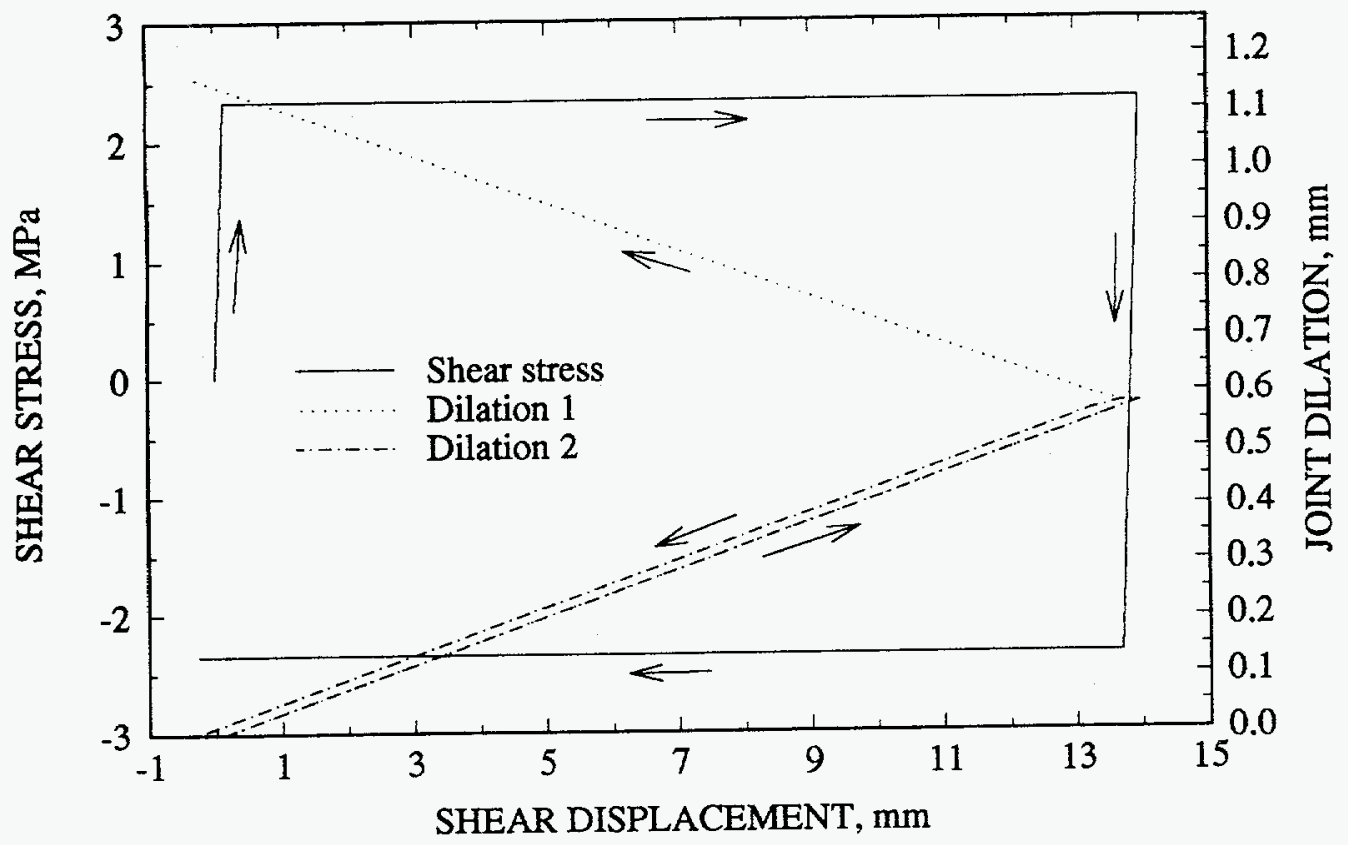

Figure 2-25. Prediction of joint behavior using Coulomb-Slip model assuming that shear stiffness $=16.93 \mathrm{GPa} / \mathrm{m}$, friction angle $=38^{\circ}$, dilation angle $=2.4^{\circ}$, and normal stress $=3 \mathrm{MPa}$ (assuming critical shear displacement is not reached)

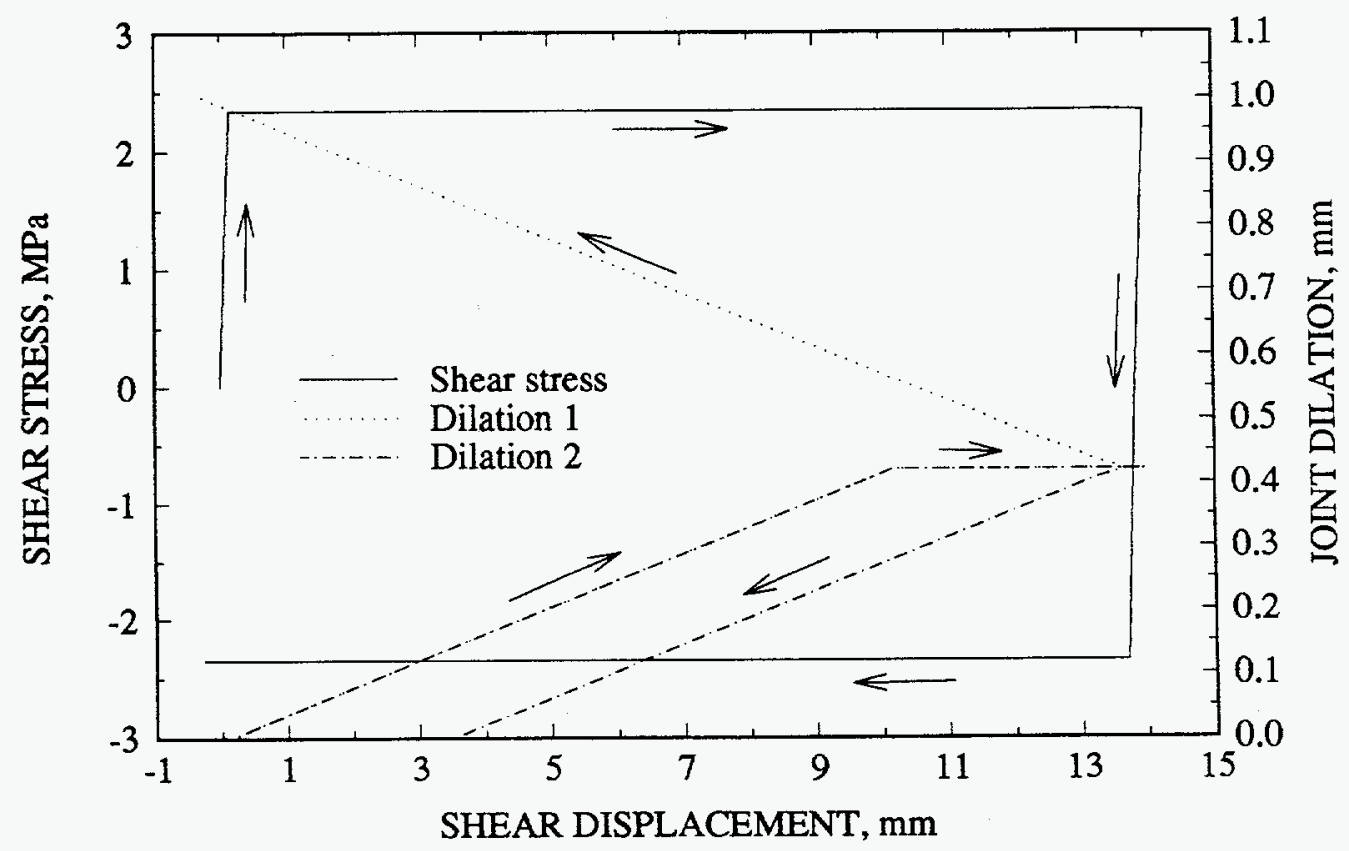

Figure 2-26. Prediction of joint behavior using Coulomb-Slip model assuming that shear stiffness $=16.93 \mathrm{GPa} / \mathrm{m}$, friction angle $=38^{\circ}$, dilation angle $=2.4^{\circ}$, and normal stress $=3 \mathrm{MPa}$ (assuming critical shear displacement has been reached) 
changed to negative as the direction of shearing is reversed. As can be observed in both figures, if dilation follows the rule set by Eq. (2-13), it will continue to increase during reverse shearing. This phenomenon substantially departs from the laboratory observations. On the other hand, if the dilation angle undergoes a sign change during reverse shearing, dilation tends to recover, that is, it is conceptually in agreement with the laboratory observations.

Assuming a joint with a JCS of $170.5 \mathrm{MPa}$, a JRC of 7.1, and a residual frictional angle of $28.4^{\circ}$, the predicted shear response using the Barton-Bandis model subjected to a normal stress, $\sigma_{n}$, of $3 \mathrm{MPa}$ is shown in Figure 2-27. In this calculation, the remaining friction property at the end of the forward shearing process is assumed to control the joint response in the reverse shearing process as was implemented in UDEC versions 1.82 and 1.83. The JRC value of the joint at the beginning of reverse shearing is half of the original JRC. Consequently, a distinct peak shear strength is observed at the beginning of reverse shearing. The peak shear strength for the reverse shearing is the same as the shear strength at the end of the forward shearing. This observation indicates that the Barton-Bandis model may not adequately represent joint shear behavior during reverse shearing. Curve Dilation 1 represents the dilation behavior following the definition of Eq. (2-17) in which the joint dilation continued to increase. If the sign of the dilation angle can be changed as the direction of shear reverses, joint dilation would tend to decrease (recover) during reverse shearing instead of increasing (curve Dilation 2). The rate of decrease in dilation or the extent of dilation recovery depends on the extent of joint wear. However, the recovery is not as extensive as that observed in the laboratory. Consequently, it will not be sufficient to explain the joint dilation behavior during reverse shearing at which dilation recovers at a much higher and increasing rate.

Assuming a joint with constant shear stiffness $\boldsymbol{K}_{s}$ of $29.312 \mathrm{GPa} / \mathrm{m}$, initial friction angle $\phi_{\max }$ of $39.3^{\circ}$, basic friction angle $\phi$ of $33.5^{\circ}$, and roughness parameter $R$ of 0.0175 , the predicted joint behavior using the Continuously-Yielding model subjected to a normal stress $\sigma_{n}$ of $3 \mathrm{MPa}$ is illustrated in Figure 2-28. Again, the peak shear strength for reverse shearing is not very different from the shear strength at the end of forward shearing. This observation indicates that the Continuously-Yielding model may not adequately represent the joint shear behavior during reverse shearing observed in the laboratory. Two dilation curves are shown in Figure 2-28. Curve Dilation 1 represents the dilation behavior following the definition of Eq. (2-27) in which the joint dilation continued to increase. If the sign of the dilation angle was changed as the direction of shear reverses, joint dilation would tend to decrease (recovery) during reverse shearing instead of increasing (Curve Dilation 2). However, the extent of recovery is not as extensive as that observed in the laboratory.

Careful examination of the respective equations representing the Coulomb-Slip, Barton-Bandis, and Continuously-Yielding rock joint models reveals that all three models are essentially for unidirectional shearing. Both Coulomb-Slip and Continuously-Yielding rock joint models assume the same joint behavior in forward and reverse shearing conditions. This assumption is not consistent with the measured shear behavior in the laboratory experiments. The shear strength during reverse shearing was always smaller than that in the forward direction. Although Barton $(1982,1988)$ gave a procedure to modify the equations for forward shearing to model the response in reverse shearing, as discussed before, this procedure seems to be inconsistent with experimental observations by different researchers and theoretical understanding. 


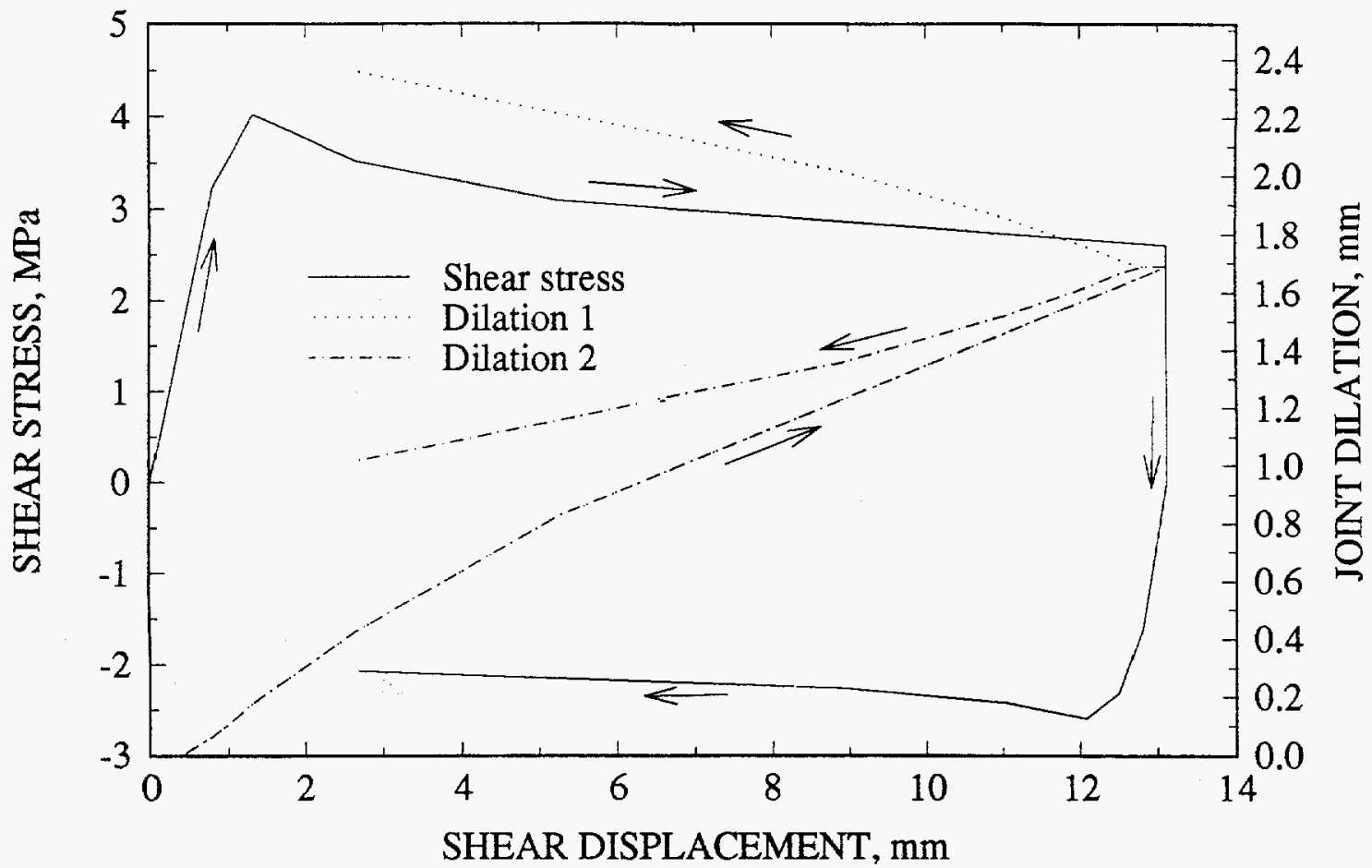

Figure 2-27. Prediction of joint behavior using Barton-Bandis model assuming joint wall compressive strengih $=170.5 \mathrm{MPa}$, residual friction angle $=28.4^{\circ}$, joint roughness coefficient $=7.1$, and normal stress $=3 \mathrm{MPa}$

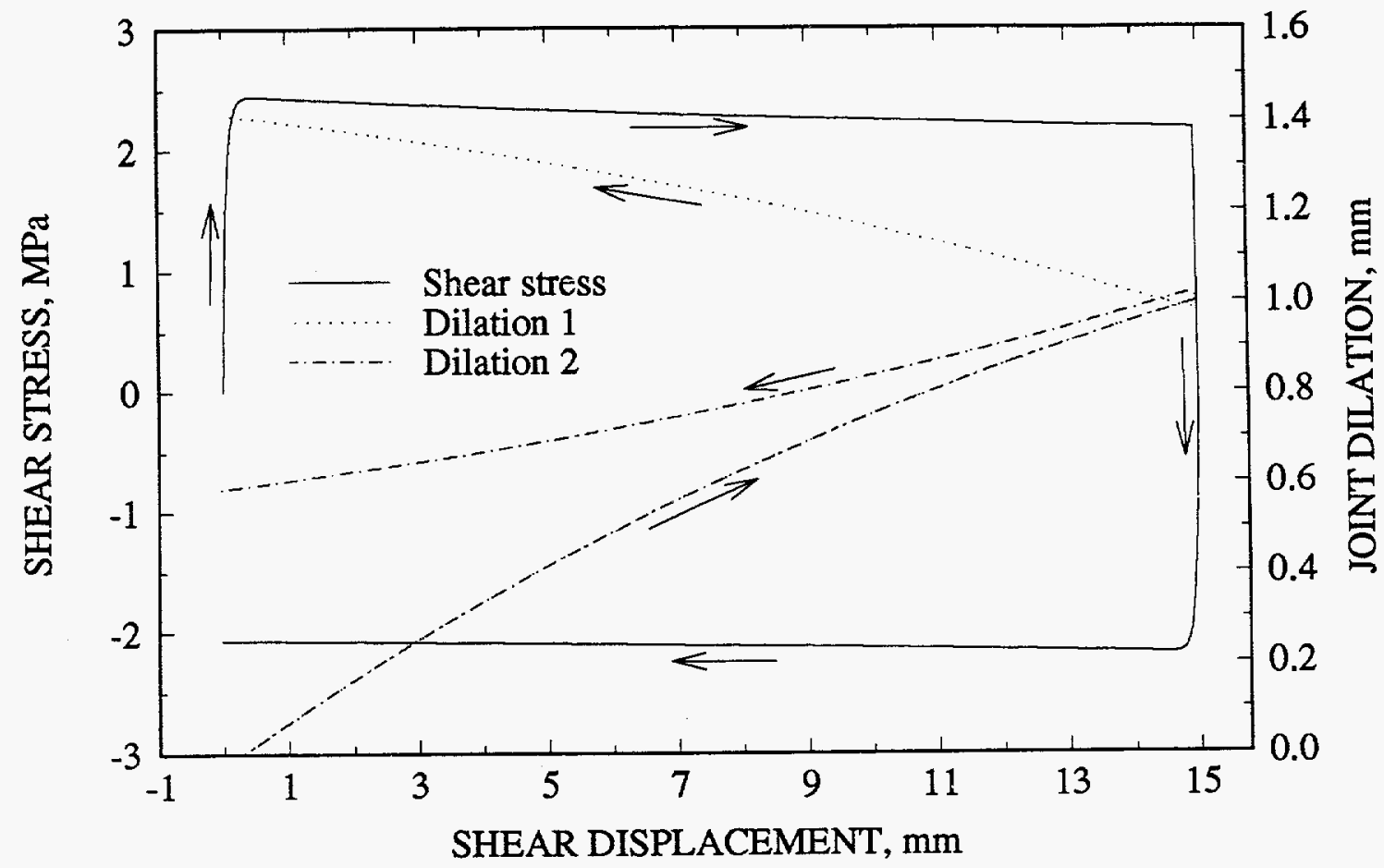

Figure 2-28. Prediction of joint behavior using Continuously-Yielding model assuming a constant shear stiffness $=29.312 \mathrm{GPa} / \mathrm{m}$, initial friction angle $=39.3^{\circ}$, basic friction angle $=33.5^{\circ}$, roughness parameter $=0.0175$, and normal stress $=3 \mathrm{MPa}$ 
The Coulomb-Slip model calculates the dilation based on a constant dilation angle. Dilation starts when peak shear strength is reached and ceases when a critical shear displacement is reached. The Barton-Bandis and Continuously-Yielding models directly link joint dilation with shear displacement through the roughness properties. Since a joint continues to wear during shearing, the dilation angle used to calculate joint dilation continues to decrease. The continuous decrease of dilation angle implies that the joint will eventually stop dilating when it is completely worn. Coulomb-Slip and ContinuouslyYielding models inherently assume an increase of joint dilation with increasing shear displacement irrespective of the direction of shearing. This assumption is inconsistent with the joint dilation behavior observed in the laboratory. Barton-Bandis model (Barton, 1982) did not provide any methodology to calculate joint dilation during reverse shearing.

In UDEC modeling, a simplified approach was taken to model the laboratory direct shear experiments by not simulating the test apparatus. Figure 2-29 shows the UDEC model. This approach neglected the possible effect of the test apparatus. For the cyclic pseudostatic shear tests, this approach was justified since the applied shear velocity was so small and the possible effect of the apparatus was nonexistent. For the typical range of input frequencies of the dynamic loadings used in the laboratory, that is, below $5 \mathrm{~Hz}$, the response of the shear apparatus should not influence joint response significantly. A separate study using the 3DEC discrete element code has indicated that neglecting the effect of the test apparatus can be tolerated if the input frequencies of a dynamic test are less than $50 \mathrm{~Hz}$ (Hsiung and Chowdhury, 1991).

As shown in Figure 2-29, a rigid block was attached to the left side of the top rock block. The attachment of this rigid block made it possible to apply an input loading condition similar to the actual test condition. The force variation measured at the centroid of this loading block resulting from resisting joint shear was directly comparable to the shear force measured from the load cell that was used for joint shear calculation. A constant normal stress was applied at the upper surface of the top block. After iterating the system to static equilibrium, a horizontal input velocity was applied to the centroid of the rigid loading block. The rigid loading block was $3 \mathrm{~mm}$ above the horizontal interface. As a result, the applied load in the form of a constant velocity through the centroid of the rigid loading block did not go through the centroid of the top rock block. Consequently, a moment was created about the centroid of the top block. Although this moment was considered small, in the final model the size of the rigid block was reduced both at the top and bottom. The sides of the bottom rock block were fixed to prevent displacement along the horizontal direction and bottom surface was set to not allow any vertical movement. Both top and bottom blocks were assumed fully deformable. The constitutive behavior of the horizontal interface between the top and bottom blocks was characterized by either of three rock-joint models-Coulomb-Slip, Barton-Bandis, and Continuously-Yielding. The vertical interface between the rigid loading block and the top rock block was governed by the Coulomb-Slip model. Cohesion and coefficient of friction of this vertical interface were assumed to be zero to allow sliding along the interface. This sliding capability was considered critical in that the applied input velocity could be maintained in the horizontal direction throughout the entire simulation. An extremely large tensile strength was also assigned to this vertical interface to prevent detachment from the top rock block. Actual loading speed used in the laboratory was a constant horizontal velocity of $4.2 \times 10^{-5} \mathrm{~m} / \mathrm{s}$. This velocity combined with the small rock density resulted in an extremely small critical time step of $5.337 \times 10^{-6} \mathrm{~s}$. Based on this time step, 178 million steps of calculation are needed for the rock block to displace $40 \mathrm{~mm}$ as it did in the laboratory experiment. At this small time step, the increments calculated for some variables at each time step were smaller than the single precision arithmetic used in UDEC registered. This error, cumulative at each step, leads to numerical instability and unreasonable results after a million or so 


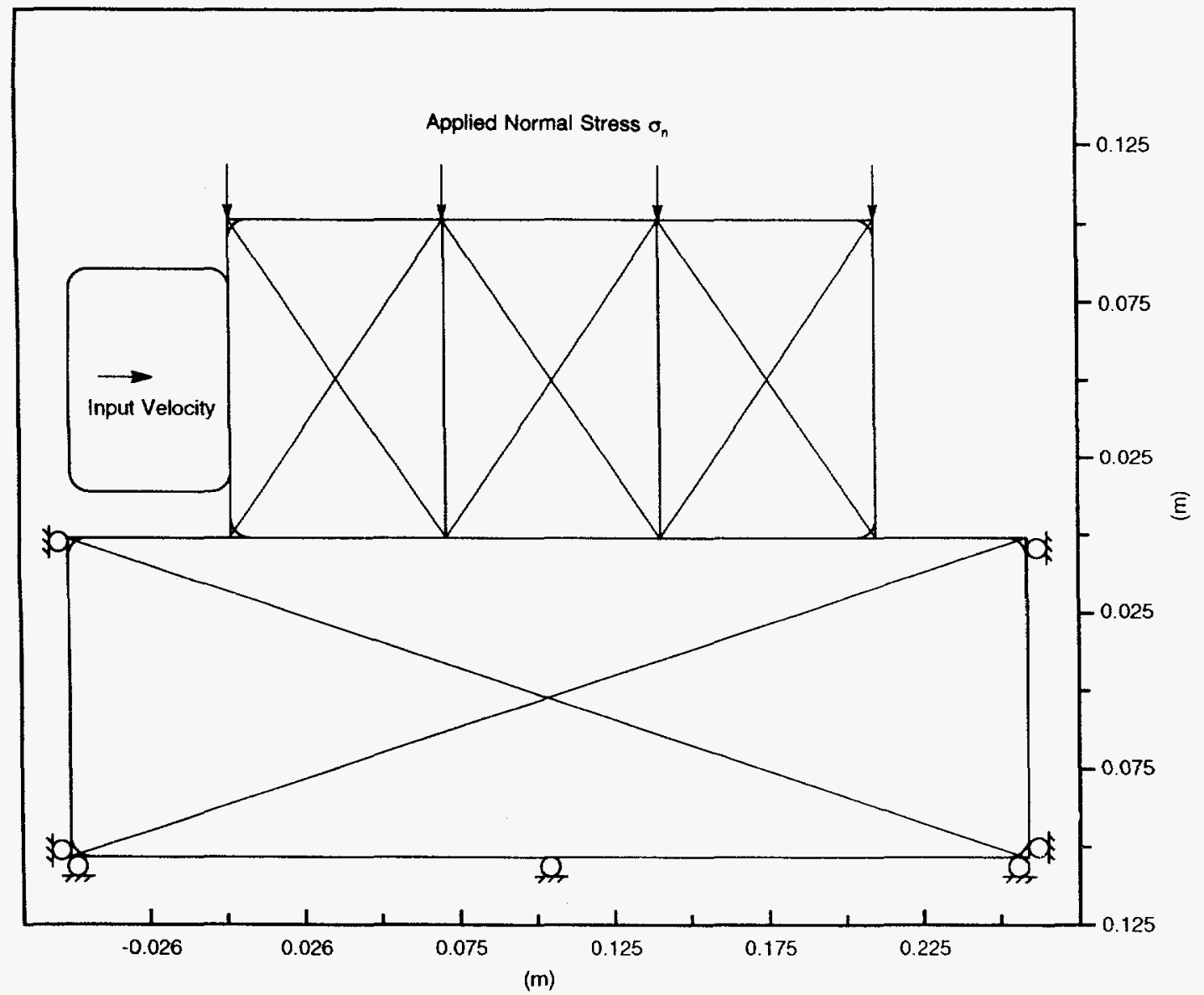

Figure 2-29. Final UDEC model for simulating laboratory tests on Apache Leap tuff specimens

cycles. To overcome this problem, the running time had to be shortened to reduce the number of calculations. There are two ways to reduce the number of calculation steps: increasing the input velocity or increasing the rock density. After some experiments, it was decided to increase the input velocity to $100 \mathrm{~mm} / \mathrm{s}$ as none of the joint constitutive models are velocity dependent. With this velocity, the numerical instability problem was eliminated. Caution was necessary to ensure adequate damping (i.e., Rayleigh) was applied to the model. The natural frequency required for the Rayleigh damping was determined by running the UDEC model with no shear load.

Simulation of the direct shear tests required accurate estimation of the stresses at each contact point along the horizontal interface. At each time step, UDEC calculates forces and displacements at each contact point in the model. The shear stress at each contact point along the joint is then calculated by dividing the shear force at that point by its associated joint length. The joint length of a contact point is equal to the sum of half distances from this point to the immediate contact points on both sides. Due to the nature of this experiment, the contact length associated with the two bottom corners of the top block varies with shear displacement. This resulted in incorrect shear stress calculation, although the caiculated shear forces were correct. Discretization of the bottom block into finite difference elements had to be modified to avoid this problem. Figure 2-29 shows the final configuration of the UDEC model. Details of the modeling, material properties used, and results obtained are given in Hsiung et al. (1994b). Only the typical results will be discussed here. It should be noted that the Coulomb-Slip rock-joint model, as implemented in the UDEC code (versions 1.82 and 1.83) assumes a constant normal stiffness for joint normal stress calculation. However, the results from laboratory experiments on the Apache Leap tuff 
joints have indicated that joint normal stiffness is not constant at different normal stress levels. In order to properly model the test condition, different normal stiffnesses, calculated from the actual test results, were used for different shear cycles.

Five pseudostatic direct shear experiments (Tests 7 through 11) were simulated using all three joint models. Input data used in each simulation are given in Hsiung et al. (1994a). Figures 2-30 through 2-32 show the joint shear stress versus shear displacement responses calculated by UDEC (versions 1.82 and 1.83) modeling of Test 11 using Coulomb-Slip, Barton-Bandis, and Continuously-Yielding models respectively. Figures 2-33 through 2-35 show the corresponding normal displacement versus shear displacement plots. Laboratory results are also shown in these figures. The joint dilation shown in the figures is the average of values measured at four contact points of the UDEC model. As expected, the Coulomb-Slip model does not show any peak behavior (Figure 2-30). This model does give a reasonable prediction of shear stress during forward shearing, especially in the residual range. The predicted shear stress during reverse shearing, on the other hand, does not seem to be adequate. This model over-predicts the strength in all cases. For all shear cycles, joint dilation reaches a maximum value that is controlled by the critical shear displacement, $u_{\mathrm{cs}}$. As discussed before, joint dilation ceases to increase when the shear displacement is greater than the $u_{\mathrm{cs}}$ value. Once the dilation ceases to increase during forward shearing, it remains constant during the entire period of reverse shearing. Figure 2-33 further indicates that dilation begins to increase again during forward shearing of the next shear cycle. Comparing the results from the UDEC simulation with those of the laboratory experiments, it is clear that the joint dilation prediction using the Coulomb-Slip model as implemented in the UDEC code (versions 1.82 and 1.83) did not predict the dilation recovery during reverse shearing.

If the critical shear displacement $u_{\mathrm{cs}}$ is not reached during the course of forward shearing, the recovery of joint dilation can be predicted using the Coulomb-Slip model as implemented in the UDEC code. This prediction indicates that the algorithm, as formulated in UDEC (versions 1.82 and 1.83), for joint dilation calculations using Coulomb-Slip involves a sign change of the dilation angle. The temporary increase in joint dilation at the beginning of reverse shearing is not real. This temporary increase is a natural result of sign change in the dilation angle during reverse shearing. The algorithm used in the UDEC code for dilation calculation for the Coulomb-Slip model probably is the same for both forward and reverse shearing. As a result, what is originally contraction behavior at the beginning of the forward shearing becomes the dilation at the beginning of reverse shearing due to sign change in dilation angle. In reality, similar contraction behavior, shown at the beginning of forward shearing, may also be observed at the beginning of reverse shearing. Careful examination of the experimental results for dilation seems to confirm this observation.

Figure 2-31 shows distinct peak shear strengths were predicted by the UDEC code in both forward and reverse shearing using the Barton-Bandis model for each shear cycle. The predicted peak shear strength during reverse shearing using the Barton-Bandis model is the same as the residual shear strength at the end of forward shearing. This predicted phenomenon does not reflect the laboratory observation. The predicted dilation using the Barton-Bandis model (Figure 2-34), as implemented in UDEC (versions 1.82 and 1.83), is at least one order of magnitude less than the laboratory measured joint dilation, depending upon the magnitude of the applied normal stress. Also, the calculated dilation indicates that dilation stops after a short period of sharp increase.

Figure 2-32 shows joint shear stress versus shear displacement plot of UDEC modeling using the Continuously-Yielding joint model for the Test 11. Prediction of shear stress variation during forward 


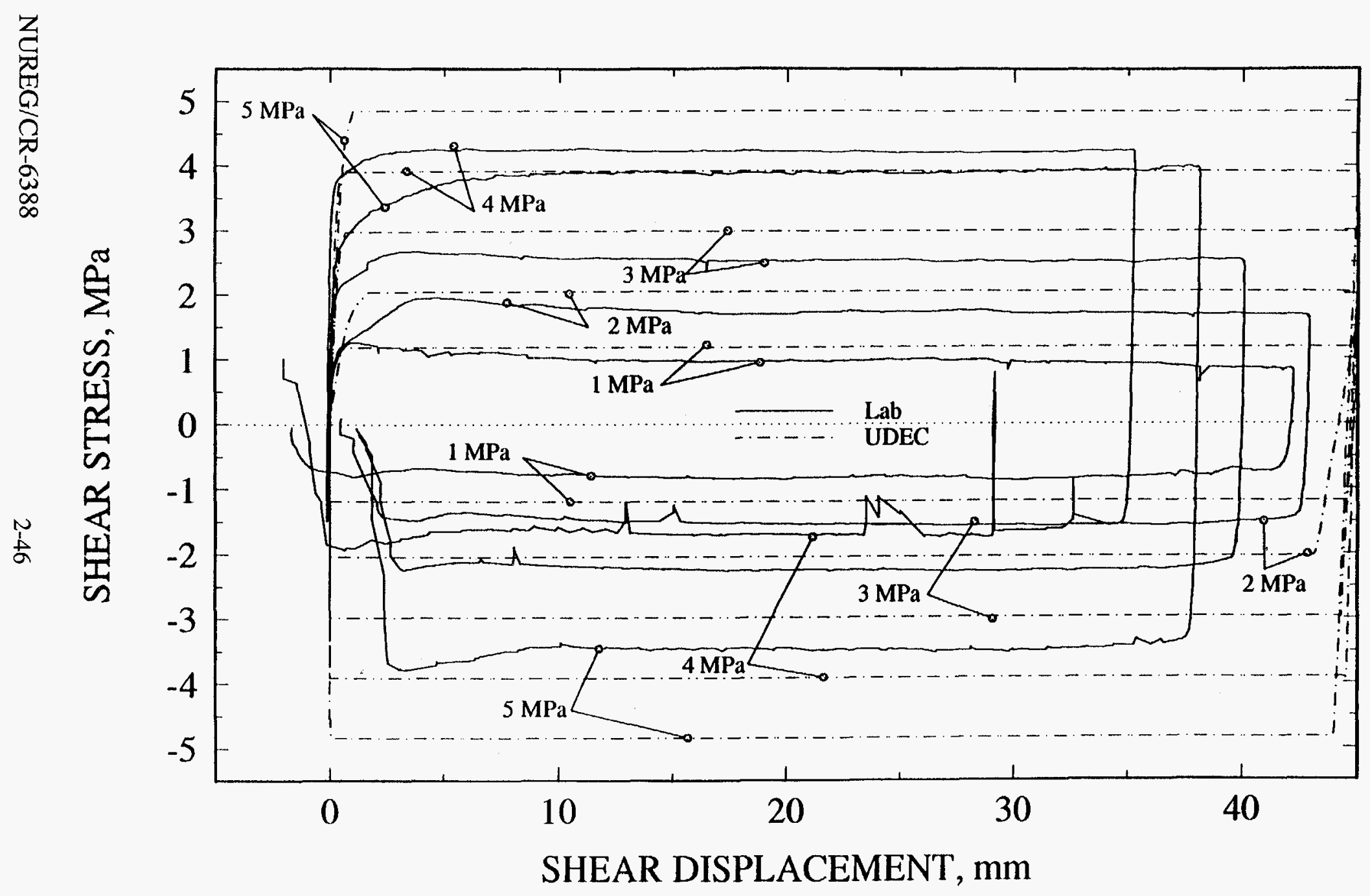

Figure 2-30. UDEC results using Coulomb-Slip joint model and laboratory test results of shear stress versus shear displacement for the same joint specimen as a function of normal stress for Test $\mathbf{1 1}$ 

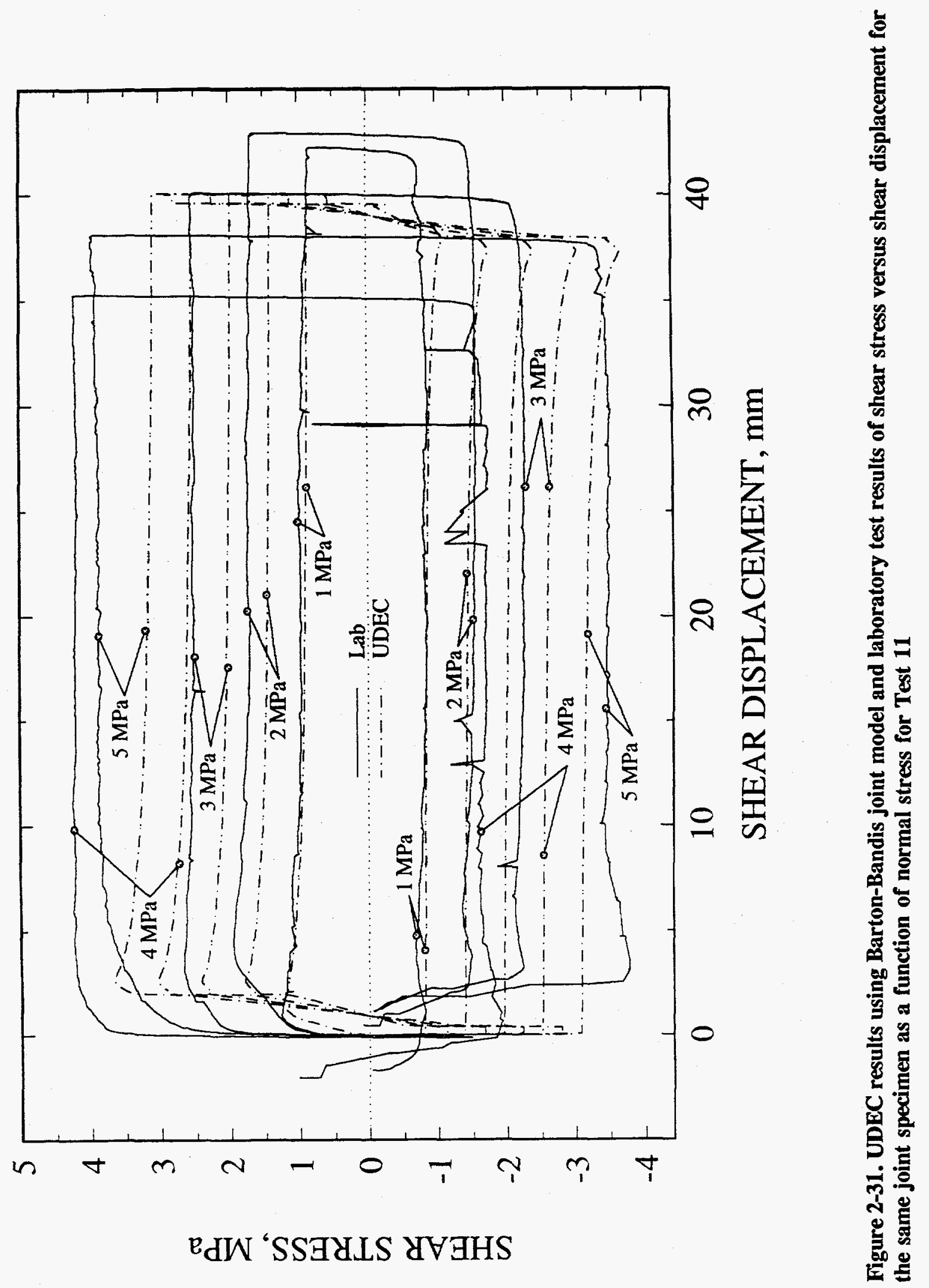


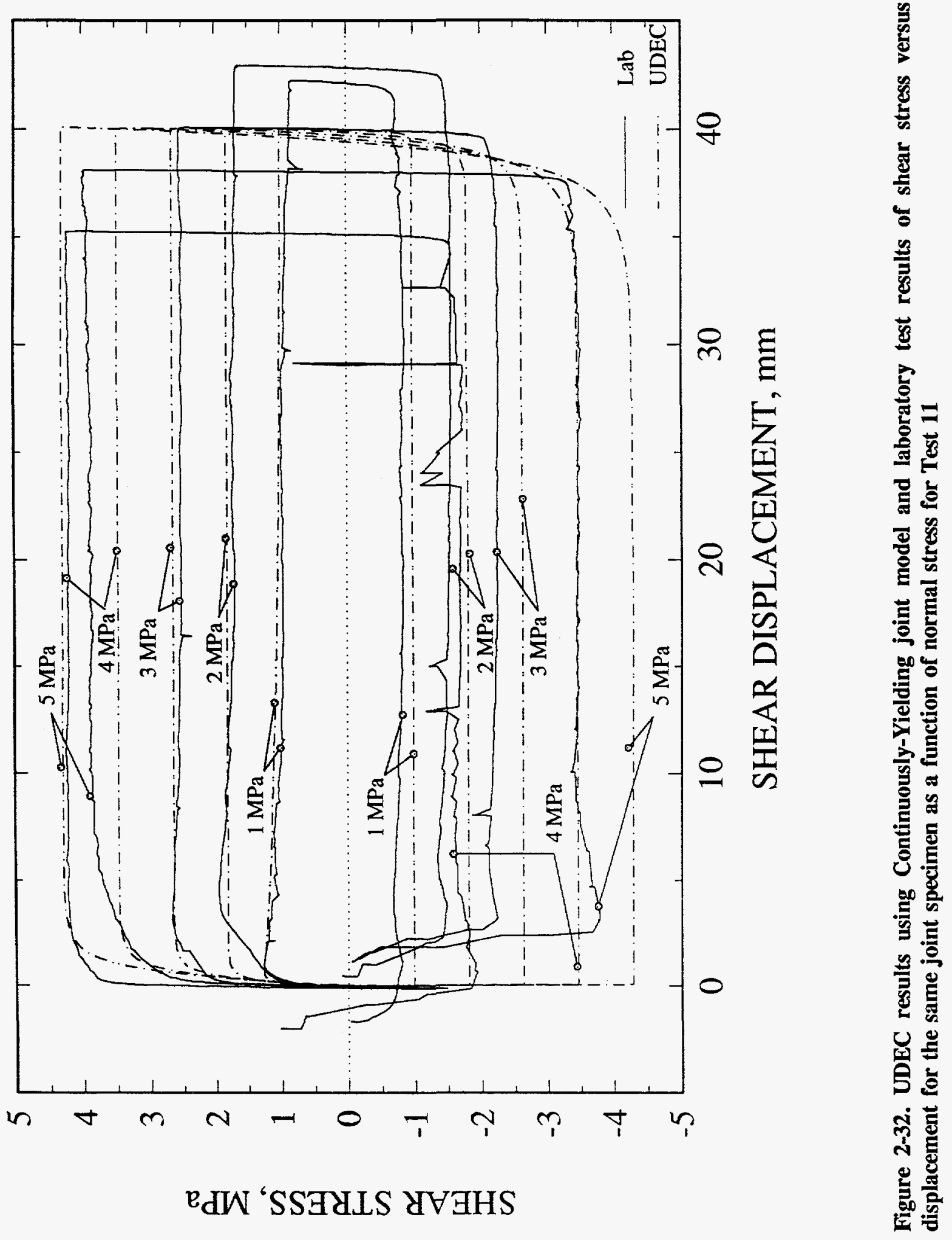




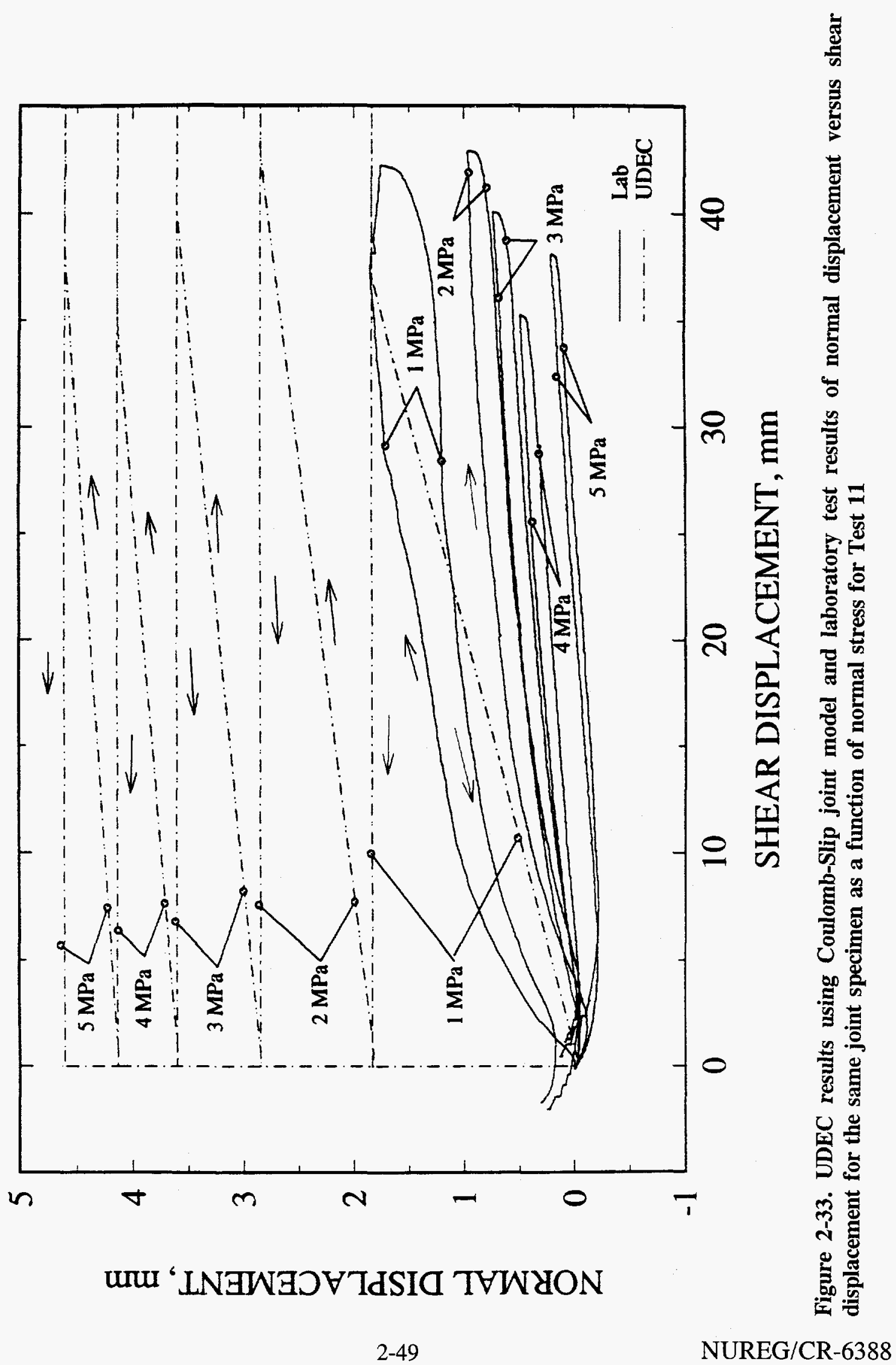




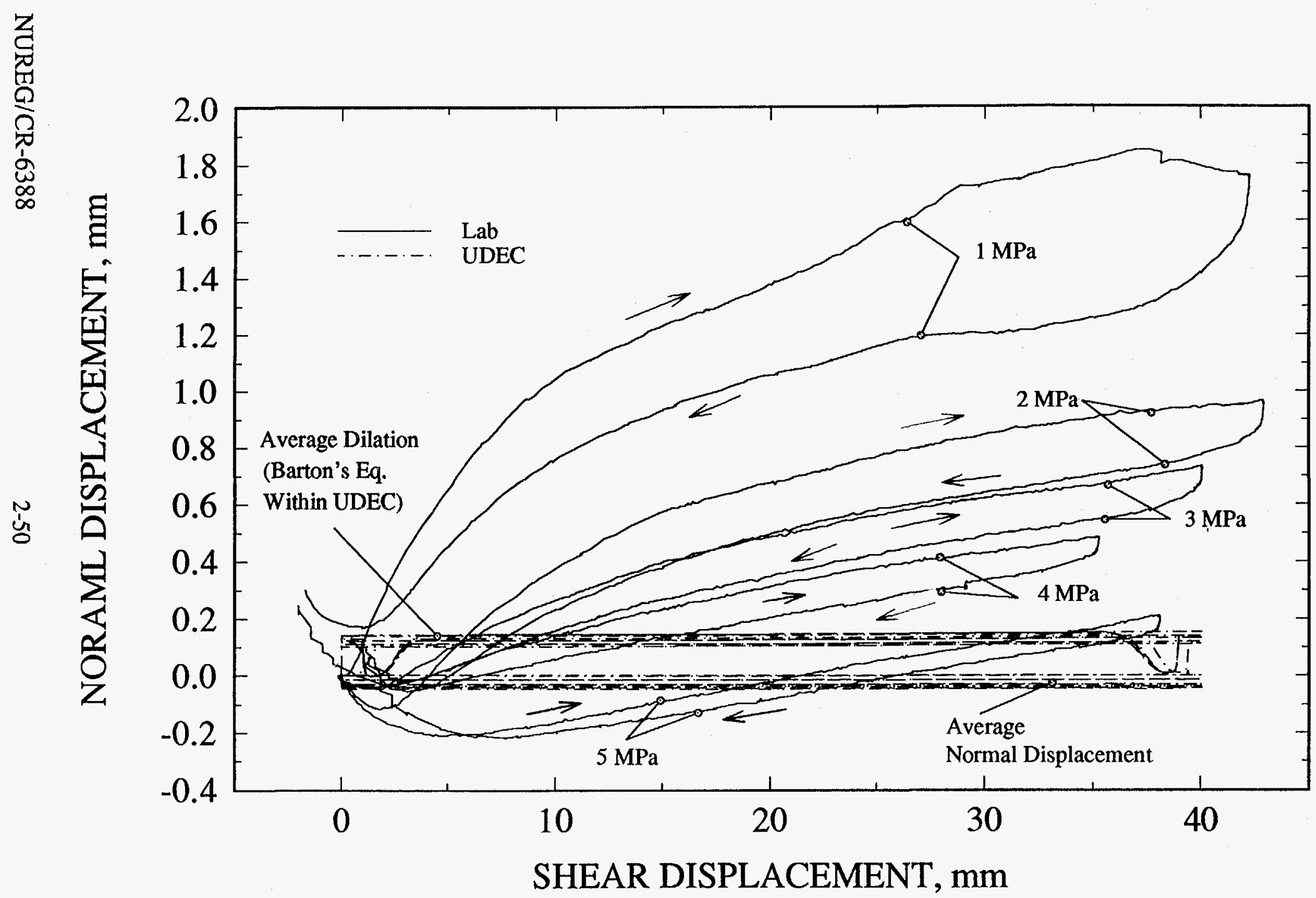

Figure 2-34. UDEC results using Barton-Bandis joint model and laboratory test results of normal displacement versus shear stress displacement for the same joint specimen as a function of normal stress for Test 11 


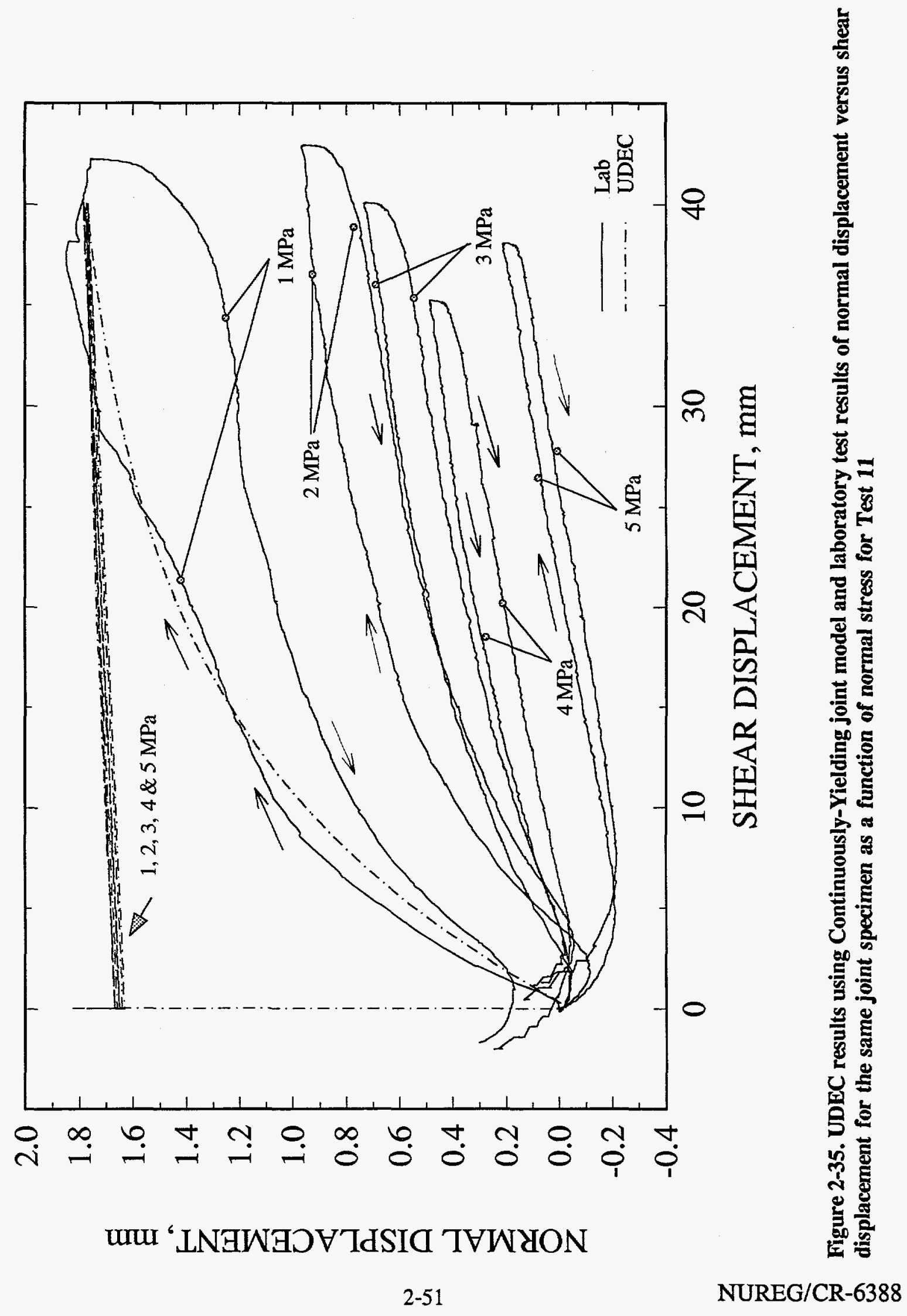


shearing by the UDEC code using the Continuously-Yielding model produced mixed results. In some tests, reasonably good agreement was observed between the modeling results and the laboratory measurements. In other tests, the modeling results and the laboratory measurements (Figure 2-32) were quite different, especially in later shear cycles with higher normal loads. In general, the prediction for the shear strength in the first shear cycle is quite close to the laboratory results for all the cyclic pseudostatic tests. This observation is expected since the joint parameters used for the Continuously-Yielding model in the UDEC code were back-calculated from the laboratory data. The shear strength prediction for reverse shearing in most cases is greater than that observed in the laboratory. Differences between the model and laboratory results for the shear strength during reverse shearing are directly dependent on the difference in the shear strengths between forward and reverse shearing measured in the laboratory tests.

Figure 2-35 shows joint dilation variation with shear displacement for both UDEC results and test measurements. Although a good agreement is shown for dilation during forward shearing of the first shear cycle between the two sets of results, the prediction of dilation during reverse shearing using the Continuously-Yielding model is inadequate. The algorithm for calculating dilation in the Continuously-Yielding model in the UDEC code (versions 1.82 and 1.83) assumes a sign change in dilation angle during reverse shearing. As a result, some recovery in dilation is noted. However, the amount of recovery is not sufficient to simulate the actual dilation recovery behavior observed experimentally. 


\section{ROCK-MASS RESPONSE UNDER REPETITIVE SEISMIC LOADS}

It is essential to understand the response of jointed rock subjected to repeated stress or strain cycles, especially the type of disturbance produced by earthquakes, to develop rational design methods for underground excavations. It is reasonable to expect that a fractured rock mass will be more susceptible to an episode of repeated load cycles than intact rock. This increased susceptibility is due to the presence of pre-existing fractures and associated mobility of individual in situ blocks (Brown and Hudson, 1974). General observations from model studies of Brown and Hudson (1974) and Barton and Hansteen (1979) regarding the time-dependent failure of jointed rock indicates that catastrophic failure may occur when accumulated deformation reaches a critical state. This observation has serious implications regarding the stability of underground excavations subjected to repetitive episodes of seismic loading in the course of their design life. However, no field observations have been reported related to excavation performance under these conditions. In this chapter, the current understanding of the effects of repeated leads on the response of individual joints and a jointed rock mass is described, based upon the information available in the literature and the results of the field and laboratory experiments conducted at the CNWRA.

\subsection{MODEL STUDY OF BROWN AND HUDSON}

Brown and Hudson (1974) studied the response of intact and jointed rock under uniaxial compression using small-scale models made of gypsum plaster. They explained the failure under repeated load cycles in terms of the residual strength locus (post peak region) of the complete force-displacement curve. Figure 3-1 shows three possible paths that a specimen at various force-displacement states on or within the locus may follow. In Figure 3-1, horizontal lines AB, DE, and HK in the prepeak, post-peak, and unloaded regions, respectively, represent creep, that is, the application of constant force. Vertical lines $\mathrm{AC}, \mathrm{DG}$, and $\mathrm{HJ}$ represents constant displacement constraints or relaxation. Time-dependent displacement can take place along $\mathrm{AB}$ or $\mathrm{HK}$ until the residual strength locus is reached. At $\mathrm{D}$, immediate failure will occur in a constant force condition. Figure 3-2 schematically explains the behavior under cyclic fatigue. Displacement progressively accumulates when the applied force is cycled between the two limiting forces $\mathrm{F} 1$ and $\mathrm{F} 2$. The cycle starts from the initial position $\mathrm{AB}$ to the final position $\mathrm{CD}$ where the residual strength locus is intersected. Experimental observations of Brown and Hudson (1974) follow a similar trend. Density of cracking increased and existing cracks opened up progressively as the cyclic loading continued. The number of cycles required to induce failure is extremely high when the cyclic loading begins in the prepeak range. In the post-peak region, the number of cycles required is significantly less. It is possible that certain parts of the rock mass around an underground excavation may be fractured and supporting load in the post-peak region of the force-displacement curve at an equilibrium point. If this rock mass is subjected to cyclic loading with magnitude greater than or equal to the equilibrium load, the load-carrying capacity will be further reduced. Part of the excess load will be redistributed to other parts of the rock mass and, in some cases, the fractured zone may fail catastrophically. Moreover, if the excavation process may unload the fractured zone, for example, to point $\mathrm{H}$ in Figure 3-1, failure due to fatigue can occur very quickly.

Brown and Hudson (1974) hypothesized that jointed rock may be more susceptible to fatigue damage than intact rock because individual rock blocks may be free to rotate and translate irreversibly. As a result, progressive accumulation of deformation along the joints or fracture may ultimately lead to the collapse of the jointed media. 


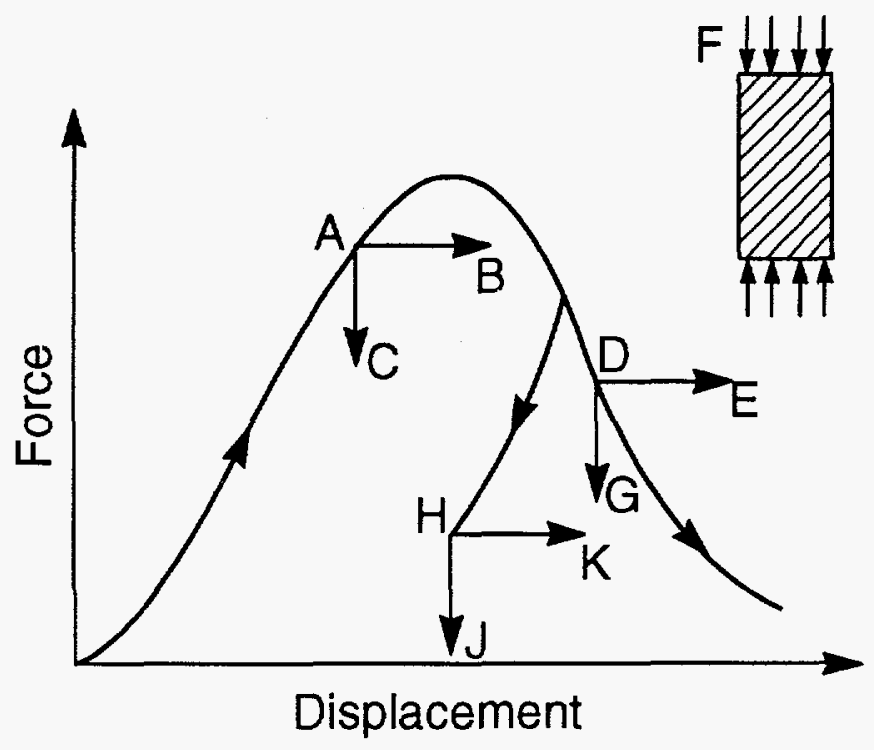

Figure 3-1. Possible paths a specimen at various force-displacement states may follow [Fatigue Failure Characteristics of Some Models of Jointed Rock, E.T. Brown and J.A. Hudson, Earthquake Engineering and Structural Dynamics, Vol. 2, pp. 380, Copyright (1974, John Wiley \& Sons, Ltd.). Reprinted by permission of John Wiley \& Sons, Ltd.]

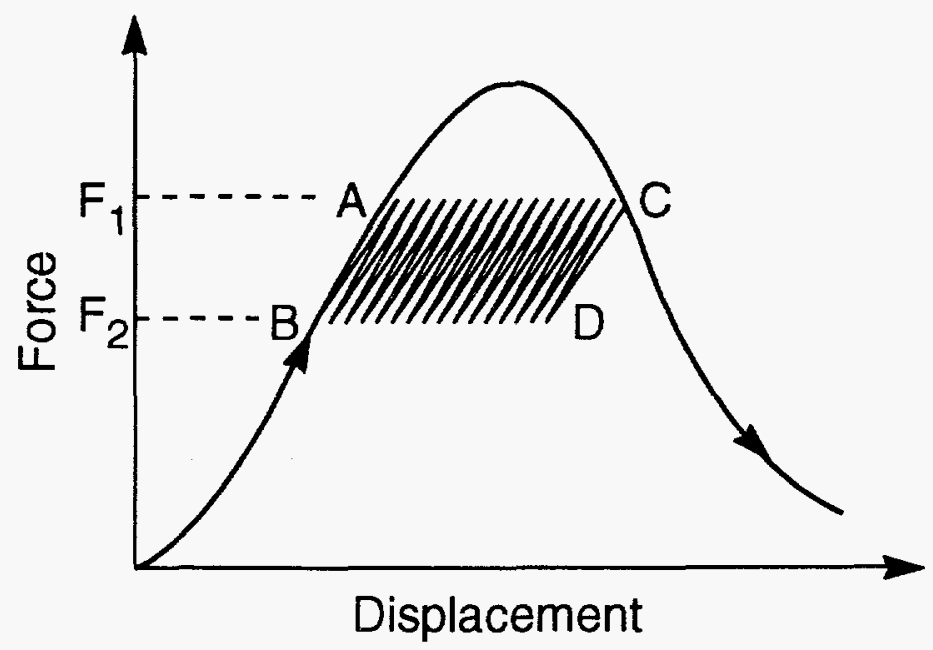

Figure 3-2. Behavior under cyclic fatigue [Fatigue Failure Characteristics of Some Models of Jointed Rock, E.T. Brown and J.A. Hudson, Earthquake Engineering and Structural Dynamics, Vol. 2, pp. 380, Copyright (1974, John Wiley \& Sons, Ltd.). Reprinted by permission of John Wiley \& Sons, Ltd.] 


\subsection{MODEL STUDY OF BARTON AND HANSTEEN}

Barton and Hansteen (1979) carried out a 1/300-scale model experiment to study the effects of seismic motion on underground openings in jointed rock mass. This experiment was conducted in plane stress condition. The blocks were made of red lead-sand-ballotini-plaster-water and simulated the in situ rock blocks. They fell progressively into the opening during the test when the simulated fractures were steeply dipping. On the other hand, the model with gently dipping joints underwent a general settlement in the neighborhood of the openings. The zone around the openings that undergoes deformation during the excavation under static conditions is also sensitive to dynamic loads. Barton and Hansteen (1979) concluded that the excavation of the opening significantly increases the ratio $\tau_{o n}$ along individual joints due to increased shear and decreased normal stresses so that they become susceptible to progressive accumulation of shear displacement from a small number of cyclic loads imposed by the seismic motion. They also concluded that many significant cycles of earthquake motion would be needed to cause settlement in an undisturbed rock mass.

\subsection{FIELD STUDY AT THE LUCKY FRIDAY MINE}

In an effort to study the effects of seismic activities on underground excavations, the Lucky Friday Mine, operated by Hecla Mining Company and located in the Coeur d' Alene region of Idaho, was selected and instrumented. This mine experiences frequent rock bursts. The recurrence time for these seismic events with relatively large magnitude (local Richter magnitude 2 to 3.5 ) is short, which provides an excellent opportunity for studying the effect of repetitive ground motions over a reasonable time span. The microseismic monitoring system that is in operation at the mine provides time history records of the waveform from micro-seismic events. The instrumented field studies at the Lucky Friday Mine include seismic effects on underground openings and on the hydrologic regime. Only those activities that are related to investigation of the mechanical response of rock masses around deep underground openings subjected to mining-induced seismicity are summarized in this section, seismic effects on groundwater pressure are given in Section 4.4. Details of the geology, mining method, instrumentation and measured responses are given in Hsiung et al (1992a,b). Only salient points will be discussed here.

The rock formation at the Lucky Friday mine consists mainly of the St. Regis member (the upper formation) and Revett member (the lower formation). The Revett formation is composed of interbedded units of vitreous quartzite, sericitic quartzite, and greenish silitic-argillite. The Revett formation contains well-defined lower, middle, and upper members. The response of underground openings to mine-induced seismicity was monitored in the Revett formation. The rock formations are folded with the syncline dipping a few degrees eastward. The ore-bearing stratum, called the Lucky Friday Vein, strikes north-east and is nearly vertical with almost $457 \mathrm{~m}$ of minable strike length. This vein lies primarily within the Revett formation and is located at the north side of the syncline. The Lucky Friday Vein is bounded on its north and south extents by faults, and is cut by several major structures. Three types of discontinuities are present in the rock mass: bedding planes, joints, and shear zones. The bedding planes, which often show evidence of past shearing, are sometimes continuous with roughly planar surfaces. They consist of interbedded quartzites and quartzitic argillites ranging in thickness from a few centimeter to $7.6-10 \mathrm{~cm}$, and dip approximately $70^{\circ}$ from horizontal, and strike conformably with the Lucky Friday Vein, at least in the southern sections of the mine.

Currently, a microseismic system with more than 30 channels is installed that continuously monitors and locates the coordinates of the microevents. The monitoring system is designed to monitor 
acoustic emissions having frequencies of 10 to $5,000 \mathrm{~Hz}$. Events of Richter magnitude greater than 0.5 are the prime target.

In situ stress measurements indicate that the maximum horizontal stress is about 1.35 times the minimum horizontal stress and vertical stress. The maximum horizontal stress in the vicinity of the Lucky Friday Mine is oriented at $\mathrm{N} 45^{\circ} \mathrm{W}$, that is, perpendicular to the strike of the vein. The mine is currently using the underhand cut-and-fill mining method for stopping the orebody. The general advance of the mining is downward. Almost all the seismic activities in the mine occurred in the footwall where the bedding planes dip toward the orebody. When the mining proceeds downward, that state of stress near the mining area is modified to such an extent that the normal stress on the bedding plane decreases while the shear stress on the bedding planes increases. This state of stress provides a favorable condition for slip to take place along the bedding planes in the footwall resulting in seismic activity or rockburst. While in the hanging wall, the bedding planes are dipping away from the orebody. The modified stress field has high normal stress and relatively low shear stress on the bedding planes. Therefore, they do not provide a favorable condition for slip.

Two sites, LFM95-C1 and LFM95-C2, that were near the bottom of the ramp system under development at the 5210 level were selected for instrumentation to monitor the response of underground excavations under repeated seismic events. These two sites were located on the opposite sides of an anticline. The sites LFM95-C1 and LFM95-C2 were $1591 \mathrm{~m}$ and $1598 \mathrm{~m}$ below ground surface, respectively. The bedding planes intersect the instrumentation cross-section of the LFM95-C1 site at an approximate $50^{\circ}$ angle and at a $15^{\circ}$ angle for the LFM95-C2 site. Both instrumentation sites had a $3.05 \mathrm{~m}$ square cross-section and were supported by $1.8 \mathrm{~m}$ long resin-grouted rebar and $5.1 \times 5.1 \mathrm{~cm}$ chain-link mesh. A support with 3.8 to $5.1 \mathrm{~cm}$ fiber-reinforced shotcrete was also used at the LFM95-C2 site.

Three basic types of instruments were used for this study: (i) extensometers to monitor displacement changes around the excavations, (ii) triaxial velocity gages to determine the transient response of the rock at excavation surfaces, and (iii) closure points to monitor opening deformations. More than 50 seismic events with magnitudes greater than 1 on the local Richter scale occurred since the inception of this study. The maximum magnitude measured was about 3.5 . The source location of this event was quite far away from the instrumentation sites. As a result, its impact was not discernible.

General observation of the seismic signals recorded throughout the mine over the period of this field investigation indicated that the durations of vibration were relatively short. Most events were over within $0.5 \mathrm{~s}$. Therefore, it is not possible to evaluate potential impacts of event durations on mechanical responses. Also, this short duration is not believed to have much effect on rock mass response from the standpoint of prolonged shaking. As a comparison, an earthquake has much longer duration and thus contains more vibration cycles, which have the potential to create greater damage. Other than these differences, mining-induced seismicity is similar to an earthquake in terms of source mechanism.

Figures 3-3 and 3-4 show the results from extensometer measurements. Position numbers (Pos \#) 1 through 5 in each figure indicate the anchor positions for an individual extensometer with Position 1 closest to and Position 5 farthest from the opening. Displacements shown in the figures were measured relative to the assembly head of the extensometer, which is at the collar of the borehole. The recorded displacements were the results of mining-related activities and mining-induced seismic events. Positive values indicate that an anchor and its corresponding assembly head move away from each other 


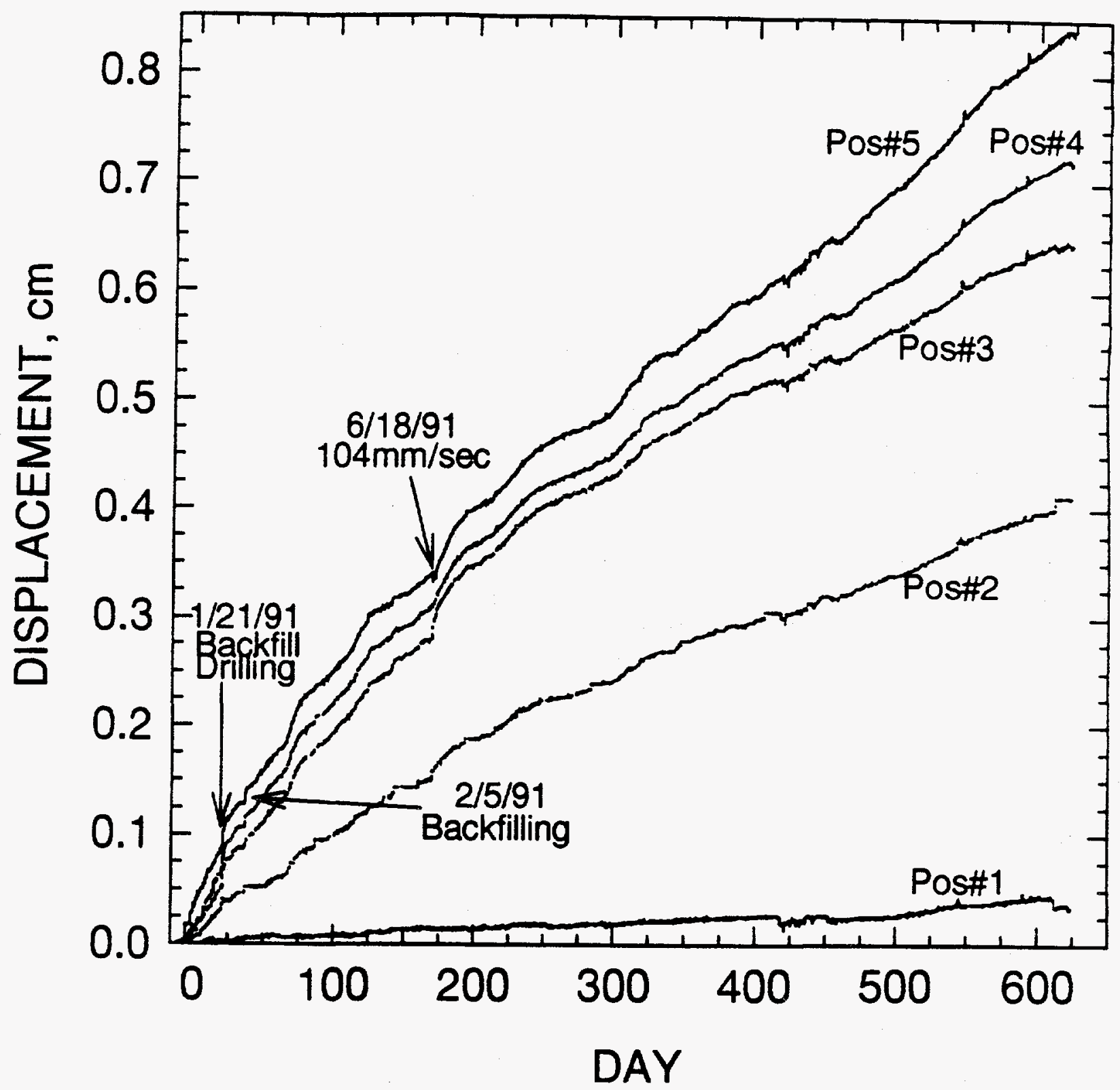

Figure 3-3. Displacement measurement for extensometer No. 3 at LFM95-C1 site 


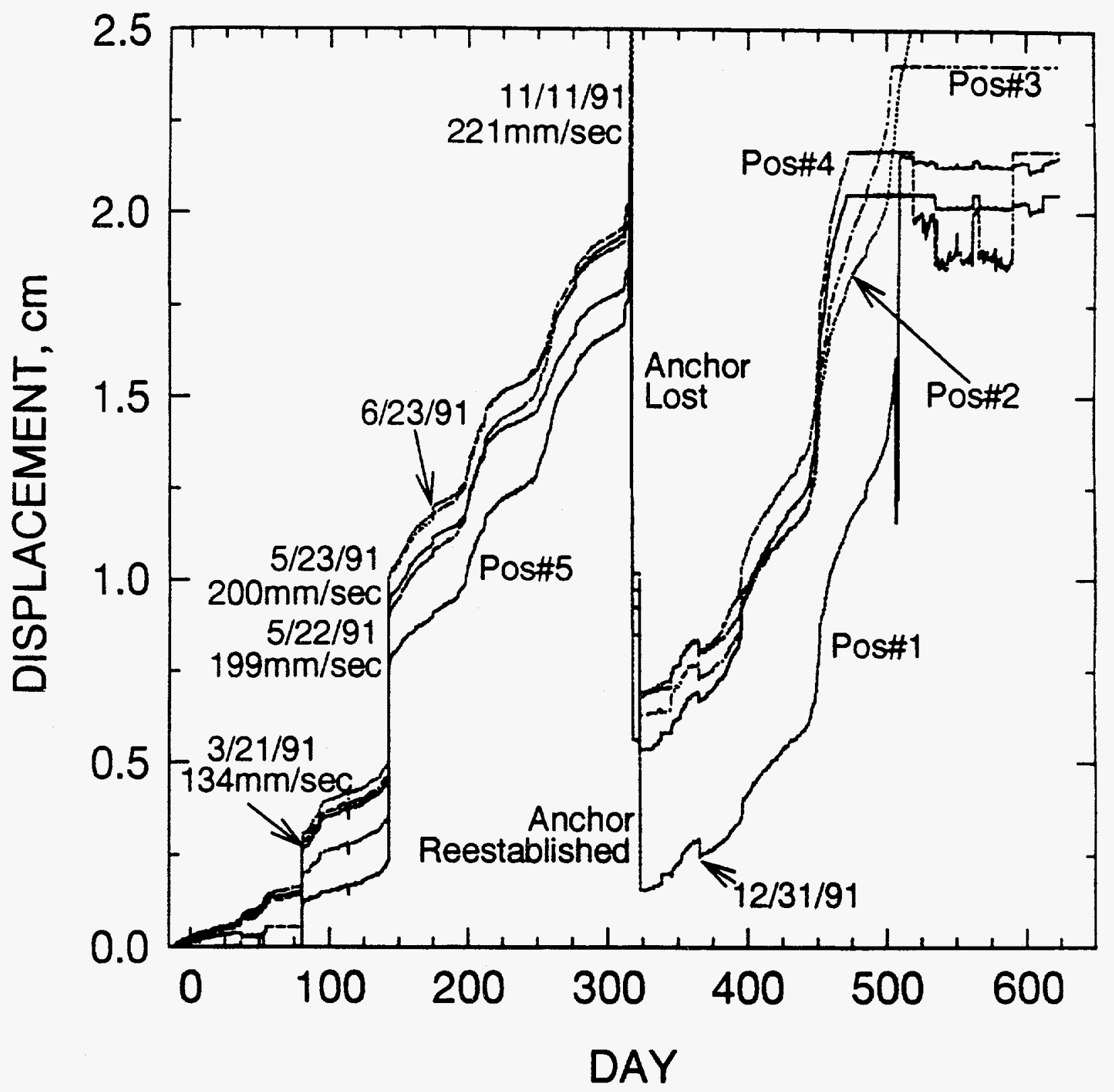

Figure 3-4. Displacement measurement for extensometer No. 5 at LFM95-C2 site 
while negative values mean that the two move toward each other.

General observation of the extensometer plots indicate that the movements of anchors were of two types. The first type showed a gradual increase in displacement. This type is believed to be the result of mining, which induces stress redistribution, and perhaps, to a certain extent, time-dependent behavior of the rock mass (creep). The second type of displacement exhibits a distinct pattern of step increase or decrease in displacements. This type of behavior may be attributed to slip of a joint or a fracture located between an anchor and the assembly head. This joint slip is triggered by stress change in the region. The stress changes may be either gradual or sudden and induced by mining-related stress changes, mining-induced seismicity, rock mass time-dependency, and other mining-related activities. There were also cases in which the cause of the step increase in displacement could not be determined.

Figure 3-5 shows the spatial distribution of some mining-induced seismic events that occurred near the study sites. Information about the event date and magnitude (local Richter scale), peak particle velocity at each site $(\mathrm{mm} / \mathrm{s})$, and approximate depth of source location below surface $(\mathrm{m})$ is provided in the figure. The depth of instrumented cross sections is also provided in the figure along with the approximate strike and dip of bedding planes at each site.

Observation indicated that rock mass displacements (both induced by mining and resulting from mining-induced seismicity) around the opening at the LFM95-C1 site were, in general, smaller than those measured at LFM95-C2 site. This observation is consistent with the relative distances of the two sites from the orebody, since the LFM95-C2 site is about $48.8 \mathrm{~m}$ closer to the vein than the LFM95-C1 site. It is also observed that the LFM95-C1 site was relatively insensitive to seismic events induced by mining compared to the responses of the opening at the LFM95-C2 site. One reason for this insensitivity may be the difference in distance from the sources of the seismic events between the two sites. Another reason may be the relatively higher stress changes at the LFM95-C2 site resulting from mining of ore, given that this site is closer to the area of mining than the LFM95-C1 site. Intuitively, a location closer to the mining area will be subjected to greater stress modification and higher stress changes (Peng and Park, 1977; Peng, 1976; Hsiung, 1984). The fact that the rock mass around the opening at the LFM95-C2 site is relatively weaker than that at the LFM95-C1 site, as indicated by the borehole scoping results, also makes it more susceptible to seismic impact.

Although the LFM95-C1 site, which is more distant than the LFM95-C2 site from the area of active mining, is relatively less sensitive to mining-induced seismicity, extensometer measurements did indicate opening responses, that is, there was a measurable rock mass displacement and/or opening closure changes as a direct result of seismic events. The smallest peak particle velocity to cause permanent displacements of the rock mass around the opening at the LFM95-C2 site was $134 \mathrm{~mm} / \mathrm{s}$, which is relatively higher than the $104 \mathrm{~mm} / \mathrm{s}$ observed at the LFM95-C1 site. No measured permanent displacement responses from the extensometers were observed for the March 27, 1991, event $(143 \mathrm{~mm} / \mathrm{s})$, January 30, 1992, event $(180 \mathrm{~mm} / \mathrm{s})$, or March 27, 1992, event $(199 \mathrm{~mm} / \mathrm{s})$. Figures 3-6 and 3-7 show the closures of the cross section of the openings for the LFM95-C1 and LFM95-C2 sites, respectively. For the LFM95-C1 site, vertical closure dominates while the horizontal closure was larger than vertical at the LFM95-C2 site. As discussed earlier, the horizontal stresses in the vicinity of Lucky Friday Mine are about 1 to 1.35 times the vertical stress, with the maximum horizontal stress being oriented at $\mathrm{N} 45^{\circ} \mathrm{W}$. It is, therefore, reasonable to expect a larger horizontal than vertical opening closure, which is evident from the closure measurements from the LFM95-C2 site. At the LFM95-C1 site, the horizontal stresses were believed to be relieved to some extent due to the completion of mining of the portion of the 


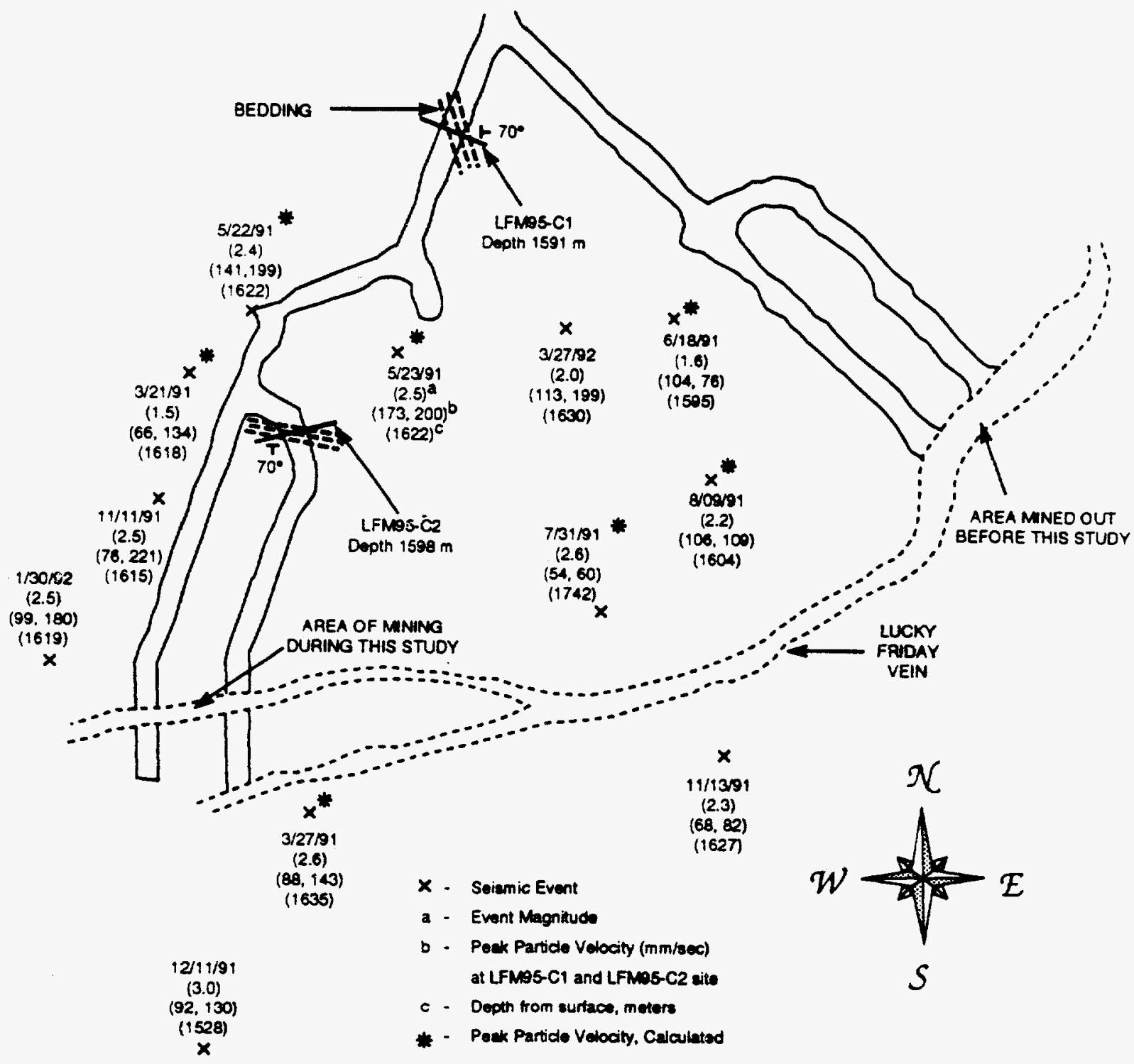

Figure 3-5. Distribution of mine seismic events at Lucky Friday mine near the instrument locations 


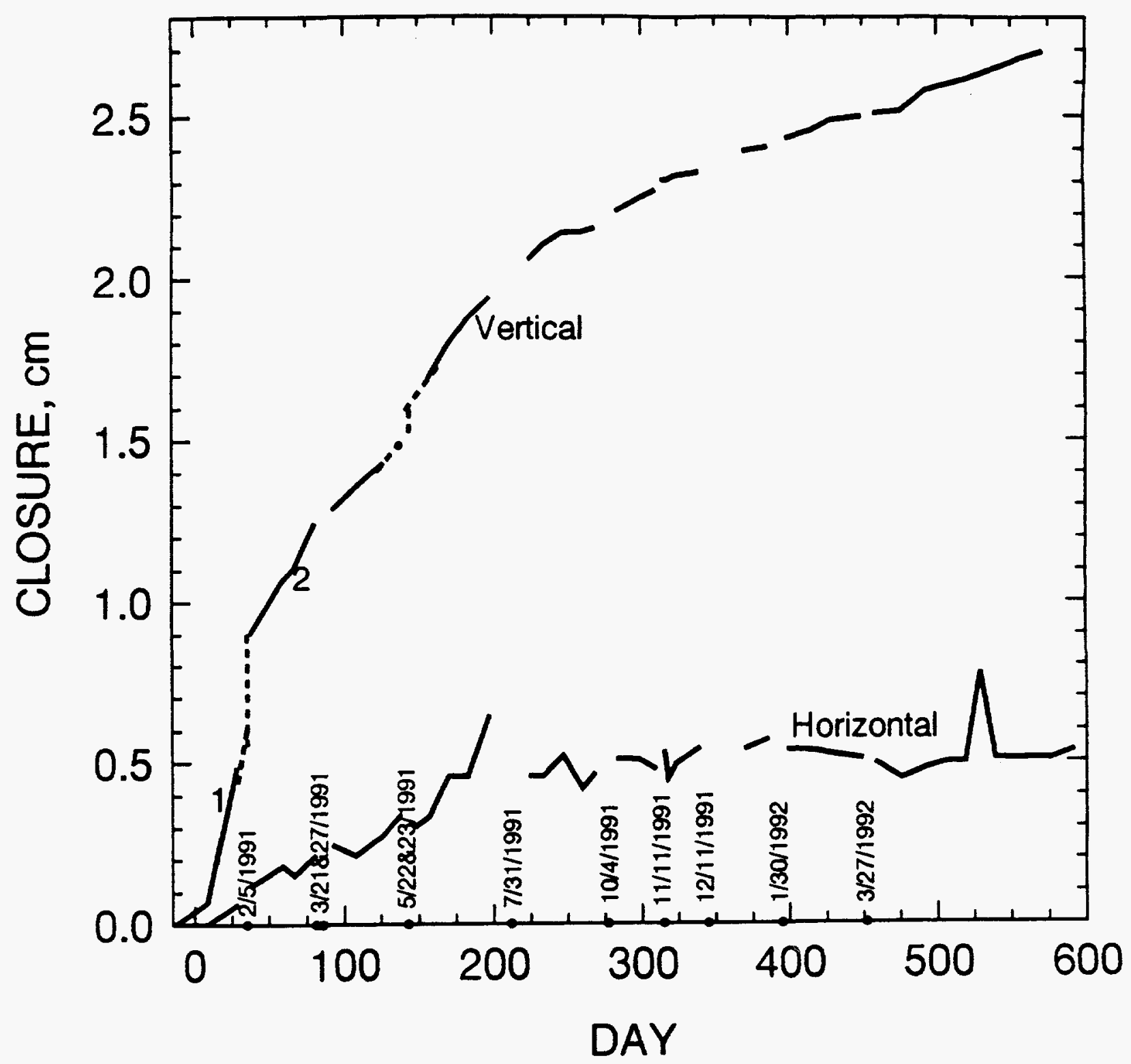

Figure 3-6. Closure of mine opening at LFM95-C1 site 


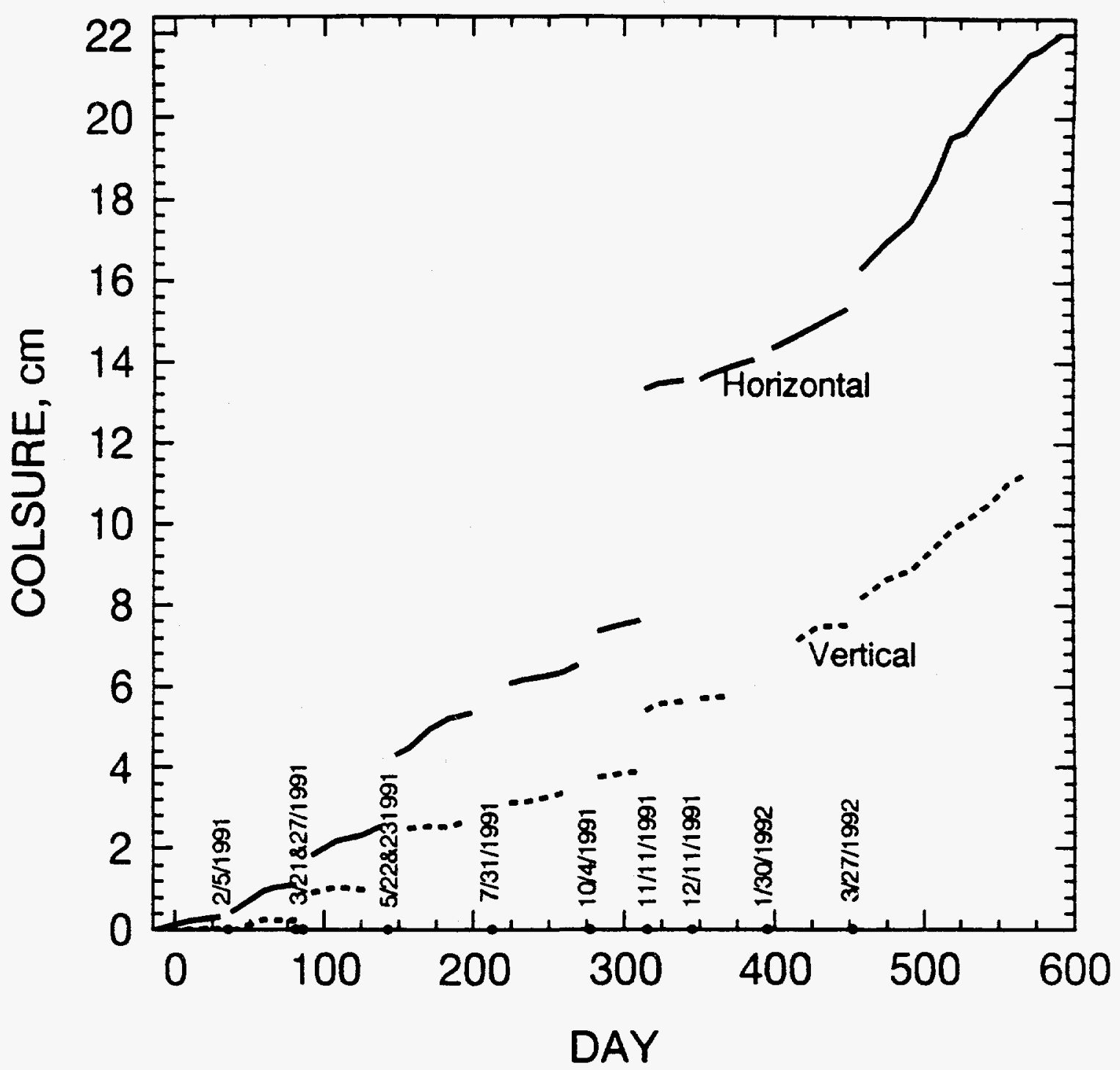

Figure 3-7. Closure of mine opening at LFM95-C2 site 
vein located at the lower right corner in Figure 3-5. This portion of the vein was mined out and backfilled before this field investigation started. Observation by the U.S. Bureau of Mines has indicated that the rock mass between the LFM95-C1 site and the mined out portion of the vein displaces slowly toward the mined out area. This relaxation of horizontal stresses may have resulted in a smaller horizontal closure. The observed vertical closure for the LFM95-C1 site was about $26.9 \mathrm{~mm}$ and the horizontal closure was about $5.38 \mathrm{~mm}$. More than $220 \mathrm{~mm}$ of horizontal closure was observed for the LFM95-C2 site, and the vertical closure was about $113 \mathrm{~mm}$. The considerably larger closure at the LFM95-C2 site may be a combined effect of higher stress changes induced by mining and weaker rock mass at the site.

The closure curves for the two figures were purposely broken into line segments to show the effects of seismic events. The total horizontal closure for the LFM95-C1 site was very small, and it did not seem to show an impact of seismic motions and mining-related activities other than perhaps mining itself. The reason the opening sometimes showed slightly horizontal expansion is not clear. A possible explanation may be measurement error. A slight influence of seismic motion on the vertical closure was observed for the May 23, 1991, event (Figure 3-6). Dashed lines show the projected closure trend assuming no seismic motion. The projected closure increase between segments 1 and 2 of the vertical closure curve seems to correlate well with the backfilling operation on February 5, 1991.

Both horizontal and vertical closures for the LFM95-C2 site gave a clear sign of seismic effects. Large closures were observed after the March 21, May 22 and 23, and November 11, 1991, events. This observation corresponds well with the responses of extensometer measurements. It is interesting to note that the November 11 event $(221 \mathrm{~mm} / \mathrm{s})$ induced more than $50.8 \mathrm{~mm}$ of horizontal closure, which is substantially greater than the horizontal closure induced by the combined effect of the May 22 and 23 events (199 and $200 \mathrm{~mm} / \mathrm{s}$ ). The closure readings at the LFM95-C2 site also indicated effects of the July 31, 1991, and March 27, 1992, events $(199 \mathrm{~mm} / \mathrm{s})$, neither of which had any effect on extensometer readings. This reading seems to suggest that, in response to the above mentioned two events, there was no relative displacement between the anchors and the assembly head. The rock mass containing these anchors and the assembly head apparently displaced as a unit into the opening.

Opening damage in the vicinity of the LFM95-C2 site as a result of mining-induced seismicity was observed. Figure 3-8 shows the damage observed after the May 22 and 23, 1991, events. Since these two events occurred about $3 \mathrm{hr}$ apart, it was difficult, if not impossible, to determine the effect of each individual event. The induced damage due to these two events included cracking of shotcrete and floor heave near the site and in a nearby upramp. Areas of slip along bedding planes in an area fairly close to the site were also observed (Figure 3-8). The observed slip along bedding planes is believed to have weakened the surrounding rock mass that led to the more severe damage that occurred later as a result of the November 11, 1991, event (Figure 3-9). The November 11, 1991, event caused the shotcrete in all ramp accesses below cross-section CC of Figure 3-9 to crack and bulge out. Shotcrete and some wall rocks at the intersection of the ramp accesses, where slip along bedding planes was observed due to earlier events, were dislodged from the walls of the opening. These observations seem to support the concept of cumulative damage resulting from the impact of repetitive seismic loading through accumulation of joint shear displacement that leads to degradation of rock mass.

Deformation of the rock mass is a combination of discrete displacements (opening or closing) of the pre-existing and excavation-induced fractures and continuous displacements due to change in strain in the intact rock. Step changes in measured displacements are most probably related to stick-slip behavior of the fractures. The extent of stick-slip is a function of joint roughness, material properties of the joint 


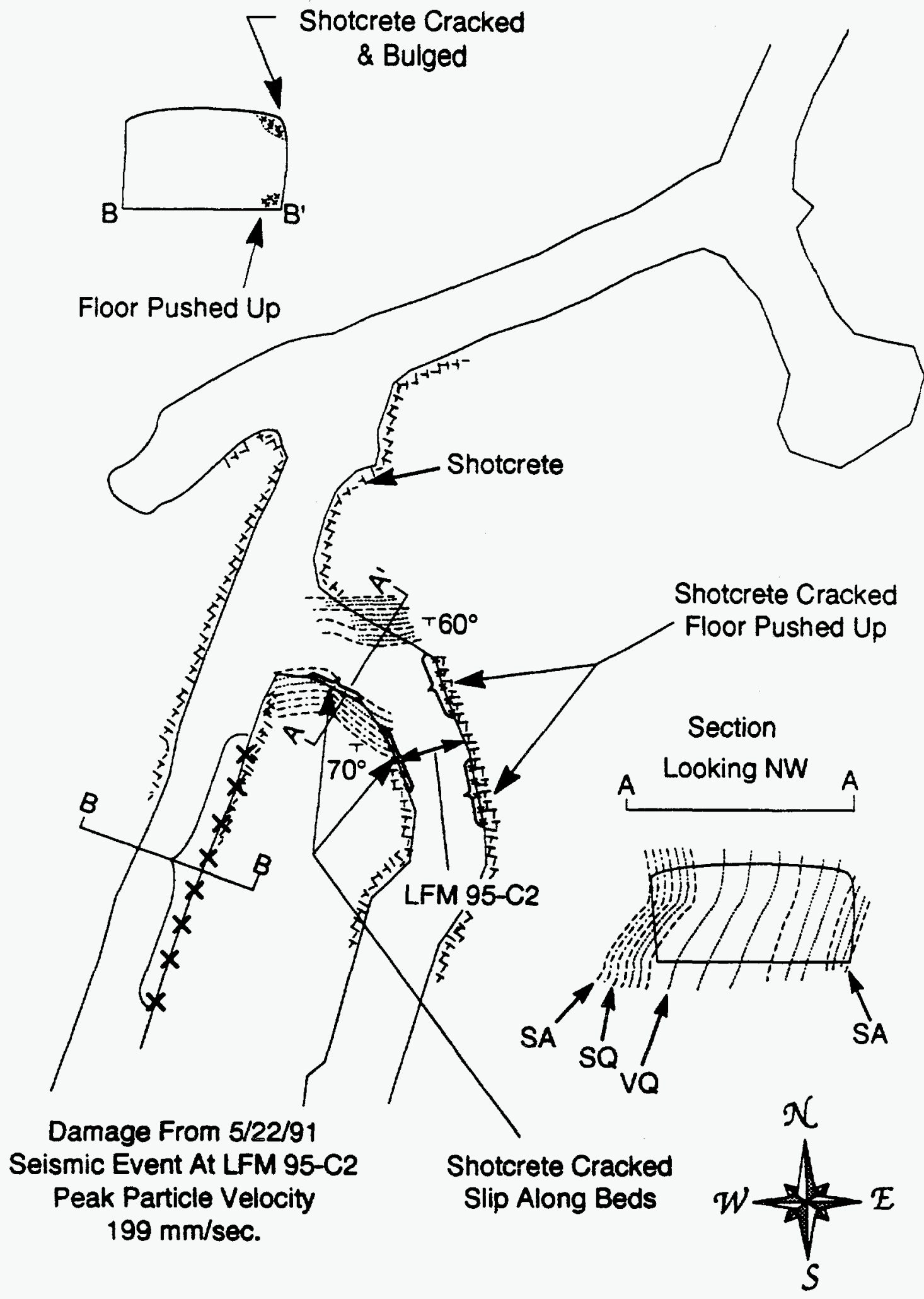

Figure 3-8. Damage recorded at the LFM95-C2 site due to the May 22 and 23, 1991, events. In this figure, SA denotes siltite argillite, $S Q$ is sericitic quartzite, and VQ means vitreous quartzite. 


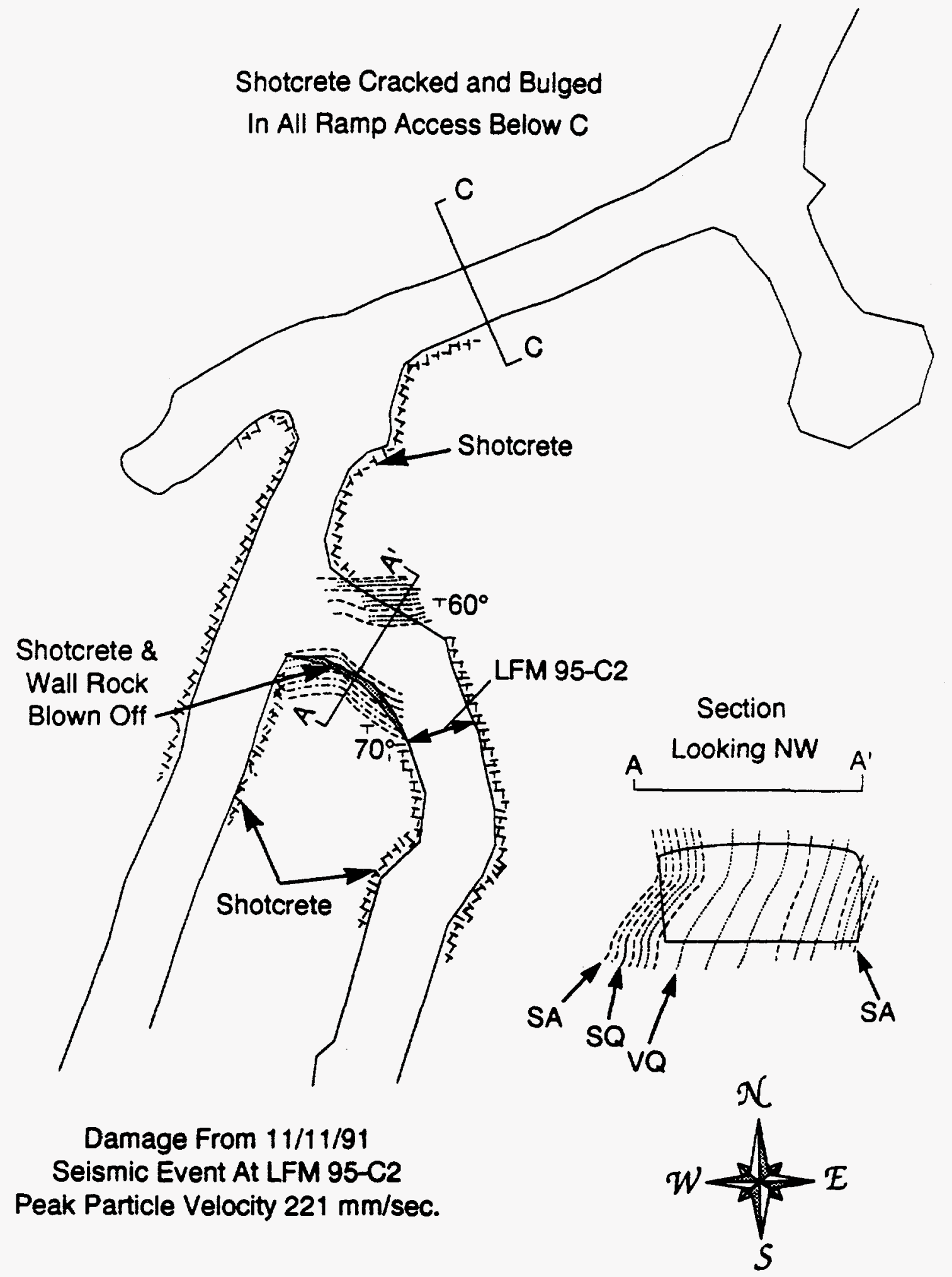

Figure 3-9. Damage recorded at the LFM95-C2 site due to the November 11, 1991, events. In this figure, SA denotes siltite argillite, $S Q$ is sericitic quartzite, and VQ means vitreous quartzite. 
surfaces, and the applied stress field.

When the applied shear stress on a fracture exceeds the mobilized shear strength, joint slip begins. This slip will continue until an increase in joint shear resistance, either through an increase in normal stress or due to asperity locking, increases the ability of the joint to resist slip or the shear stress falls below the shear strength during the course of slipping. The termination of joint slip is the stick component of the phenomenon.

In a mining environment, the state of stress changes constantly due to mining and mining-related activities. Time-dependent degradation of a rock mass may also contribute to stress changes. When an opening is subjected to seismic motion, the stress conditions on the joints in the rock mass around the opening change continuously with the passage of the waves. If the seismic wave has sufficient energy and the existing mining-induced stresses are large enough, joint shear can be induced in the form of step change in displacement (slip). The magnitude and incident of the seismic wave with respect to a joint play important roles on the likelihood of joint slip by controlling the state of stress. A joint with shear stress close to the shear strength is more susceptible to slip because the energy contained in the seismic wave may be sufficient to increase the shear stress or decrease the normal stress to induce slip. This phenomenon has been observed in the Lucky Friday Mine. Although the May $22(199 \mathrm{~mm} / \mathrm{s})$ and May $23(200 \mathrm{~mm} / \mathrm{s}), 1991$, events occurred about $3 \mathrm{hr}$ apart and have almost the same peak particle velocities at the LFM95-C2 site, their effects on displacements were quite different.

The joint stick-slip behavior forms the basis for the progressive accumulation of joint deformation and, consequently, rock mass fatigue. The observed rock mass fatigue and deterioration around the instrumented openings at the Lucky Friday Mine resulted from the combined effect of mining and repetitive seismic events induced by mining. As the opening continued to deteriorate, it became more and more vulnerable to seismic events. The minor damage and slip of bedding planes observed at the LFM95-C2 site due to the May 22 and 23, 1991, events and followed by the more serious damage observed at the same area support the hypothesis of accumulative effect of repetitive seismic events on the degradation of a rock mass.

\subsection{DYNAMIC SCALE-MODEL EXPERIMENT OF A JOINTED ROCK MASS}

In this study, a scale model consisting of an aggregate of simulated rock material blocks was used to simulate the earthquake response of a larger segment of the reference repository rock mass. This model was a follow-on to direct shear experiments on single, naturally jointed, welded tuff fractures that were used to determine the joint normal and shear response under both cyclic pseudostatic and dynamic loadings. A detailed discussion regarding the design of this scale-model experiment is given by Kana et al. (1995).

A two-dimensional conceptual diagram of a rock mass with a circular opening is shown in Figure 3-10. The square cross section of the rock mass is assumed to be influenced by the overburden mass, $M_{0}$, and lateral boundary masses, $M_{1}$. The value of $M_{0}$ was determined by an assumed overburden

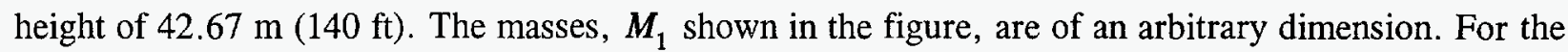
purpose of calculation, length equal to one opening dimension was assumed. A depth of $42.67 \mathrm{~m}$ (140 $\mathrm{ft}$ ) was selected to have a scaled vertical stress of about $1 \mathrm{MPa}$. The earthquake excitation was assumed to be purely horizontal and to have a wavelength much greater than the length of the affected rock-mass 


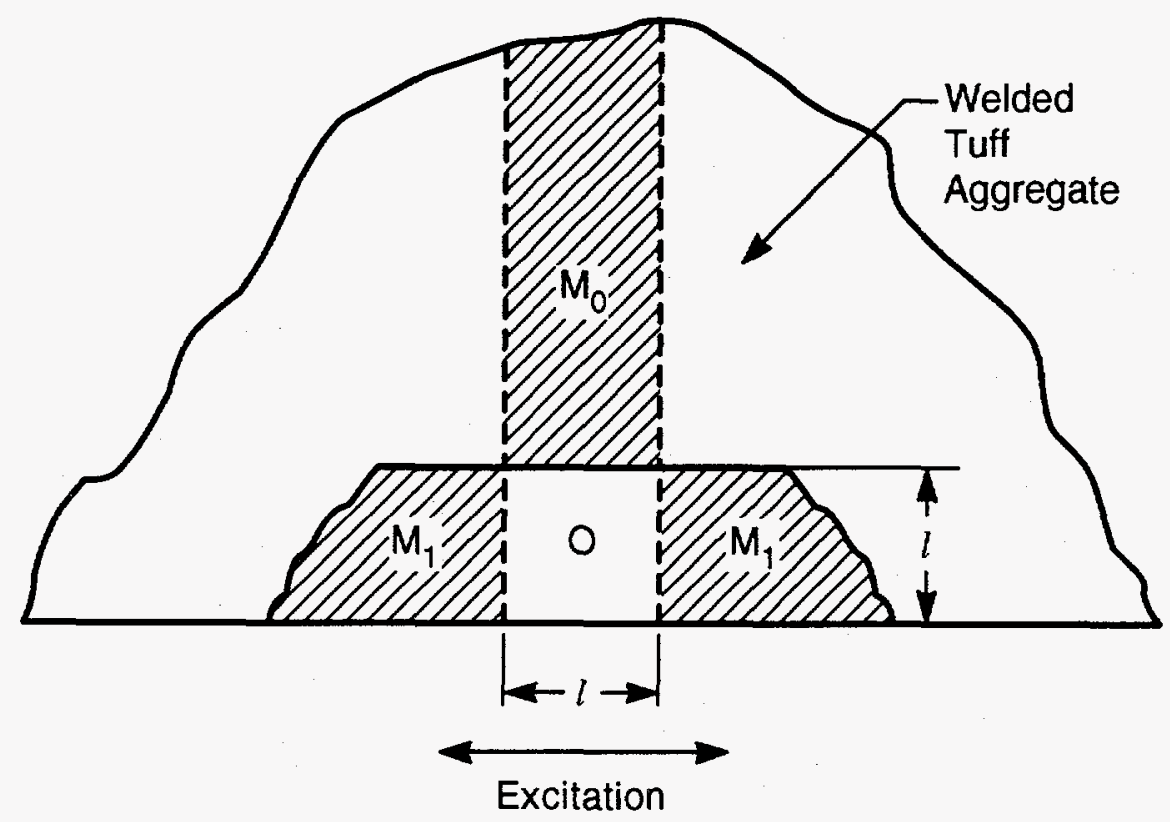

Figure 3-10. Conceptual model of underground rock mass with opening

segment. Under these conditions, the excitation could be represented by a spatially uniform displacement motion. Values for some dimensions were selected in order to be a reasonable representation of a practical physical problem, and at the same time to allow scaling for a $1 / 15$-scale model system. The dimensions and weight capacity of the seismic simulator had to be compatible with these values. The exact nature of the effective boundary conditions had to be estimated.

A similitude analysis of the model in Figure 3-10 results in the following nondimensional equation for shear and relative displacement response:

$$
\left(\frac{\tau}{\rho l}, \frac{u}{l}\right)=F\left(\frac{E}{\rho l g}, \phi, v, \frac{\sigma_{N}}{\rho l g}, \frac{M_{o} g}{\rho l^{3}}, \frac{M_{1} g}{\rho l^{3}}, \frac{a}{l}, \frac{x_{o}}{l}, \frac{\omega^{2} l}{g}, \omega t\right)
$$

where $F$ denotes a function of given parameters, $a$ is the thickness of the model $(9.14 \mathrm{~m}$ or $30 \mathrm{ft}), M_{0}$ is the overburden mass $\left(1.72 \times 10^{7} \mathrm{~kg}\right.$ or $\left.3.78 \times 10^{7} \mathrm{lb}\right), l$ is the opening dimension $(1.83 \mathrm{~m}$ or $6 \mathrm{ft}), E$ is the material Young's Modulus ( $40 \mathrm{GPa}$ or $5.8 \times 10^{6} \mathrm{psi}$ ), $v$ is the material Poisson's ratio, $\rho$, is the material density $\left(2403 \mathrm{~kb} / \mathrm{m}^{3}\right.$ or $\left.150 \mathrm{lb} / \mathrm{ft}^{3}\right), M_{1}$ is the effective boundary mass $\left(7.36 \times 10^{6} \mathrm{~kg}\right.$ or $\left.1.62 \times 10^{7} \mathrm{lb}\right), \sigma_{N}$ is the normal stress on rock mass ( $1 \mathrm{MPa}$ or $\left.145 \mathrm{psi}\right), \tau$ is the shear stress, $u$ is the relative shear displacement, $\phi$ is the friction factor $(0.5), g$ is the gravity $\left(9.86 \mathrm{~m} / \mathrm{s}^{2}\right), x_{0}$ is the excitation displacement, $\omega$ is the excitation frequency, and $t$ is the time duration. Potential coupling between $M_{0}$ and $M_{1}$ is not included in Eq. (3-1) for simplicity. 
It is possible to make the nondimensional numbers more meaningful by presenting them as the following ratios:

$$
\begin{gathered}
\left(\frac{\sigma_{N} \phi}{\rho l}\right)\left(\frac{l a}{l a}\right)=\frac{\text { Overburden Shear Force }}{\text { Segment Inertia Force }} \\
\left(\frac{M_{0} g}{\rho l^{3}}\right)\left(\frac{l g}{a g}\right)=\frac{\text { Overburden Shear Force }}{\text { Segment Inertia Force }} \\
\left(\frac{M_{1} g}{\rho l^{3}}\right)\left(\frac{l g}{a g}\right)=\frac{\text { Lateral Boundary Inertia Force }}{\text { Segment Inertia Force }}
\end{gathered}
$$

Thus, system boundaries (overburden and lateral boundaries of the square cross section rock mass in Figure 3-10) were replaced with normal and lateral pressures and masses, and $\sigma_{N}$ is the overburden pressure. This concept of replacing the system boundaries was the one on which the scale model design was based. It was desirable to design the scale model with as little distortion of similitude as possible, consistent with dimensions and force capacity of the available seismic simulator. As in any scale-model design, several independent variables were chosen, and others were then determined by satisfying similarity requirements. It was decided that a $1 / 15$-geometric scale would be feasible. Therefore, if $s$ is the scale factor and is equal to 15 , then

$$
\frac{l_{m}}{l_{p}}=\frac{1}{s}
$$

where $l_{m}$ and $l_{p}$ are the rock mass dimensions for the model and the prototype, respectively. In subsequent discussion, subscripts $m$ and $p$ represents the model and the prototype parameters, respectively. Furthermore, we let

$$
\frac{\phi_{m}}{\phi_{p}}=\frac{1}{k}
$$

where $k$ is equal to 2.0 , which was determined by comparison of the shear test results of the simulated rock interfaces and actual rock joints. For a detailed discussion regarding the shear tests of the simulated rock interfaces, readers are referred to a separate report prepared by Kana et al. (1995). Finally,

$$
\frac{\rho_{m}}{\rho_{p}}=\frac{1}{q}
$$


where $q$ is equal to 6.67 . This value was based on the preliminary estimates of total model weight compared to the maximum capacity of the seismic simulator. With these independent parameters, the similarity requirements are:

$$
\begin{gathered}
\sigma_{\mathrm{nm}}=\frac{k}{q s} \sigma_{\mathrm{Np}}=0.02 \mathrm{MPa}(2.9 \mathrm{psi}) \\
M_{\mathrm{om}}=\frac{1}{q s^{3}} M_{\mathrm{op}}=762 \mathrm{~kg}(1,680 \mathrm{lb}) \\
M_{1 m}=\frac{1}{q s^{3}} M_{1 p}=327 \mathrm{~kg}(720 \mathrm{lb}) \\
E_{m}=\frac{1}{q s} E_{p}=400 \mathrm{MPa}\left(57,971 \mathrm{lb} / \mathrm{in}^{2}\right) \\
\rho_{m}=\frac{1}{q} \rho_{p}=360 \mathrm{~kg} / \mathrm{m}^{3}\left(22.5 \mathrm{lb} / \mathrm{ft}^{3}\right)
\end{gathered}
$$

The parameters above necessitated that the effective density of simulated rock be significantly reduced over that for the prototype tuff material. This requirement would be very useful for controlling overall model weight. However, such an approach generally requires a change of simulated rock material or a hollowing out of simulated rock centers which is impractical. Furthermore, it was felt that the simulant material needed to remain brittle and exhibit surface wear properties approximating those of the prototype material. Therefore, as a practical compromise, it was decided to use simulated rock of solid material and a density ratio, $q$, of 1.43 , which would be applied for the rock simulant within the rock-mass segment only. The original ratio of 6.67 would be applied to the material outside the segment. This simulation effectively produced a model whose exterior masses were more manageable in terms of seismic simulator capacity, but at the same time, caused the interior rock mass to be 4.67 times too high. Although this condition was an obvious physical distortion, the result should still be useful for providing a better understanding of the seismic effects on a simulated rock mass and for providing a database for verification of computer codes. Furthermore, since the greatest shear load on the interior segment was anticipated to result from the overburden mass lateral moment, it was felt that the effects of mass 
exaggeration within the interior segment would be less pronounced on the dynamic response. Therefore, the overburden mass, $M_{0}$, was maintained as discussed above, but the boundary masses were reduced in order to maintain total model mass within the shaker table capacity, and, in some measure, to counteract the effects of exaggerated interior segment mass. Confirmation of these assertions was established by the analysis of a preliminary discrete element analytical model of the system.

The final physical design and associated dimensions are given in Figure 3-11. The model consisted of an aggregate of many stacked simulated rock ingots, each $61 \mathrm{~cm}$ long, with the interfaces oriented at a $45^{\circ}$ angle to the horizontal. The ingot cross sections varied from $5.5 \mathrm{~cm}$ square for basic ingots, to half-section ingots at the boundaries, to curved-section ingots around the center circular opening. This opening was $15.2 \mathrm{~cm}$ in diameter. The four boundaries of the stack were interfaced with 6.4-mm thick rubber, which is bonded to the rock on the inside and lubricated with silicone at the interface with the confining box boundaries. These boundaries were a very stiff construction of welded aluminum plates and $10.2-\mathrm{cm}$ I-beam frames. The proper pressure, $\sigma_{N}$, was maintained on the system by eight vertical cables and eight horizontal cables. The two end structures were hinged to the bottom support structure at the baseplate and were held against top rollers at each upper corner. Therefore, the end structures could pivot laterally, while the top structure can pivot and float up and down as necessary to follow the confined rock motion.

As noted earlier, although several rock properties were identified as being important for modeling purposes, it was felt that the brittle nature and associated wear properties of the jointed interfaces were the most important for model characterization. Furthermore, it was recognized that an exact modeling of welded tuff behavior was probably neither possible nor was actually necessary for a successful verification of computer codes. Therefore, the technical approach adopted for development of a suitable rock simulant consisted of following the previously presented similitude guidelines as much as practical, but allowing distortions so long as they could be quantified.

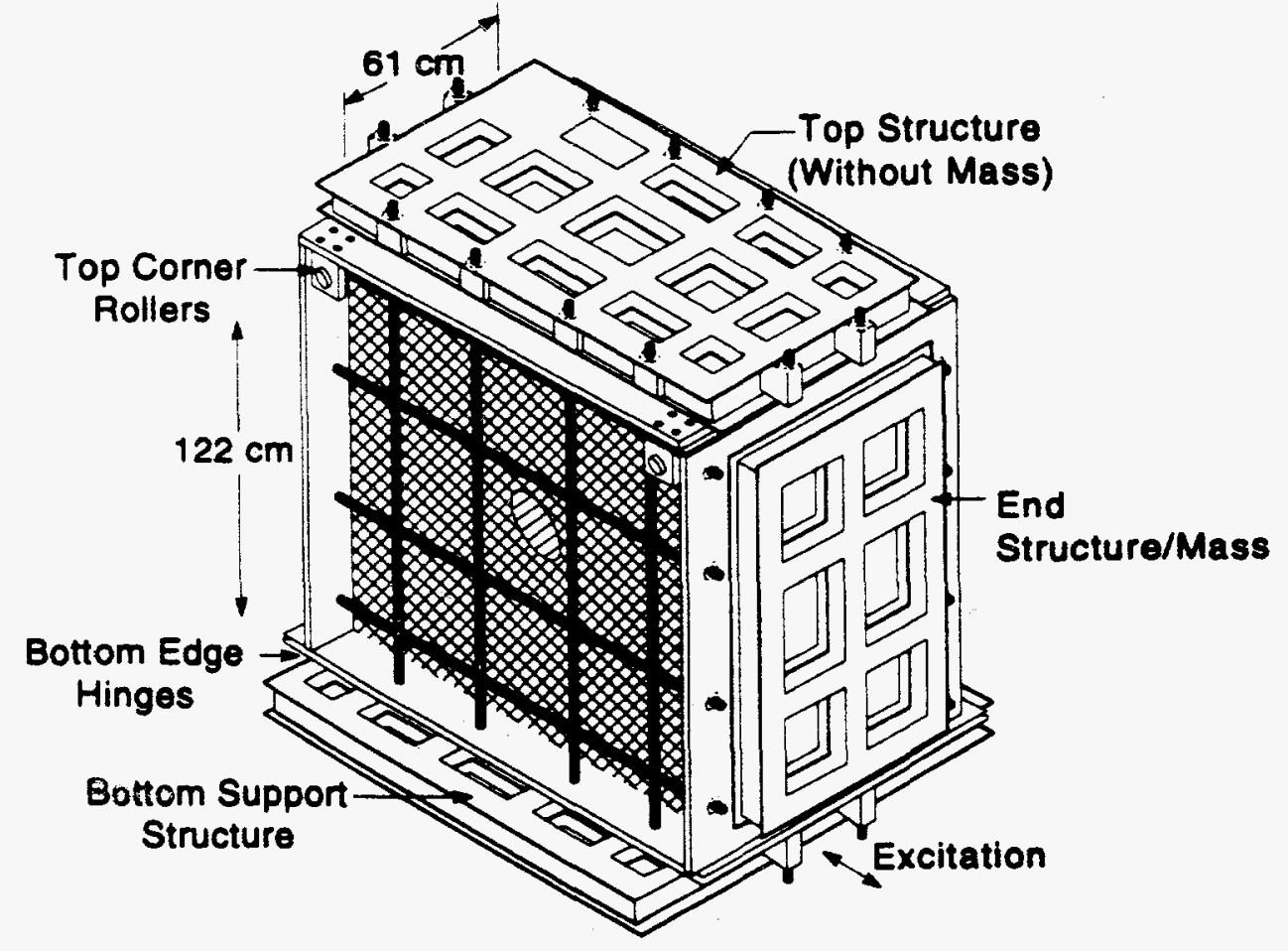

Figure 3-11. Physical design of scale-model rock mass with opening 
Initial development of the rock simulant was based on repeated trials of various constituent mixtures and testing of material properties of cylindrical specimens cast from these mixtures. The specimens were cast as $5.0 \mathrm{~cm}$ ( 2 in.) in diameter by $10.0 \mathrm{~cm}$ (4 in.) in length that were instrumented with strain gages and tested in uniaxial compression test machines. A list of the ingredients that were ultimately found to provide a material having the appropriate properties is given by Kana et al. (1995).

Generally, it was recognized that relative normal and shear displacement at the rock interfaces, and overall structure motions were of interest, and that the transducers used for such measurements should offer negligible resistance to rock interface movement. Therefore, several types of transducers were selected for measurement of these responses. These transducers included accelerometers, strain gages, specially designed cantilever beam shear displacement measurement devices, Bentley proximeters, and linear variable differential transducers. Figure 3-12 shows some of the instrumentation on and near the tunnel opening. The data from these transducers were collected via a $486(66 \mathrm{MHz})$ computer. The sampling rate was 2,800 data points/s. A total of 50 data channels was used during the tests. It was also recognized that relatively large displacements for the blocks around the opening might be expected due to repetitive shaking. The transducers mentioned above were not expected to function under large displacements. Consequently, one video camera was mounted axially with the opening at each side of the scale model apparatus to capture large displacements.

Test procedures were based on what can be called an incremental fragility level philosophy. Test runs were started at a very low peak excitation displacement level, and this amplitude was incrementally increased as the series of experiments progressed. The excitation displacement input signal used for the dynamic scale-model experiments was derived from an accelerogram measured at the Guerrero array for the September 1985 Mexico City earthquake, a well-characterized seismic event, using a $1 / 15$ scale. Both videotape and digital data were acquired for each run. At the end of each run, all 50

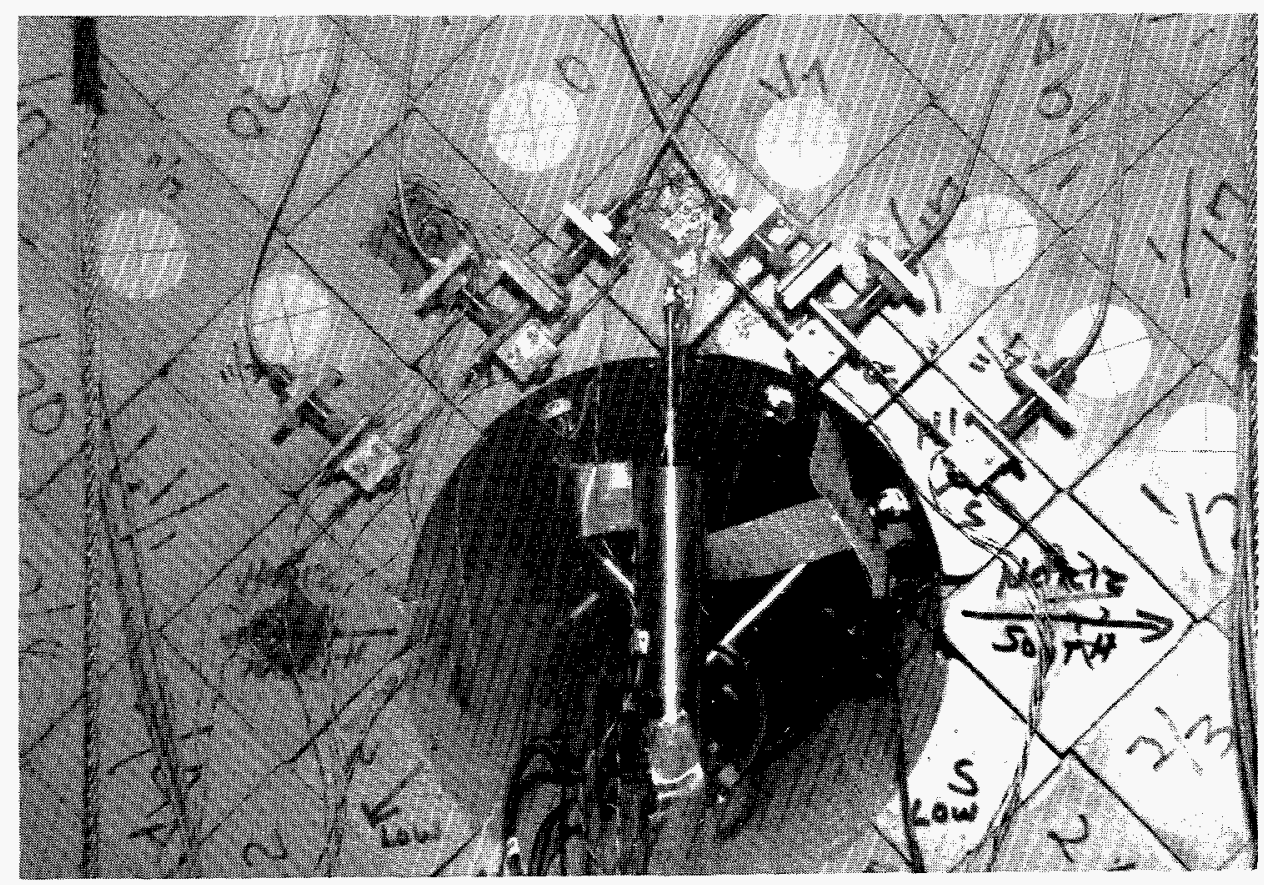

Figure 3-12. Instrumentation on and near the opening 
channels were converted to engineering units, and a preliminary review of the data was performed visually on the computer monitor. When transducer or other component malfunction occurred, adjustments were performed prior to the next run. Furthermore, some shifting of filter channels or transducer locations was performed as response information was acquired and evaluated in order to ensure the fidelity of the data acquired.

Actual shaking table excitation displacement for an intermediate level run is shown in Figure 3-13. Corresponding to this excitation, permanent shifts in simulated rock ingot positions are evident in the cantilever beam response of Figure 3-14 and the Bentley proximeter response of Figure 3-15. From these data, it is apparent that the near side upper right corner ingot at the opening has shifted downward relative to its adjacent ingots. Further analysis showed that both upper ingots as well as those immediately below them migrate downward radially into the opening, as would be expected under the influence of gravity. This behavior continued for each run. Figure 3-16 shows the condition of the far side opening face after the test series was completed. It is obvious that very significant joint displacements near the opening have occurred. It was noted that the displacements at the near face were not so pronounced. In fact, a fracture of the top ingot had occurred near the center along its length, so that the marked differences could accumulate as a result of one segment rotating downward relative to the other segment. This behavior probably resulted from nonuniformity in the ingots or loading conditions.

Rock motion with respect to a single ingot was measured using rock surface-mounted strain gages and accelerometers. In most cases, only amplitude digitization noise was apparent in the signals measured by strain gages indicating negligible strain response present in any of the strain gage data.

The results of this experimental investigation show that a threshold level of seismic input amplitude is required before any significant amount of permanent rock mass deformation will occur and begin to accumulate. Figure 3-17 shows the permanent tunnel closure resulting from each run. The closures of the tunnel diameter measured by six LVDTs are plotted in the figure along with the input amplitude. This figure shows that significant permanent deformation takes place once the amplitude of the input seismic signal is raised to $15.5 \mathrm{~mm}$. Measurements of permanent normal and shear deformations of the interfaces show this trend. More discussion and the associated plots are given in Kana et al. (1995). Thus, lower amplitude seismic events will not have much effect on underground opening stability. Multiple seismic events at a higher amplitude, on the other hand, are likely to have an impact through cumulative effect of permanent deformations around underground tunnels or openings. Thus, once the threshold seismic amplitude can be determined, this level can be used as a limiting value for seismic design of underground facilities. This investigation confirmed the CNWRA field study result at the Lucky Friday Mine that shows that rock mass deformation around an excavation as a result of repetitive episodes of seismic events is in the form of accumulation of joint shear displacement, which gradually weakens the rock mass.

In summary, results obtained in the dynamic scale-model experiments along with the results from field studies at Lucky Friday Mine indicate that the deformation around underground excavations accumulates when subjected to repetitive episodes of seismic events. Progressive accumulation of damage through slippage along the joints tends to weaken the rock mass and may lead to instability of the excavations, depending on the state of stress on individual joints, and strengths and material properties of intact rock and joints. It is, therefore, necessary to consider the effects of repetitive seismic load in design of an underground facility which, due to its location in a seismically active region and intended duty life, will experience several episodes of seismic activity. Although the studies described here have 


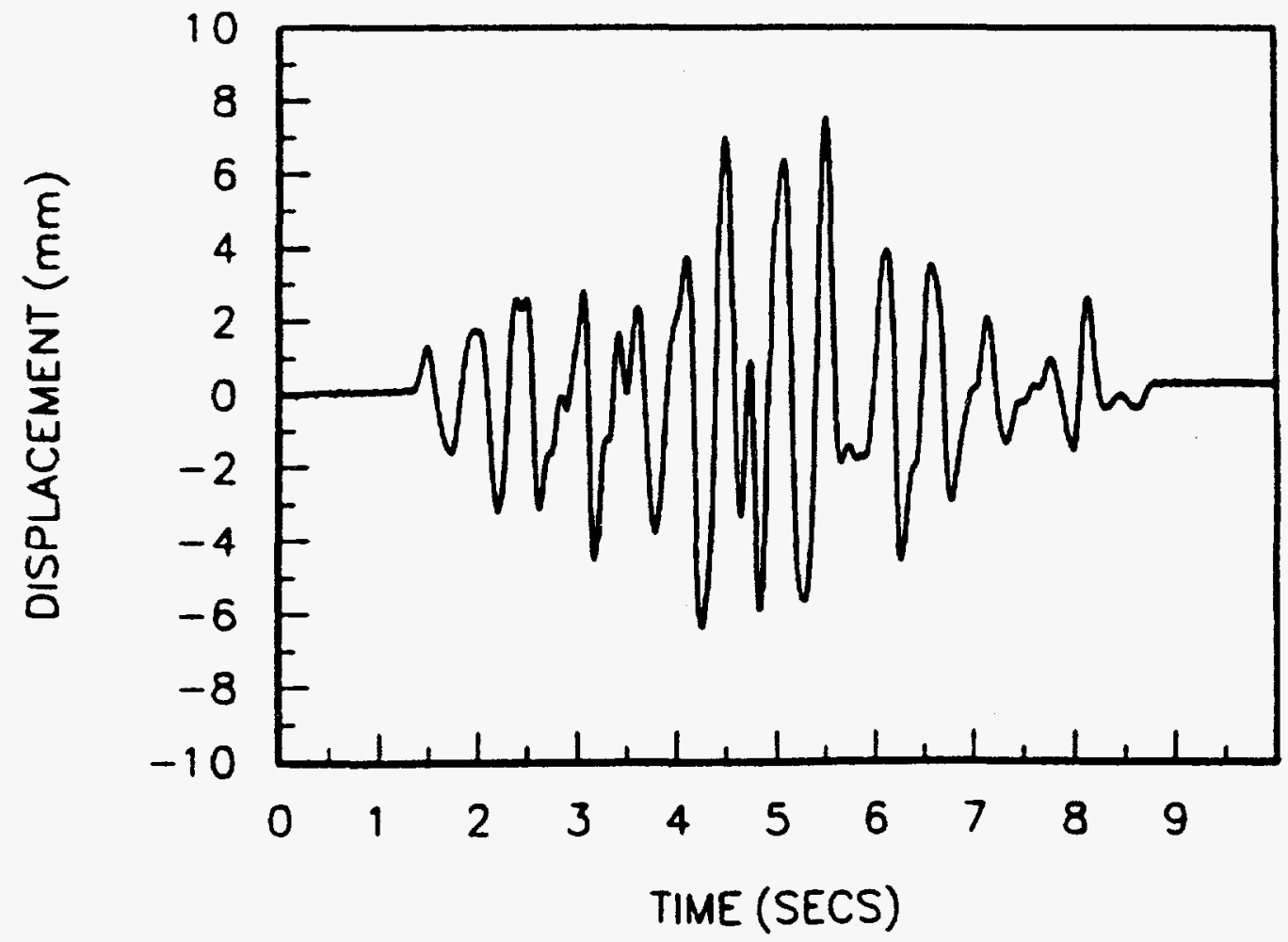

Figure 3-13. Horizontal table displacement for scale-model earthquake data set 14: maximum input displacement amplitude is $7.6 \mathrm{~mm}$

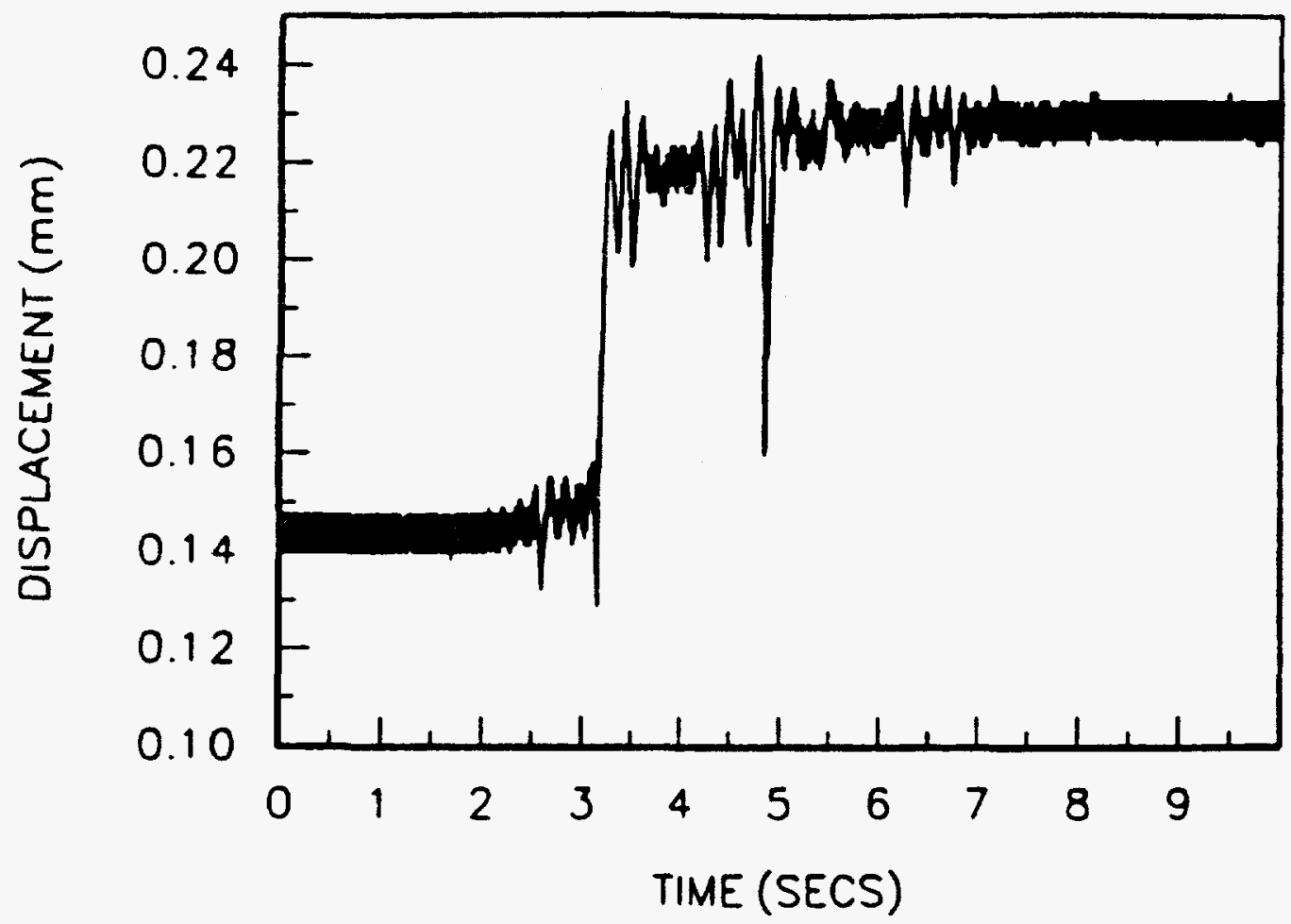

Figure 3-14. Near side tunnel block displacement for data set 14: maximum displacement amplitude input is $7.6 \mathrm{~mm}$ 


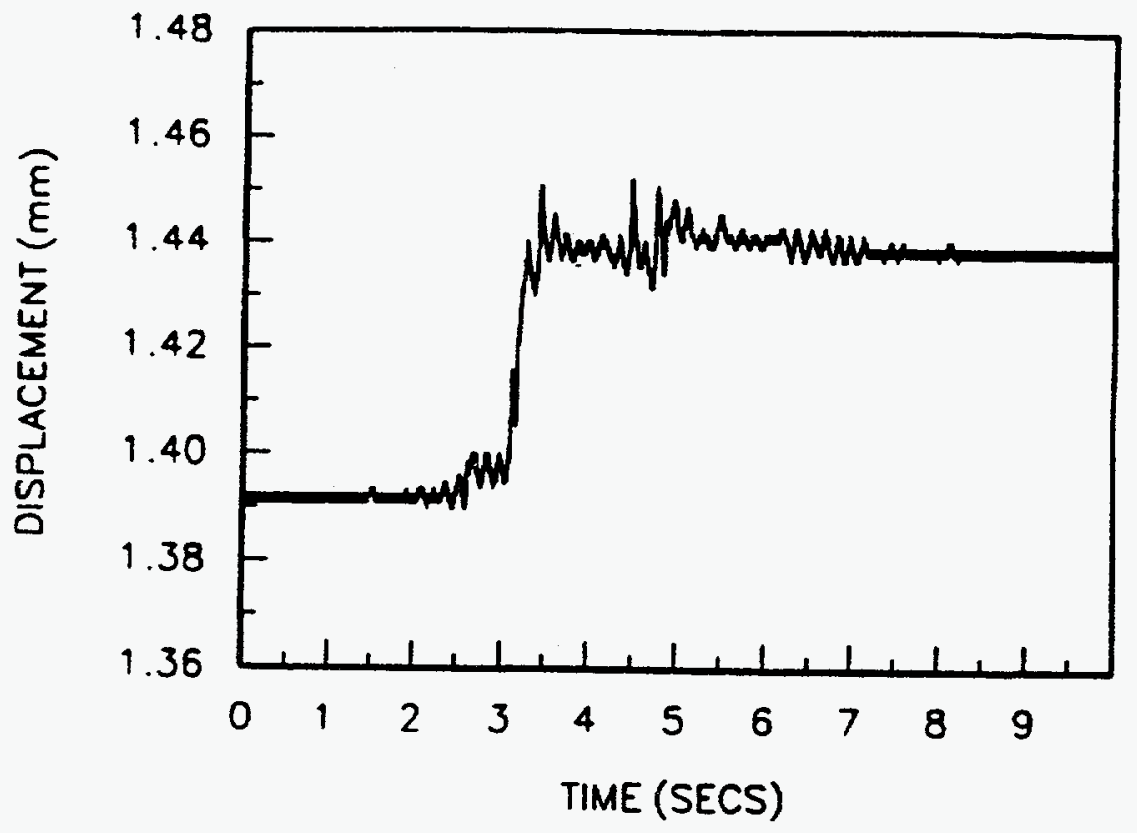

Figure 3-15. Relative displacement along the joint in the left of the tunnel wall (near side) for data set 14: maximum input displacement amplitude is $7.6 \mathrm{~mm}$

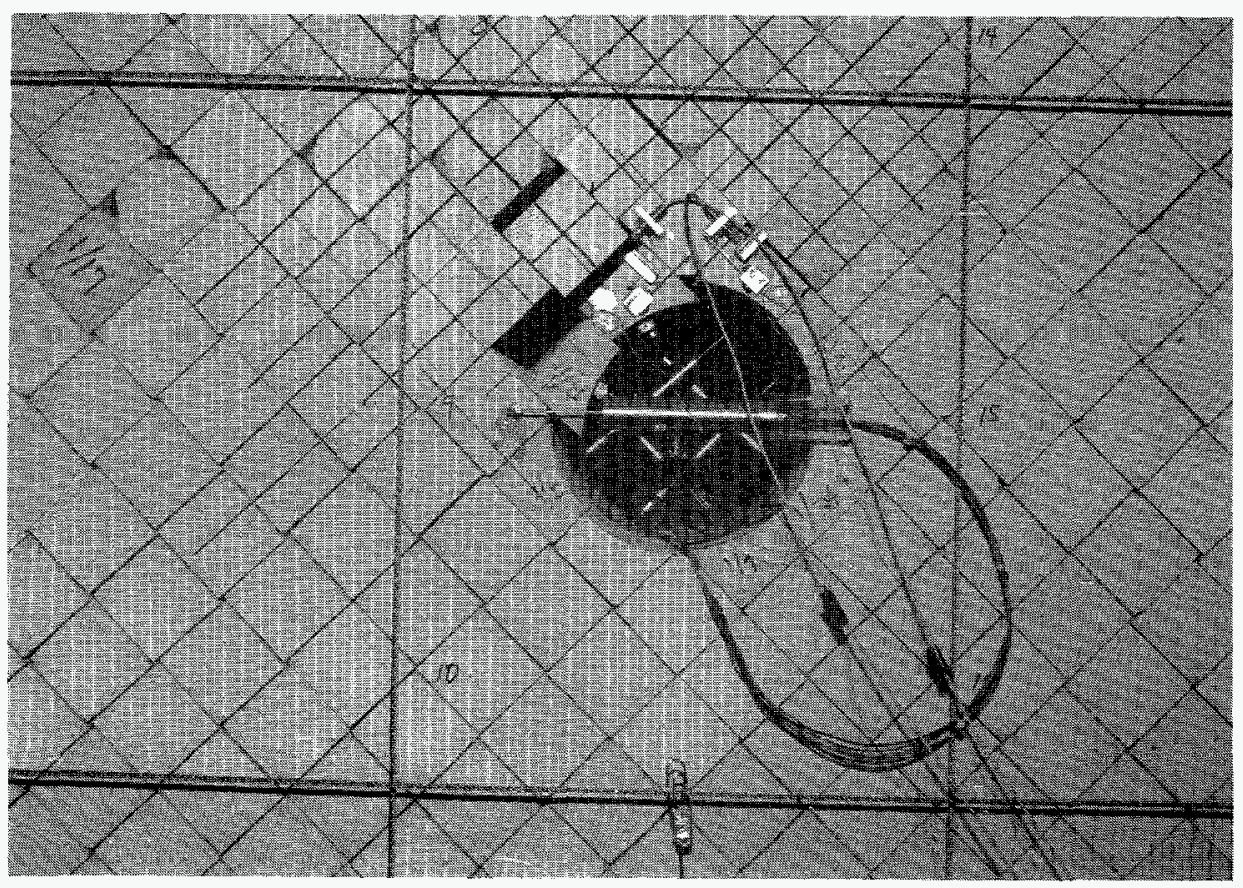

Figure 3-16. Accumulated permanent shift of ingots on far side of opening at end of test series 


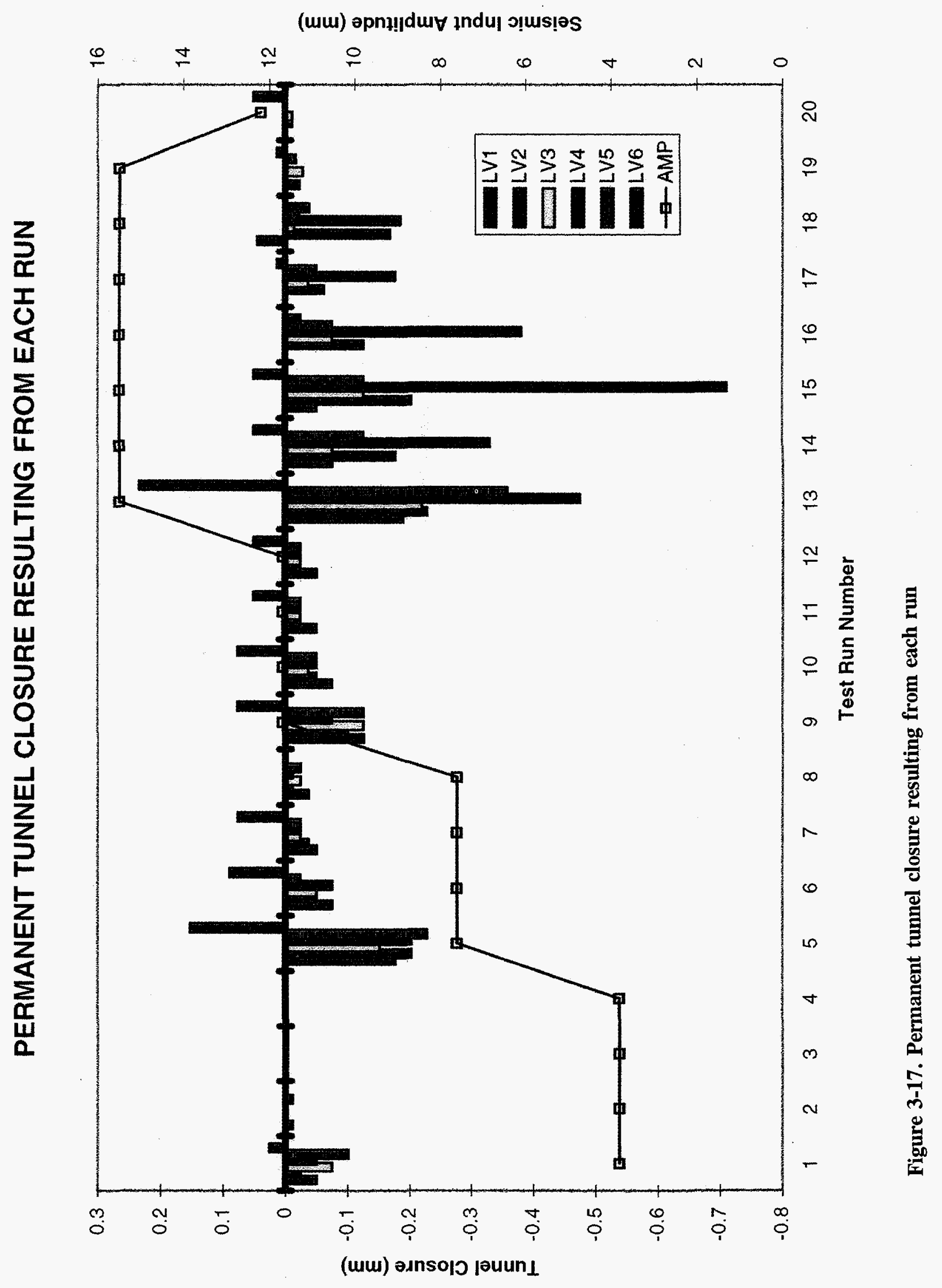


clearly identified the phenomenon of progressive damage of underground openings, the currently available seismic design methodology for subsurface facilities does not explicitly take such effects into account. Further analysis of the data is necessary in conjunction with modeling efforts to determine how to take into account the effects of repetitive seismic loads in the current design methodology. 


\section{EFFECT OF SEISMICITY ON GROUNDWATER HYDROLOGY}

The effects of earthquakes on groundwater flow may have implications with respect to the performance of an underground repository. For example, it may affect the distribution of hydraulic gradient and, consequently, the GWTT. It may also affect the possibility of water flow toward the waste packages. In order to understand such implications, techniques are required for simulating both rock mass and groundwater response to earthquakes. A reliable set of field data reflecting the relationship between seismically induced hydrologic changes and the causal earthquakes would contribute to the development of the required simulation techniques. With these factors in mind, a field study was undertaken by the CNWRA under contract with the NRC.

Hydrologic changes associated with earthquakes have been reported in the literature, mainly in terms of observed changes in stream discharge and groundwater levels. Waller (1966) described the effects of the March 27, 1964, Alaska earthquake (Richter magnitude 8.4 to 8.6) on the hydrology of the Anchorage, Alaska, area. His observations were made through a network of observation wells and stream-gauging stations, which had been in operation for about $15 \mathrm{yr}$ prior to the earthquake. Increased stream discharge and both decrease and increase in groundwater levels were observed after the earthquake. Some of the changes occurred immediately following the earthquake and lasted for a short time, but others developed more slowly and lasted for up to $6 \mathrm{mo}$. For example, it was noted that the piezometric levels in the glacio-fluvial aquifer system initially decreased by as much as $7.3 \mathrm{~m}(24 \mathrm{ft})$ and then recovered gradually over a period of about $6 \mathrm{mo}$, stabilizing at up to $4.6 \mathrm{~m}(15 \mathrm{ft})$ lower than pre-earthquake levels. Observations in one well suggest that similar changes may have occurred in the tertiary bedrock about

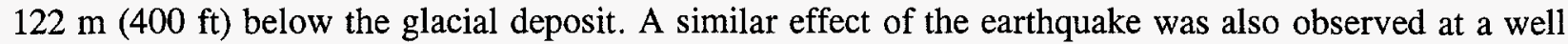
in Ottawa, Canada (Bower and Heaton, 1978). The water level in the well dropped suddenly by about $0.3 \mathrm{~m}(1 \mathrm{ft})$ and then recovered slowly over a period of several days.

The hydrologic effects of the magnitude 7.3 Borah Peak (Idaho) earthquake of October 28, 1983, were documented by Wood et al. (1985). The effects include an increase in spring and stream discharge, and both increase and decrease in groundwater levels. A piezometric head increase of up to $35 \mathrm{~m}$ (115 ft) was observed in the epicentral area. The earthquake was caused by a normal fault, and the associated hydrologic changes were observed to occur more in the hanging wall area than in the footwall area. Similar to the Alaskan earthquake, some of the effects occurred immediately and lasted for a short time, whereas others lasted much longer. At a shaft in the Clayton Silver Mine, located in the hanging wall about $24 \mathrm{~km}$ west of the nearest surface faulting associated with the earthquake, the water level rose by about $55 \mathrm{~m}(182 \mathrm{ft})$ despite continuous pumping at about 930 gal. $\left(3.5 \mathrm{~m}^{3}\right)$ per minute. The water level declined slowly over a period of about $2 \mathrm{mo}$, after the pumping rate was increased to about 2,000 gal. $\left(7.6 \mathrm{~m}^{3}\right)$ per minute.

Raney (1988) provided a summary of the hydrologic effects of selected earthquakes that occurred during 1852 through 1983 in the Western North American Intermontane Region. The earthquakes occurred at Pleasant Valley, Nevada; Cedar Mountain, Nevada; east of Fallon, Nevada; Dixie Valley, Nevada; and Hebgen Lake, Montana. Their hydrologic effects included flooding of mines, increase or decrease of flow in springs and streams, formation of new springs, and drying up of some existing ones.

Rojstaczer and Wolf (1992) studied the hydrologic consequences of the magnitude 7.1 Loma Prieta, California, earthquake of October 17, 1989. They reported that groundwater levels in the highland parts of the Pescadero drainage basin dropped by as much as $21 \mathrm{~m}$ within weeks to months following the 
earthquake, whereas the discharge rate of springs and streams within the basin increased within 15 minutes after the earthquake. The increase in discharge dissipated within months.

Three earthquakes occurred on June 28 and 29, 1992, namely, a magnitude 7.5 earthquake near Landers, California; a magnitude 6.6 event near Big Bear Lake, California; and a magnitude 5.6 event near Little Skull Mountain, Nevada. These earthquakes caused significant water-level changes throughout the Yucca Mountain area (O'Brien, 1993). The Landers earthquake caused the water level to fluctuate by as much as $0.9 \mathrm{~m}$ in well USW H-5, which is located on the crest of Yucca Mountain. The Big Bear Lake earthquake caused a water level fluctuation of $0.2 \mathrm{~m}$ in the same well. The Little Skull Mountain earthquake occurred about $23 \mathrm{~km}$ from Yucca Mountain, and caused a maximum water level rise of $0.39 \mathrm{~m}$ in well USW H-5. The magnitude 6.8 Northridge earthquake of January 17, 1994, which occurred in San Fernando Valley, California, caused a rapid water level increase of 3 to $18 \mathrm{~cm}(0.1$ to $0.6 \mathrm{ft}$ ) in wells located in Chino Basin about $75 \mathrm{~km} \mathrm{(50} \mathrm{miles)} \mathrm{from} \mathrm{the} \mathrm{epicenter} \mathrm{(Thrupp} \mathrm{and} \mathrm{Wuthrich,}$ 1994).

\subsection{MECHANISMS OF EARTHQUAKE-INDUCED HYDROLOGIC CHANGES}

1992):

Earthquake-induced hydrologic changes generally fall into two categories (Rojstaczer and Wolf,

- Short-term effects on groundwater levels, which build up and dissipate very quickly (within a matter of hours or a few days following the earthquake)

- Long-term changes in stream flow and groundwater levels, some of which have been known to persist for 6 to 12 months following the earthquake

The short-term effects can readily be attributed to groundwater response to compressional waves associated with earthquakes (Rojstaczer and Wolf, 1992). For example, the water level fluctuations observed in USW H-5 and H-6 wells associated with the Little Skull Mountain earthquake were most likely related to seismically induced cyclic compression of water in rock fractures and pores. The mechanisms that have been suggested to account for the long-term changes belong to two groups, namely, (i) aquifer compression, and (ii) changes in aquifer/aquitard permeability.

The stress changes associated with an earthquake cause changes in water pressure, due to an increase or decrease in the volume of fracture or pore space available for water storage in the rock mass. The excess pressure dissipates over a period of time because the water flows into areas of lower hydraulic head. The phenomenon is actually initiated long before the earthquake by the gradual buildup of crustal stress as a result of viscous motion at depth (Kemeny and Cook, 1990; Nur, 1974). The gradual stress buildup continues until fault strength is overcome at some point, at which time rupture occurs. Following the rupture, stresses drop rapidly to lower values, at least locally. In extensional regions of the crust, associated with normal faulting, the stress buildup causes a decrease in horizontal stress, which in turn causes an increase in crack and pore volumes, and a decrease in water pressure. Following the occurrence of rupture and the consequent stress drop, the horizontal stress increases rapidly, leading to a rapid increase in water pressure. Thereafter, the excess pressure dissipates slowly as the water flows into areas of lower hydraulic head. The stress change accompanying normal fault earthquakes is usually more pronounced in the hanging wall than in the footwall. Therefore, its hydrologic consequences, that is, 
increase in groundwater pressure and stream discharge, tend to occur more in the hanging wall area (Wood et al., 1985).

The mechanism for this category of long-term hydrologic effects is similar to the one discussed earlier for the short-term effects. The important difference between them is that the short-term effects are caused by the seismic energy released by fault rupture (or fault slip), whereas the long-term effects under this category are caused by stress changes that occur prior to, and after the release of seismic energy. The importance of this difference relates to the magnitude and time rate of the associated hydrologic effects and to the method and input data required to model the effects numerically.

Muir-Wood and King (1993) applied the concept of aquifer compression to explain the increase in stream discharge associated with the Hebgen Lake and Borah Peak earthquakes. They argued that the hydrologic effect of pure reverse faults (associated with gradual increase in horizontal stress, and a rapid decrease following faulting) should be the opposite of pure normal faults; that is, pure reverse faults should cause a decrease in groundwater pressure and stream discharge. Though there is insufficient empirical data to verify the hydrologic signature of reverse fault earthquakes, the data available for normal faults, and the theoretical understanding of the stress changes associated with normal faulting, offer strong evidence in support of the aquifer compression mechanism for some long-term earthquake-induced hydrologic changes.

Earthquake-induced rock deformation may cause changes in the permeability of an aquifer or the neighboring aquitard or both, leading to significant changes in discharge rates and, consequently, hydraulic heads. A good example was reported recently by Rojstaczer and Wolf (1992). They examined stream flow and water chemistry data, as well as groundwater level data from utility wells, for the San Lorenzo and Pescadero drainage basins (California), following the 1989 Loma Prieta earthquake. They observed an increase in stream discharge above the normal seasonal changes, along with a decrease in groundwater levels, especially in areas of high elevation. They also observed an increase in calcite saturation index and a decrease in water temperature (for the stream water), which were interpreted to indicate that the additional stream discharge was derived from groundwater from surrounding highlands. Furthermore, they suggested that these changes were most likely caused by an increase in permeability due to seismically induced opening of micro- and macrofractures. The earthquake-induced deformations caused an enhancement of the fracture networks that control groundwater flow in the area. As a result, groundwater flow rates increased initially, causing a surge in stream discharge rates. The increased discharge caused groundwater levels to drop, especially in relatively elevated areas. The excess stream discharge dissipated rapidly because of the decay of the driving hydraulic head.

The permeability of a rock mass may change significantly as a result of rock fracturing and the re-opening or closure of existing fractures under the influence of earthquake-related stress change. Significant changes in the hydrologic regime of a rock mass may occur as a result. This phenomenon is difficult to model, because of the involvement of a suite of complicated processes, including nonlinear deformation of intact rock and rock fractures, the relationship between such deformation and the rock mass permeability, and the transient flow of water through variably saturated rock. The following processes need to be accounted for in developing a numerical model of earthquake-induced long-term hydrologic change related to change in rock mass permeability:

- Rock fracturing, which may occur as a result of rock strength being overcome locally by the superposition of earthquake-related stress change on the existing rock stress; 
- Opening and closing of existing fractures and pores, due to changes in compressive stress;

- Shear-induced dilation of rock joints and faults;

- Possible changes in fracture connectivity as a result of any of the above deformations; and

- Changes in the water storage capacity and conductivity of the rock, as a result of the above deformations.

\subsection{GROUNDWATER PRESSURE MONITORING AT LUCKY FRIDAY MINE}

The intact rock of the lower Revett Formation has very low permeability. On the other hand, several structurally controlled high-permeability zones occur, such as the Osburn and Whiteledge Faults, the ore vein, and associated fractures. Therefore, the groundwater pressure monitoring program required the installation of instruments within the high-permeability structures. In addition, the groundwater level at the Lucky Friday Mine lies above the current mining depth, and significant drawdown of the water table occurs as a result of mining. Therefore, it was necessary to locate the instruments below the current mining level to ensure that they remain in the saturated zone during the period of the field studies.

Within the Silver Shaft (main access shaft for the mine), the 5700 level station, which was $121.9 \mathrm{~m} \mathrm{(400} \mathrm{ft)} \mathrm{below} \mathrm{the} \mathrm{deepest} \mathrm{mining} \mathrm{level} \mathrm{at} \mathrm{the} \mathrm{time,} \mathrm{was} \mathrm{selected} \mathrm{as} \mathrm{the} \mathrm{seat} \mathrm{of} \mathrm{the} \mathrm{monitoring}$ program, with the intention of locating instruments in permeable zones below the station. An NQ size ( $7.6 \mathrm{~cm}$ diameter) borehole was drilled from the station, plunging $20^{\circ}$ in $S 20^{\circ} \mathrm{E}$ direction. The borehole was intended to intersect the ore vein and South Control fault. It was drilled to a length of about $360 \mathrm{~m}$ $(1,180 \mathrm{ft})$. All the permeable zones of interest were intersected within $310 \mathrm{~m}(1,017 \mathrm{ft})$ length of the borehole.

It was determined through core logging that five fracture zones (three associated with faults and two with mineral vein) were intersected by the borehole between $183 \mathrm{~m}$ (600 ft) and $360 \mathrm{~m}(1,180 \mathrm{ft})$ along its length. The structures were located at a distance of about $207 \mathrm{~m}(680 \mathrm{ft}), 242 \mathrm{~m}(795 \mathrm{ft}), 269 \mathrm{~m}$ $(883 \mathrm{ft}), 288 \mathrm{~m}(945 \mathrm{ft})$, and $307 \mathrm{~m}(1,006 \mathrm{ft})$ along the borehole, from its collar. Four of the structures were selected for groundwater pressure monitoring. The fracture zone at $269 \mathrm{~m}(883 \mathrm{ft})$ was considered minor; therefore, it was not selected.

The selected fracture zones were packed off using inflatable straddle packers. The packers were inflated with water pressure to $2.76 \mathrm{MPa}$ (400 psi), to cause the packers to expand to the borehole size, provide for resistance against groundwater pressure, as well as hold the packers in place. A vibrating wire pressure transducer (piezometer) was installed between each of the straddle-packer pairs to measure water pressure.

These four Geokon Model $4500 \mathrm{H}$ vibrating-wire transducers were calibrated using a National Institute of Standards and Technology-Traceable Ashcraft Dead Weight Tester. Each piezometer was calibrated individually, with the pressure being increased from 0 to $3.45 \mathrm{MPa}$ ( $500 \mathrm{psi}$ ) at a $0.69-\mathrm{MPa}$ (100-psi) interval and then decreased in similar fashion to 0 . The cycle was repeated twice for each piezometer. Details of the field instrumentation and experiments are given in Ofoegbu et al. (1995). Figure 4-1 shows the locations of the packers and the permeable zones isolated by each packer pair. The structural feature associated with each permeable zone is also identified in the figure. The deepest zone, 
referred to as Zone 1, contains the Associated Fractures, a fracture zone parallel to the South Control Fault; the next zone, Zone 2, contains the South Control Fault; the next two zones, Zones 3 and 4, contain the Main Vein and the Footwall Vein, respectively. The inflation line of the packer system for Zone 4 was ruptured when the packers were being inflated. Consequently, Zone 4 was not properly sealed, and water pressure measurements obtained from this zone proved to be incorrect. The piezometers for Zones 1, 2, and 3 were installed at borehole distances of $294.4 \mathrm{~m}(966 \mathrm{ft}), 279.5 \mathrm{~m}(917 \mathrm{ft})$, and $221.9 \mathrm{~m}(728 \mathrm{ft})$, respectively, from the collar. The piezometer locations are summarized in Table 4-1, in terms of the East-North-Depth coordinate system.

The piezometer data were collected through a data acquisition system that consisted of two underground dataloggers and a surface personal computer. A 32-channel datalogger with power supply was located at the LFM95-C1 mechanical response site. The second datalogger was placed at the 5700 -level station of the Silver Shaft. The four piezometers were connected through a multiplexer to the datalogger at the 5700-level station. The two dataloggers were networked via a coaxial cable. All instruments communicated with the surface computer via the datalogger at the 5700 level. Groundwater pressure measurements were made initially at an interval of $2.25 \mathrm{hr}$. The interval was later reduced to 1 min after it was determined that the seismic-induced changes lasted for very short durations (of the order of hours to a few days).

Access tubes for additional groundwater pressure measurements were also installed at the piezometer locations. An initial water pressure measurement was taken as soon as it was determined that the packers were properly seated. The initial measurement gave water pressure values of $2.61 \mathrm{MPa}$ (378 psi) for Zone 1, 2.50 MPa (363 psi) for Zone 2, $2.15 \mathrm{MPa}$ (312 psi) for Zone 3, and 0.58 $\mathrm{MPa}$ ( $84.5 \mathrm{psi}$ ) for Zone 4 . These values compared well with those calculated using data from the access tubes, except for Zone 4 . The relatively small value measured for Zone 4 was because of the leakage of the packer pair for that zone, as noted earlier.

Based on these measurements and the elevation data given in Table 4-1, the initial groundwater heads at the piezometer locations were 546, 551, and $567 \mathrm{~m}$ below sea level, for Zones 1, 2, and 3, respectively, corresponding to depths of 1,571, 1,576, and 1,592 $\mathrm{m}$ below ground surface. Therefore, there was an initial water table drawdown toward the mine. It is also believed that the general decrease in hydraulic head that occurred during the period of the field study was caused by mine drainage. A general decrease in head of up to $6 \mathrm{~m}$ occurred in 1991; on the other hand, only about a 2-m decrease occurred in 1992, except in Zone 1, where the hydraulic head declined by about $5 \mathrm{~m}$ between January and December.

Table 4-1. Coordinates of piezometer locations

\begin{tabular}{||l|c|c|c|c|}
\hline \multicolumn{1}{|c|}{ Zone } & $\begin{array}{c}\text { Borehole } \\
\text { Distance (m) }\end{array}$ & East (m) & North (m) & $\begin{array}{c}\text { Depth below } \\
\text { sea level (m) }\end{array}$ \\
\hline \hline Borehole collar & 0.0 & -46.0 & 143.3 & 710 \\
\hline Zone 1 Piezometer & 294.4 & 5.49 & -128.6 & 811 \\
\hline Zone 2 Piezometer & 279.5 & 2.74 & -114.9 & 806 \\
\hline Zone 3 Piezometer & 221.9 & -7.32 & -61.6 & 786 \\
\hline
\end{tabular}




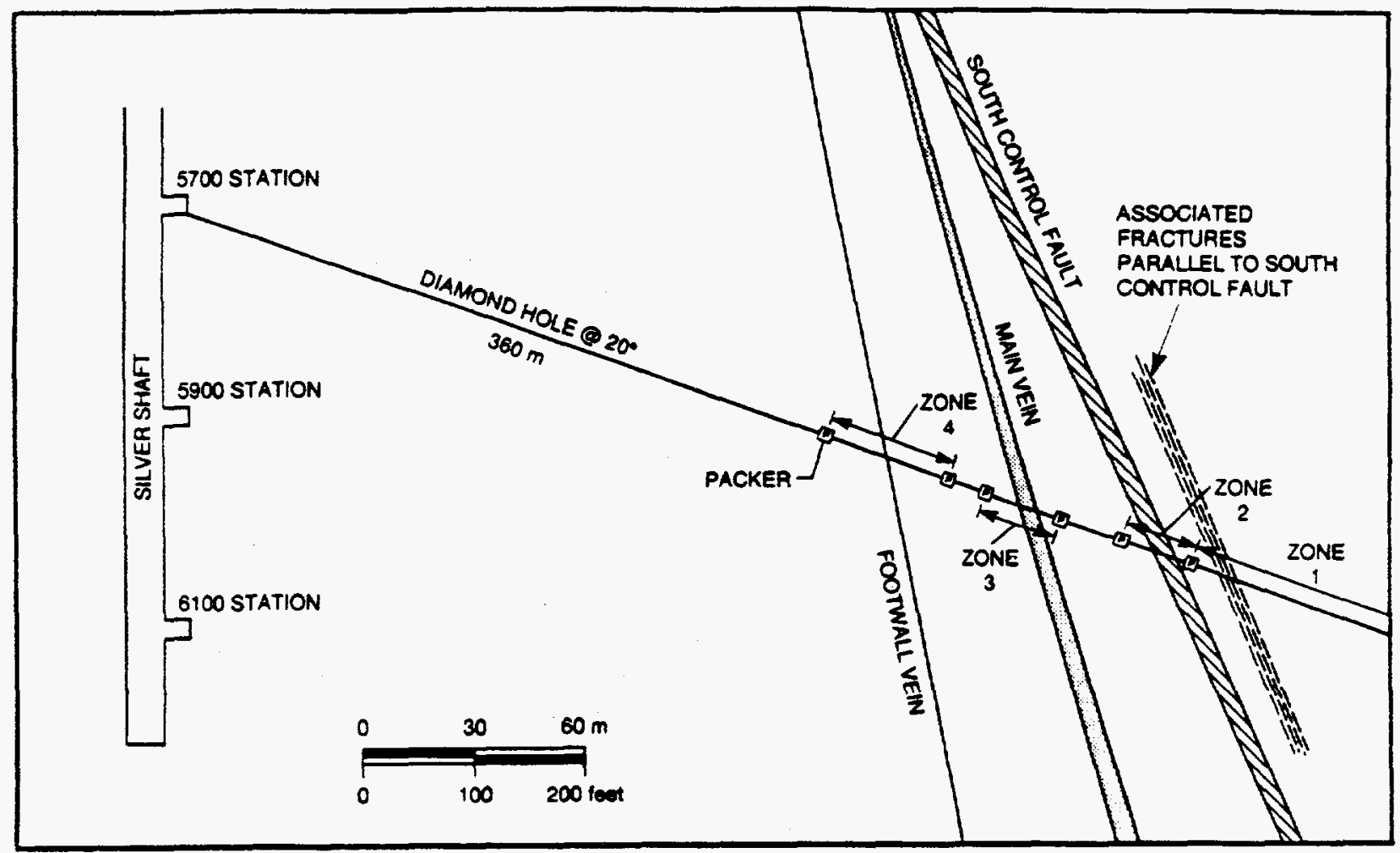

Figure 4-1. Zones packed off for water pressure measurement along the borehole drilled from Lucky Friday Silver Shaft at a depth of $1,737 \mathrm{~m}$ below the ground surface

It is possible that normal seasonal hydrologic variations and long-term seismically induced hydrologic effects contributed to these changes. As discussed before, the data collected are not sufficient to permit a separation of the contributions of these three processes to the observed long-term changes in hydraulic head. Short-term seismically induced changes did occur, which were associated with the various seismic events.

\subsection{SHORT-TERM SEISMIC EFFECTS ON GROUNDWATER PRESSURE}

The primary difference between short- and long-term seismically induced changes in groundwater pressure is that the former build up and dissipate more rapidly than the latter. Both are caused by changes in the water-storage capacity, and sometimes permeability, of rock due to seismically 
induced deformation. On the other hand, whereas the short-term changes are related more to deformations associated with the seismic waves, the long-term changes are related more to deformations associated with the earthquake-related static and dynamic stress changes that occur prior to, during, and after the seismic event. However, the two are not mutually exclusive; that is, most observed seismically induced changes in groundwater pressure are likely to involve both short- and long-term effects.

Figures 4-2, 4-3, and 4-4 show the groundwater pressure histories for Zones 1, 2, and 3, respectively, for September 18 through 20, 1991. An event of magnitude 3.5 on the Richter scale occurred at 0920 hour on September 19, 1991. As the plots show, an increase in groundwater pressure occurred rapidly (almost instantaneously) at about the time of the event. The increase dissipated completely within $24 \mathrm{hr}$; more than half of the increase in Zones 2 and 3 dissipated during the first $3 \mathrm{hr}$ following the event. The groundwater pressure histories shown in these plots display the typical characteristics of short-term seismic effects (i.e., rapid buildup and dissipation).

The next example, shown in Figures 4-5, 4-6, and 4-7, displays the characteristics of combined short- and long-term seismic effects, with the long-term effects probably dominant. The groundwater pressure histories shown in these plots are associated with a magnitude 2.6 seismic event that occurred at 0458 hours on March 27, 1991. As the plots show, an increase in groundwater pressure occurred, with a buildup time of about 3 days and a dissipation time of 8 to 12 days. Although the groundwater pressure buildup and dissipation shown in these plots occurred over a relatively long time, it is possible to attribute it to the seismic event for two reasons. First, the build up started at about the same time as the event; it is unlikely that an increase in groundwater pressure related to seasonal variations or mine-backfilling would begin to occur at the same time as a seismic event. Second, the increase is superimposed on a general trend of decreasing groundwater pressure, which suggests that it was caused by an event with hydrologic consequences counter to the ambient hydrologic trend.

All seismic events did not produce measurable hydrologic effects during the field studies. In general, the magnitude of groundwater pressure change increased as the event magnitude increased. For a given event magnitude, the groundwater pressure change decreased as the distance of the observation point from the source location increased. Figure 4-8 shows the change in ground water pressure associated with these events, measured in Zone 3, in terms of the scaled distance. Scaled distance is defined as $r / M^{1 / 3}$ where $r$ is the radial distance from the source of the seismic events to the point of measurement and $\mathrm{M}$ is the magnitude of the event (Hsiung et al., 1992b, 1993a). Further information on measured data and analyses results are available in Ofoegbu et al. (1995), Hsiung et al. (1992b, 1993a). Figure 4-8 illustrates that the magnitude of the change in water pressure decreases with the increase in scaled distance. The least-square regressed line follows the trend in the data quite well, although the coefficient of determination is only 54 percent. This means scaled distance can explain only 54 percent of the variation observed in the data. Other factors, not taken into consideration explicitly into the regression analyses, account for the rest 46 percent variation. These factors include possible damaged zones in between the sources of the events and the monitored locations giving anisotropic rate of seismic wave attenuation, possible error in locating the sources, etc. 


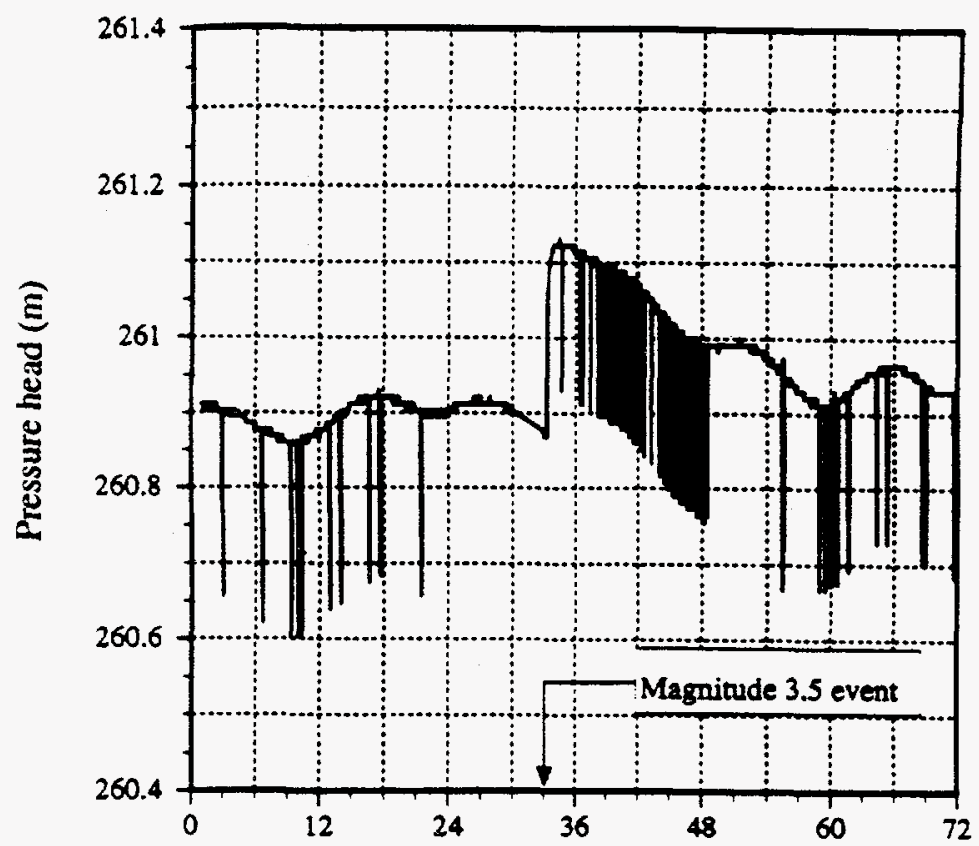

Hours (from midnight, September 17)

Figure 4-2. Groundwater pressure history for Zone 1, September 18 through 20, 1991

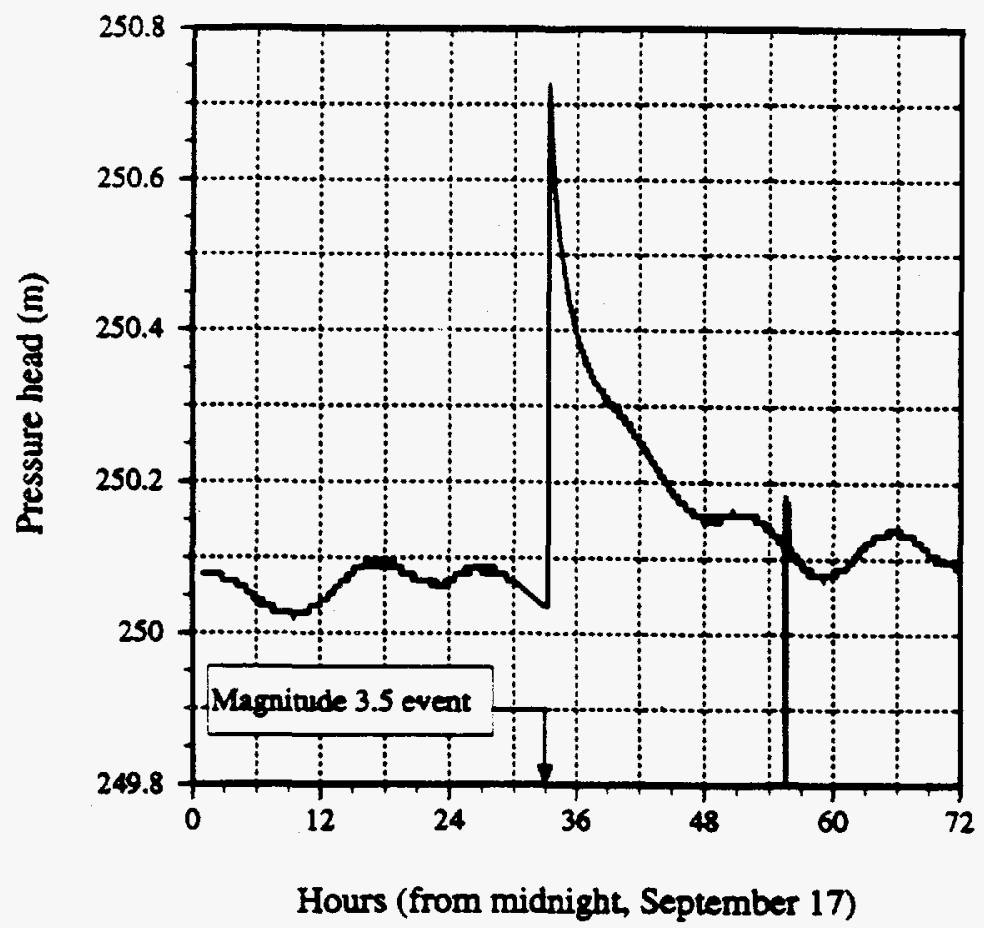

Figure 4-3. Groundwater pressure history for Zone 2, September 18 through 20, 1991 


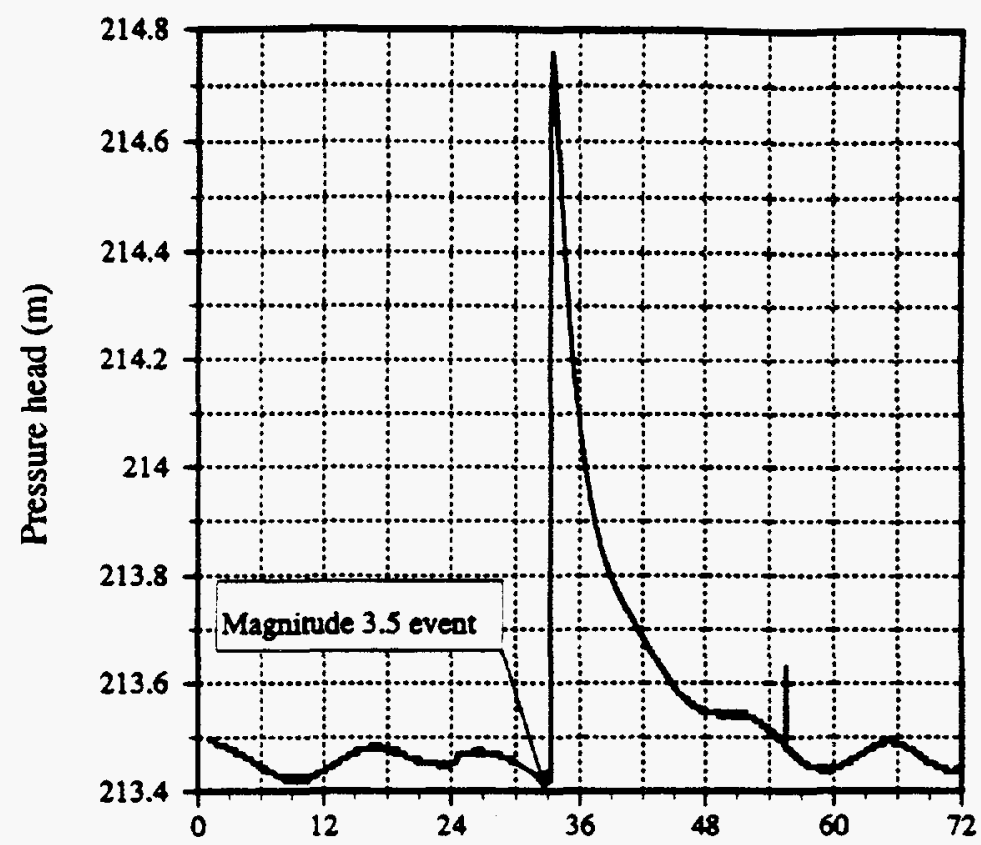

Hours (from midnight, September 17)

Figure 4-4. Groundwater pressure history for Zone 3, September 18 through 20, 1991

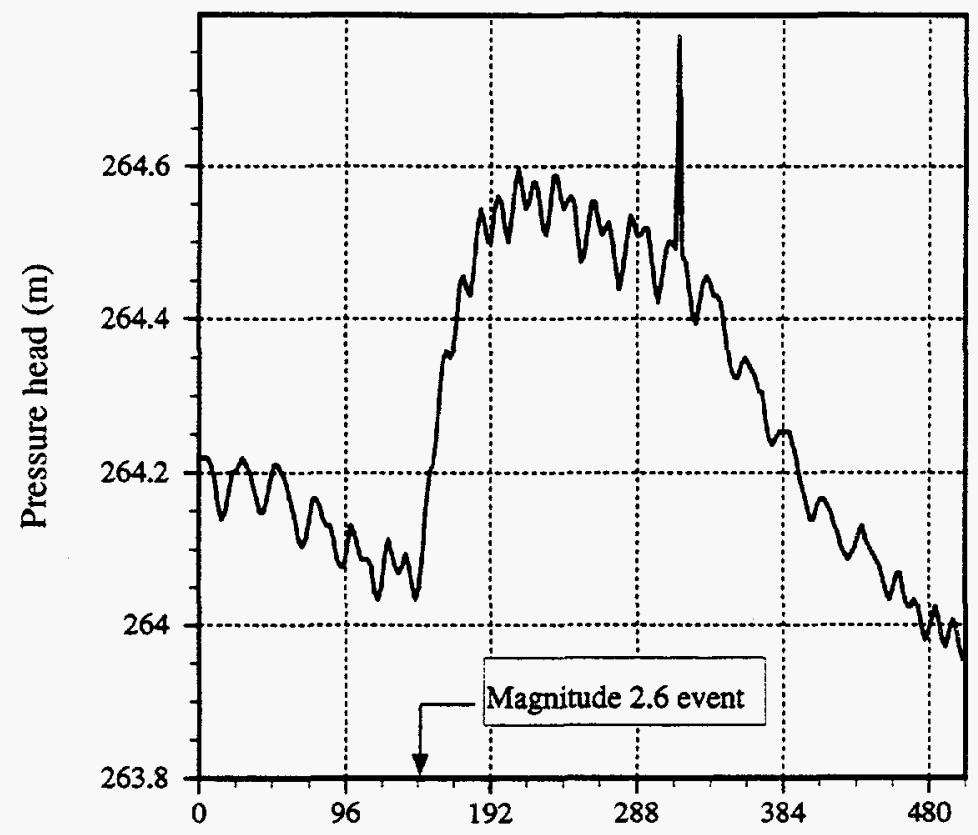

Hours (from midnight, March 20)

Figure 4-5. Groundwater pressure history for Zone 1, March 21 through April 10, 1991 


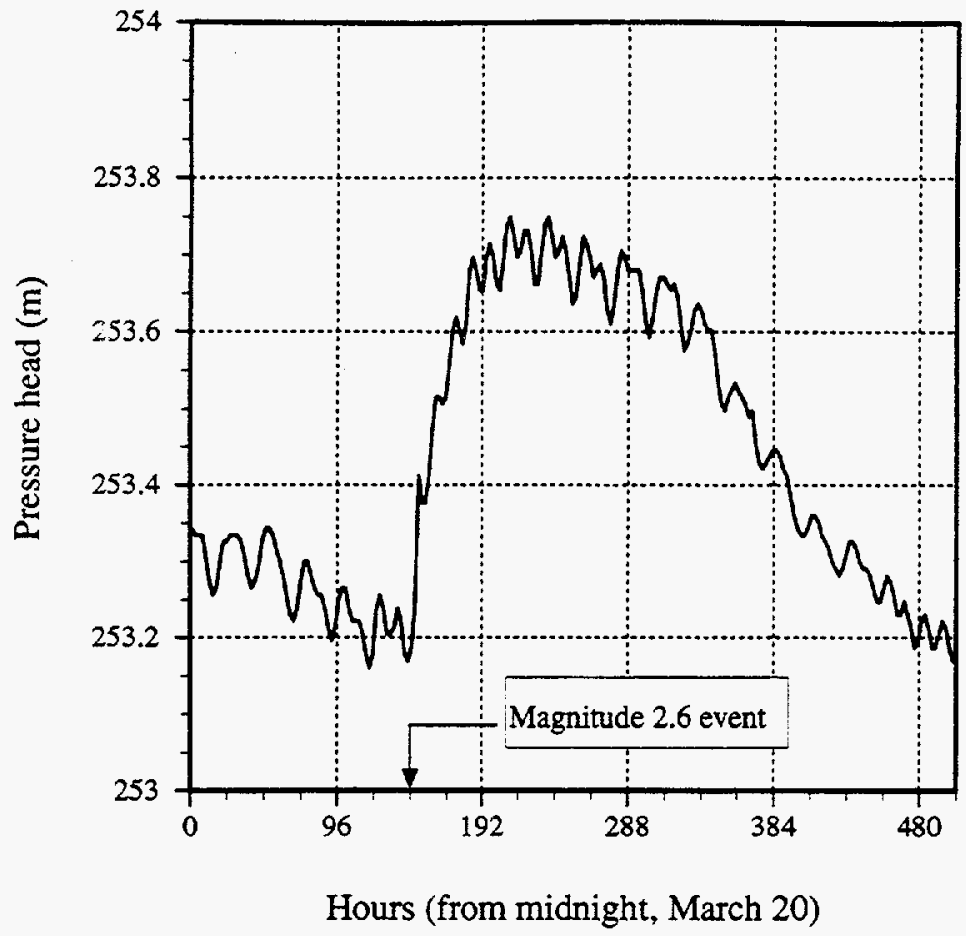

Figure 4-6. Groundwater pressure history for Zone 2, March 21 through April 10, 1991

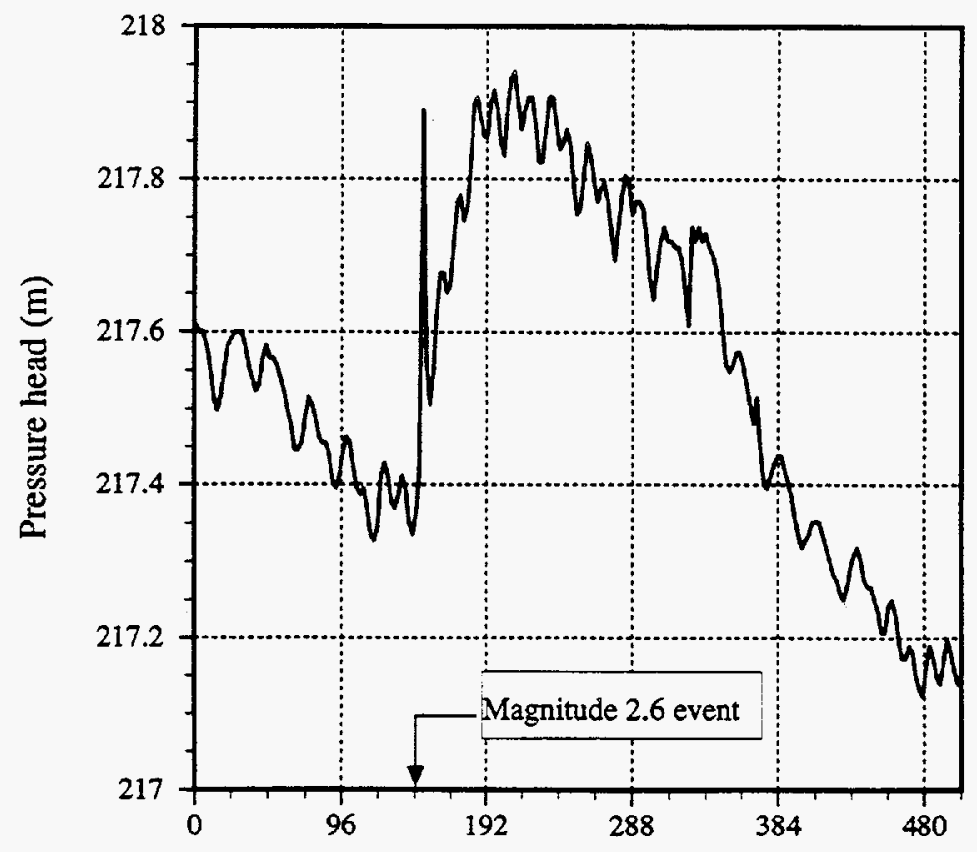

Hours (from midnight, March 20)

Figure 4-7. Groundwater pressure history for Zone 3, March 21 through April 10, 1991 


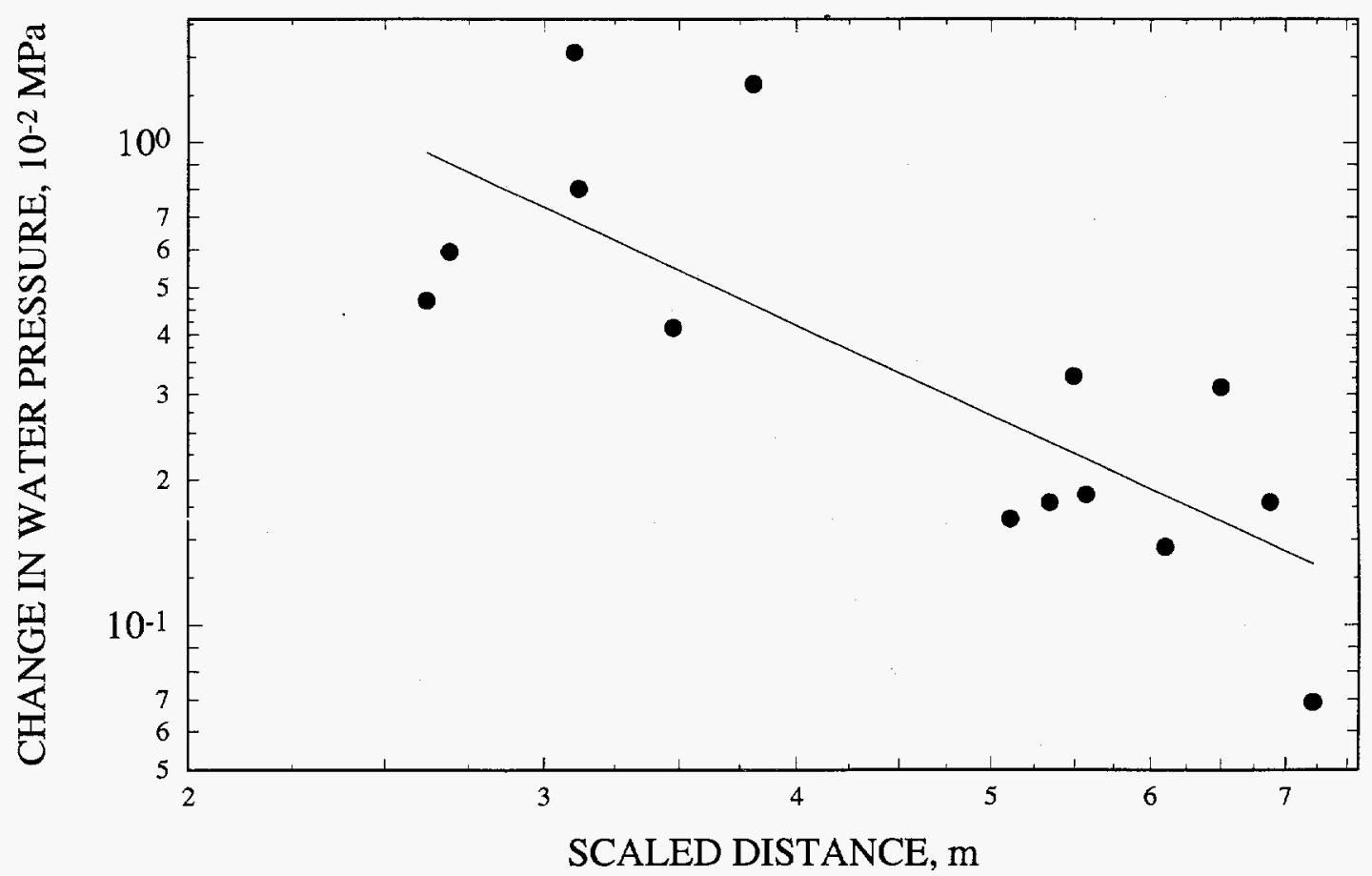

Figure 4-8. Change in groundwater pressure with scaled distance 



\section{CONCLUSIONS AND RECOMMENDATIONS}

The overall objectives of the seismic aspect of the Rock Mechanics Research Project were to develop an understanding of the key parameters affecting repository performance under repeated seismic loading and evaluating current capabilities for calculating such effects. Critical assessment of the information obtained from a literature review conducted at the beginning of this research project identified several technical deficiencies and/or lack of information with regard to analysis and prediction of dynamic response of underground structures excavated in fractured rock masses. A series of laboratory experiments was conducted on natural single joints that generated a reliable data set for the cyclic pseudostatic and dynamic joint behavior and for evaluating the ability of existing rock-joint models to represent dynamic joint behavior. The results compare very well with the results of other researchers available in the literature. A scale-model experimental investigation provided data for understanding the effects of repetitive seismic events on a jointed rock mass surrounding an underground opening. The instrumented field studies at the Lucky Friday Mine generated field-scale data on mechanical response of fractured rock mass around deep underground openings and limited information regarding hydrologic response of water bearing fractures due to mining-induced seismicity. Evaluation of the existing rock-joint models and their implementation in computer codes provided information on their capabilities to predict the seismic behavior of jointed rock masses surrounding underground openings.

The findings of these research activities are grouped in terms of individual activity and presented below. Technical recommendations for use of these findings and/or further development work for enhancement of the use of these findings are also provided herein.

\subsection{COMPREHENSIVE LITERATURE REVIEW}

- The current seismic design methodology for subsurface facilities does not take into account the potential effects of repetitive episodes of seismic events

- There are no validated rock-joint models and verified computer codes for analyzing the response of jointed rock masses, subjected to seismic loading

\subsection{ROCK-JOINT LABORATORY EXPERIMENTS}

- Experimentally measured shear behavior of the rock-joint, subjected to cyclic pseudostatic and seismic loads, shows that shear strength in reverse direction is significantly smaller than that in the forward direction

- A major portion of joint dilation resulted from forward shearing recovers during reverse shearing

- Within the range of variation of the test input shearing velocity, the effect of shearing velocity on the peak joint shear strength is negligible.

- The first two findings are the opposite of the common notion that (i) rock joints behave the same under both forward and reverse shearing conditions and (ii) joint dilation increases irrespective of the direction of shearing. 


\subsection{ROCK-JOINT MODELS AND ASSOCIATED COMPUTER CODE EVALUATIONS}

- Rock-joint models available during this study, namely Coulomb-Slip, Barton-Bandis, and Continuously-Yielding models, cannot adequately predict shear and dilation behavior in the direction of reverse shearing

- The UDEC computer code with appropriate rock-joint model appears, in general, to be suitable for dynamic analysis of natural rock joints

\subsection{ROCK MASS DYNAMIC RESPONSE FIELD STUDY AND LABORATORY EXPERIMENTS}

- The permanent deformation of a jointed rock mass subjected to repetitive episodes of seismic events is cumulative in nature. Consequently, the cumulative effects of repetitive seismic loading may weaken the rock mass and govern design of stable underground excavations.

- Underground excavations at high states of stress (depending upon rock conditions) are more sensitive to seismic loads. This sensitivity has implications for both waste retrievability and post-closure performance of underground excavation because the seismic events will take place in the environment of higher state of stress caused by thermal loads.

- There is a seismic threshold value below which permanent rock mass deformation will not take place.

\subsection{HYDROLOGIC RESPONSE FIELD STUDY}

- The extent of the groundwater pressure response to the mining-induced seismicity (small seismic magnitude) at the Lucky Friday Mine is relatively minor. However, the hydrological response of a rock mass is sensitive to seismic motion. Studying the effect of larger seismic event seems to be needed. This threshold value may be site specific and may deepened on the state of stress.

\subsection{RECOMMENDATIONS}

The goal of the research on seismic response of rock-joints and jointed rock mass surrounding the EBS was to support the NRC program relevant to licensing a HLW geologic repository. The information developed in this research project will be used for: (i) conducting prelicensing reviews and providing guidance to the Department of Energy, (ii) developing CDMs for specific sections of the LARP, (iii) supporting IPA, and (iv) further developing analytical capabilities for License Application (LA) review. The recommendations for using the results of this research project for the above purposes are provided as follows.

\subsubsection{Prelicensing Reviews and Guidance to DOE}

The DOE prelicensing activities relevant to seismic design of subsurface facilities in jointed rock mass include seismic design of the ESF [Site Characterization Plan (SCP), ESF design packages], and development of seismic design methodology and seismic inputs for repository design seismic topical reports, the LA annotated outline, and the repository ACD. The major findings of the research project 
provide much needed focus on evaluating these DOE prelicensing activities relevant to seismic design of underground facilities. These research findings are being used by the NRC staff to provide guidance to DOE on seismic design of subsurface facilities, in the form of Site Characterization Analysis (SCA) comment No. 121; NRC review comments on ESF design packages; DOE topical reports on seismic design methodology for a geologic repository at $\mathrm{YM}$, and on seismic design inputs for a geologic repository at YM; repository ACD; and LA Annotated Outline (LAAO), as well as during NRC/DOE technical exchanges and related interactions.

\subsubsection{Development of CDMs for LARP}

The CDMs for the LARP will specify review procedure and acceptance criteria that the NRC staff will use to judge DOE compliance with the NRC design and performance objectives regulatory requirements. The results of this research project will be used to develop the following CDMs:

CDM 4.4-Assessment of Compliance with Design Criteria for the Underground Facility,

CDM 4.5.2-Assessment of Integrated Compliance with the Performance Objectives: Retrievability of Waste,

CDM 4.3-Assessment of Compliance with Design Criteria for Shafts and Ramps,

CDM 5.2-Assessment of Compliance with the Design Criteria for the Waste Package and its Components,

CDM 5.3-Assessment of Compliance with the Design Criteria for the Post-Closure Features of the Underground Facility,

CDM 5.4-Assessment and Engineered Barrier System Compliance with the Performance Objectives, and

CDM 6.2-Assessment of Compliance with the Requirements of Cumulative Releases of Radioactive Materials.

\subsubsection{Iterative Performance Assessment}

Emplacement drift instability that might be caused by the cumulative effects of repetitive seismic loads may affect waste package performance due to impingement of falling rocks, including: (i) rupturing the waste package, which may result in a loss of containment; a scenario at a later state of design life of waste packages and (ii) contributing to local acceleration of waste package degradation which may result in a loss of containment or an unpredictable release rate. It shall be noted that the importance of the first effect will largely depend on waste package design. These two effects will be more pronounced if the emplacement drifts are not backfilled after permanent closure, a viable option that is under consideration by DOE. Repetitive seismic loads may cause change of permeability of rock surrounding the waste packages, including creation of preferential water pathways to connect the emplacement areas with perched water zones, neighboring steep hydraulic gradient zones, or the moisture condensation zone above the emplacement area that may have impact on both waste package and total system performance. 
The results of this research project, complemented with the further development of capabilities for LA review as discussed in Section 5.6.4, will provide the necessary tools to assess the impact of emplacement drift instability on waste package performance. As appropriate, models may then be abstracted in more simplified form for use in IPA studies.

\subsubsection{Further Development of Analytical Capabilities for LA Review}

The primary objectives of this research project-obtaining a better understanding the effects of repeated seismic loadings on repository performance and evaluating the capabilities for calculating such effects-were accomplished. The key finding indicates that rock mass deformation around excavations is cumulative in nature when subjected to repetitive episodes of seismic events. Such accumulation tends to weaken the rock mass and may lead to instability of the excavations, depending upon the state of stress and rock mass strength. It is, therefore, important to consider such effects in design of underground facilities where seismic loads are of concern. However, as noted in Section 5.1, the currently available seismic design methodology for subsurface facilities does not explicitly take such effects into account. Consequently, further investigation is needed to develop a method and acceptance criteria to support review of subsurface facility seismic designs more effectively. The objective of this investigation can be accomplished through a detailed analysis of the information generated from this research project, including results from both laboratory and field experiments. This analysis may be enhanced by conducting parallel numerical simulations.

As discussed in Sections 2.3.4 and 5.3, the Mohr-Coulomb, Barton-Bandis, and ContinuouslyYielding rock joint models cannot adequately predict cyclic joint shear behavior. Development of a rock joint model with proper joint roughness characteristics is needed. The model development will make use of the rock-joint shear constitutive behavior that has been experimentally developed in this research project. Once developed, the rock-joint model will be incorporated into thermal-mechanical (TM) and thermal-mechanical-hydrological (TMH) codes. The resulting TM CDM code then can be used to assist the numerical simulation activities discussed in the previous paragraph.

Since the hydrological response of a rock mass is sensitive to seismic motion, it seems logical to conduct groundwater hydrology field study at larger magnitude earthquake zones to complement the Lucky Friday Mine groundwater hydrology study that has been carried out at low magnitude seismic events. This additional field study, in conjunction with the Lucky Friday Mine study, will assist in developing the capability of assessing potential hydrological response. 


\section{REFERENCES}

Amadei, B., and S. Saeb. 1992. Modelling rock joints under shear and normal loading. International Journal of Rock Mechanics and Mining Sciences \& Geomechanics Abstracts 29(3): 267-278.

Amadei, B., and W.Z. Savage. 1993. Effect of joints on rock mass strength and deformability. Comprehensive Rock Engineering Principles, Practice \& Projects. J.A. Hudson, editor-in-chief. Oxford, England: Pergamon Press Ltd.: 1: 331-365.

Archard, J.F. 1958. Elastic deformation and the laws of friction. Proceedings of the Royal Society of London A 243: 190-205.

Bandis, S.C. 1993. Engineering properties and characterization of rock discontinuities. Comprehensive Rock Engineering Principles, Practice \& Projects. Hudson, J.A., editor-in-chief: Oxford, England.: Pergamon Press: 155-183.

Bandis, S.C., A.C. Lumsden, and N.R. Barton. 1981. Experimental studies of scale effects on the shear behavior of rock joints. International Journal of Rock Mechanics and Mining Sciences \& Geomechanics Abstracts 18: 1-21.

Bandis, S.C., A.C. Lumsden, and N.R. Barton. 1983. Fundamentals of rock-joint deformation. International Journal of Rock Mechanics and Mining Sciences \& Geomechanics Abstracts 20(6): 249-268.

Barton, N.R. 1982. Modeling Rock Joint Behavior From In Situ Block Tests: Implications for Nuclear Waste Repository Design. ONWI-308. Columbus, OH: Office of Nuclear Waste Isolation.

Barton, N.R. 1986. Deformation phenomena in jointed rock. Geotechnique 36(2): 147-167.

Barton, N.R. 1988. Some aspects of rock joint behaviour under dynamic conditions. Proceedings of the Second International Conference on Mechanics and Rock Engineering. Torino, Italy: Politecnico di Torino 17: 1-14.

Barton, N.R., and S.C. Bandis. 1982. Effects of block size on the shear behavior of jointed rock. Proceedings of the 23rd U.S. Symposium on Rock Mechanics. Berkeley, CA.

Barton, N.R., S.C. Bandis, and K. Bakhtar. 1985. Strength, deformation and conductivity coupling of joints. International Journal of Rock Mechanics and Mining Sciences \& Geomechanics Abstracts 22(3): 121-140.

Barton, N.R., and V. Choubey. 1977. The shear strength of rock joints in theory and practice. Rock Mechanics 10: 1-54.

Barton, N., and H. Hansteen. 1979. Very large span openings at shallow depth: Deformation magnitudes from jointed models and finite element analysis. Proceedings of the Fourth Rapid Excavation and Tunnelling Conference 2: 1,331-1,353. 
Biegel, R.L., W. Wang, C.H. Scholz, and G.N. Boitnott. 1992. Micromechanics of rock friction 1. Effects of surface roughness on initial friction and slip hardening in westerly granite. Journal of Geophysical Research 97(B6): 8,951-8,964.

Bower, D.R., and K.C. Heaton. 1978. Response of an aquifer near Ottawa to tidal forcing and the Alaskan earthquake of 1964. Canadian Journal of Earth Sciences 15(3): 331-340.

Bowden, F.P., and Tabor, D. 1950. The Friction and Lubrication of Solids. Part I. Oxford, U.K.: Oxford at the Clarendon Press.

Brady, B.H.G., and E.T. Brown. 1985. Rock Mechanics for Underground Mining. London, U.K.: George Allen \& Unwin (Publishers) Ltd.: 527.

Brady, B.H.G., S.M. Hsiung, and A.H. Chowdhury. 1990. Qualification Studies on the Distinct Element Code UDEC Against Some Benchmark Analytical Problems. CNWRA 90-004. San Antonio, TX: Center for Nuclear Waste Regulatory Analyses.

Brandshaug, T., B. Dasgupta, B.H.G. Brady, S.M. Hsiung, and A.H. Chowdhury. 1990. Qualification Studies on the Finite Element Code HONDO II Against Some Benchmark Analytical Problems. CNWRA 90-006. San Antonio, TX: Center for Nuclear Waste Regulatory Analyses.

Brown E.T., and J.A. Hudson. 1974. Fatigue failure characteristics of some models of jointed rock. Earthquake Engineering and Structural Dynamics 2: 379-386.

Brown, E.T. 1993. The nature and fundamentals of rock engineering. Comprehensive Rock Engineering Principles, Practice \& Projects. J.A. Hudson, editor-in-chief. Oxford: England: Pergamon Press Ltd.: 1: 1-23.

Byerlee, J. 1978. Friction of rocks. Pure and Applied Geophysics 116: 615-626.

Celestino, T.B., and R.E. Goodman. 1979. Path dependency of rough joints in bi-directional shearing. Proceedings of the Fourth International Congress on Rock Mechanics. Montreux, France. 1: 91-98.

Crotty, J.M., and L.J. Wardle. 1985. Boundary integral analysis of piecewise homogeneous media with structural discontinuities. International Journal of Rock Mechanics and Mining Sciences \& Geomechanics Abstracts 22(6): 419-427.

Cundall, P.A., 1988. Formulation of a three-dimensional distinct element model: Part I-A scheme to detect and represent contacts in a system composed of many polythedral blocks. International Journal of Rock Mechanics and Mining Sciences \& Geomechanical Abstracts 25 (3): 107-116.

Cundall, P.A., and J.V. Lemos. 1988. Numerical simulation of fault instabilities with the continuously-yielding joint model. Proceedings of the Second International Symposium on Rockbursts and Seismicity in Mines. Minneapolis, MN: University of Minnesota.

Dieterich, J.H. 1972. Time-dependent friction in rocks. Journal of Geophysical Research 77(20): $3,690-3,697$. 
Dieterich, J.H. 1979. Modeling of rock friction 1. Experimental results and constitutive equations. Journal of Geophysical Research 85(B5): 2,161-2,168.

Fishman, K.L. 1988. Constitutive Modeling of Idealized Rock Joints Under Quasi-Static and Cyclic Loading. Ph.D. Dissertation. Tucson, AZ: University of Arizona: 286.

Fortin, M., D.E. Gill, B. Ladanyi, M. Aubertin, and G. Archambault. 1990. Simulating the effect of a variable normal stiffness on shear behavior of discontinuities. Mechanics of Jointed Rock. H.P. Rossmanith, ed. Balkema: 381-388.

Gerrard, C. 1985. Formulations for the mechanical properties of rock joints. Proceedings of the International Symposium on Fundamentals of Rock Joints: 405-422.

Gillette, D.R., S. Sture, H.-Y. Ko, M.C. Gould, and G.A. Scott. 1983. Dynamic behavior of rock joints. Proceedings of the 24th U.S. Symposium on Rock Mechanics. College Station, TX: Texas A\&M University: 163-179.

Goodman, R.E. 1976. Methods of Geological Engineering in Discontinuum Rock. St. Paul, MN: West Publishing Company.

Goodman, R.E., and G.H. Shi. 1985. Block Theory and Its Application in Rock Engineering. Englewood Cliffs, NJ: Prentice-Hall.

Hoek, E., and E.T. Brown. 1980. Underground excavations in rock. The Institution of Mining and Metallurgy. London, U.K.:

Hoskins, E.R., J.C. Jaeger, and K.J. Rosengren. 1968. A medium-scale direct friction experiment. International Journal of Rock Mechanics and Mining Sciences 5: 143-154.

Hsiung, S.M. 1984. Structural Design Guidelines for Longwall Panel Layout. Ph.D. Dissertation. Morgantown, WV: West Virginia University.

Hsiung, S.M. 1994. Dynamic scale model study of opening stability in a jointed rock mass. Workshop on Rock Mechanics Issues in Repository Design and Performance Assessment. San Antonio, TX: Center for Nuclear Waste Regulatory Analyses.

Hsiung, S.M., and A.H. Chowdhury. 1991. Report on Research Activities for Calendar Year 1990. NUREG/CR-5817. W.C. Patrick, ed. San Antonio, TX: Center for Nuclear Waste Regulatory Analyses.

Hsiung, S.M., and A.H. Chowdhury. 1993. NRC High-Level Radioactive Waste Research at CNWRA. January-June 1992. NUREG/CR-5817: 3: W.C. Patrick, ed. Washington, DC: U.S. Nuclear Regulatory Commission.

Hsiung, S.M., A.H. Chowdhury, W. Blake, M.P. Ahola, and A. Ghosh. 1992a. Field Site Investigation: Effect of Mine Seismicity on Jointed Rock Mass. CNWRA 92-012. San Antonio, TX: Center for Nuclear Waste Regulatory Analyses.

Hsiung, S.M., W. Blake, A. H. Chowdhury, and T.J. Williams. 1992b. Effects of mining-induced seismic events on a deep underground mine. PAGEOPH 139 (3/4): 741-762. 
Hsiung, S.M., A.H. Chowdhury, W. Blake, and J. Philip. 1993a. Field investigation of mining-induced seismicity on local geohydrology. Proceedings of the Fourth International Conference on High-Level Radioactive Waste Management. La Grange Park, IL: American Society of Civil Engineers: 1: 913-920.

Hsiung, S.M., M.P. Ahola, and A.H. Chowdhury. 1993b. NRC High-Level Radioactive Waste Research at CNWRA. Calendar Year 1991. NUREG/CR-5817: 2. W.C. Patrick, ed. Washington, DC: Nuclear Regulatory Commission.

Hsiung, S.M., A. Ghosh, M.P. Ahola, and A.H. Chowdhury. 1993c. Assessment of conventional methodologies for joint roughness coefficient determination. International Journal of Rock Mechanics and Mining Sciences and Geomechanics Abstracts 30(7): 825-829.

Hsiung, S.M., D.D. Kana, M.P. Ahola, A.H. Chowdhury, and A. Ghosh. 1994a. Laboratory Characterization of Rock Joints. NUREG/CR-6178. San Antonio, TX: Center for Nuclear Waste Regulatory Analyses.

Hsiung, S.M., A. Ghosh, A.H. Chowdhury, and M.P. Ahola. 1994b. Evaluation of Rock-Joint Models and Computer Code UDEC Against Experimental Results. NUREG/CR-6216. San Antonio, TX: Center for Nuclear Waste Regulatory Analyses.

Hsiung, S.M., A. Ghosh, and A.H. Chowdhury. 1995a. On natural rock-joint profile characterization using self-affine fractal approach. Proceedings of the 35th U.S. Symposium on Rock Mechanics. Reno, NV: University of Nevada.

Hsiung, S.M., A. Ghosh, A.H. Chowdhury, and M.P. Ahola. 1995b. Laboratory investigations of rock-joint dynamic behavior. Proceedings of the Second International Conference on Mechanics of Jointed and Faulted Rock. Rotterdam, The Netherlands: A.A. Balkema.

Huang, X., B.C. Haimson, M.E. Plesha, and X. Qie. 1993. An investigation of the mechanics of rock joints, Part I. Laboratory investigation. International Journal of Rock Mechanics and Mining Sciences \& Geomechanics Abstracts 30(3): 257-269.

International Society for Rock Mechanics. 1978. Suggested methods for the quantitative description of discontinuities in rock masses. Commission on Standardization of Laboratory and Field Tests. International Journal of Rock Mechanics and Mining Sciences \& Geomechanics Abstracts. 15: 319-368.

ITASCA Consulting Group, Inc. 1989. Universal Distinct Element Code (UDEC), Version ICG1.5. Minneapolis, MN: ITASCA Consulting Group, Inc.

ITASCA Consulting Group, Inc. 1992. UDEC Universal Distinct Element Code Version 1.8 Volume I: User's Manual. Minneapolis, MN: ITASCA Consulting Group, Inc.

Jaeger, J.C., and N.G.W. Cook. 1979. Fundamentals of Rock Mechanics. Third Edition, London, U.K.: Chapman and Hall Ltd.: 592.

Jing, L., E. Nordlund, and O. Stephansson. 1992. An experimental study on the anisotropy and stress-dependency of the strength and deformability of rock joints. International Journal of Rock Mechanics and Mining Sciences \& Geomechanics Abstracts 29: 535-542. 
Kana, D.D., D.C. Scheidt, B.H.G. Brady, A.H. Chowdhury, S.M. Hsiung, and B.W. Vanzant. 1990. Development of a Rock-Joint Dynamic Shear Test Apparatus. CNWRA 90-005. San Antonio, TX: Center for Nuclear Waste Regulatory Analyses.

Kana, D.D., B.H.G. Brady, B.W. Vanzant, and P.K. Nair. 1991a. Critical Assessment of Seismic and Geomechanics Literature Related to a High-Level Nuclear Waste Underground Repository. NUREG/CR-5440. San Antonio, TX: Center for Nuclear Waste Regulatory Analyses.

Kana, D.D., A.H. Chowdhury, S.M. Hsiung, M.P. Ahola, B.H.G. Brady, and J. Philip. $1991 b$. Experimental techniques for dynamic shear testing of natural rock joints. Proceedings of International Congress on Rock Mechanics. W. Wittke, ed. Rotterdam, The Netherlands: A.A. Balkema: 519-526.

Kana, D.D., D.J. Fox, S.M. Hsiung, and A.H. Chowdhury. 1995. An Experimental Model Study of Seismic Response of an Underground Opening in Jointed Rock. CNWRA 95-012. San Antonio, TX: Center for Nuclear Waste Regulatory Analyses.

Kemeny, J., and N. Cook. 1990. Rock mechanics and crustal stress. Demonstration of Risk-Based Approach to High-Level Waste Repository Evaluation. R.K. McGuire, ed. EPRI NP-7057. Golden, CO: Risk Engineering Inc.: 5-1 to 5-20.

Key, S.W. 1987. SPECTROM-331. A Finite Element Computer Program for the Large Deformation, Elastic and Inelastic, Transient Dynamic Response of Three-Dimensional Solids and Structures. Topical Report RSI-0299. Rapid City, SD: RE/SPEC Inc.

Key, S.W., Z.E. Beisinger, and R.D. Krieg. 1978. HONDO II-A Finite Element Computer Program for the Large Deformation Dynamics Response of Axisymmetric Solids. SAND78-0422. Albuquerque, NM: Sandia National Laboratories.

Krahn, J., and N.R. Morgenstern. 1979. The ultimate frictional resistance of rock discontinuities. International Journal of Rock Mechanics and Mining Sciences \& Geomechanics Abstracts 16: 127-133.

Leichnitz, W. 1985. Mechanical properties of rock joints. International Journal of Rock Mechanics and Mining Sciences \& Geomechanics Abstracts 22(5): 313-321.

Lorig, L.J., and B.E. Hobbs. 1990. Numerical modeling of slip instability using the distinct element method with state variable friction laws. International Journal of Rock Mechanics and Mining Sciences \& Geomechanics Abstracts 27(6): 525-534.

Morrow, C., and Byerlee, J. 1984. Frictional sliding and fracture behavior of some Nevada test site tuffs. Proceedings of 25th U.S. Symposium on Rock Mechanics. Evanston, IL: Northwestern University: 467-474.

Muir-Wood, R., and G.C.P. King. 1993. Hydrologic signatures of earthquake strain. Journal of Geophysical Research 98(B12): 22,035-22,068.

Murrell, S.A.F. 1965. The effect of triaxial stress systems on the strength of rocks at atmospheric temperatures. Geophysics Journal 10: 231-281. 
Nuclear Regulatory Commission. 1994. License Application Review Plan for a Geologic Repository for Spent Nuclear Fuel and High-Level Radioactive Waste. NUREG-1323. Rev. 0. Washington, DC: Nuclear Regulatory Commission.

Nur, A. 1974. Matsushiro, Japan, earthquake swarm: Confirmation of the dilatancy-fluid diffusion model. Geology 2: 217-221.

O'Brien, G.M. 1993. Earthquake-induced water-level fluctuations at Yucca Mountain, Nevada, June 1992. U.S. Geological Survey Open-File Report 93-97. Denver, CO: U.S. Geological Survey.

Ofoegbu, G.I., S.M. Hsiung, and A.H. Chowdhury. 1995. Field Site Investigation: Effect of Mine Seismicity on Groundwater Hydrology. NUREG/CR-6283. San Antonio, TX: Center for Nuclear Waste Regulatory Analyses.

Ohnaka, M. 1975. Frictional characteristics of typical rocks. Journal of Physics of Earth 23: 87-112.

Patton, F. 1966. Multiple modes of shear failure in jointed rock. Proceedings of the First International Congress of ISRM. Lisbon, Portugal. 1: 509-513.

Peng, S.S. 1976. Roof Control Studies at Olga No. 1 Mines, Coalwood, WV. Final report to the U.S. Bureau of Mines. Contract No. J0155125.

Peng, S.S., and D.W. Park. 1977. Rock Mechanics Study for the Shortwall Mining at the Valley Camp No. 3 Mine. Triadelphia, WV. Final report to the U.S. Bureau of Mines. Contract No. J0155125.

Plesha, M.E., and B.C. Haimson. 1988. An advanced model for rock-joint behavior: Analytical, experimental and implementational consideration. Proceedings of the 29th U.S. Symposium on Rock Mechanics. Minneapolis, MN: University of Minnesota.

Qiu, X., M.E. Plesha, X. Huang, and B.C. Haimson. 1993. An investigation of the mechanics of rock joints Part II. Analytical investigation. International Journal of Rock Mechanics and Mining Sciences \& Geomechanics Abstracts 30(3): 271-287.

Raney, R.G. 1988. Reported Effects on Selected Earthquakes in the Western North American Intermountain Region, 1852-1983, on Underground Workings and Local and Regional Hydrology: A Summary. Spokane, WA: U.S. Bureau of Mines.

Rojstaczer, S., and S. Wolf. 1992. Permeability changes associated with large earthquakes: An example from Loma Prieta, California. Geology 20: 211-214.

Roko, R.O., G.S. Adisoma, and J.J.K. Daemen. 1986. A new approach in direct shear testing to obtain the "true" residual properties of rock joints. Proceedings of the 27th U.S. Symposium on Rock Mechanics. University of Alabama. Society of Mining Engineers, Inc. Littleton, CO: 33-39.

Swan, G., and S. Zongqi. 1985. Prediction of shear behavior of joints using profiles. Rock Mechanics and Rock Engineering 18: 183-212. 
Thrupp, G.A., and D.R. Wuthrich. 1994. Earthquake-induced water level fluctuation recorded in Chino Basin Wells (abstract). Eighty-Ninth Annual Meeting of the Seismological Society of America April 5-7, 1994. Pasadena, CA: Pasadena Convention Center.

Waller, R.M. 1966. Effects of the March 1964 Alaska Earthquake on the Hydrology of the Anchorage Area. United States Geological Survey Professional Paper 544-B. Washington, DC: U.S. Government Printing Office.

Wibowo, J., B. Amadei, S. Sture, R.H. Price, and A.B. Robertson. 1993. Effect of Boundary Conditions on the Strength and Deformability of Replicas of Natural Fractures in Welded Tuff: Comparison Between Predicted and Observed Shear Behavior Using a Graphical Method. SAND92-2247. Albuquerque, NM: Sandia National Laboratories.

Williams, J.R., G. Hocking, and G.G.W. Mustoe. 1985. The theoretical basis of the discrete element method. Proceedings of the NUMETA'85 Conference, Swansea: 897-906.

Wood, S.H., C. Wurts, T. Lane, N. Ballenger, M. Shaleen, and D. Totorica. 1985. The Borah Peak, Idaho earthquake of October 28, 1983 hydrologic effects. Earthquake Spectra 2(1): 127-150.

Yoshinka, R., and T. Yamabe. 1986. 3. Joint stiffness and the deformation behavior of discontinuous rock. International Journal of Rock Mechanics and Mining Sciences \& Geomechanics Abstracts 23(1): 19-28.

Zubelewicz, A., K. O'Connor, C.H. Dowding, T. Belytschko, and M. Plesha. 1987. A constitutive model for the cyclic behavior of dilatant rock joints. Proceedings of the Second International Conference on Constitutive Laws for Engineering Materials: Theory and Applications. Vol. II, C.S. Desai, E. Crempl, P.D. Kiousis, and T. Kundu, eds. New York, NY: Elsevier. 



\begin{tabular}{|c|c|c|}
\hline \multirow[t]{3}{*}{ Selsmic Response or Rock Joints and Jointed Rock vass } & \multicolumn{2}{|c|}{ 3. DATE REPORT PUBLISHED } \\
\hline & $\begin{array}{l}\text { MONTH } \\
\text { June }\end{array}$ & $\begin{array}{l}\text { YEAR } \\
1996\end{array}$ \\
\hline & \multicolumn{2}{|c|}{$\begin{array}{l}\text { 4. FIN OR GRANT NUMBER } \\
\text { B6643 }\end{array}$} \\
\hline \multirow{2}{*}{$\begin{array}{l}\text { 5. AUTHOR(S) } \\
\text { A.Ghosh, S.M. Hsiung, A.H. Chowdhury }\end{array}$} & \multicolumn{2}{|c|}{ 6. TYPE OF REPORT } \\
\hline & \multicolumn{2}{|c|}{ 7. PERIOD COVERED (thclusive Dates $)^{-\prime}$} \\
\hline
\end{tabular}

Center for Nuclear Waste Regulatory Analyses

Southwest Research Institute

6220 Culebra Road

San Antonio, TX 78228-0510

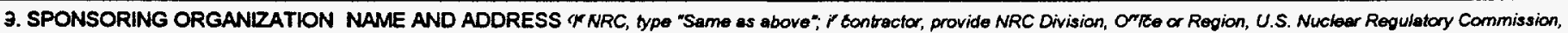
and meiling eddross."'s

\section{Division of Regulatory Applications}

Office of Nuclear Regulatory Research

U.S. Nuclear Regulatory Commission

Washington, DC $20555-0001$

10. SUPPLEMENTARY NOTES

J. Philip, NRC Project Manager

11. ABSTRACT (200 wards or lass')'

Two key technical uncertainties (KTU) that can potentially pose a high risk of noncompliance with the performance objectives of 10 CFR Part 60 are the prediction of (i) thermal-mechanical effects on stability of emplacement drifts and the engineered barrier system (EBS), and (ii) thermal-mechanical-hydrological effects on the host rock surrounding the EBS. This final report summarizes the research activities concerned with the repetitive seismic load aspect of both these KTUs. This research project has the dual focus of (i) understanding the key parameters affecting repository performance under repeated seismic loading, and (ii) evaluating current capabilities for calculating such effects. Laboratory experiments on Apache Leap tuff joints using cyclic pseudostatic and dynamic loads indicate that the shear strength in the reverse direction of shearing is less than that in the forward direction. But the reverse shear strength predicted by UDEC (versions 1.82 and 1.83 ) is found to be inconsistent with these findings. Thus, a new joint model is desirable. Field experiments at Lucky Friday Mine, scale-model experiments conducted at CNWRA, and information in the literature show that for excavations subjected to repetitive seismic motions, accumulation of shear displacement along the joints is the primary mode of deformation for the rock mass. However, the currently available seismic design procedure for underground excavations is based on the probable peak particle motion concept and does not explicitly take into account of either the time history of individual events or the effects of repetitive seismic events. An adequate seismic design methodology is desirable. The results of this research project will be used to: conduct prelicensing reviews, provide guidance to DOE, develop CDMs, support IPA, and provide basis for developing seismic design methodology.

\section{KEY WORDS/DESCRIPTORS (Gist words $\alpha$ phrases that will assist researchers in locating the repori.)"}

rock joint, cyclic, loads, pseudostatic, dynamic loadings, joint shear strength, joint dilation, forward shearing, reverse shearing, joint roughness coefficient, shearing velocity effect, earthquake loads, normal stress, normal stiffness, normal displacement, shear stress, shear stiffness, shear displacement, harmonic loads, scale-model, groundwater, pressure, Coulomb-Slip, Barton-Bandis, Continuously-Yielding, residual angle of friction, joint profile.

\begin{tabular}{|c|}
\hline $\begin{array}{l}\text { 13. AVALABILITY STATEMENT } \\
\text { unlimited }\end{array}$ \\
\hline 14. SECURITY CLASSIFICATION \\
\hline $\begin{array}{l}\text { This Pago"s } \\
\text { unclassified }\end{array}$ \\
\hline $\begin{array}{l}\text { This Reporp" } \\
\text { unclassified }\end{array}$ \\
\hline 15. NUMBER OF PAGES \\
\hline 16. PRICE \\
\hline
\end{tabular}




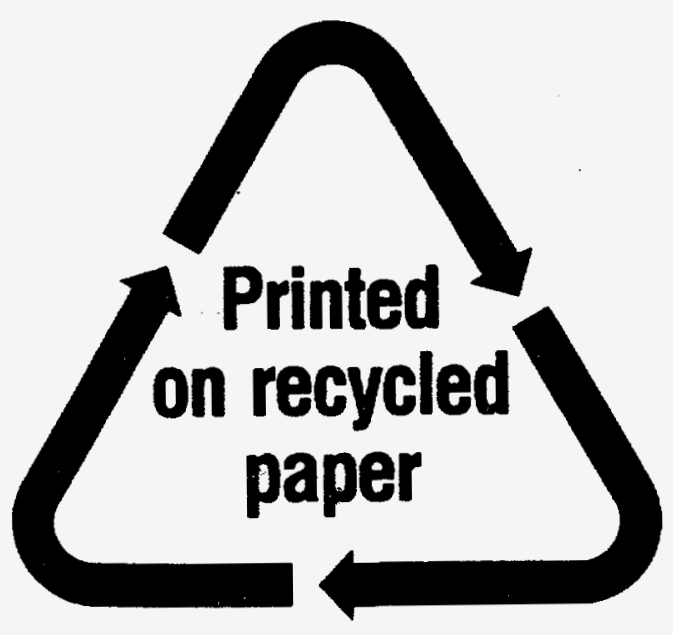

Federal Recycling Program 